\title{
الاضطرابات السلوكية
}

\section{لاى أطفال الروضة المهجرين من رفح وأطفال العريش والقاهرة}

\section{إعداد \\ د / مهى ضياءالدين عبدالحميد(")}

مقدمة:

الأطفال هم الثروة البشرية المستقبلية لأى مجتمع، فإن أراد صلاح حاله لابد من السعى نحو صلاح حال

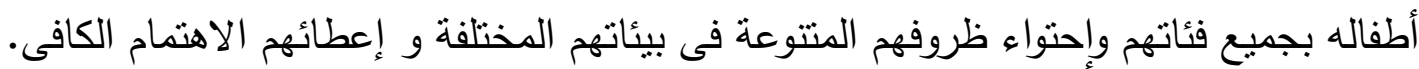

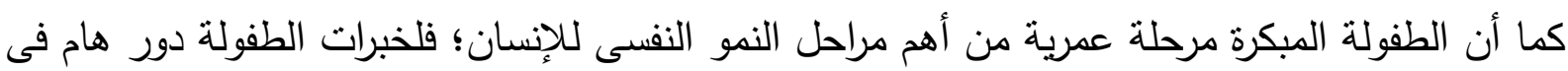

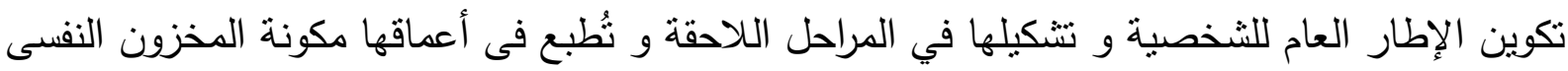

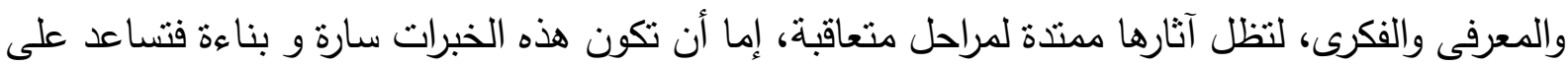

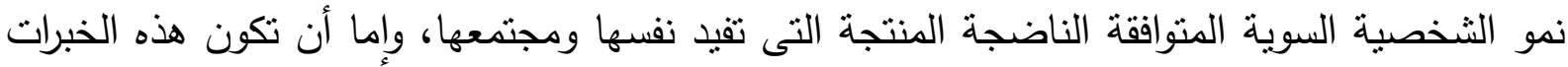
مؤلمة ومصدر شقاء و تعاسة للطفل فيعانى فى طفولته من الاضطرابات السلوكية، وفى مراهتته ورشده من الاضطرابات النفسية و العقلية و تتثأ شخصية أقل تكاملا، مما يعود على الفرد و مجتمعه بالمردود العابل

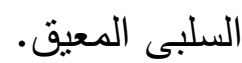
وأطفال محافظة شمال سيناء بكل مدنها (رفح مصر والعريش وغيرهما) يتعرضون لخبرات مؤلمة؛ ومعاناة

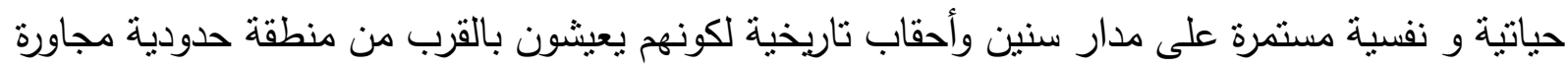

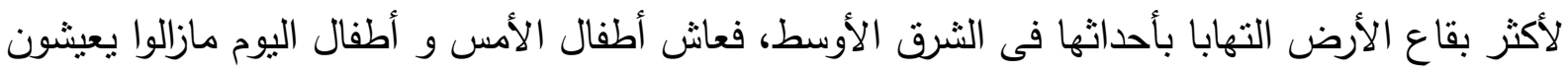

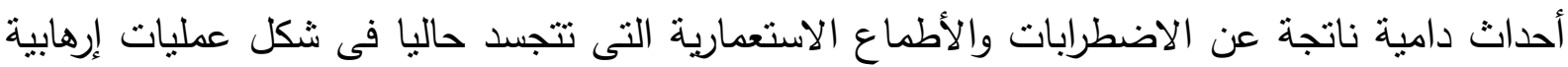

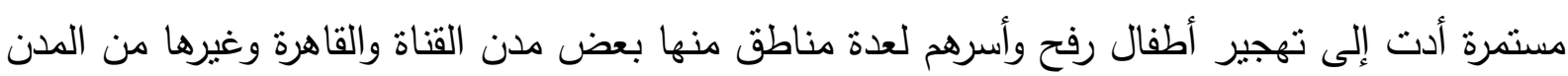

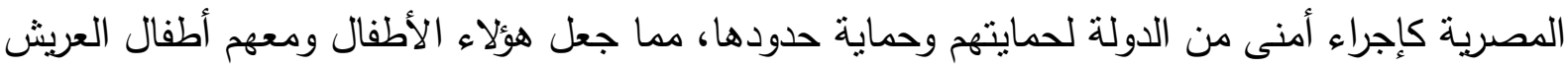

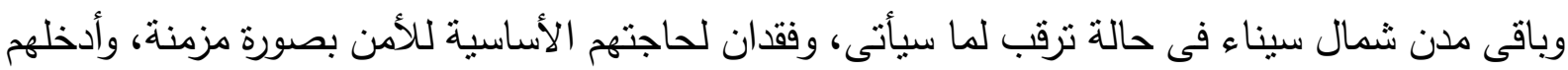

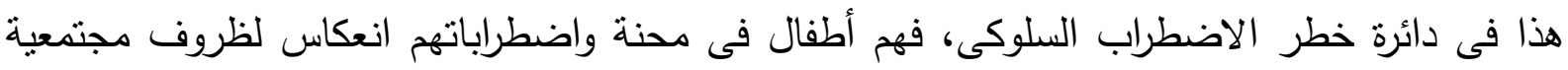

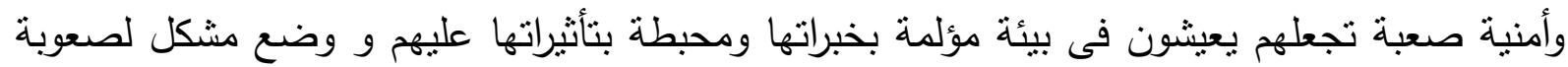

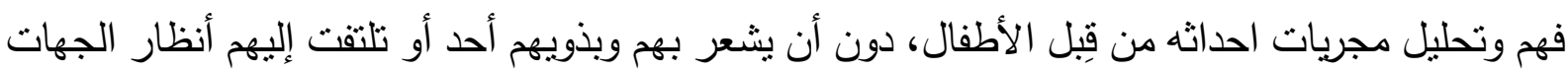

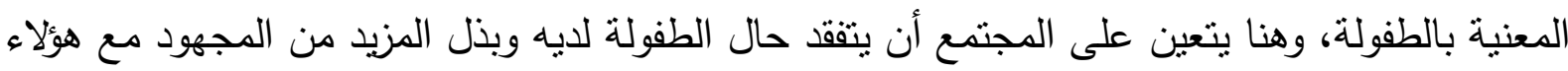

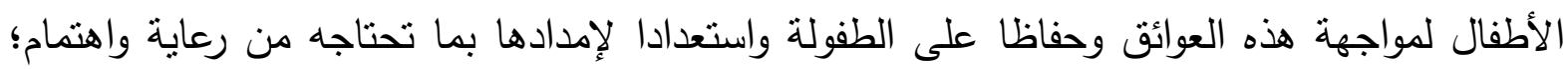

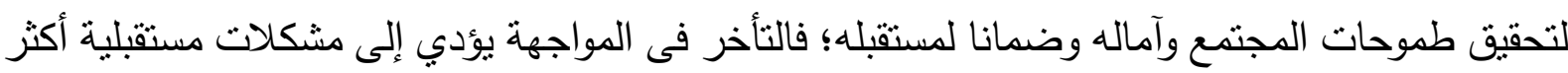

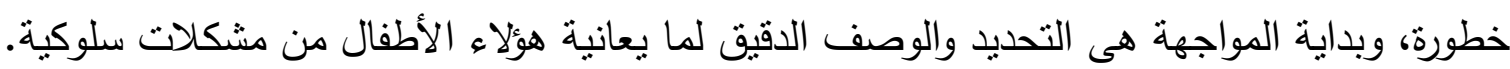
مشكلة البحث: مطنة

(*) مدرس بقسم العلوم النفسية-كلية التربية للطفولة المبكرة-جامعة القاهرة 
سلوك الطفل يعبر عن قدرته على التوافق مع البيئة والمجتمع المحيط به وإحساسه بالأمان والانتماء، كما

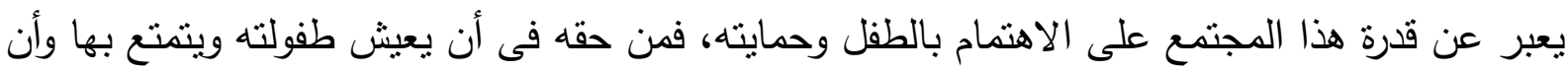

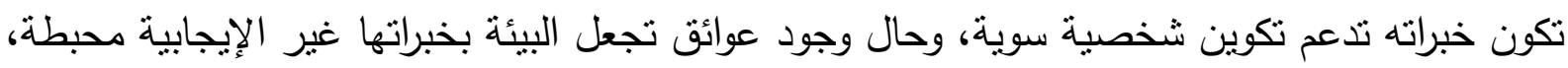

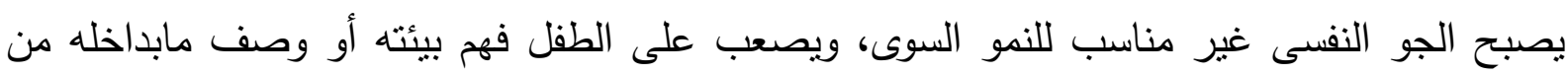

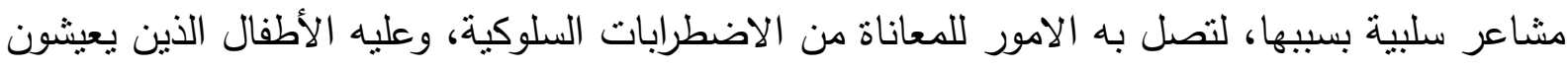

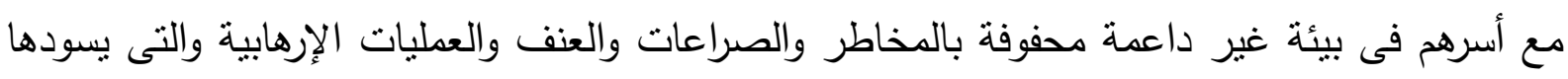

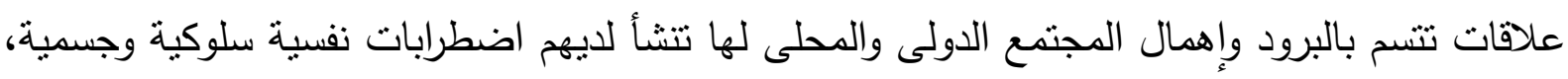

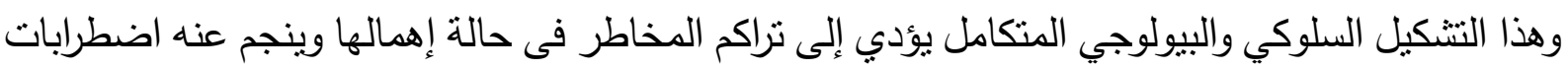

الصحة العقلية والامراض النفسية المزمنة.(Repetti,Taylor,\&Seeman,2002,330) وأثنار لهذا الإعلان العالمى للاتفاقية الدولية لحقوق الطفل منذ سنوات طويلة بعد عقد مؤتمر القمة العالمى

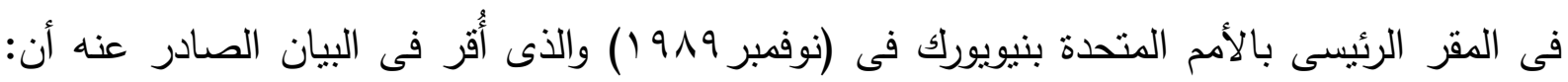

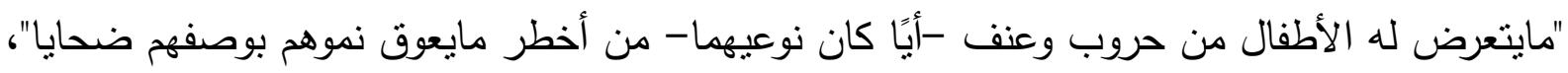

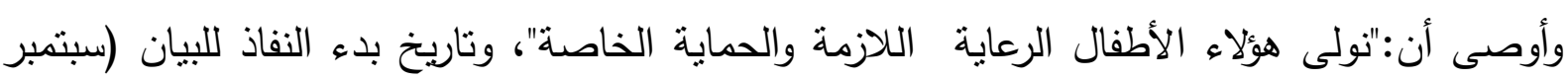

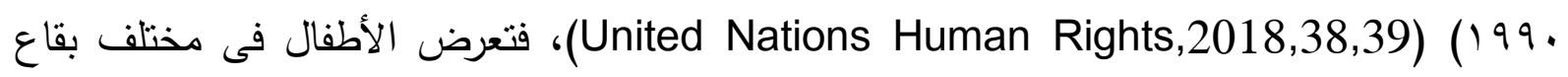
الأرض للعديد من المشكلات التى تعوق تمتعهم بالأمن، والتى لاتحفظ حقهم فى اللعب والتعلم وأخذ دورهم

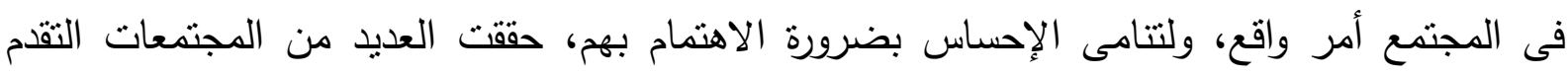

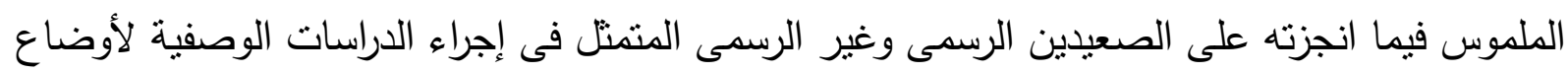
الطفولة النفسية والجسدية، منل دراسة الطويل ونيل واسكر وآخرون (Altawil,Nel,Asker,et al,2010) عن:"الآثار النفسية للحروب المستمرة على أطفال رفح الفلسطينية"، التى هدفت لبحث النى التأثيرات النفسية

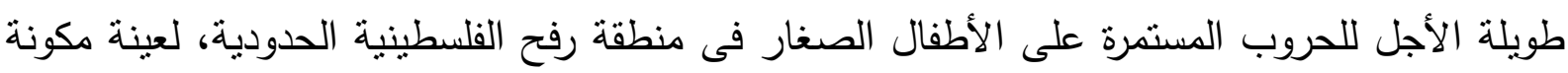

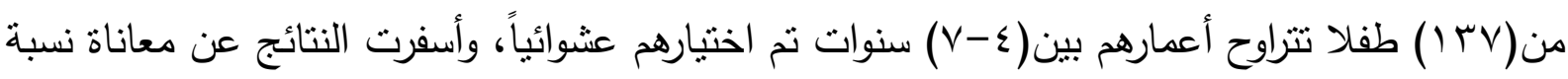

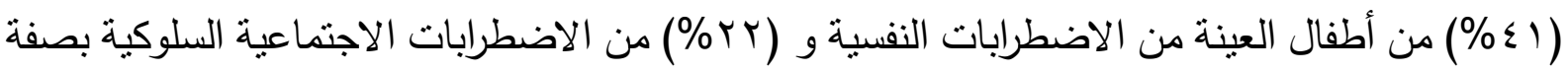

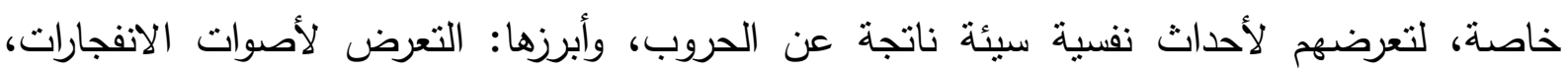
والاعتداءات، وخبرات الخوف من مشاهدة الآليات العسكرية والمدفعيات والطائرات الحربية، ونفس النتائج جاءت بها دراسة لبانتير وجودمان وتول وايجيرمان (Panter,Goodman,Tol,\&Eggerman,2011) الطولية عن:"محن الطفولة فى كابول افغانستان و الصحة النفسية"، كفئة معرضة لخطئة لخطر الاضطرابات السلوكية. كما أكدت دراسة اتانى وجاءلوك وفايد وآخرون (Itani,Jaalouk,Fayyad,et al, 2015)

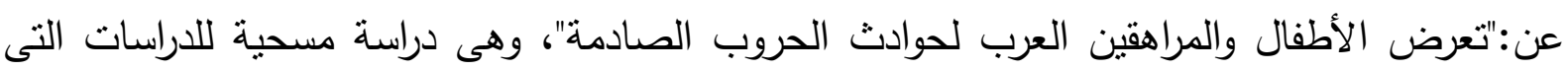

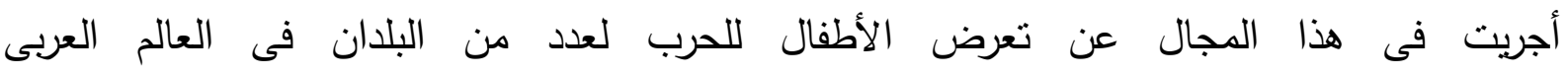

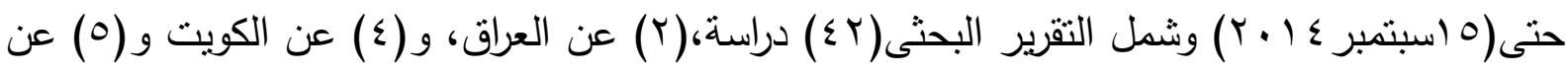

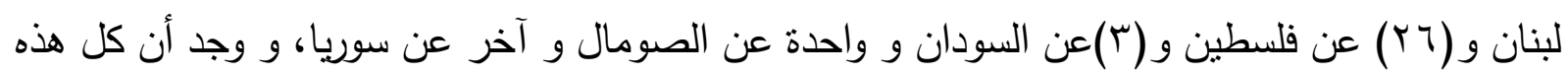


الدراسات ناقتت فى نتائجها أحداث الحرب المروعة بشكل عام منل مشاهدة الجرحى وتدمير المنازل

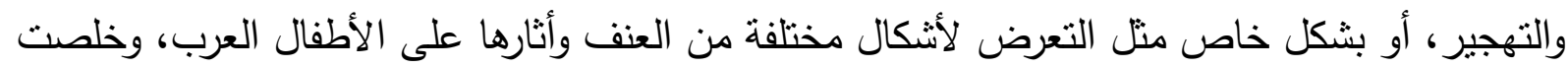

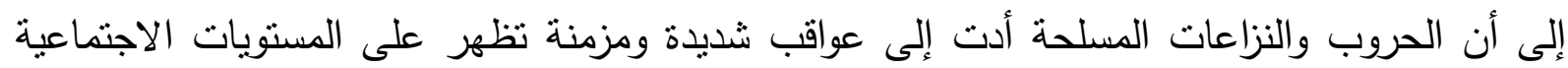
والنفسية ، ولابد من إعطائها الاهتمام الكافى. إلى جانب الدراسات الوصفية أجريت دراسات اهتمت بالإجراءات التطبية التشية على أرض الواقع لرعاية الأطفال

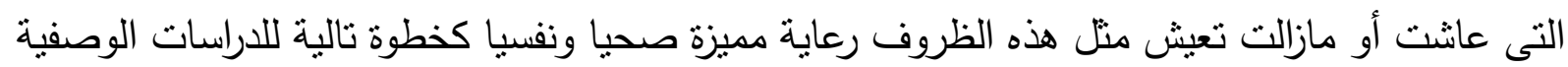
المفصلة، منل دراسة جابولايد وريناود وروبنتين وآخرون(Gaboulaud,Reynaud,Roptin,et al,2010) بعنوان:"الدعم النفسي المقدم لأطفال ماقبل المدرسة الفلسطينيين: تحليل بيانات برنامج لتخفيف الاضطرابات

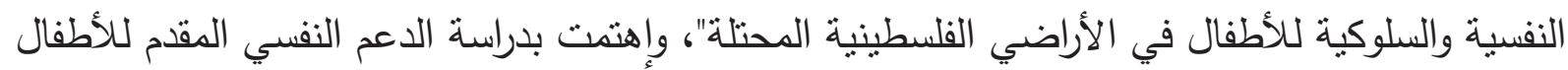
في الأراضي الفلسطينية المحتلة وفاعلية البرنامج المقام لخفض الاضطية الإرابات النفسية والسلوكية للأطفال

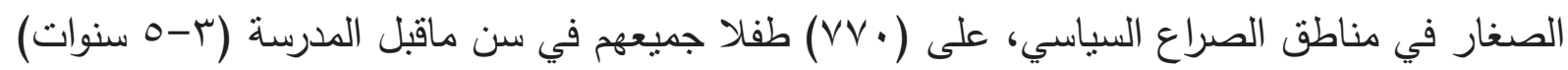

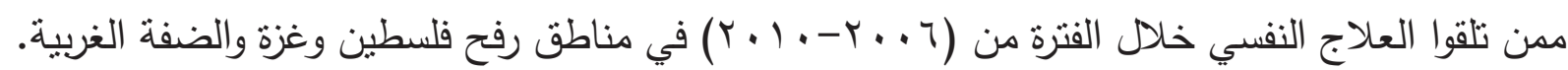

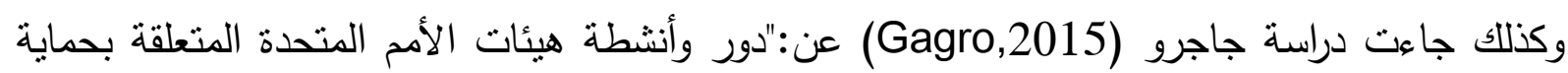

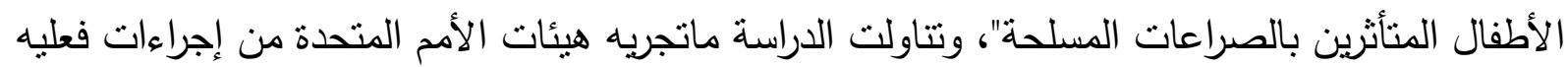

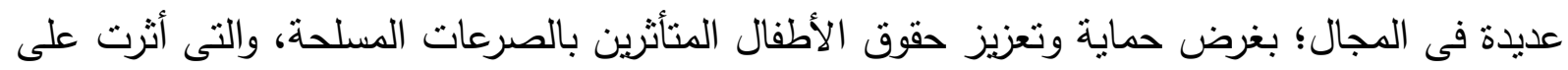

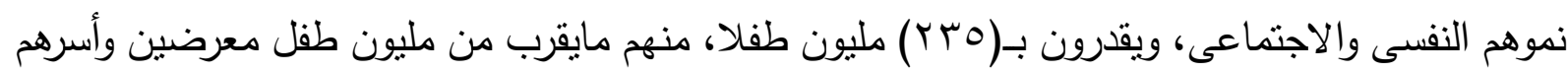

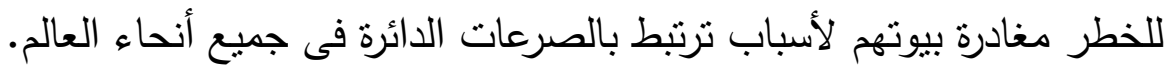

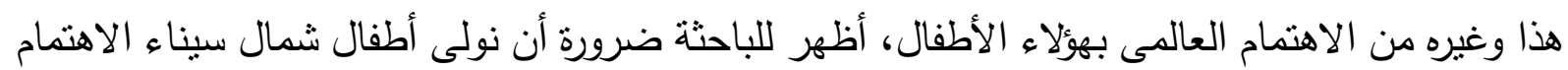

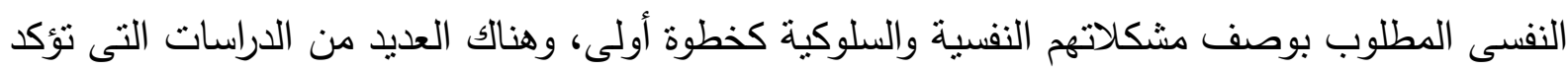
إحساس الباحثة لخطورة الموقف كدراسة ينج وكيناردى وكوبهام(Young,Kenardy,\&Cobham,2011)

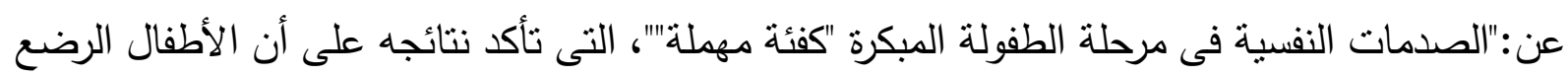

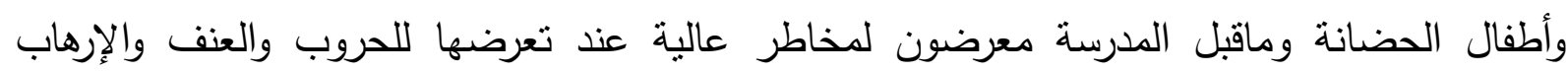
والصدمات؛ لأنهم فى مرحلة نمو نشط سريع يتأثر بالنتائج السلبية، كما أنهم أكثر اعتمادية على على القائمين

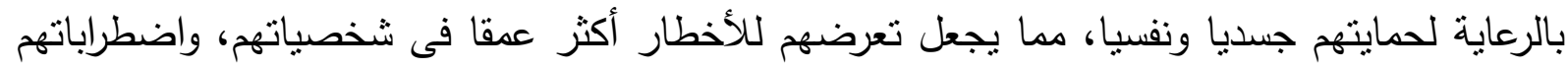

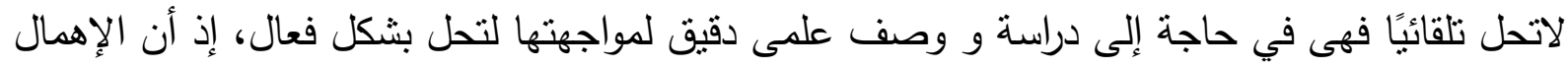

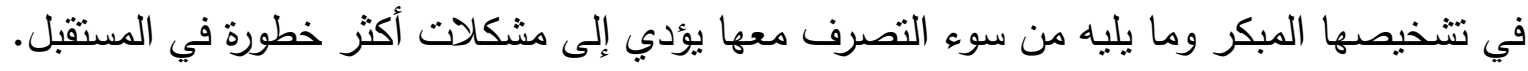

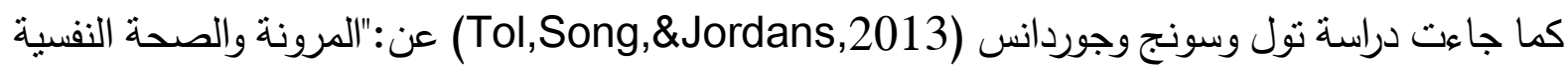

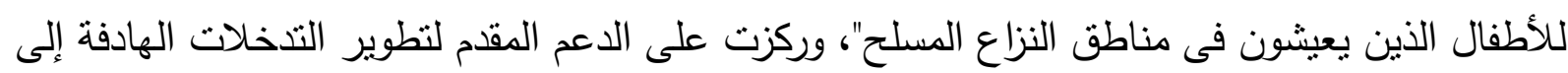

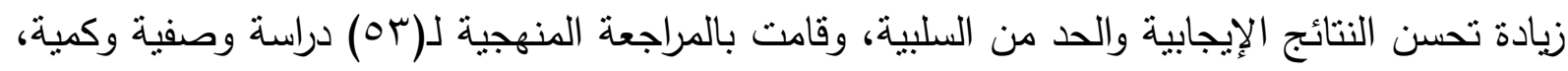

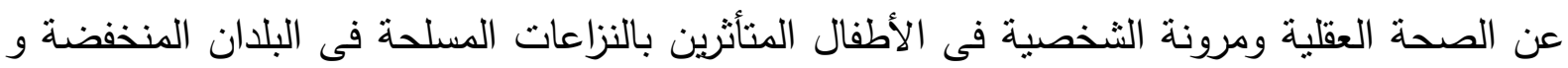

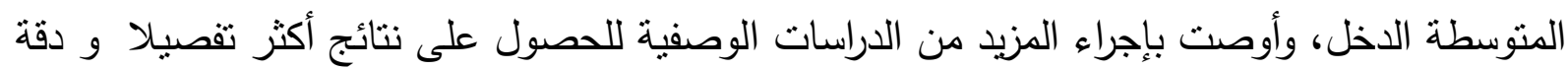


كيفية وكمية على الطفولة المبكرة بصفة خاصة، ونفس الثئ أكدته نتائج دراسة أجريت حديثا على أطفال

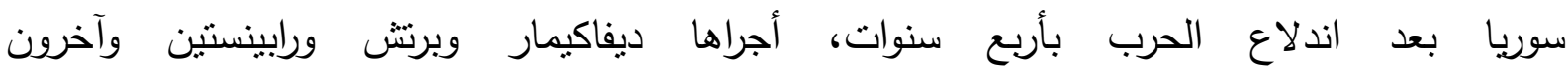
(Devakumar,Birch,Rubenstein,et al,2015)، بعنوان:"صحة الطفل فى سوريا: الآثار الدائمة للحرب على الصحة"، بالاضافة لتأكيدها على أن الحرب نسبيت بحدوث الضرر الثديد بصحة الأطفال

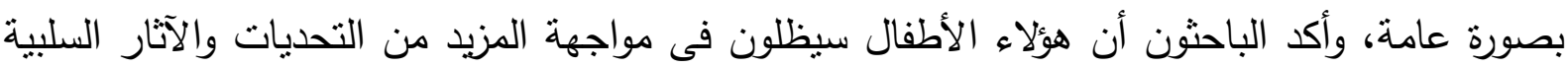
طويلة المدى على الصحة الجسمية والنفسية والأخلاقية. دعم كل هذا الاهتمام العالمى بالأطفال فى مثل هذه الظروف المحبطة اهتمام الباحثة بضرورة البحث

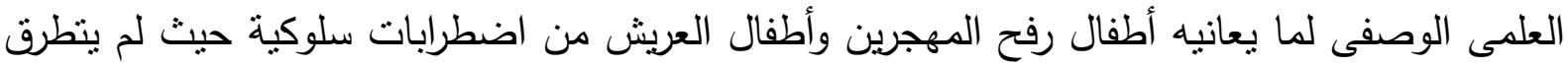

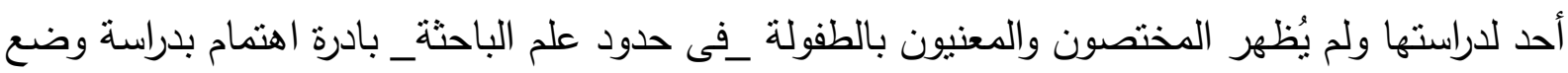
صحتهم النفسية، بداية من تحديد و وصف مايعانوه من اضطرابات سلوكية كخطوة ضرورية سابقة لتقديم الدعم لهم فى ضوء النتائج؛ وانتهاء بتجاوزهم محنتهم ونمو شخصياتهم المستقبلية السوية المتوافقة نفسيا وتمكنهم من التماسك النفسى والمواجهة البناءة حنى فى حال استمرار الوضع البيأيى المحبط كأمر واقع. عليه يمكن تحديد مشكلة البحث فى السؤال التالى: ما مدى الاضطرابات السلوكية لدى أطفال الروضة المهجرين من رفح مقارنةً بأطفال العريش و أطفال

القاهرة؟

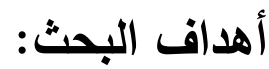

1- التعرف على مدى الاضطرابات السلوكية لدى أطفال رفح المهجرين وأطفال العريش. r- المقارنة بين مدى الاضطرابات السلوكية لدى أطفال رفح المجرين وأطفال العريش العرئ وأطفال القاهرة.

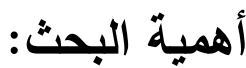

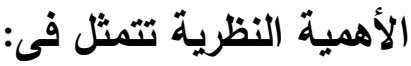

1- تقايم اسهاما نظريا وتراثا فى مجال الاضطرابات السلوكية لاى الأطفال المعرضين لمعاناة حيانية

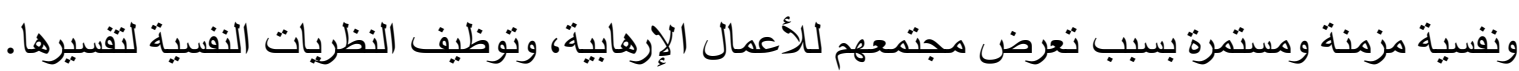

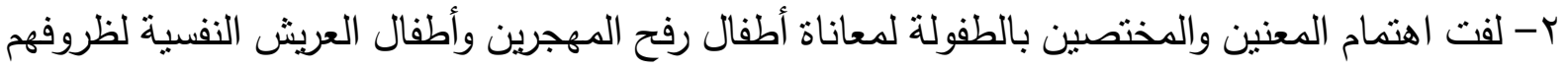
البيئية والمجتمعية، ولخطورة الأمر على الصحة النفينة بلفية للأطفال فى هذه المرحلة العمرية.

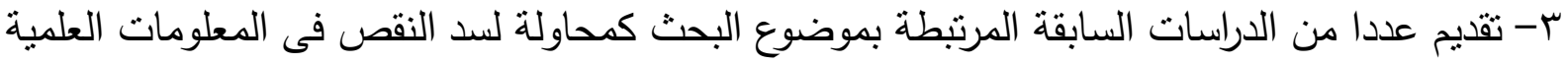

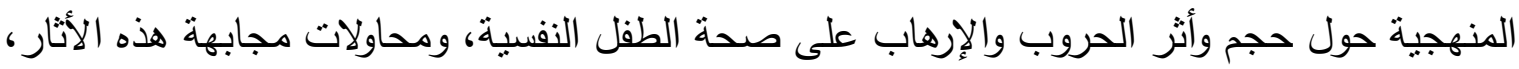

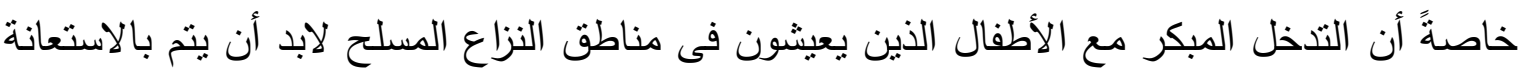
بنماذج لدراسات علمية على الصحة النفسية عبر ثقافات مختلفة.

(Alexandra, 2012, 15),(Tol, Song, \&Jordans, 2013,456) 


\section{• الأهمية التطبيقية تتمثل فى:}

1- تقديم التوصيات والمقترحات من خلال ماتوصل إليه البحث من نتائج إلى جميع القائمين والمهتمين

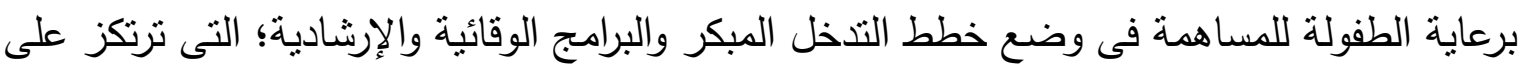

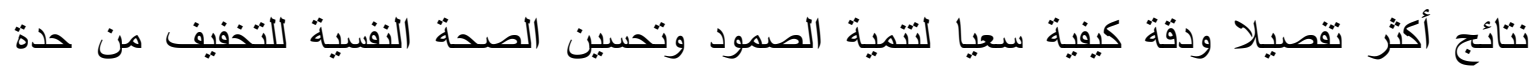
الاضطرابات السلوكية لدى أطفال رفح المهجرين والعريش.

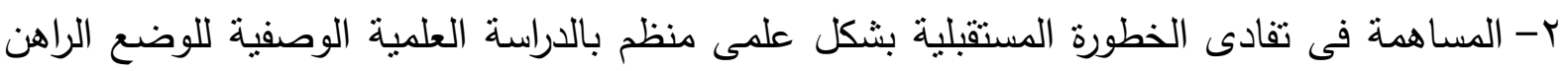

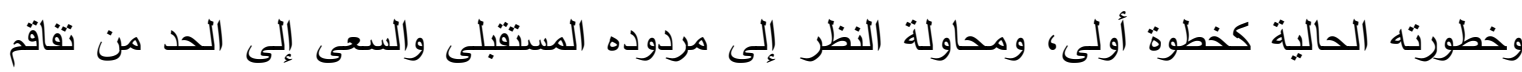
اضطرابات الأطفال النفسية فى مراحل عمره اللاحقة وإدارتها.

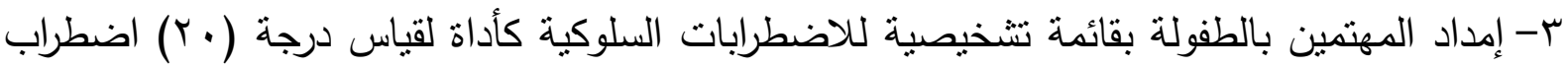

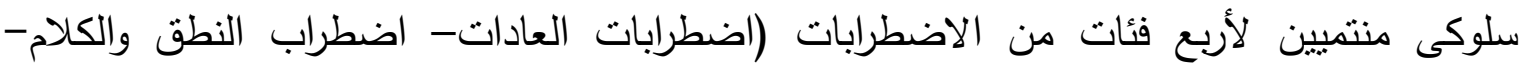
الاضطرابات الوجدانية- الاضطرابات السلوكية الاجتماعية)، لكل منهم درجته المنفصلة وللقائمة

التثخصية درجة كلية تنثل درجة الاضطرابات السلوكية ككل.

مصطلحات البحث ومفاهيمه الاجرائية:

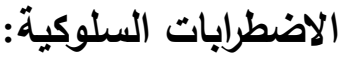

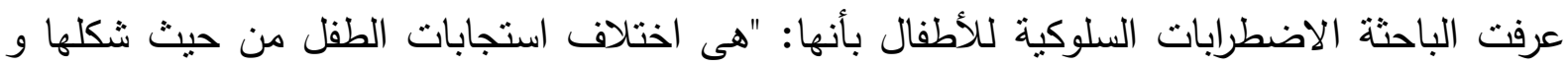
تكرارها وشدتها عما يعد استجابة طبيعية فى ضوء الموقف والعمر الطفل الزمني وجنسه وثقافة مجتمعه

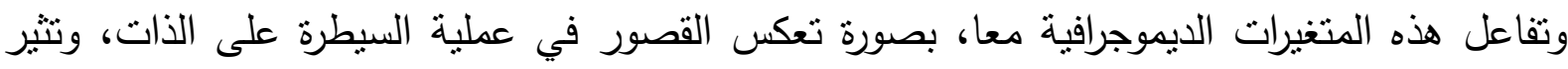
الثكوى لدى الطفل والمحيطين به"، ويستدل عنها اجرائيا بالدرجة التى يحصل عليها الطلل على القائمة التشخيصية للاضطرابات السلوكية، من إعداد الباحثة.

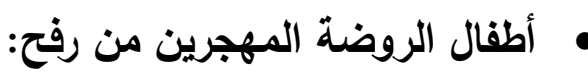
تعرفهم الباحثة بأنهم:"الأطفال الذين تتراوح أعمارهم من (0:

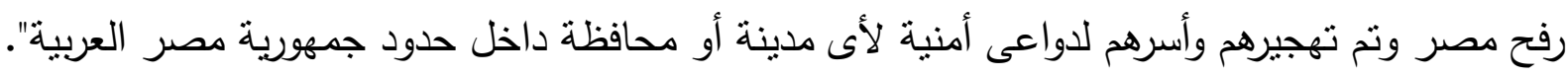

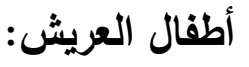
تعرفهم الباحثة بأنهم:"الأطفال الذين نتراوح أعمارهم من(0: مدينة العريش عاصمة محافظة شمال سيناء بجمهورية مصر العربية. أطفال القاهرة: تعرفهم الباحثة بأنهم: "الأطفال الذين تتراوح أعمارهم من(0: 7, 7) سنوات الذين كانوا ومازالوا من ساكنى محافظة القاهرة بجمهورية مصر العربية. حدود البحث:

أحدود البشرية متمثلة فى: عينة البحث المكونة من ثلاث مجموعات من الأطفال جميعهم تتراوح

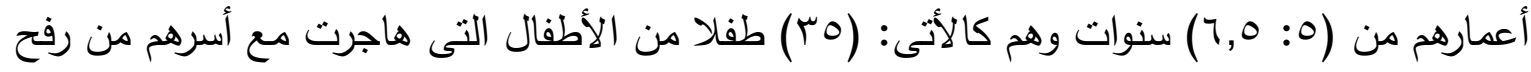




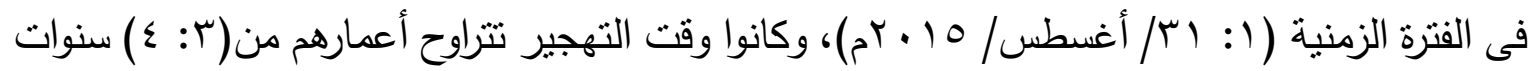

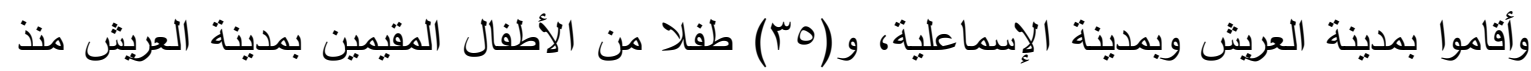
ميلادهم، و (ب0) طفلا من الأطفال المقيمين بالقاهرة منذ ميلادهم.

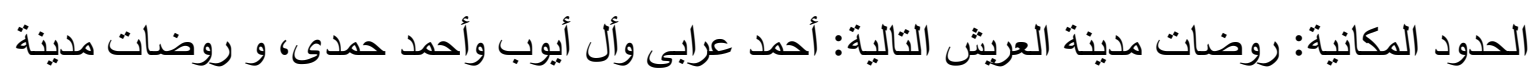

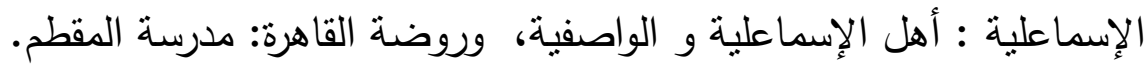

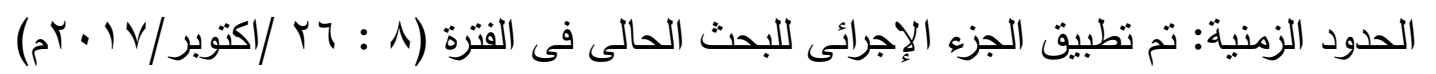

إطار نظرى و دراسات سابقة:

الاضطرابات السلوكية Behavior Disorders:

مفهوم الاضطراب السلوكى يثنير إلى:"مجموعه من المثاكل السلوكية والعاطفية لدى الأطفال والناتجة عن تجارب الحياة المؤلمة، تظهر معها صعوبة كبيرة فى اتباع القواعد والتصرف بطريقة غير مقبوله اجتماعيا".

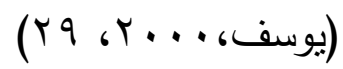

ويعرف بأنها:"مجموعة من الاضطرابات فى علاقة الطفل بذاته و بالآخرين".(باظة، ا . . ؟-أ، ج)

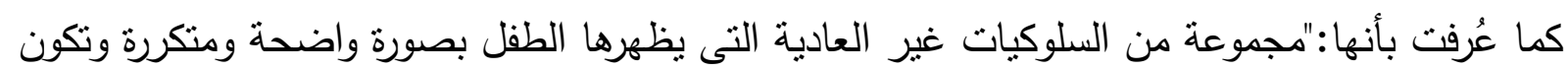
غير ملائمة للمرحلة العمرية للطفل، بحيث تصبح هذه السلوكيات غير مقبولة للمحيطين بها، فيسؤ توافقه

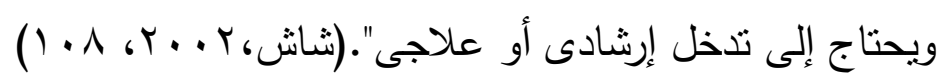
كذلك عُرفت بأنها:"حالة اضطرابت فيها علاقة الأنا بالآخر بل واضطرابت فيها صيغة الأنا للتعبير عن

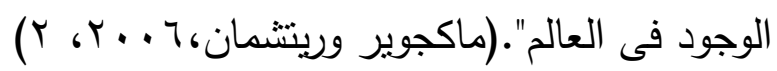

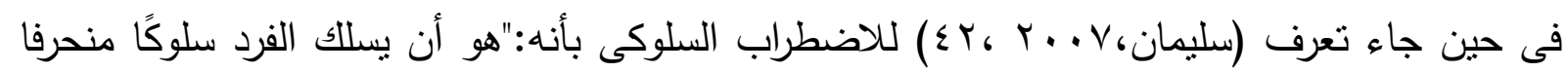

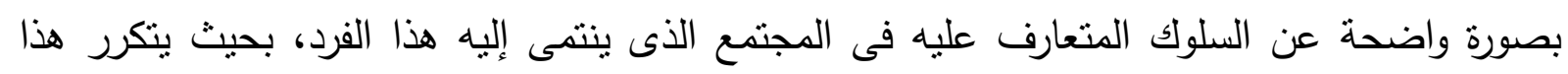
السلوك باستمرار، ويمكن ملاحظته والحكم عليه من قبل الاثخاص الذين يشاهدونه". كما أن السلوك المضطرب هو :"النمط الثابت المتكرر من السلوك العدوانى أو غير العدوانى الذى تتتهك

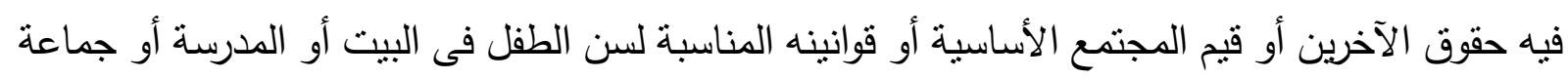
الرفاق وفى المجتمع، على أن يكون هذا السلوك أكثر من مجرد الإزعاج المعتاد أو مزاحات الأطفال

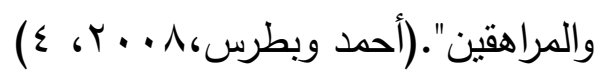

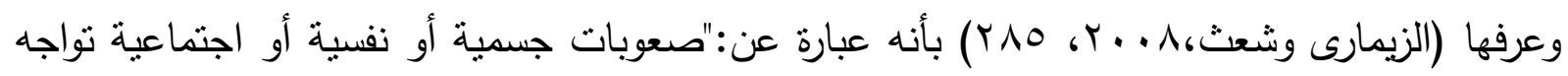
بعض الأطفال بشكل متكرر، وتمتاز بنوع من الثدة، ولا يمكنهم التغلب عليها بأنفسهم، ولا يتجاوبون مع

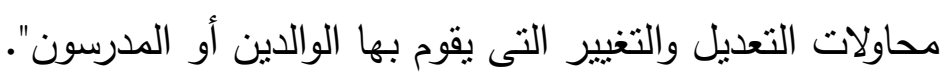
أما كيرك جالاجير وكوليمان وآخرون (Kirk,Gallagher,Coleman,et al,2009,183) يرون أنها: "انحراف عن السلوك الملائم للعمر والذى يتذخل فى نمو الفرد وتطوره وحياة اللآخربن". 


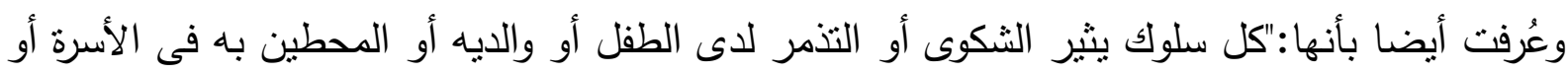

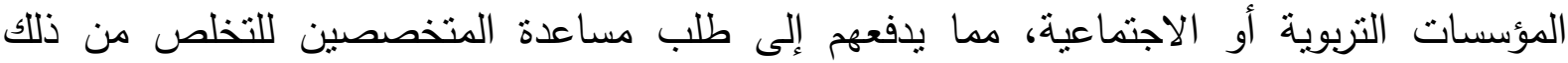

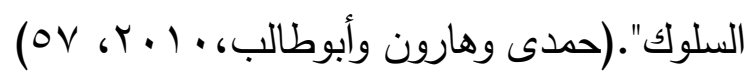

وبأنها:"انحراف عن السلوك السوى، ويزداد إذا ترك دون بحث أسبابها وطرق الوقاية والوان والعلاج، وتتعدد وتتتوع

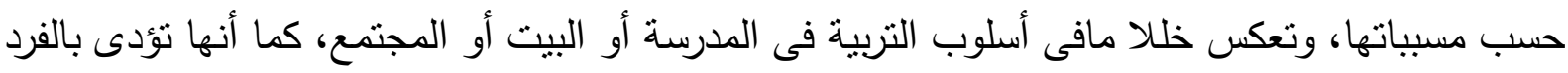

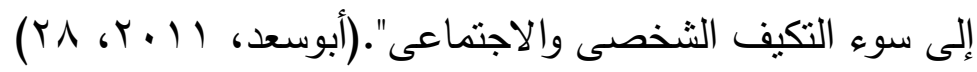

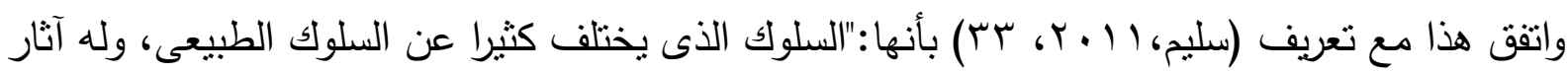
جانبية أو عواقب غير مرغوبة، ويؤدى إلى توتر الطفل".

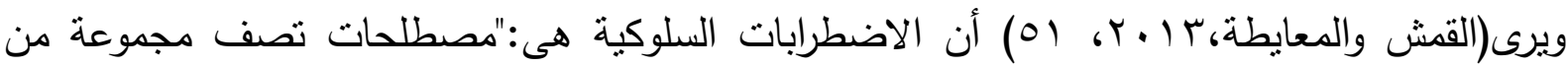
الأشخاص الذين يظهرون و بشكل متكرر أنماط مختلفة من السلوك".

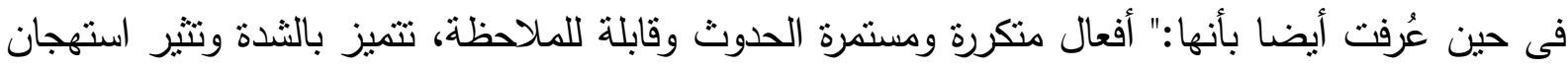

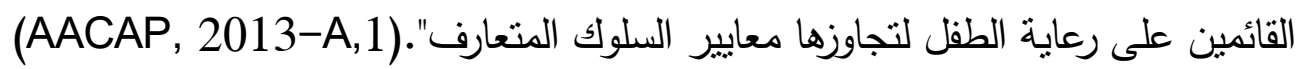
بناء على كل ماسبق من تعريفات عرفت الباحثة الاضطرابات السلوكية للأطفال بأنها:"هى اختلاف استجابات الطفل من حيث شكلها وتكرارها وشدتها عما يعد استجابة طبيعية فى ضوء الموقف والعمر الطفل الزمني وجنسه وثقافة مجتمعه وتفاعل هذه المتغيرات الديموجرافية معا، بصورة تعكس القصور في عملية السيطرة على الذات، وتثثير الثنكوى لدى الطفل والمحيطين به".

\section{محكات و معايير الاضطرابات السلوكيات:}

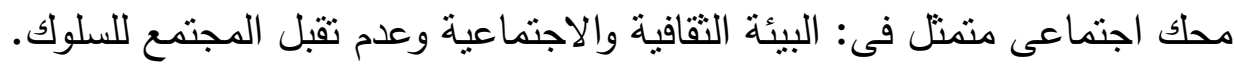
ه محك نفسى اجتماعى متمنل فى: أن تكون اضطرابات سلوكية وظيفية وليس عضوية (يوسف، .... T،

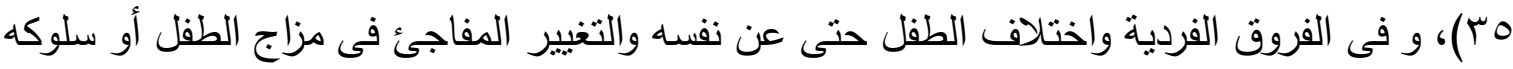

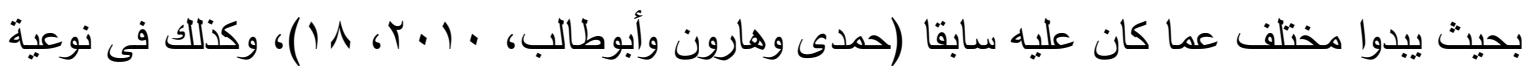

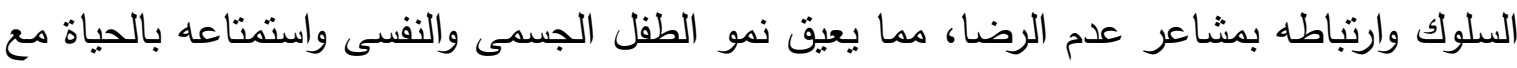

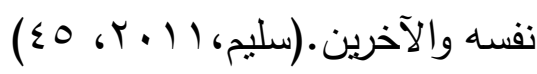

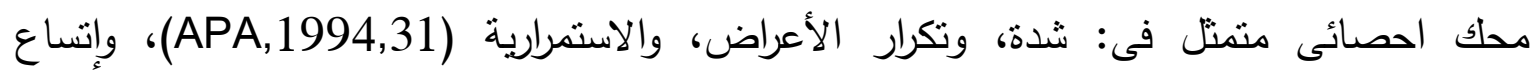

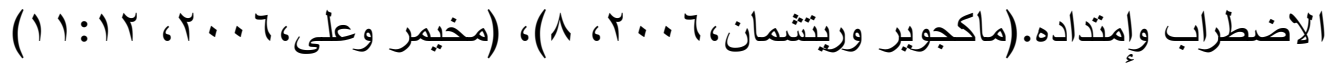
محك قانونى متمثل فى: خطورة الانتهاك أو المخالفة.

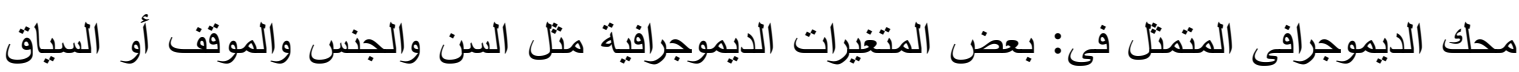
الاجتماعى الذى يحدث فيه السلوك. العوامل المسببة للاضطرابات السلوكية لاى الأطفال:

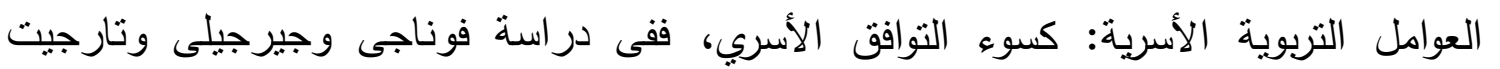

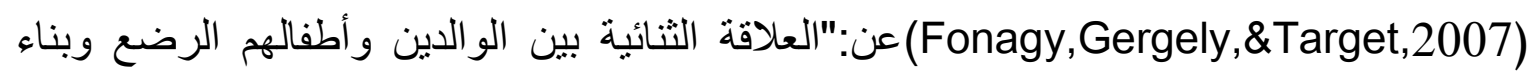


الذات"، وجد أن العلاقات غير الأمنة وغير المتوقعة بين الوالدين والطفل تخلق بيئة غير مدعمة لاكتساب المهار ات العقلية والنفسية والقدر ات الجسمية المطلوبة من الطفل، كما أشثارت دراسة شاندريكا كليسو (Kelso,2008)عن:"تأثنر العنف المنزلى على المشكلات السلوكية للأطفال"، إلى أن الأطفال الذين يتعرضون للعنف المنزلى من قبل الآباء تظهر عليهم اضطرابات سلوكية انفعالية واجتماعية. العوامل الجسمية والصحية: كالإصابة ببعض الأمراض منل السكر . العوامل البيولوجية: كالعوامل الجينية والبيوكيميائية والعصبية.

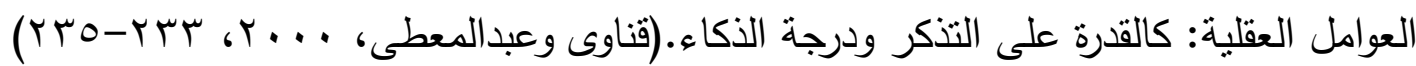
العوامل النفسية: كالإحباط، والحاجة للاهنمام والتقدير والأمان والثقة بالنفس، وعدم النضج الانفعالي أو التكوين النفسي الثاذ "الجعبة السلوكية المنفرة لباندورا"، فالاضطرابات السلوكية فى معظمها رد فعل لما يعانيه الطفل من عقبات وإحباطات فى بيئته تحول بين الطفل وإثباع احتياجاته النفسية، فيلجأ إلى أنواع من السلوك فى محاولة منه للتغلب على حرماناته وإثباع حاجاته الأساسية المختلفة.

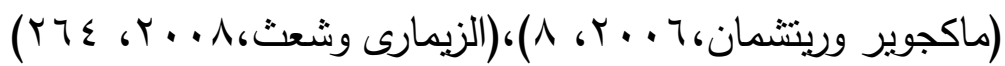

والبيئة غير الأمنة المحبطة المحفوفة بمخاطر الإرهاب تجمع فى طياتها كل العوامل النفسية المسببة للاضطرابات السلوكية، فتواجد الإرهاب ومايترتب عليه من الحرب ضده له انعكاساته السلبية المباشرة على الإه كل فئات المجتمع، والوضع أسوأ على الصحة الأطفال النفسية؛ حيث تظهر لديهم زيادة الإحساس بالتوتز (Garbarino,Governale,Henry,\&Nesi,2015,31)، وفى دراسة ثابت وسترينش وفوستانيس (Thabet,Stretch,\&Vostanis,2000) عن :"تأثير العنف على الصحة النفسية للأطفال الفلسطينيين"،

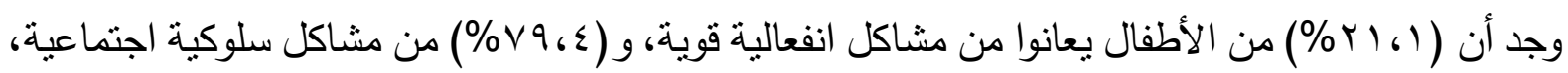
و كذلك دراسة والسين وأحمد والفون (Wahlsten,Ahmad,\&A-Lvon, 2001) عن:"التجارب الأليمة والمشاكل والاضطرابات النفسية عند الأطفال من كردستان العراق والسويد"، على عينة مكونة من مجموعتين،

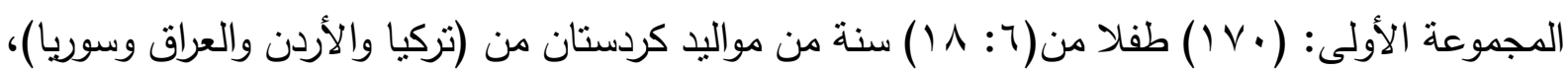
والثانية: (1) (1) طفلا من السويد بنفس العمر ، و وجد أن هناك أعراض للاضطرابات و المشاكل السلوكية، و أن الأطفال تختلف عن الكبار بإظهار أوجه التشابة أكثر بينهم بثأن تأثنر التجارب المؤلمة عليهم، كما

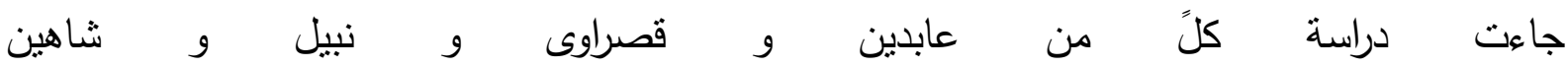
(Abdeen, Qasrawi,Nabil,\&Shaheen,2008) الاحتلال الإسرائيلي: دراسة على الأطفال في رفح الفلسطينية"، لعينة قوامها ( • (Y) طفلا فلسطينيا من سبعة

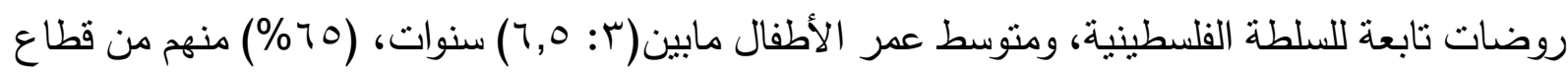
غزة ونسبة (0ب\%) من مدينة رفح، مستخدمة مقياس تفاعلات الأطفال الوجدانية مع العنف، وأظهرت النتائج أن نسبة حوالي(9\%\%) من المشاركين تعرضوا إلى العنف المباشر، وأن (\%1\%) من أطفال غزة وأطفال رفح يعانون من معدلات مرتفعة من الاضطرابات السلوكية. 
كما أجرى دييو وبوكسير وهوسمان وآخرون (Dubow,Boxer,Huesmann,et al,2010) دراسة عن:"أثر التعرض للصراع والعنف: دراسة التوافق النفسي بين الأطفال الفلسطينيين في مدينة رفح"، بهدف

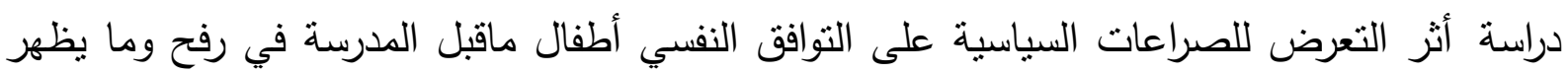

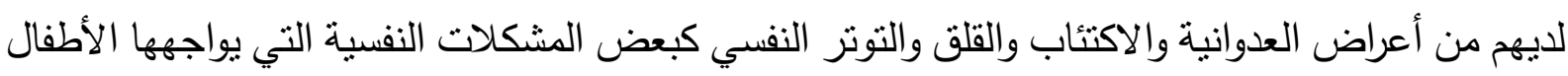

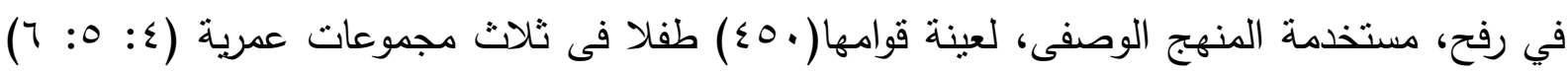

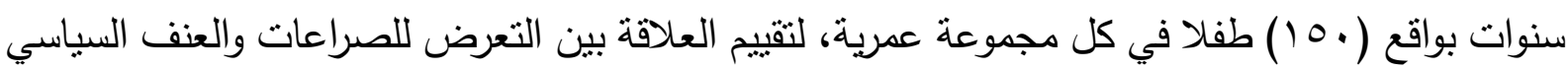

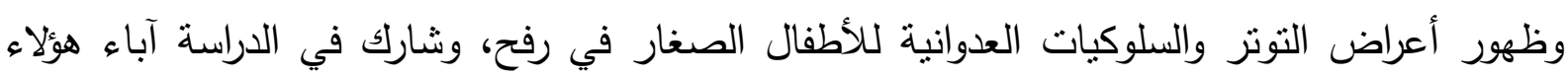

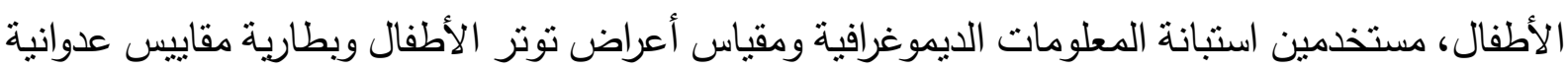

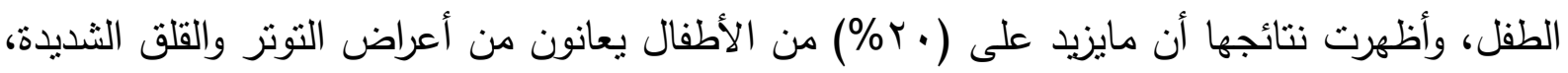

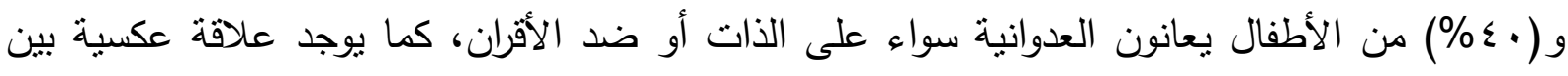

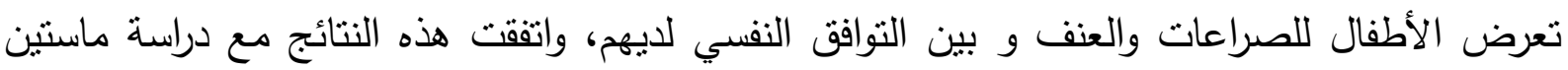

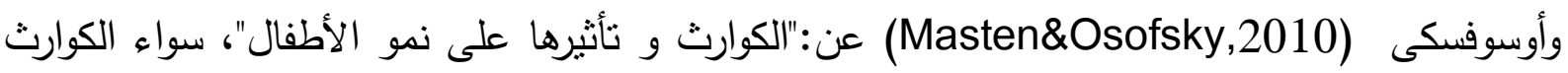

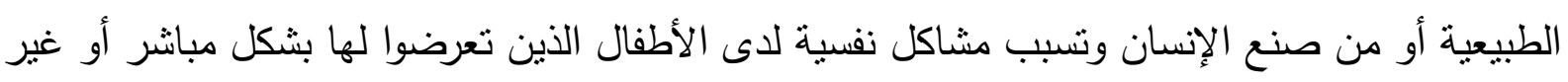

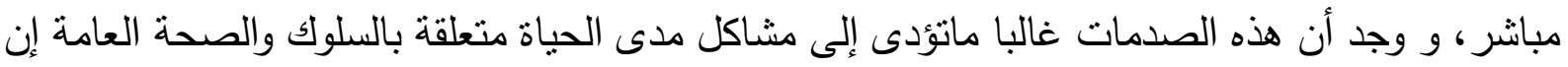

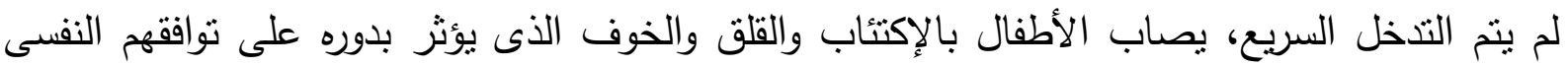

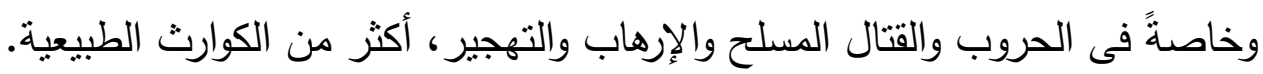

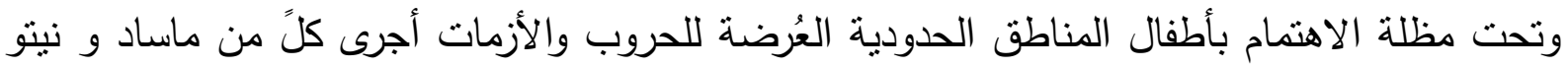
وبالتا وآخرون (Massad,Nieto,Palta,et al,2010) دراسة بعنوان:"الصحة النفسية والعقلية بين أطفال

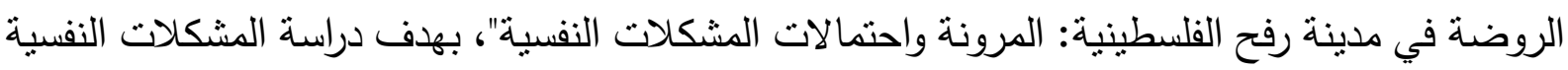

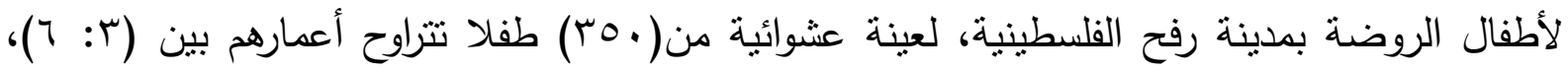

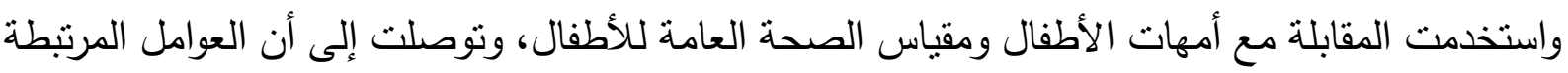

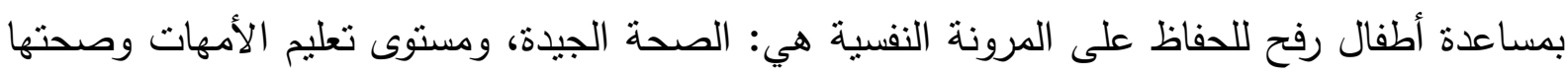

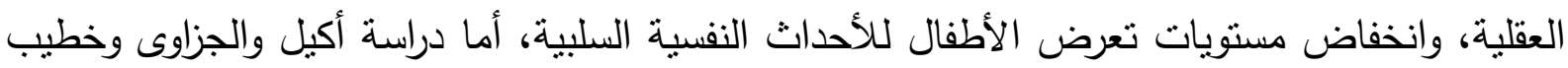
وآخرون (Aqeel, Al-Ghzawi, Khatib, et al, 2011) عن:"معدل اضطرابات النوتر النفسي لدى الأى الأطفال الصغار في غزة ورفح"، بهدف قياس التوافق النفسي بين الأطفال بالمدن الحدودية الواقعة تحت التحن

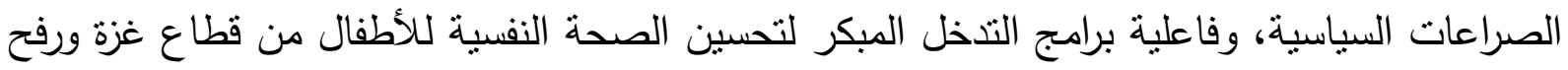

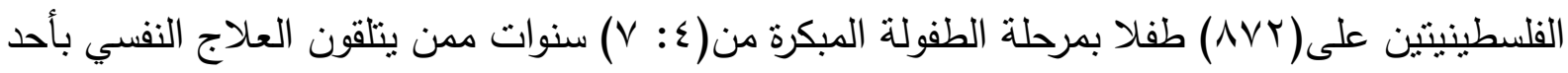

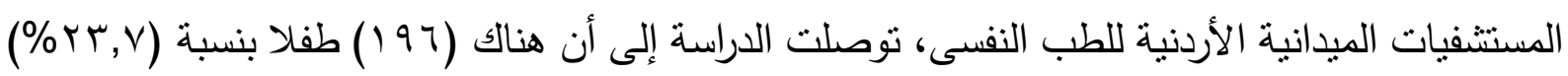
مِن المتواجدين فى عيادة الطب النفسي يعانون من أحد الاضطرابات السلوكية.

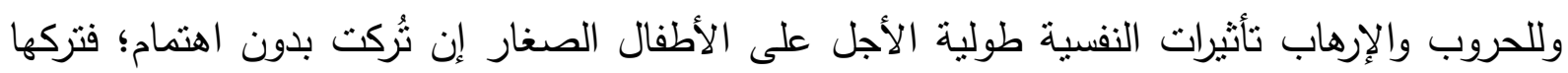

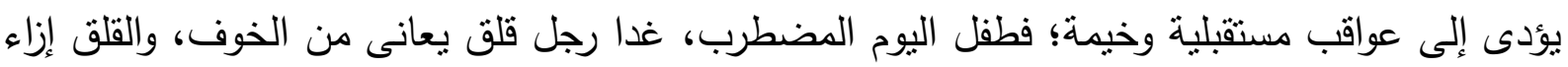


الأخطار حين يتجاوز حدوده المعقولة يسبب ضررا فادحا فى الثخصية، وعلى قدر ماتتزايد مساحة الخوف

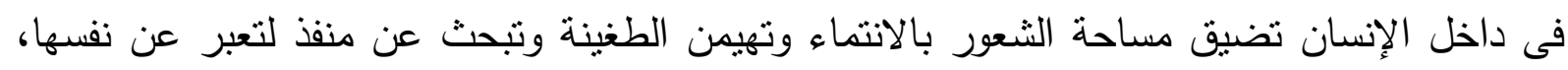

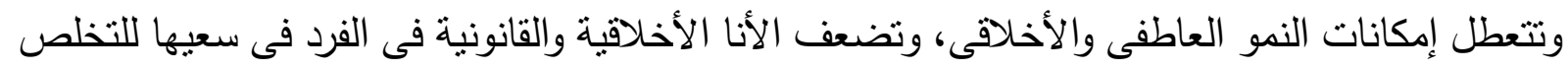

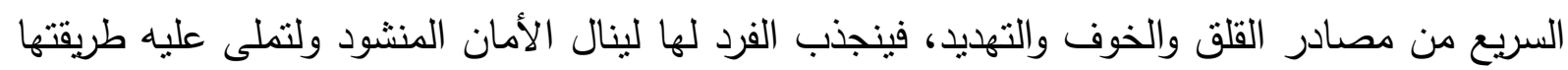

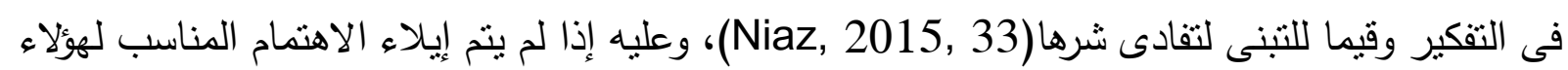
الأطفال بوصف اضطراباتهم السلوكية لتتاولها بالإرشاد النفسى المناسب كخطوة لاحقة قبل تفاقمها، فإنهم

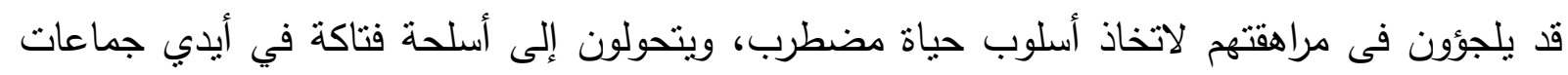

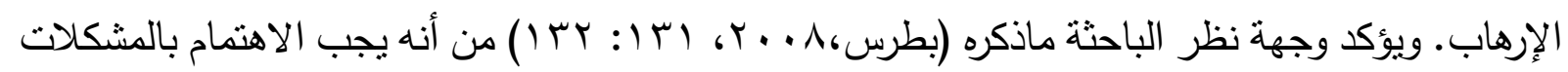

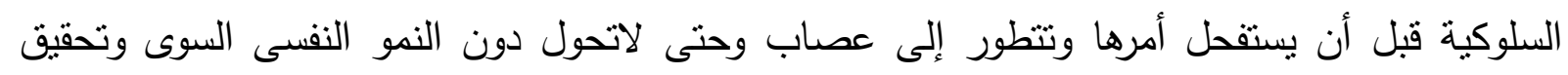

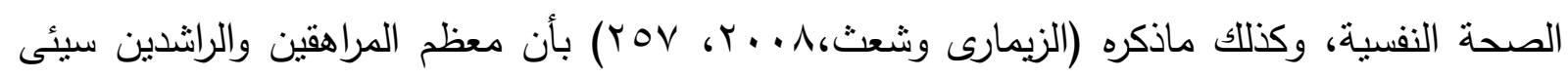

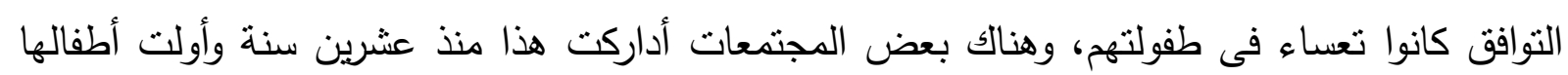

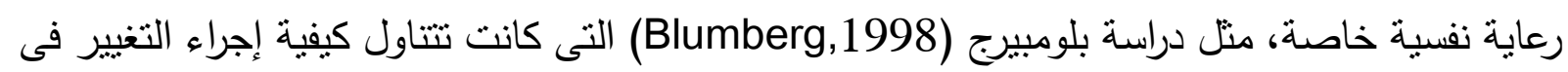

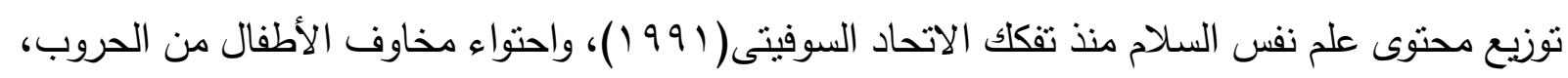

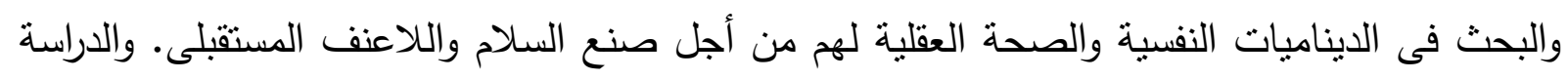
المسحية التى أجراها جيرويتش وفيفربام وليفتونت (Gurwitch,Pfefferbaum,\&Leftwich,2002) بعنوان:"أثر الإرهاب على الأطفال: اعتبارات لحقبة جديدة"، والتى تم فيها عمل دراسة مسحية للاراسات

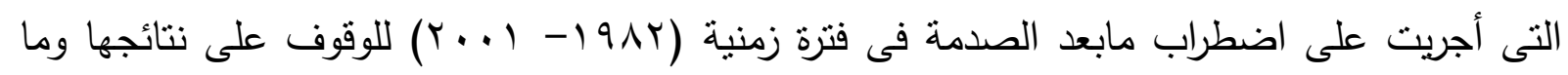

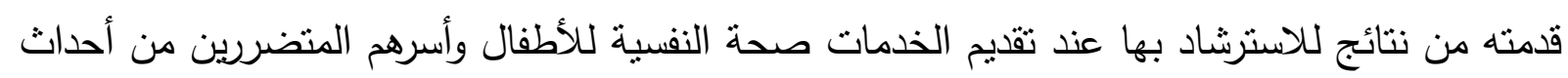

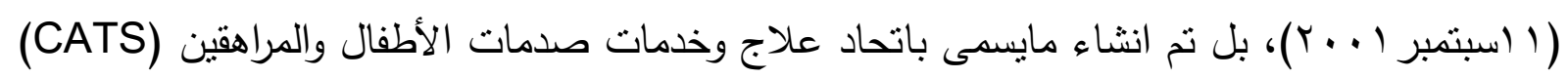

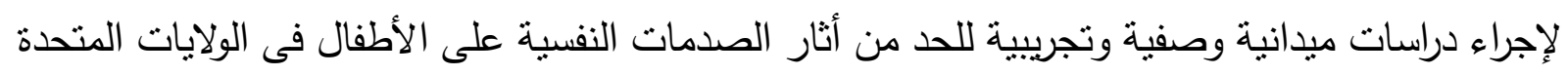

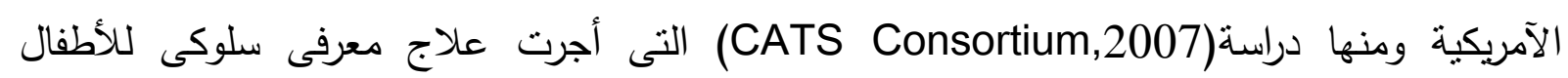

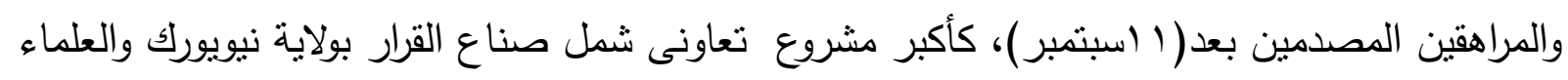

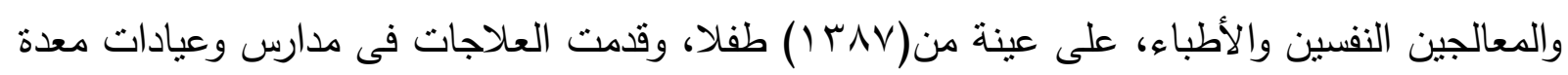

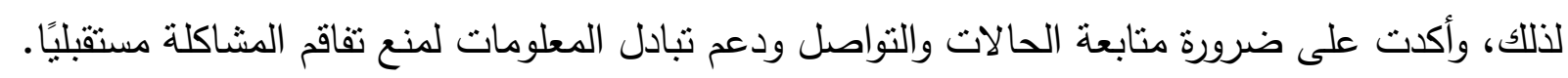

\section{النظريات المفسرة للاضطرابات السلوكية:}

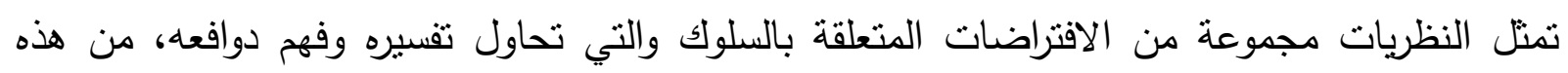

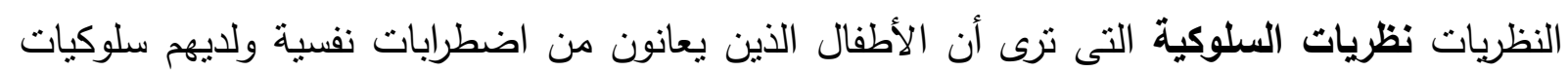

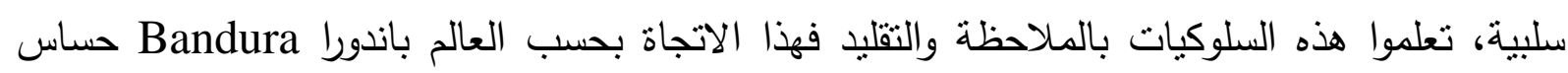

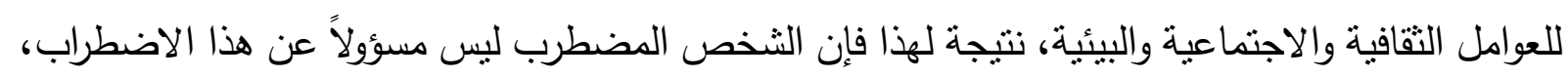

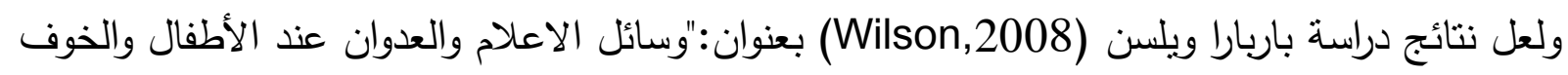

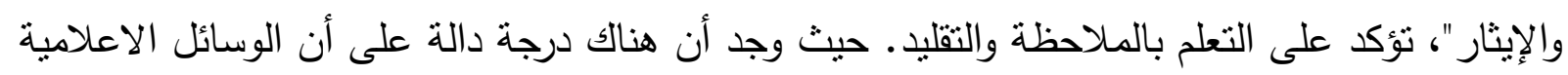


ومادتها المعروضة يمكنها أن تسهم فى نمو مشاعر القلق والخوف عند الأطفال وحالات من اضطراب

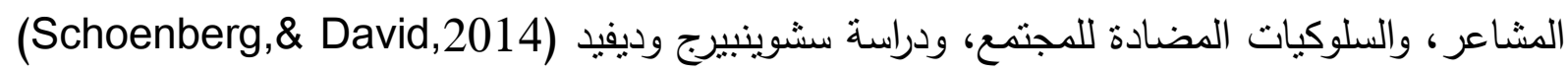

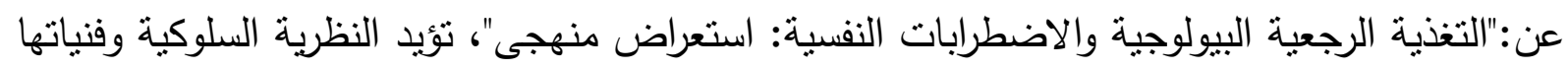

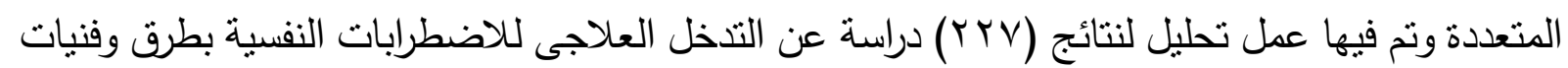

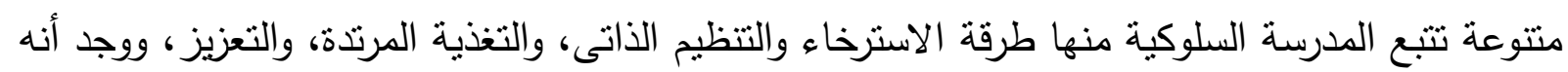

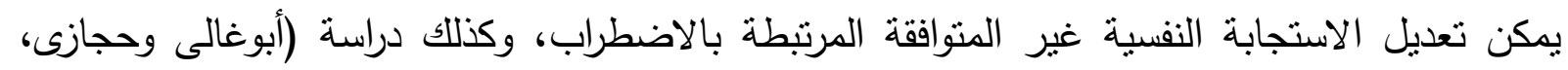

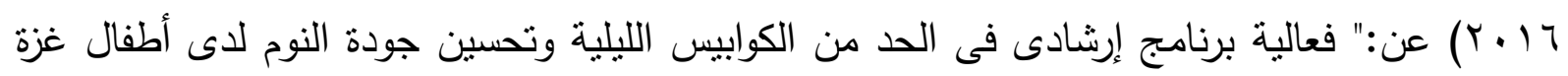

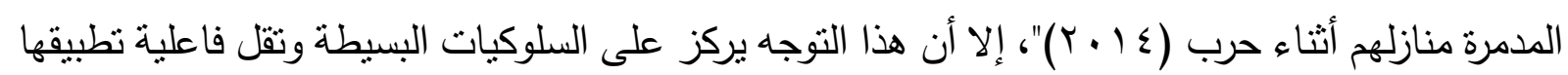

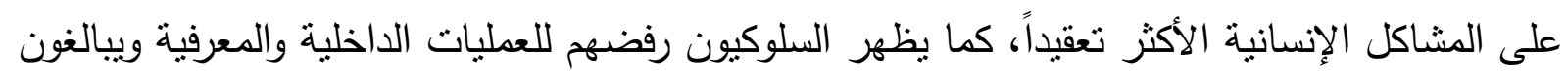

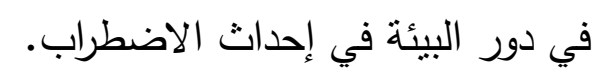

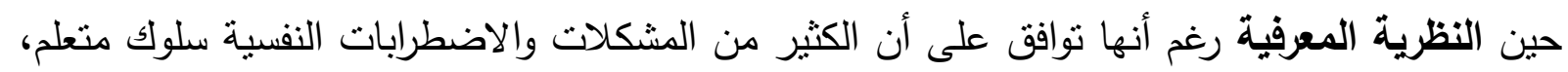

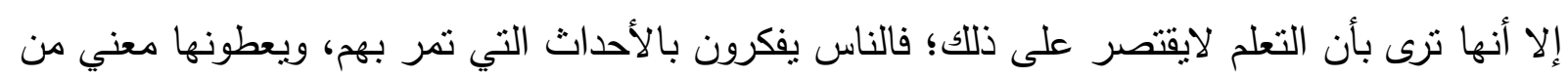

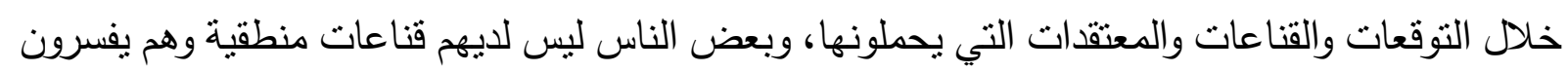

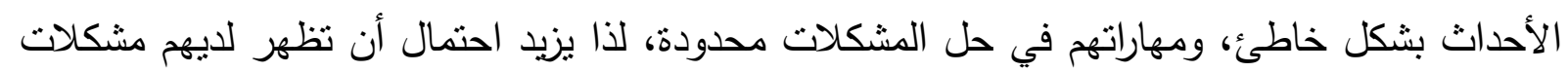

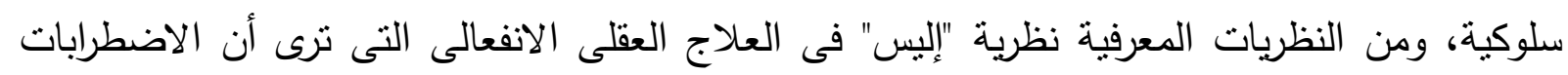

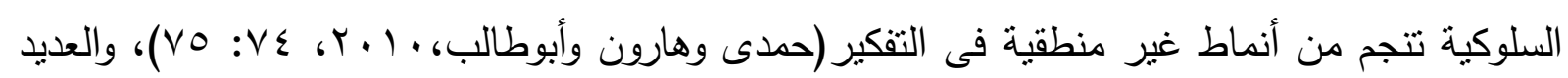

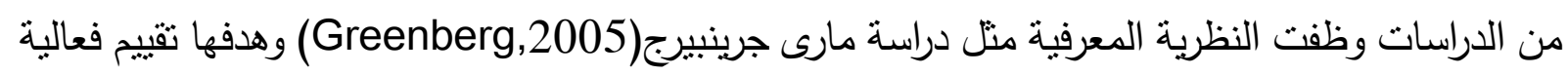

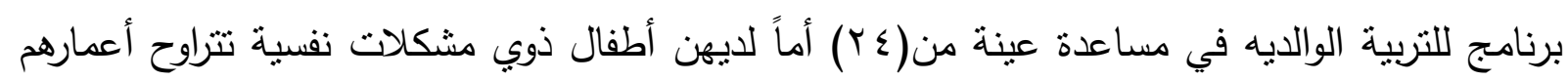

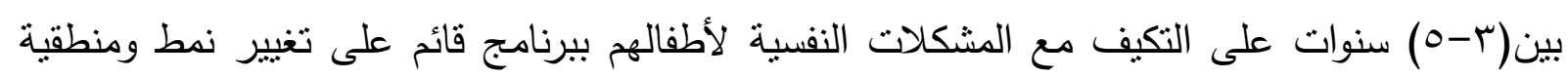

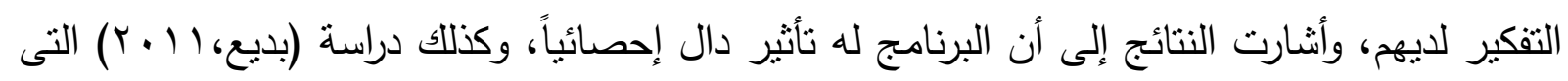

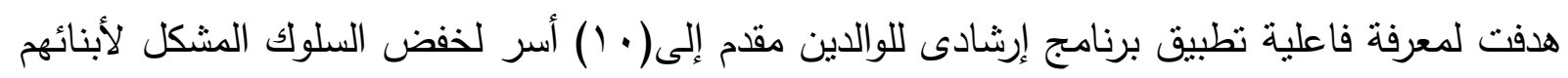

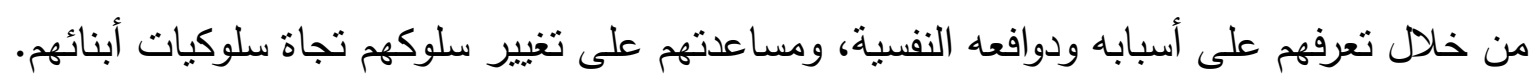

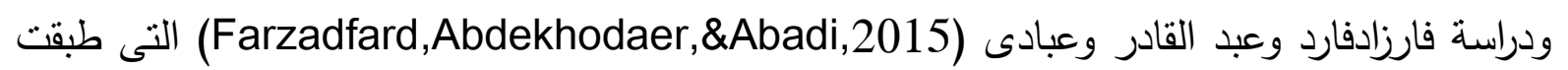
العلاج المعرفى على الأطفال مبانرةً مستخدمة "العلاج بالألعاب الهادفة و وبالنشاط القاد القصصى" لزيادة

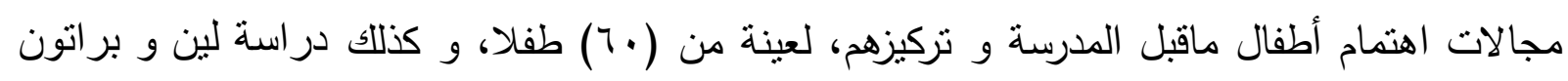

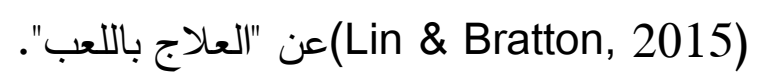
أما نظريات الاتجاه البيئي فى تقسير الاضطرابات السلوكية بركز أصحاب هذا الاتجاه على أن تفاعل القوى التحى

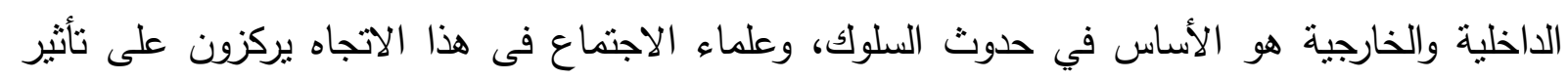

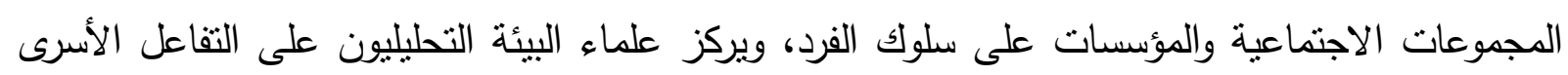

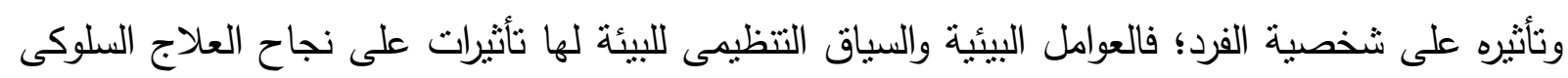

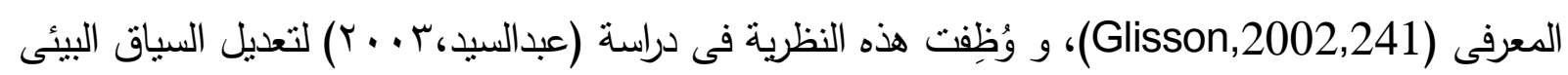


للأطفال بتقديم برنامج إرشادى لتحسين المهارات الوالديه بهذف خفض المشكلات السلوكية لدى الأطفال، لعينة من( • r آبًا و • r أمًا) ممن لديهم أطفال ويعانون من المشكلات السلوكية، وأثنارت النتائج إلى فاعلية البرنامج. ودراسة هاتمان وستين وإيكيلبيرجر وآخرون (Hautmann,Stein,Eichelberger,et al,2011) بعنوان: "فاعلية تدريب الأطفال ذوى مشاكل السلوك فى بيئة طبيعية"، لعينة من ( • V أسرة أطفالهم تتراوح أعمارهم بين

( (- - () سنوات لديهم مشاكل سلوكية، اظهرت نتائج فاعلية البرنامج فى خفض السلوك التخريبى للأطفال. حين يستتد الاتجاه الاينامي في تفسيره للاضطرابات السلوكية على فهم سلوك الإنسان من خلال تحليل العمليات الداخلية المتواجدة فيه، وتعتبر النظرية التحليلية لفروبد من أهم نظريات الاتجاه الدينامي، وهى الاهى ترى أن أحداثاً كثيرة في حياة الإنسان اليومية تستثير محتويات اللاشعور وتؤدي إلى شعور الفرد بالقلق والاضطراب. وأحدث اتجاه للنظريات الدينامية هو الاتجاه الإنساني الذى يقرر بأن سلوك الإنسان موجه

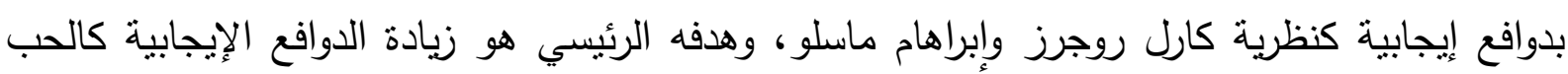
والاهتمام وتحقيق الذات، كقوى تحرك السلوك، ومساعدة الفرد في تتمية إمكاناته إلى أقصى مايمكن، والنظر

إلى الثخصية على أنها دينامية تتغير ، وأن الإنسان قادر على تعلم السيطرة وتعديل دوافعه الداخلية. كما قدمت النظرية النفسية الاجتماعية لأريكسون تصور يتعلق بالنمو الإنساني و مايرتبط به من مشكلات سلوكية، والنجاح في مواجهة مشكلاته، يعزز إمكانات النجاح في المرحلة التالية. أما أدلر فى نظريته الميل الاجتماعي للفرد فيفترض أن سلوك الإنسان تحركه الحوافر والاهتمامات الاجتماعية، ويسعى باستمرار ليكون أسلوبه الفريد في الحياة، ويضع هدفاً لحياته يعمل على تحقيقه ويحثه على بذل الجهد للتغلب على شعوره بالنقص من خلال الكفاح في سبيل التقوق وتحقيق الهدف، وإن لم تتم العملية بشكل سلس يتسبب هذا للإنسان بالاضطرابات السلوكية.

تصنيفات الاضطرابات السلوكية:

أولاً: تصنيف الاليل التثخيصي و الإحصائي للاضطرابات النفسية والسلوكية التى يعانيها الأطفال: يعتمد هذا التصنيف على وجهة الطب النفسي التي تفترض وجود أسباب داخلية لاضطرابات السلوك و تعتبرها اضطرابات عقلية، وهى كالأتى: هاضطرابات النمو العصبية مثل:اضطرابات صعوبات التعلم واضطرابات التواصل واضطراب طيف الذاتوبة واضطراب فرط الحركية ونتنت الانتباة. الاضطرابات الاكنئابية. الاضطرابات المتعلقة بالصدمة. مشكلات متعلقة باضطراب السلوك: كالعدوان والغضب والسرقة والتخربب والجنوح والكذب. مشكلات القلق: كقلق الانفصال و القلق الاجتماعى. الاضطرابات المرتبطة بسلوك التغذية والأكل.

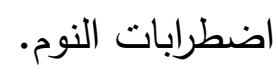
اللوازم الحركية: كمص الأصابع و قضم الأظافر • 


$$
\text { اضطرابات الإخراج: كالتبول اللإرادى و التغوط. }
$$

اضطرابات أخرى: ذهان الطفولة و السلوك الاجترارى. (APA, 2013,xiii: xl)

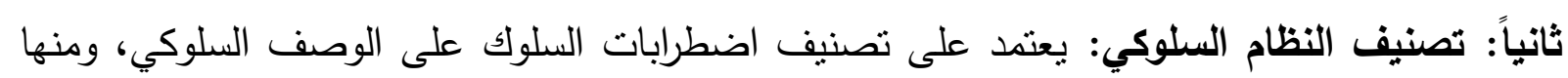
تصنيف كوفمان Kauffman حيث يصنف ان السلوك إلى: الحركة الزائدة والتخريب، والاندفاعية، و

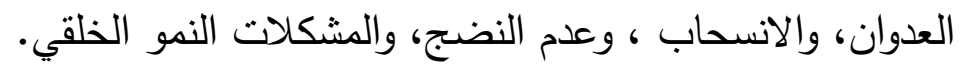

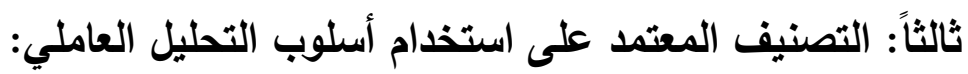

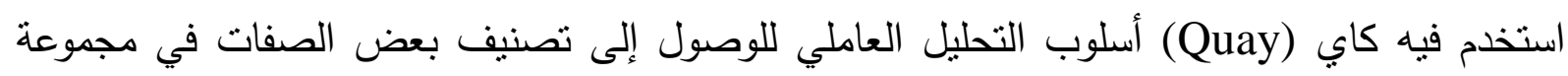
متجانسة حيث قسم اضطرابات السلوك إلى ما يلي: الئل

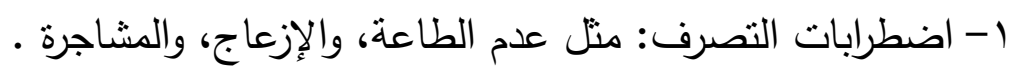
r- الاضطرابات النمائية العامة، والاضطرابات النمائية المحددة كالذاتوية.

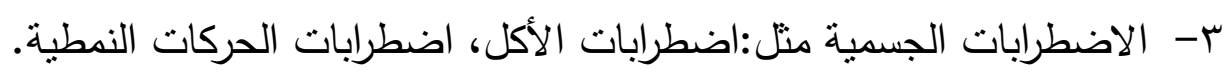

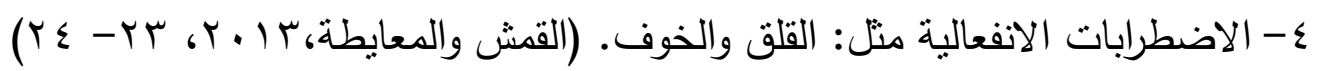
رابعاً: التصنيف اعتماداً على شدة الاضطراب السلوكي وهى كالأتى: الإنى

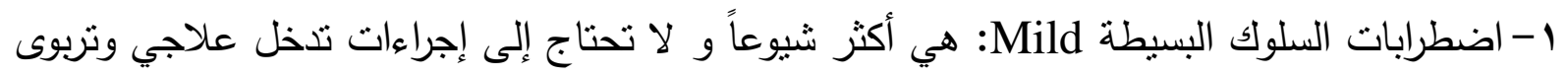
كبير وتشمل مشكلات سوء التكيف البسيطة و المشكلات الموقفية.

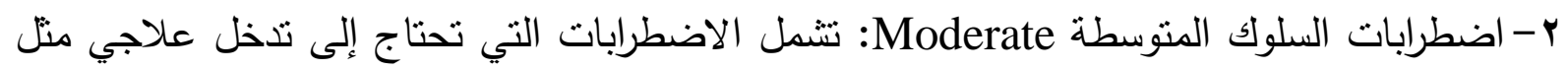

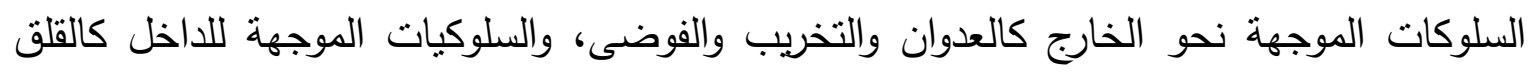

$$
\text { والانسحاب الاجتماعي والخوف المرضي. }
$$

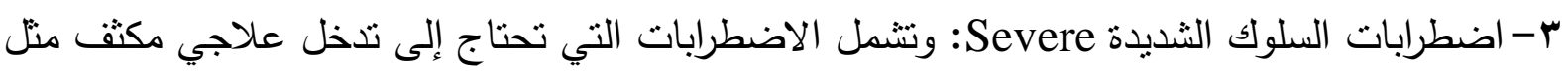
حالات ذهان الطفولة أو فصام الطفولة.

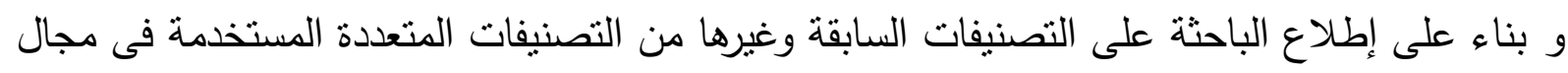

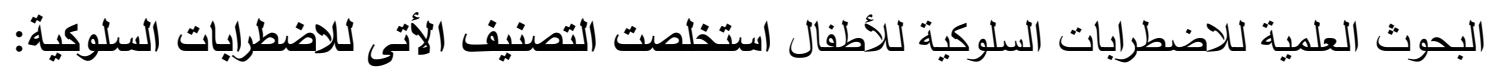

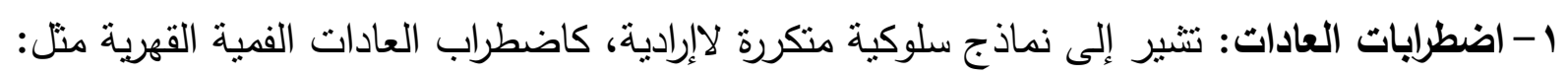

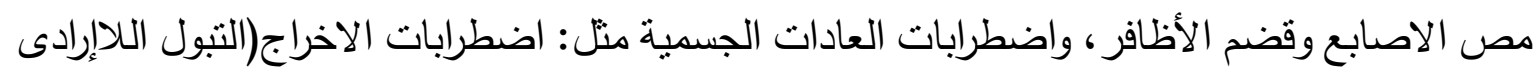
وسلس الغائط) ، واضطراب عادات التغذية، واضطراب عادات النوم.

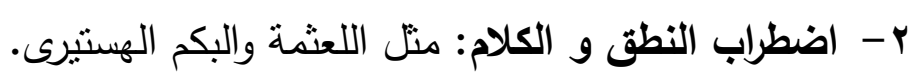
r- الاضطرابات الوجدانية: منل القلق الانفصال، والخوف، والخجل والإنل والانسحاب الاجتماعى (الإنطواء)،

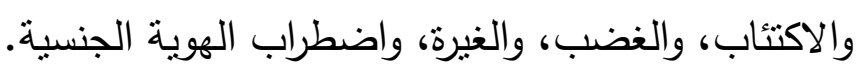

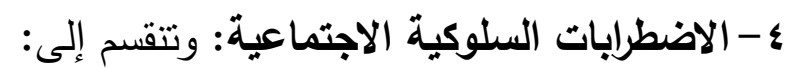
أ- مشكلات السلوك غير الناضج: كالاعتمادية الزائدة والانانبة (التمركز حول الأنات). 
ب- مشكلات مضادة للمجتمع: هو السلوك الذى يظهر فيه اعتداء على حقوق الغير، وخرقا للمعايير والقوانين الاجتماعية بما لايلائم المرحلة العمرية التى يمر فيها الطفل منل: الكذب، والعناد، والسرقة، والتمرد والتخريب، والعدوان سواء كان فى شكل عدوان بدنى نحو الذات والآخرين أو عدوان تعبيرى

$$
\text { (لفظى/غير لفظى) على الذات أو على الآخرين. }
$$

ه- اضطرابات العصبية: وتشمل العديد من الاضطرابات منل صعوبات التعلم، وبطء التعلم، وفرط الحركة

وتتنت الانتباه، وضعف الدافعية للاراسة، والاضطرابات النمائية الثاملة.

و لم يتم تتاول مشكلات السلوك غير الناضج فى هذا البحث نظرا إلى أنها تعتبر من طبيعة مرحلة الطفولة المبكرة ولاتمثل اضطراباً، وغالبا يتخلص منها الأطفال بشكل تلقائى مع الانتقال للمراحل العمرية المقبلة. كما لم يتم تناول اضطرابات العصبية فى البحث الحالى لظروف واقع عينة البحث.

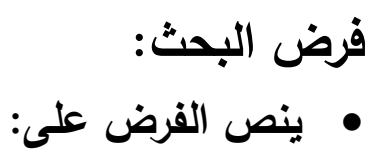
"توجد فروق ذات دلالة إحصائية بين منوسطات درجات أطفال كلً من رفح المهجرين و أطفال العربش و أطفال القاهرة على القائمة التشخيصية للاضطرابات السلوكية من حيث ( اضطرابات العادات- اضطراب دماب دهن النطق والكلام - الاضطرابات الوجدانية- الاضطرابات السلوكية الاجتماعية) بأبعادها الفرعية و الدرجة

الكلية على القائمة النتخيصية فى اتجاة أطفال رفح المهجرين".

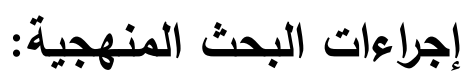
منهج البحث:

في ضـوء أهداف الدراسـة و فرضـها اسـتخدمت الباحثة المنهج الوصـفي المقارن للتعرف علي الفروق بين المجموعات الثثلاثة فى مستوي الاضطرابات السلوكية.

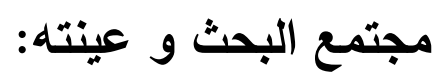

عينة البحث مكونة من ثلاث مجموعات من الأطفال جميعهم نتراوح أعمارهم من (0: 0,7) سنوات أخذوا من ثلاث مجتمعات، هم كالأتى: (ب) طفلا من الأطفال التى هاجرت مع أسرهم من رفح فى الفترة الزمنية

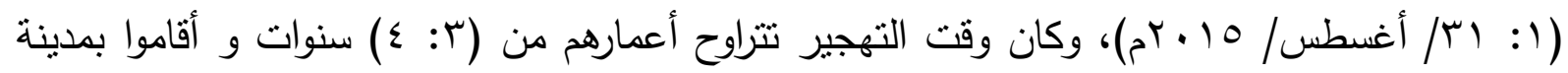
العريش أو بمدينة الإسماعلية، و (ب) طفلا من الأطفال المقيمين بمدينة العربش منذ ميلادهم، و (ب) (بم) طفلا من الأطفال المقيمين بالقاهرة منذ ميلادهم. تم مراعاة بعض الثروط عند اختيار عينة الأطفال (المهجرين من رفح- العريش- القاهرة) لمراعاة ضبط متغيرات البحث والعوامل التى قد تؤثز على النتيجة بقدر الإمكان، وهى كالتالى: ا- أن تكون العينات الثلاث لايقل عمر الأطفال بها عن (0) سنوات و لايزيد عن (1,7) سنوات. r- لا يكون أطفال العينات الثلاث من ذوى الاحتياجات الخاصة. r- تكون أسر الأطفال بالعينات الثلاثة مكتملة بوجود الأب والأم. ع - تكون أمهاتهم متعلمات وقادرات على القراءة والكتابة. 
0- تنتنمل العينات الثناث على أطفال من الجنسين.

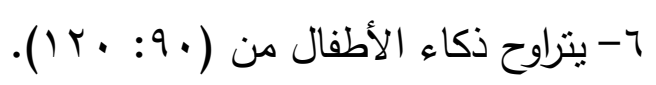

V- تكون عينة أطفال العريش و أطفال القاهرة مقيمين بشكل دائم منذ ميلادهم بمدنهم ( العريش -القاهرة)،

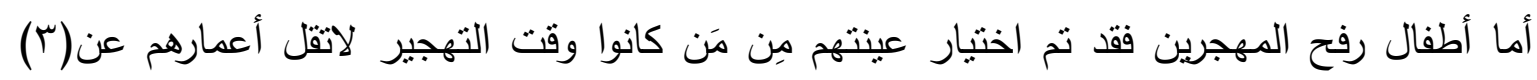

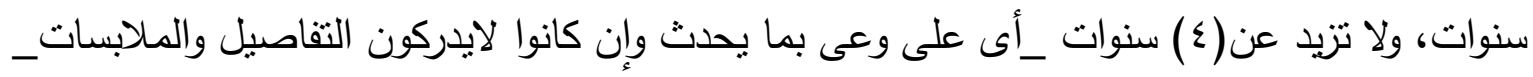

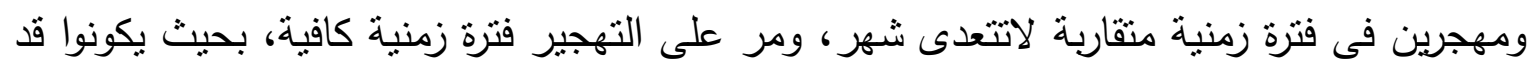
تعدوا تماما مرحلة الصدمة. ᄉ- تقارب مستوى الروضات المنتمى إليها الأطفال فى المجموعات الثلاثة بقدر الامكان، فى محاولة لضبط متغير المستوى الاجتماعى و الاقتصادى.

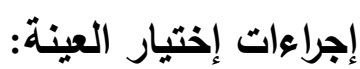

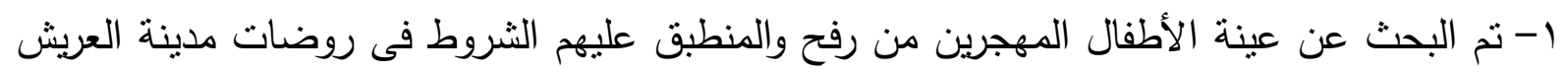

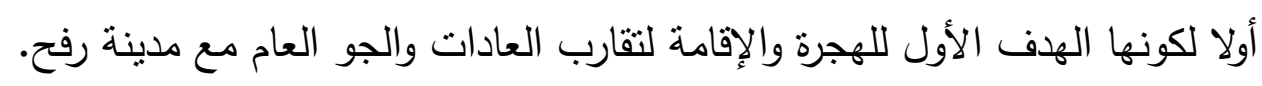

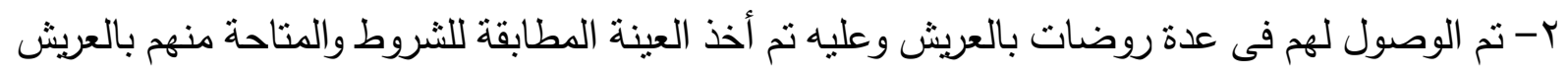

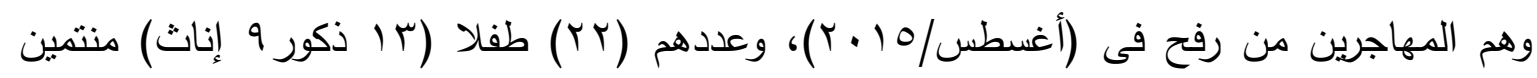

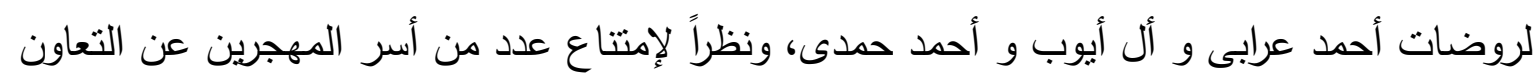

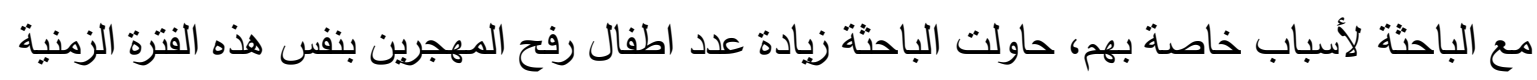

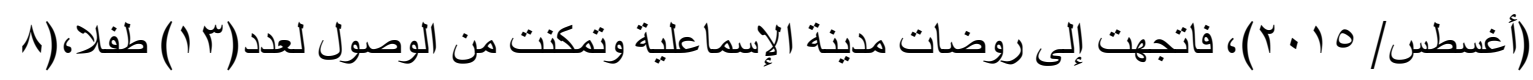

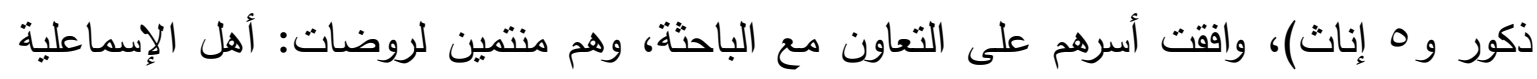

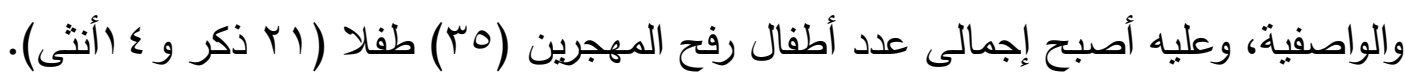

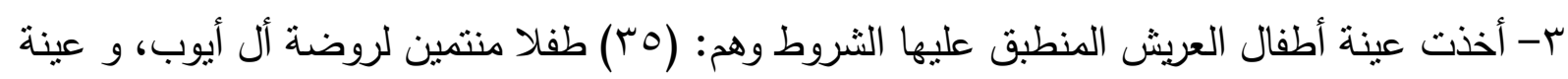

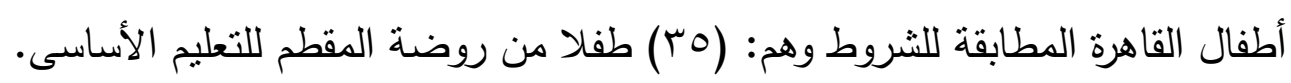

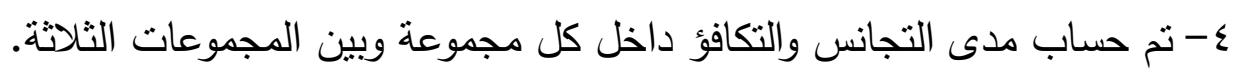

\section{تجانس عينة الأطفال فى كل مجموعة من المجموعات الثلاثة:}

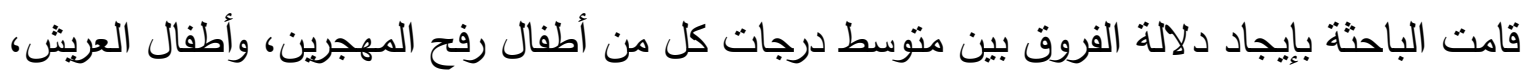

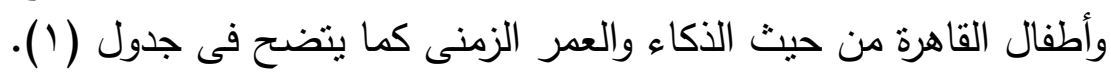




\section{جدول (1)}

دلالة الفروق بين متوسط درجات كل من أطفال رفح المهجرين وأطفال العريش وأطفال القاهرة من حيث الأكاء

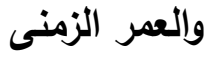

\begin{tabular}{|c|c|c|c|c|c|c|c|}
\hline \multicolumn{2}{|c|}{ حدود الدلالة } & \multirow{2}{*}{ درجة } & \multirow{2}{*}{ مستوى الدلالة } & \multirow[t]{2}{*}{ كاr } & \multirow[t]{2}{*}{ المتغيرات } & \multirow[t]{2}{*}{ عدد الأطفال } & \multirow[t]{2}{*}{ المجموعة } \\
\hline., .0 & $\cdot, \cdot 1$ & & & & & & \\
\hline ro & $\overrightarrow{r \cdot, r}$ & 10 & غيردالة & $1 \cdot, y_{0}$ & الأكاء & \multirow[t]{2}{*}{ ro } & \multirow[t]{2}{*}{ أطقال رفح } \\
\hline $1 \wedge, r$ & $r r, r$ & 1. & غيردالة & 10,7 & العمر الزمنى & & \\
\hline$\overline{r q, r}$ & rr & 17 & غيردالة & $19, \wedge 1$ & الأكاء & \multirow[t]{2}{*}{ ro } & \multirow{2}{*}{ أطريش أطفال } \\
\hline 10,0 & $r \cdot, l$ & $\Lambda$ & غيردالة & $\wedge, 9 \vee$ & العمر الزمنى & & \\
\hline$r 4, r$ & rr & 17 & غيردالة & $V, Y_{0}$ & الأكاء & \multirow[t]{2}{*}{ ro } & \multirow[t]{2}{*}{ أطفال القاهرة } \\
\hline 17,9 & 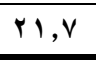 & 9 & غيردالة & $1 r, \wedge 0$ & العمر الزمنى & & \\
\hline
\end{tabular}

يتبين من جدول (1) عدم وجود فروق دالة إحصائيا بين متوسط درجات أطفال رفح المهجرين وأطفال العريش وأطفال القاهرة من حيث الذكاء و العمر الزمنى مدا يثير إلى تجانس أطفال كل مجموعة من المجموعات الثنلاثة.

\section{التكافؤ بين المجموعات الثُلاث (أطفال رفح المهجرين و العريش و القاهرة):} قامت الباحثة بحســاب التكافؤ بين المجموعات الثلاثثة من حيث (العمر الزمني ونســبة الذكاء)، وذلك باسـتخدام اختبار تحليل التباين البسـيط أحادي الاتجاة (One Way Anova) للمجموعات الثلاثة فى المتغيرات المشنار إليها. و يوضــح جدول(ب) المتوســطات والإنحرافات المعيارية للمجموعات الثلاثة فى متغيرات العمر الزمنى والذكاء.

\section{جدول (r)}

المتوسطات والاتحراقات المعيارية للتكافؤ بين المجموعات الثلاثة فى العمر الزمني و مستوى الأكاء(ن = ه . 1 )

\begin{tabular}{|c|c|c|c|c|c|c|}
\hline \multicolumn{2}{|c|}{ 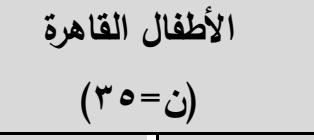 } & \multicolumn{2}{|c|}{ 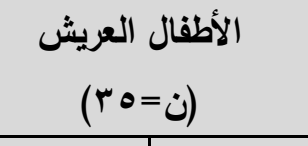 } & \multicolumn{2}{|c|}{ 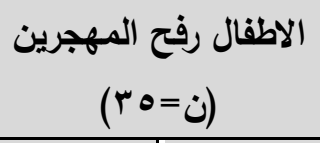 } & \multirow[t]{2}{*}{ المتغيرات } \\
\hline$\varepsilon$ & מי & $\varepsilon$ & קי & $\varepsilon$ & p & \\
\hline צ ד, & $7 q, r v$ & rיד & 99,11 & r זיד r & 99,10 & العمر \\
\hline $7, O Y$ & $1 \cdot v, 71$ & $Y, Y$. & $1.7,7 r$ & $7,1 \vee$ & $1 \cdot V, 70$ & الأكاء \\
\hline
\end{tabular}

ويوضح جدول(ب) نتائج تحليل التباين للفروق بين المجموعات الثناثة فى العمر والذكاء 
جدول (ז) - (ז)

نتائج تحليل التباين للفروق بين المجموعات الثلاثة فى العمر والذكاء (ن= ه ـ 1)

\begin{tabular}{|c|c|c|c|c|c|c|}
\hline مستوى الدلالة & قيمة "فـ" & متوسط المربعات & درجات الحرية & مجموع المربعات & مصدر التباين & المتثيرات \\
\hline \multirow{3}{*}{$\cdot, \wedge \leqslant 9$} & \multirow{3}{*}{ ·, $17 \varepsilon$} & $r,|A|$ & r & L, & بين المجموعات & \multirow[b]{3}{*}{ العمر } \\
\hline & & Ir,rra & 1.r & $1 r 09,9 .$. & داخل المجموعات & \\
\hline & & & $1 . \varepsilon$ & 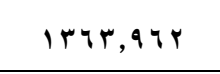 & الاجمالى & \\
\hline \multirow{3}{*}{ - VYV } & \multirow{3}{*}{. } & 19,490 & $r$ & ro,ra. & بين المجموعات & \multirow[b]{3}{*}{ الذكاء } \\
\hline & & $r q, v \leqslant 1$ & $1 . r$ & \&.or,,.. & داخل المجموعات & \\
\hline & & & 1.8 & 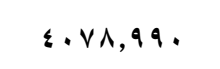 & الاجمالى & \\
\hline
\end{tabular}

وبالنظر فى الجدول(ץ) يتضح أنه: لا توجد فروق دالة إحصائي بين المجموعات الثلاثة فى كلً من العمر الزمني، ونسبة الذكاء، وهو ما يشير إلى تكافؤ مجموعات الثناث في فئ هذه المتغيرات حيث كانت قيمة ف غير دالة. أدوات البحث: ا - اختبار المصفوفات المتتابعة الملون " لجون رافن John-Roven r- القائمة التشخصية"اللاضطرابات السلوكية": "Diagnostic List of behavioral disorders”

• اختبار المصفوفات المتتابعة الملون Cpm "لجون رافن John-Roven": هو اختبار عبر حضارى صالح للتطبيق في نقافات مختلفة، عندما يكون الهذف البعد عن أثز التقافة على إنى

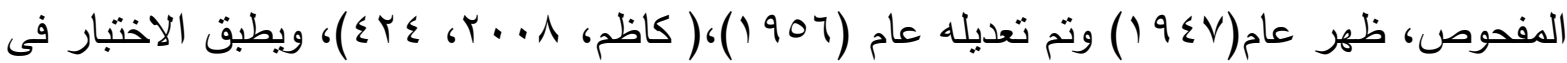

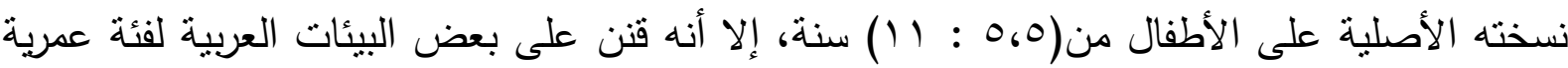

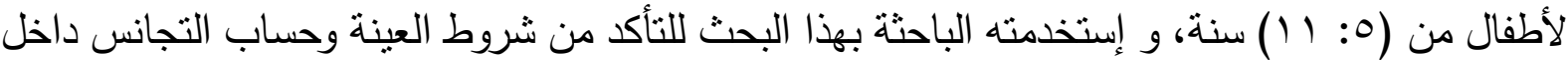
كل مجموعة، والتكافؤ بين المجموعات الثلاثة.

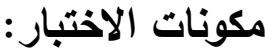

يتكون من(ץ) مجموعات وهى: المجموعة (A)، و(AB)، و (B)، كل مجموعة من المجموعات السابقة

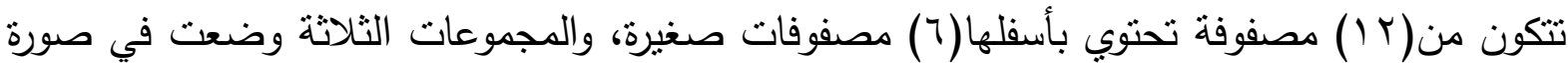
مرتبة وملونة بألوان مختلفة؛ لجذب انتباه الطفل المفحوص والبعد عن تنتت انتباهه. 


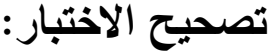

يحسب لكل سؤال صحيح أجابه الدفحوص درجة، و السؤال الذي لم يجاب يوضع له (· ·)، وتجمع الدرجات المفحوص لمعرفة الدرجة الكلية، ومعرفة مايقابل هذه الدرجة الخام من درجة مئينية ونسبة ذكاء. الخصائص السيكومترية للاختبار: تراوح دعامل الارتباط بين مصفوفات رافن الملونة بالجزء اللفظي لاختبار وكسلر للأطفال بين(اس، ؛:

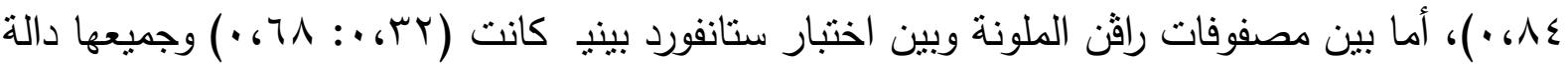

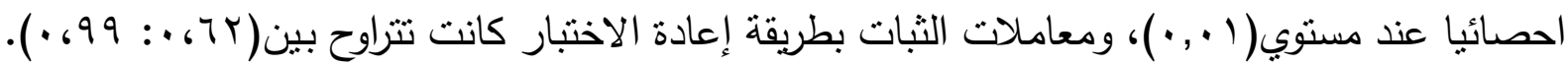

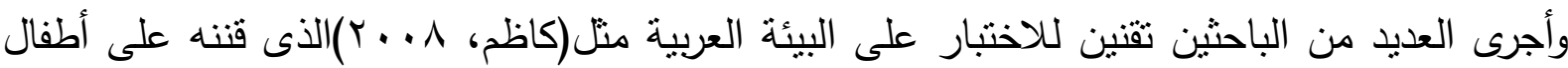

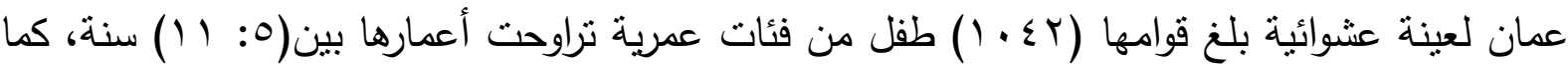

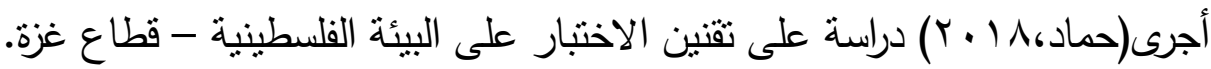

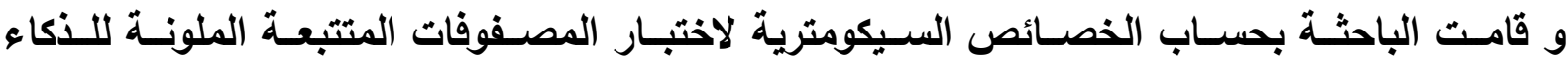

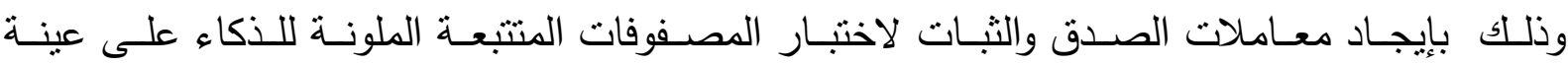

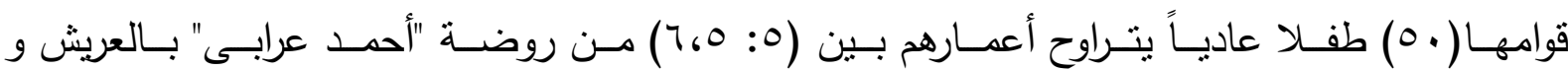
روضة "أبو الهول" بالجيزة و كالاتى:

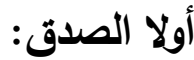
قامت الباحثة في البحث الحالى بإستخدام صدق المحك الخارجي مع إختبار رسم الرجل (هاريس، ـ . ب)،

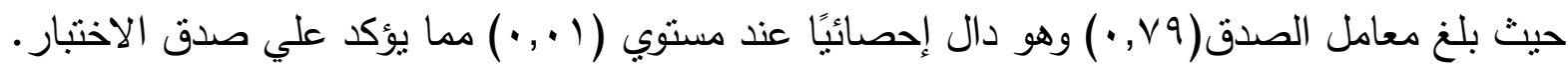

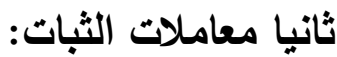
قامـت الباحثـة بايجـاد معـاملات الثبـات لاختبـار المصـفوفات المتتبعـة الملونــة للــكاء باسـتخدام

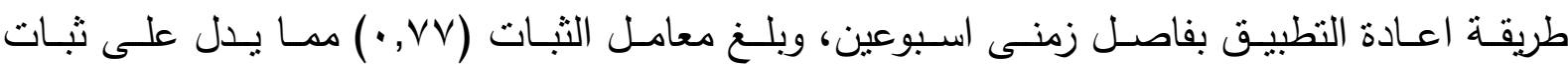

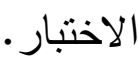

القائمة التشخيصية للاضطرابات السلوكية:

”Diagnostic List of behavioral disorders”

أ- الهذف من القائمة التشخيصية للاضطرابات السلوكية: تقدير شدة الاضطرابات السلوكية من خلال قياس شدة (·ץ) اضطراباً منتمين لاضطرابات العادات، و ولاتهات اضطراب النطق والكلام، والاضطرابات الوجدانية، والاضطرابات السلوكية الاجتماعية، لاى الأطفال الذين

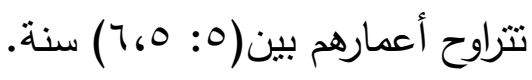

ب- مبررات إعداد القائمة التثخيصية للاضطرابات السلوكية: ا-ضرورة القياس العلمى لتحديد شدة الاضطرابات السلوكية لدى الأطفال الذين يتعرضون مع أسرهم لظروف بيئية اجتماعية غير داعمة محفوفة بالمخاطر والصراعات والعنف والعمليات الإرهابية، لمقارنتهم بالأطفال الذين يعيشون وأسرهم فى بيئة أمنة. 
r- تحديد شدة الاضطرابات السلوكية الفرعية -(•) اضطراب- المنتمية لأربع أنواع من الاضطرابات السلوكية(اضطرابات العادات- اضطراب النطق والكلام- الاضطرابات الوجدانية- الاضطرابات

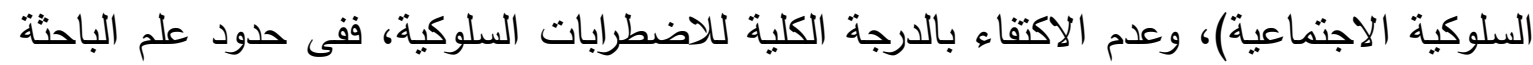

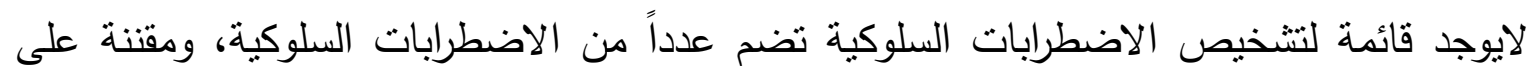
الأطفال أعمارهم ما بين(0: قائمة 0، 7) سنوات.

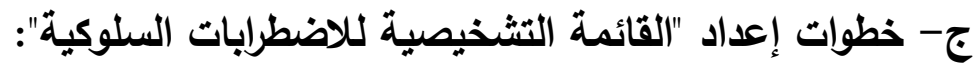

اتبعت الباحثة الخطوات التالية قبل التوصل للصورة النهائية للقائمة التتخيصية للاضطرابات السلوكية: الخطوة الأولى: الرجوع للمصادر العلمية؛ للتحديد الدقيق للفهوم الاضطرابات السلوكية وتصنيفتها المتتوعة

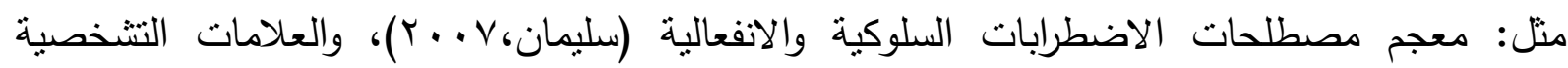

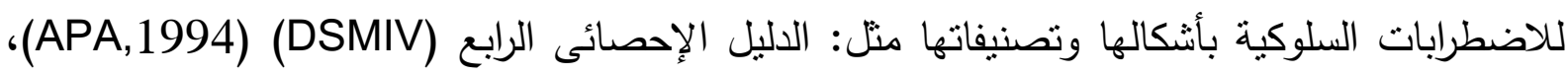

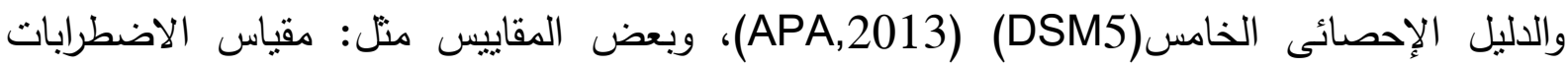

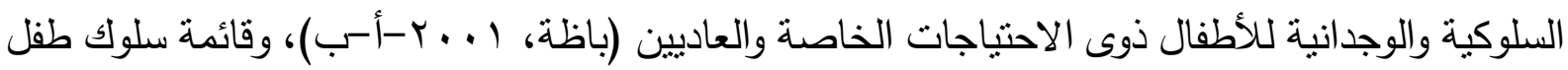

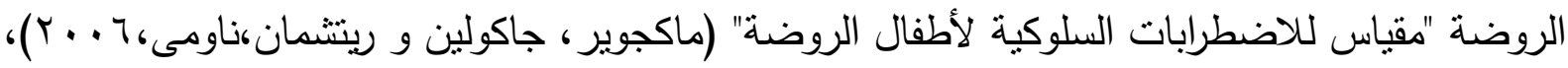

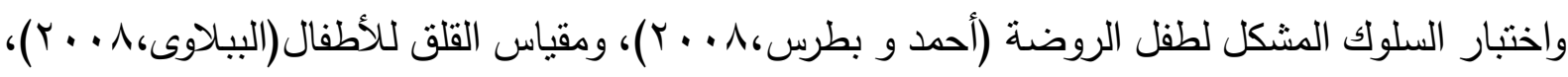

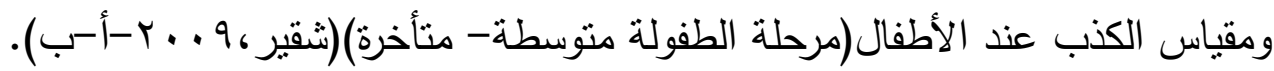

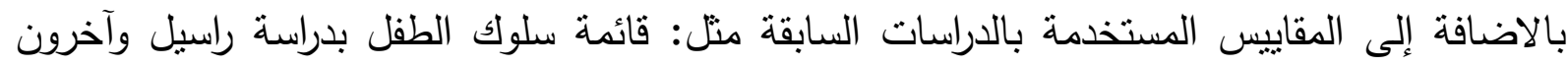

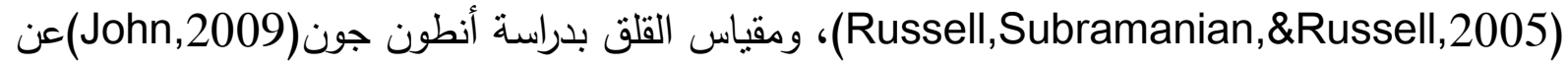
تخفيف حدة القلق لدى أطفال ماقبل المدرسة، و إستمارة لقياس السلوك المشكل لدى الأطفال بدراسة هاتمان

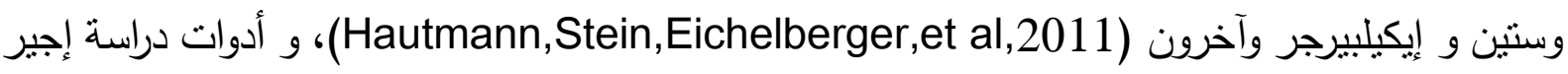
وانجولد (Egger\&Angold, 2011) لاضطرابات الإنفعالية والسلوكية الثائعة فى أطفال ماقبل المدرسة.

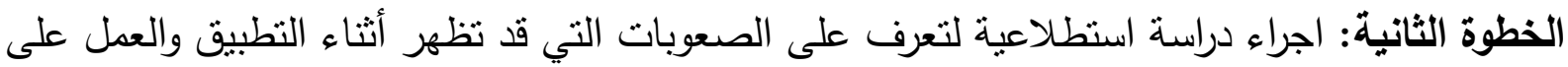

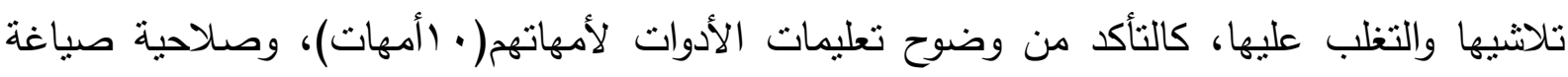
العبارات و وضوحها فى المعنى أثناء تعاملهن مع القائمة التشخيصية للاضطرابات السلوكية، وتم تعديل صياغة العبارات التى اتفقت (بالأمهات) على غموضهاء

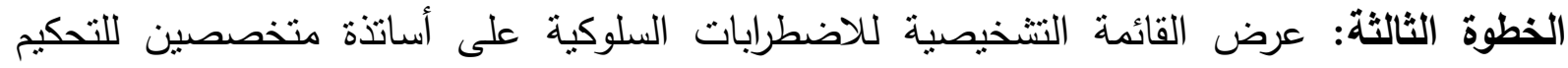

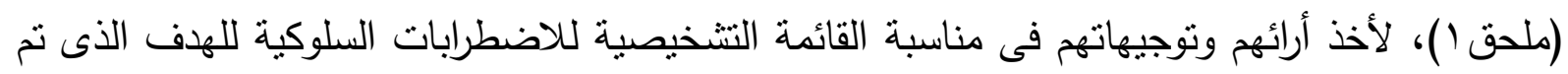
إعدادها له، وما تتضمنه من اضطرابات وعبارات تعبر عنها، ومدى مناسبتها لطبيعة عينة البحث، وطريقة

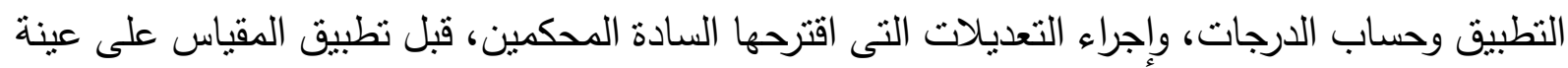

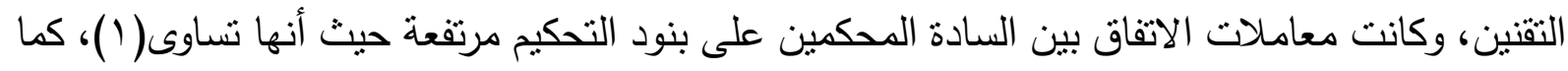

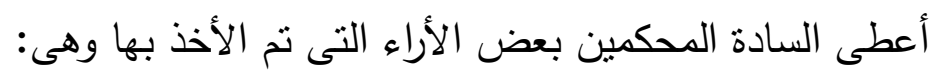

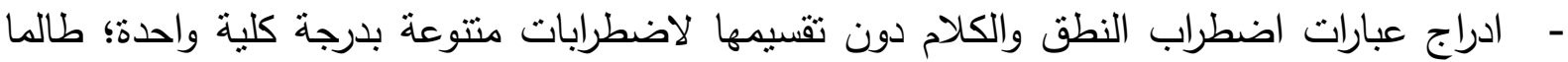

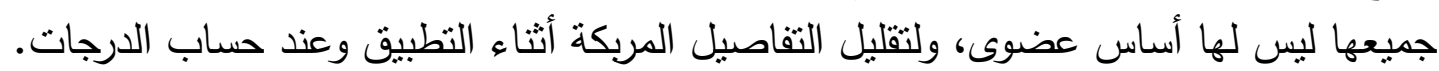


- طلب المحكمون بتصنيف اضطراب الهوية الجنسية تحت الاضطرابات الوجدانية، بعد أن كانت الباحثة تدرجها تحت اضطرابات العادات على اعتبار أن الطفل اعتاد على سلوكيات لاتتاسب جنسه. الخطوة الرابعة: الوصول لمرحلة حساب الخصائص السيكومترية للقائمة التشخيصية للاضطرابات السلوكية لحساب خصائصها السيكومتربية. • الخصائص السيكومترية للقائمة التشخيصية للاضطرابات السلوكية: قامت الباحثة بإيجاد معاملات الصــدق والثبات للقائمة التشـخيصـية للاضــطرابات السـلوكية على عينة

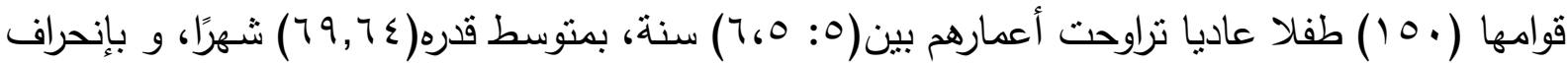
معياري قدره (Y T,T)، و روعي فيهم أن تتفق خصـائصـهم مع العينة الأسـاسـية للبحث بحيث بمثل فيها

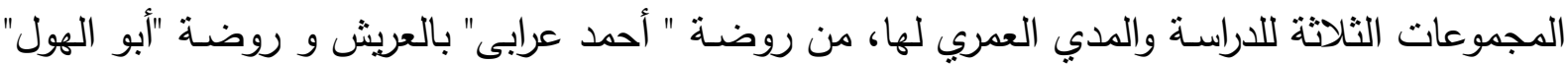

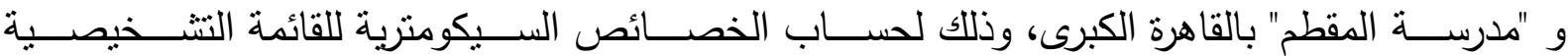
للاضطرابات السلوكية وجاءت هذه الخصائص السيكومتربة للقائمة على النحو التالى:

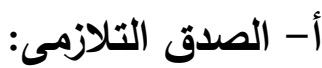

قامت الباحثة بإيجاد معامل الارتباط بين قائمة التشخيصية للاضطرابات السلوكية اعداد الباحثة، واختبار السلوك المشكل إعداد(أحمد و بطرس،م . . r ) حيث بلغ معامل الارتباط بين أداء الأفراد علي المقياسين

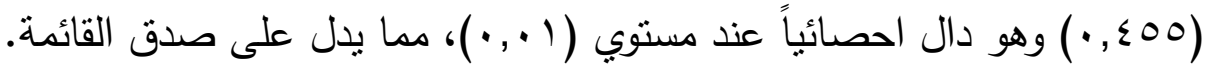
ب- صدق الاتساق الداخلي للأبعاد: قامت الباحثة بحساب الارتباطات الداخلية للأبعاد الأربعة للقائمة التشخيصية للاضطرابات السلوكية، كما تم حساب ارتباطات الأبعاد الأربعة بالارجة الكلية للقائمة كما هو موضح في جدول (ع).

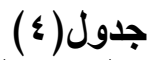

درجة الارتباط بين أبعاد القائمة التشخيصية للاضطرابات السلوكية ببعضها البعض ويالارجة الكلية

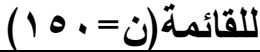

\begin{tabular}{|c|c|c|c|c|c|}
\hline الارجة الكلية & لاضطرابات السلوكية & الاضطرابات & اضطرابات & اضطرابات & أبعاد المقياس \\
\hline- & - & - & - & 1 & اضطرابات العادات \\
\hline- & - & - & 1 & $* * \cdot$. & اضطرابات النطق والكلام \\
\hline- & - & 1 & $* *$. ، $\{1 \varepsilon$ & $* * .019$ & الاضطرابات الوجدانية \\
\hline- & 1 & **. . เ7 & $* * .600 r$ & $* *$. ، $\{r \leq$ & لاضطرابات السلوكية|لاجتماعية \\
\hline 1 & $* *, 00 \leq 1$ & **. . V V Or & ***6ו1 & ***. ، \IV & الارجة الكلية للقائمة \\
\hline
\end{tabular}

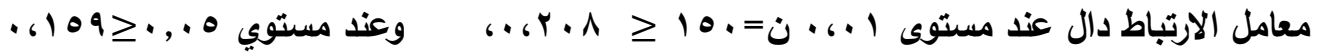

يتضح من الجدول(ع) أن جميع معاملات ارتباط الأبعاد ببعضها وبالدرجة الكلية جاءت مرتفعة ودالة احصائياً عند مستوي I •, • وهو مايؤكد علي ارتباط الأبعاد وصدق ارتباطها ببعضها وبالدرجة الكلية للقائمة التشخيصية. من ثم يتضح أن مؤشرات صدق القائمة التشخيصية للاضطرابات السلوكية كلها تعزز الثقة بالمقياس. 


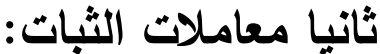

قامت الباحثة بحساب ثبات القائمة التشخيصية للاضطر ابات السلوكية بإستخدام الطرق التالية: أ- معادلة ألفا كروذباخ: لأن المقياس على متدرج ثلاثي ومن ثم يصـــلـح معه هذا النوع من أنواع معادلات حساب الثبات وكانت النتائج كما يوضحها جدول (0). جدول (•)

معاملات الثبات لقائمة الاضطرابات السلوكية باستخدام معادلة ألفا كرونباخ (ن =ه ـ 1)

\begin{tabular}{|c|c|c|c|}
\hline معاملات الثبات & الأبعاد & الأبعاد & \\
\hline$\cdot, \mathrm{V} \bullet$. & مص الاصابع & \multirow{3}{*}{ اضطرابات العادات الفمية } & \multirow{10}{*}{ العادرات العابات } \\
\hline - Vדr & قضم الاظافر & & \\
\hline$\cdot, \vee \wedge$. & الارجة الكلية & & \\
\hline$\cdot, V I r$ & التبول الاارادى & \multirow{3}{*}{ اضطرابات الاخراج } & \\
\hline$\cdot, V Y \leq$ & سلس الغائض & & \\
\hline$\cdot, \mathrm{VTr}$ & الارجة الكلية & & \\
\hline$\cdot, \vee \vee \wedge \wedge$ & اضطراب عادات التغذية & \multirow{3}{*}{ اضطراب العادات الجسمية } & \\
\hline$\cdot, \vee \wedge \wedge$ & اضطراب عادات النوم & & \\
\hline$\cdot, \wedge \ldots$ & الارجة الكلية & & \\
\hline$\cdot, \wedge r \cdot$ & \multicolumn{2}{|c|}{ الارجة الكلية لاضطرابات العادات } & \\
\hline$\cdot, \vee \wedge$. & \multicolumn{2}{|c|}{ اضطراب النطق والكلام } & \\
\hline$\cdot, \Lambda \cdot \varepsilon$ & & قلق الانفصال & \multirow{8}{*}{ الاضطرابات } \\
\hline$\cdot, \mathrm{V} \bullet 0$ & & الخوف & \\
\hline$\cdot, V Y O$ & & الخجل والانسحاب الاجتماعي & \\
\hline$\cdot, \vee \wedge 1$ & & الاكتئاب & \\
\hline$\cdot, 847$ & & الغضب & \\
\hline$\cdot, v \circ \leq$ & & 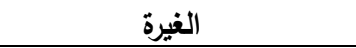 & \\
\hline$\cdot, V I r$ & & اضطراب الهوية الجنسية & \\
\hline$\cdot$, А५ & & الدرجة الكلية للاضطرابات الوجدانية & \\
\hline$\cdot$, VTr & & 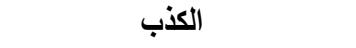 & \multirow{9}{*}{ الاضطرابات الإنلمية } \\
\hline$\cdot, \vee \vee 1$ & & 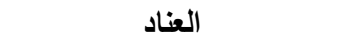 & \\
\hline$\cdot, \vee \vee \wedge q$ & & السرقة & \\
\hline$\cdot, \wedge \cdot 1$ & & التمرد و التخريب & \\
\hline$\cdot, \mathrm{V} \leq 0$ & العدوان البدنى & \multirow{3}{*}{ 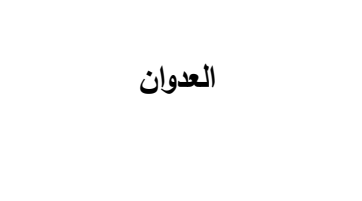 } & \\
\hline$\cdot, \vee \vee$ & 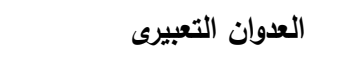 & & \\
\hline Val & الارجة الكلية للعدوان & & \\
\hline$\cdot, \wedge r$. & \multicolumn{2}{|c|}{ الارجة الكلية للاضطرابات السلوكية الاجتماعية } & \\
\hline$\cdot, \wedge 9$. & ضطرابات السلوكية & الارجة الكلية & \\
\hline
\end{tabular}


يتضح من(0) أن جميع معاملات ثبات ألفا كرونباخ جاءت مرتفعة وتعزز الثقة فى ثبات القائمة التشخيصية ل لاضطرابات السلوكية.

ب- اعادة التطبيق: قامت الباحثة بإيجاد معاملات الثبات للقائمة التتــخيصـية للاضـــرابات السـلـوكية

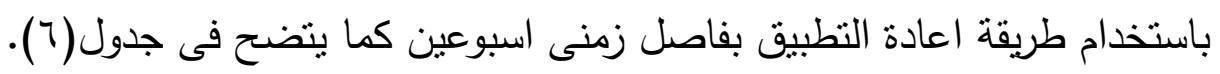

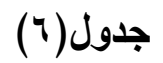

معاملات الثبات للقائمة التشخيصية للاضطرابات السلوكية باستخدام طريقة اعادة التطبيق (ن= ، 10 )

\begin{tabular}{|c|c|c|c|}
\hline معامل الثبات إعادة التطبيق & الأبعاد & الأبعاد & \\
\hline$\cdot, \mathrm{V} \leq$ & مص الاصابع & \multirow{3}{*}{ اضطرابات العادات الفمية } & \multirow{10}{*}{ العطرابات } \\
\hline$\cdot, v \circ 0$ & قضم الاظافر & & \\
\hline$\cdot, \vee \vee 1$ & الارجة الكلية & & \\
\hline$\cdot, V Y \leq$ & التبول الارادى & \multirow[t]{3}{*}{ اضطرابات الاخراج } & \\
\hline$\cdot, V \cdot \bullet$ & سلس الغائض & & \\
\hline$\cdot, v \cdot \wedge$ & الارجة الكلية & & \\
\hline$\cdot, \vee \wedge$ & اضطراب عادات التظذية & \multirow{3}{*}{ اضطراب العادات الجسمية } & \\
\hline$\cdot, \wedge \bullet \diamond$ & 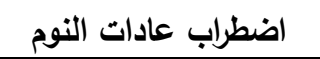 & & \\
\hline •, & الارجة الكلية & & \\
\hline$\cdot, \wedge r \mathrm{~V}$ & \multicolumn{2}{|c|}{ الارجة الكلية لاضطرابات العادات } & \\
\hline$\cdot, \vee \vee \vee \leq$ & \multicolumn{2}{|c|}{ اضطراب النطق والكلام } & \\
\hline$\cdot, \wedge \div \leq$ & & قلثق الانفصال & \multirow{8}{*}{ الاضطرابات } \\
\hline$\cdot, \vee \vee \leftarrow \varepsilon$ & & 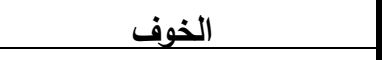 & \\
\hline$\cdot, \vee \vee \neg \varepsilon$ & & الخجل والانسحاب الاجتماعى & \\
\hline$\cdot, \vee \vee \vee$ & & الاكتئاب & \\
\hline$\cdot, V \leq V$ & & الغضب & \\
\hline$\cdot, \mathrm{v} 7 \mathrm{r}$ & & 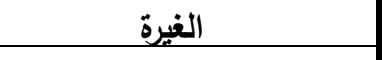 & \\
\hline., $\mathrm{V} T \mathrm{~V}$ & & اضطراب الهوية الجنسبة & \\
\hline$\cdot, \Lambda \cdot \varepsilon$ & & الارجة الكلية للاضطرابات الوجدانية & \\
\hline$\cdot, \vee \leqslant$ & & 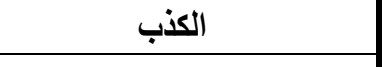 & \multirow{8}{*}{ الاضطرابات } \\
\hline$\cdot, \vee \vee ५$ & & العناد & \\
\hline$\cdot, \wedge 0 \leq$ & & 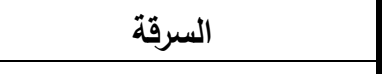 & \\
\hline$\cdot, \wedge r$. & & التمرد و التخريب & \\
\hline$\cdot, \wedge \uparrow$. & 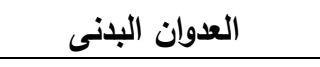 & \multirow{3}{*}{ 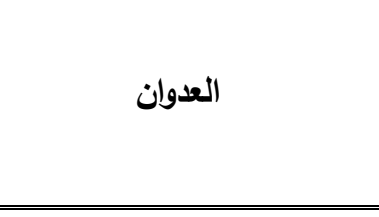 } & \\
\hline$\cdot, \vee \wedge$ & العدوان التعبيرى & & \\
\hline$\cdot, \vee \vee १ \wedge$ & الارجة الكلية للعدوان & & \\
\hline$\cdot, \wedge \cdot 0$ & \multicolumn{2}{|c|}{ الدرجة الكلية للاضطرابات السلوكية الاجتماعية } & \\
\hline$\cdot, \wedge \vee q$ & \multicolumn{3}{|c|}{ الارجة الكلية للقائمة التثخيصية للاضطرابات السلوكية } \\
\hline
\end{tabular}


يتضـح من جدول (؟) تمتع القائمة النتـخيصية للاضطرابات السلوكية بمعاملات ثبات مرتفعة ومطمئنة للاستخدام فى البحث الحال. كما يتضح من العرض السابق أن القائمة التشخيصية للاضطرابات السلوكية تتتتع بخصائص سيكومترية جيدة ومطئنة للاستخدام فى البحث الحالى، بهذا تصل القائمة التشخيصية لصورتها النهائية. د- وصف القائمة التشخيصية للاضطرابات السلوكية: تتكون القائمة التتخيصية للاضطرابات السلوكية "Diagnostic List of behavioral disorders"

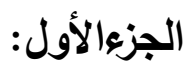

عبارة عن بيانات أولية عن الطفل موضوع القياس كاسم القائم بالتطبيق:(الأم/ الأب/ آخر)، ونوع الطفل

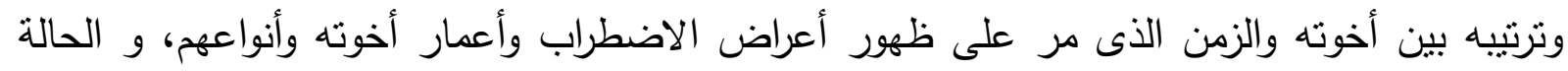

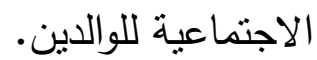

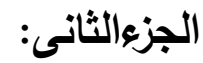

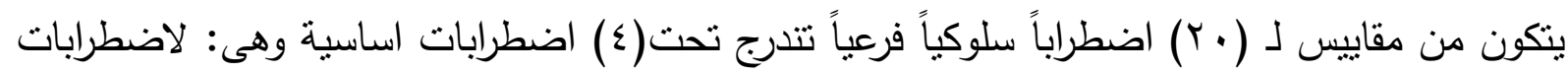
العادات، واضطراب النطق والكلام، والاضطرابات الوجدانية، والاضطرابات السلوكية الاجتماعية.

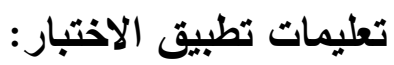
1- تتم الاجابة على هذه القائمة التتخيصية للاضطرابات السلوكية من قبل الأمهات لعلمها التام بتفاصيل

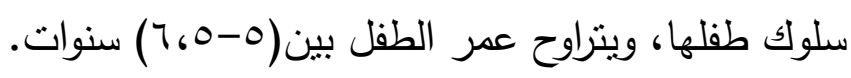
r- على القائم بالتطبيق قراءة بنود المقاييس الفرعية بالقائمة التتخيصية للاضطرابات النئرات السلوكية جيدا لاختيار درجة انطباق البند على الطفل.

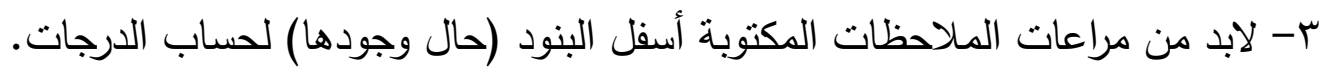

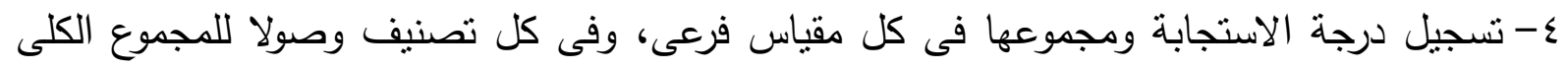

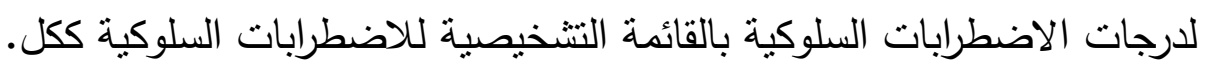

طريقة حساب الارجات وتصحيح الاستجابات على القائمة التشخيصية للاضطرابات السلوكية: يتم حساب مستوى كل اضطراب على ثلاث مستويات هى: الجدول (V) يوضح تصنيف الاضطرابات الأساسية و الاضطرابات الفرعية المنتمية لها و عدد العبارات لكل اضطراب و النهاية الصغرى و النهاية العظمى و متوسط الدرجات. 


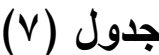

تصنيف الاضطرابات الاساسية و الفرعية المنتمية لها على القائمة التشخيصية للاضطرابات السلوكية

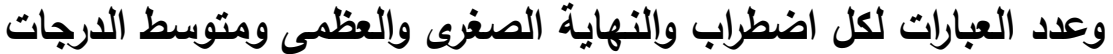

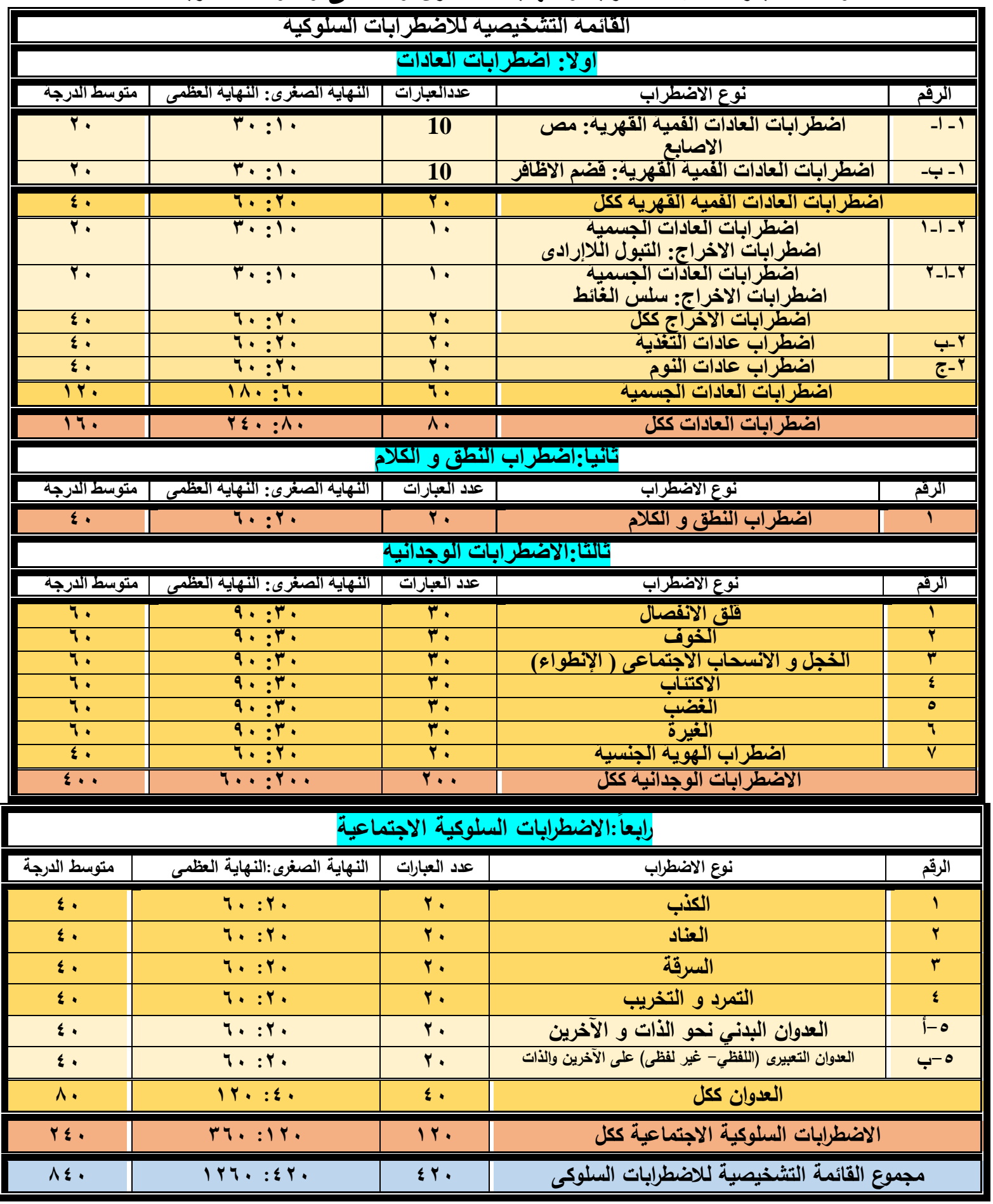

فيمايلى التعريفات الإجرائية لكل الاضطرابات التى تحتويها القائمة التشخيصية للاضطرابات السلوكية: أولا: اضطرابات العادات Habits disorders : تعرفها الباحثة بأنها:"مجموعة من الاضطرابات تجنمع فيما بينها فى أنها تعكس خلل فى توظيف وتحكم الطفل فى عاداته المرتبطة بالنواحى الفمية والجسمية 
ولاعلاقة لها بالأسباب الفسيولوجية، مما يجعلها تبدو بشكل غير لائق اجتماعيا، ضار على صحة الطفل

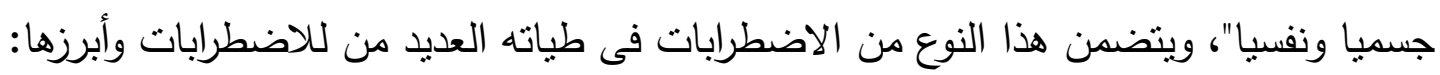

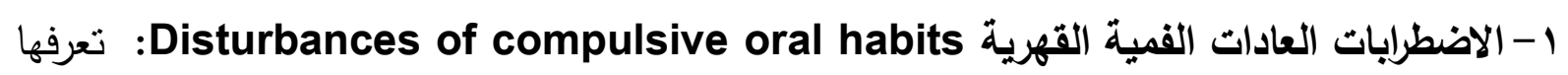
الباحثة بأنها:"الاضطرابات التى تظهر فى صورة اضطرابات للوظائف الفمية ويُسيأ فيها الطفل استخدام

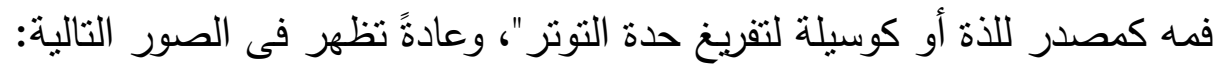
أ- مص الاصابع Fingers Sucking:"عادة قهرية يضع فيها الطفل أحد أصابعه في فمها، غالبًا مايكون إبهامه، أو أى جزء من جسمه، وإغلاق الثفتان عليه، يتبعها سلسلة من الحركات المنتظمة البسيطة

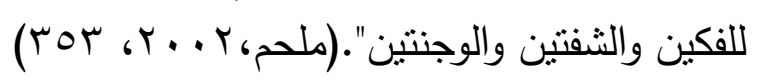

ب- قضم الأظافرNails Biting:"عادة قهرية يقضم فيها الطفل أظافره، وهى وسيلة لتخفيف من التوتر

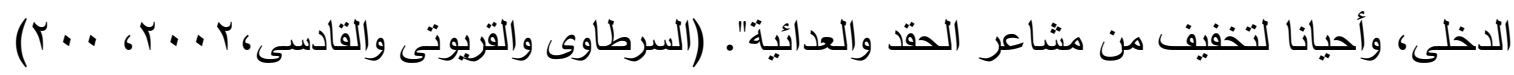

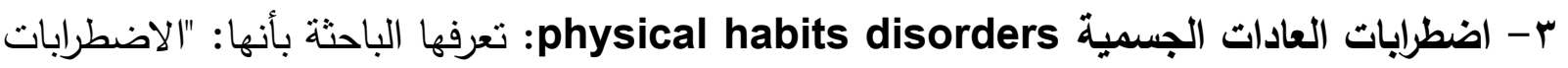

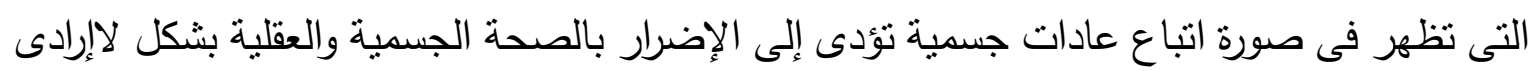
مزعج للطفل وللمحطين به"، وعادة نظهر في الصور التالية: أ- اضطرابات الاخراج defication and urination disorders: تعرفها الباحثة بأنها: "الاضطرابات

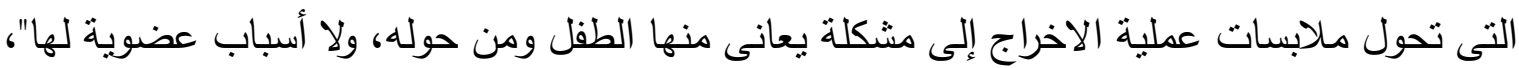

$$
\text { وصورها هى: }
$$

1- اضطراب التبول اللاإرادى:Enuresis:"أن الطفل لايستطيع السيطرة على مثانته وتكرار عدم التحكم

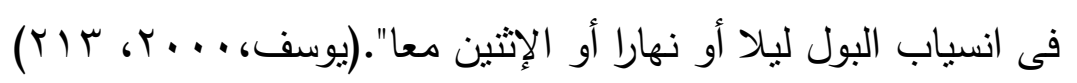
r- اضطراب سلس الغائط Fecal incontinence : تعرفه الباحثة بأنه:"عدم قدرة الطفل على السيطرة

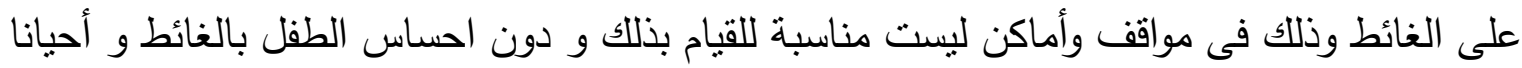

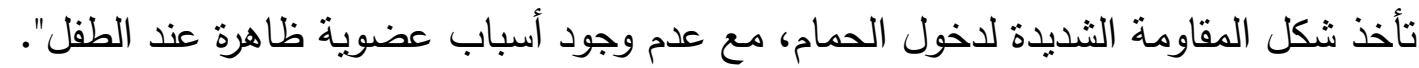
ب- اضطراب عادات التظذية Nutrition Habits Problems: تعرفه الباحثة بأنه:"حدوث اضطرابات فى شهية الطفل للأكل وظهور عادات سلوكية غذائية غير مرغوبه تضر بصحته وتزعج المحيطين به".

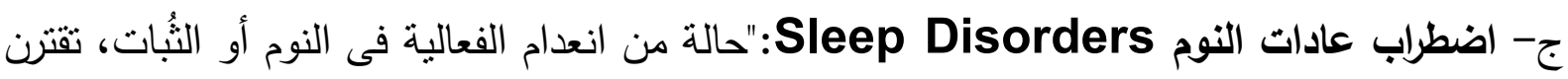

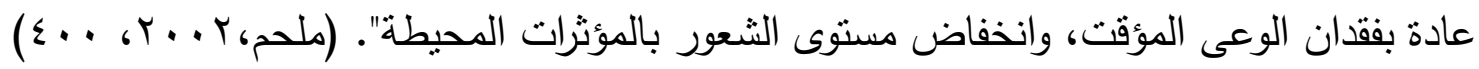
ثانياً: اضطراب النطق والكلام Pronunciation and speech disorder: تعرفه الباحثة بأنه:"تثنوش انسياب الكلام ونقص قدرة الطفل التحكم فى تدفق الكلام بإيقاع ومعدل منوازن مفهوم بطريقة

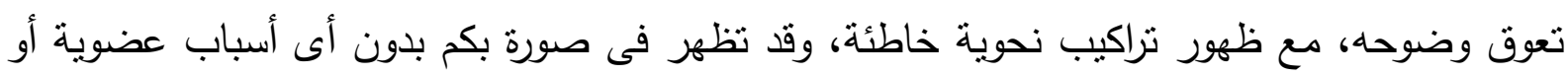
تتريحية فى جهازى السمع و الكلام". 
ثالثا:الاضطرابات الوجدانية emotional Disturbances : تعرفها الباحثة بأنها:"المشكلات الانفعالية المتجهة للداخل Internalizing Emotional problems يعانى الطفل معها صراعات ومشاعر وجدانية مؤلمة، وهى أقل إزعاجاً للآخرين، واستمرارها ينعكس سلباً على مجالات نمو الطفل".

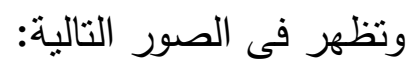
1-قلق الانفصال Separation Anxiety :"قلق زائد لايتتاسب مع مرحلة نمو الطفل، وحالة من العسر

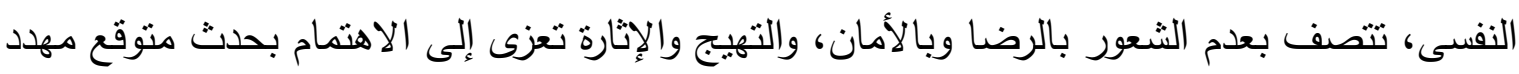

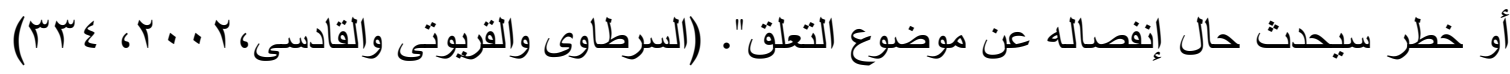
r- الخوف2 Fear :"حالة شعورية وجدانية يصاحبها انفعال نفسى وبدنى تتناب الطفل عندما يشعر بالخطر ويكون مصدر هذا الخطر داخليا من نفس الطفل أو خارجيا من البيئة".

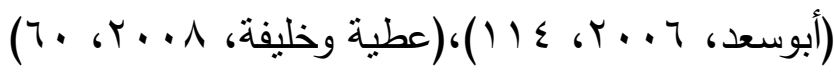

r- با - الخجل والانسحاب الاجتماعى(الإنطواء) Shyness and Social Avoidance

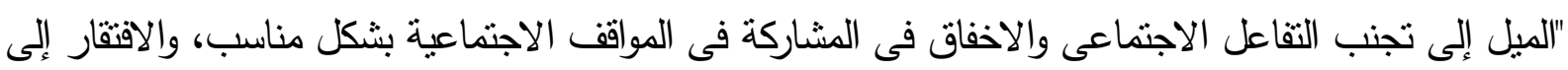
أساليب التواصل الاجتماعى، وانكماش اجتماعى مفرط من الاختلاط بالغرباء، وعدم الاكتراث بما يحثث فى البيئة المحيطة". (Coelho,\& Romao,2018, 220) ع - الاكتئاب Depression :"زملة أعراض يُشمل فى اضطراب يتمثل فى فقدان الاستمتاع بغالبية نشاطات

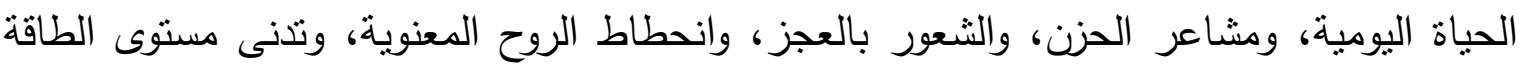

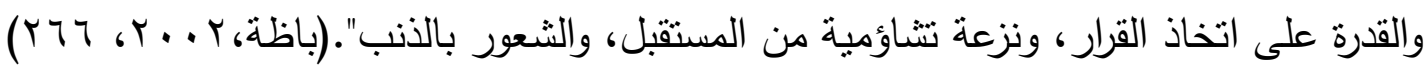
ه- الغضب:Anger:"انفجار انفعالى مصحوب بحالة انفعالية سالبة تسيطر على الطفل حينما يجد مايعيقه

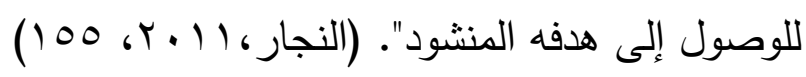

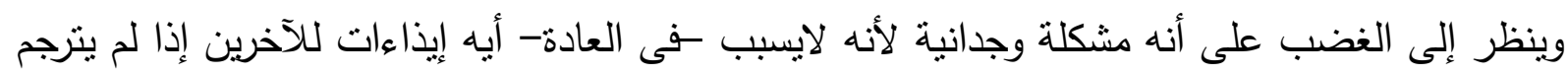

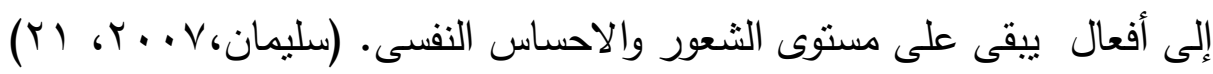

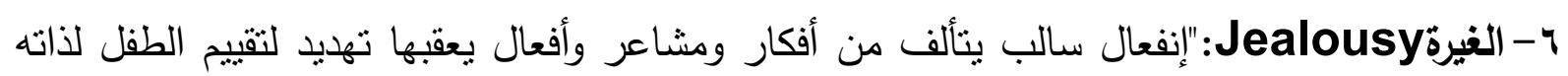

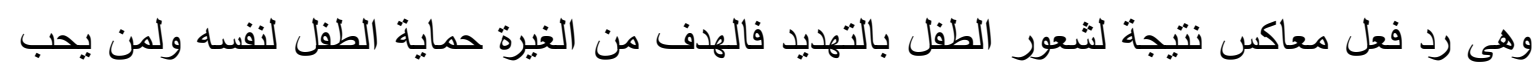

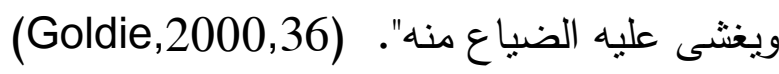
V- اضطراب الهوية الجنسية Sexual Identity Disorder:"اضطراب حاد ينتاب الطفل حول جنسه

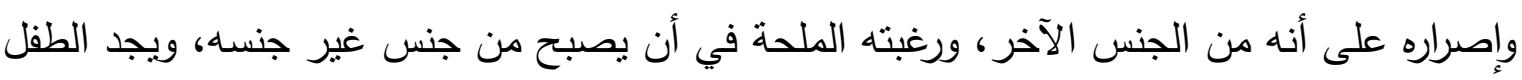

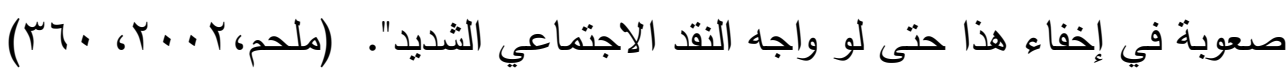

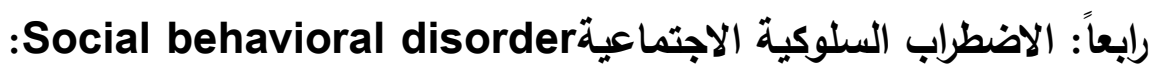
تعرفها الباحثة بأنها:"المشكلات السلوكية المتجهة للخارج Externalizing Behavioural problems يعانى الطفل معها من سلوكه بأنه غير مرغوب من الآخرين ولايستطيع معها إنثاء علاقات اجتماعية فعالة مع غيره"، وتظهر فى الصور التالية: 
1- الكنبLying:"نكر شئ غير حقيقى فى القول والعمل والسلوك بنية غش وخداع شخص آخر من أجل

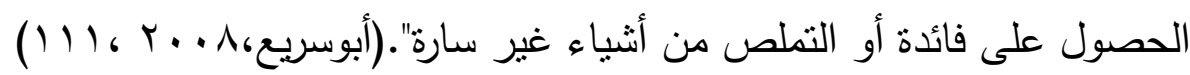

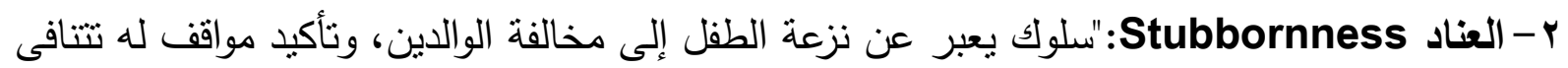

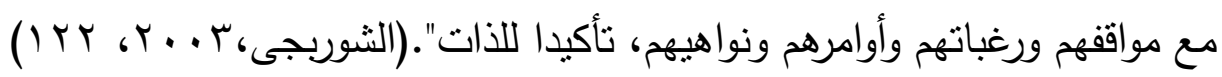

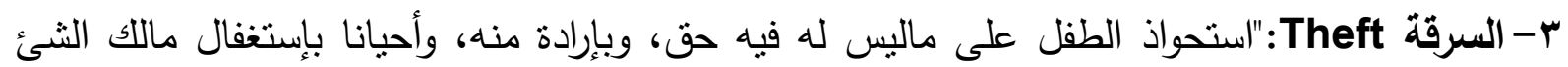

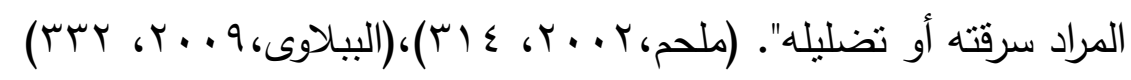

ع - التمرد وإلتخريب Rebellion and Sabotage

تعرفه الباحثة بأنه:"الخروج عن المعايير السلوكية العامة والقيم والعادات المتفق عليها، والإعتداء المباشر

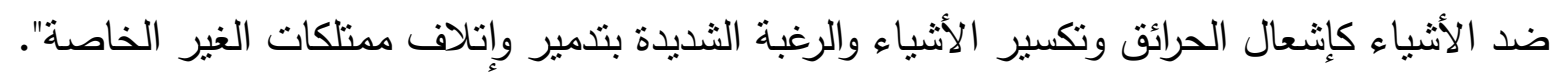
ه- العدوانAgression:"سلوك مؤذى ومؤلم باستخدام القوة الجسدية واللفظية يهدف لإثارة قلق الآخرين

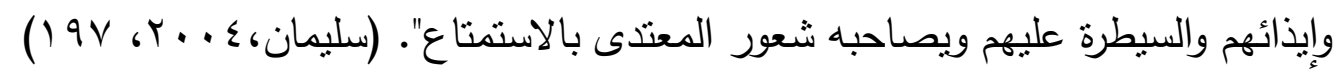

أ- العدوان البذني نحو الذات والآخرين Physical aggression towards self and others

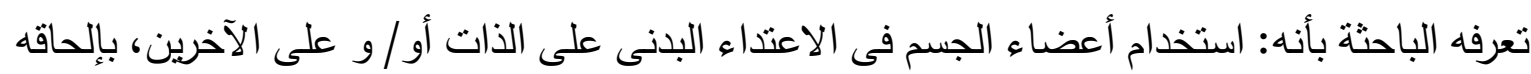

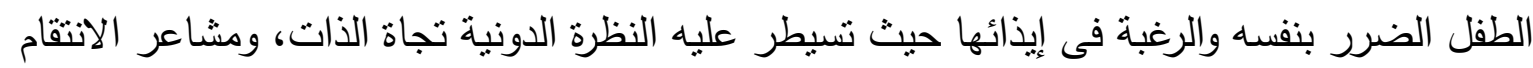

$$
\text { نحو الآخرين. }
$$

ب-العدوان التعبيرى (اللفظي/غير لفظى) على الآخرين والذات:

Expressive (Verbal/non-verbal) aggression against others and self:

تعرفه الباحثة بأنه:"عدوان لفظى أو اثنارى(غير لفظى) على الذات أو / و على الآخرين". الخطوات الإجرائية للبحث: البهن

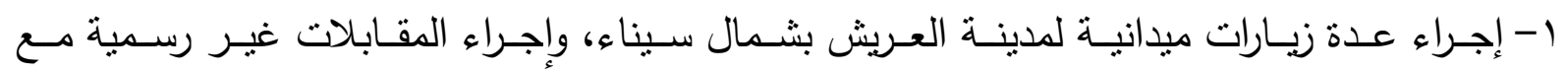

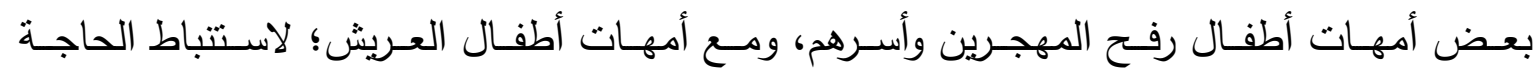

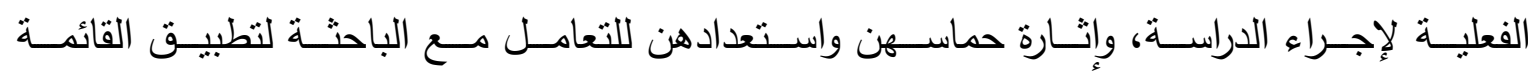
التشخيصية للاضطرابات السلوكية بجدية على أطفالهن. r- تحديد مواصفات عينة البحث من الأطفال وشروطها. r- إعداد القائمة التشخيصية للاضطرابات السلوكية. ع - تجهيز أدوات البحث كلها وحساب الخصائص السيكومترية لها للتأكد من صلاحيتها.

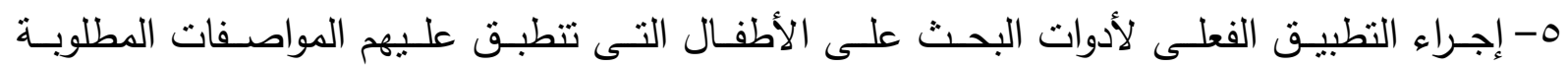
سواء من أطفال رفح المهجرين أو العريش أو القاهرة. ؟- إجراء المعالجات الإحصائية لنتائج النطبيق. V- تفسير النتائج ومناقثتها فى ضوء التزاث النظرى والدراسات السابقة وظروف التطبيق. 1- تقديم التوصيات والبحوث المقترحة فى ضوء النتائج. 


\section{الأساليب الإحصائية المستخدمة:}

Y الإصـــار الخـامس والعشـرون للعـام 17 SPSS

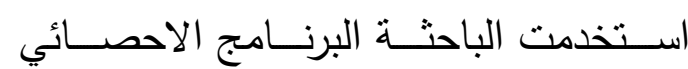

بهذف حساب الاختبارات الإحصائية التالية:

المتوسطات والانحرافات المعيارية.

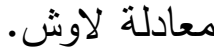

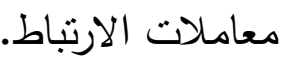

م-chronbach coefficient معامل الفا كرونباخ

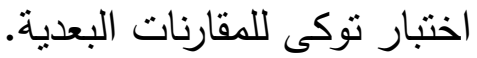

تحليل التباين البسيط أحادى الاتجاة (ANOVA)

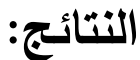

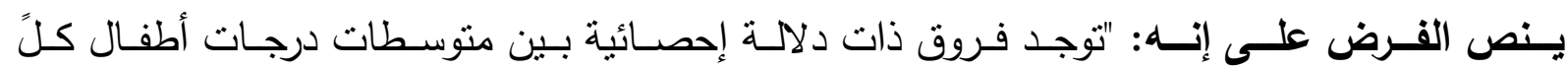

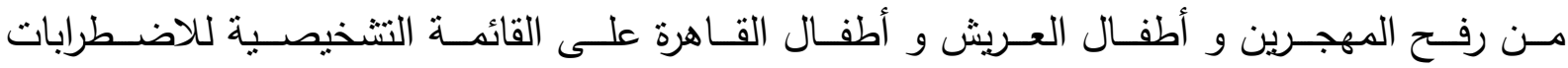

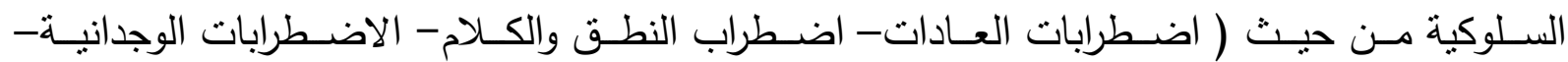

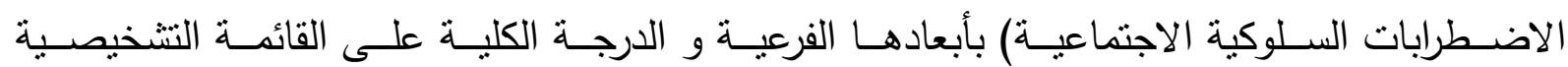
فى اتجاة أطفال رفح المهجرين".

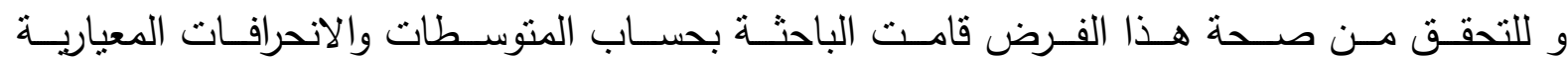

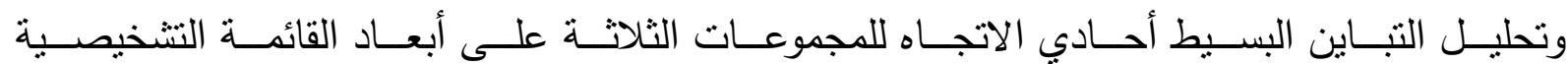

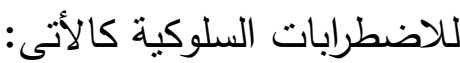

أولاً: النتائج الخاصة باضطرابات العادات و أبعادها: قامـت الباحثـة بايجـاد الفـروق بـين درجـات أطفـال رفـح المهجـرين وأطفـال العـريش وأطفـال القـاهرة

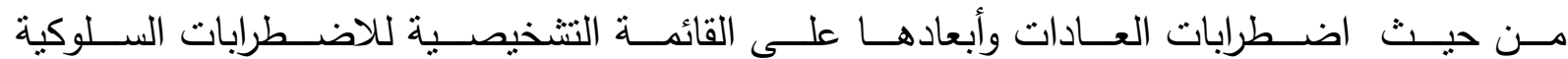

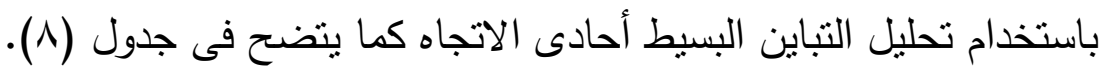




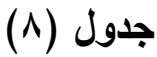

نتائج تحليل التباين البسيط احادى الاتجاة بين المجموعات الثلاث من حيث اضطرابات العادات وأبعادها على

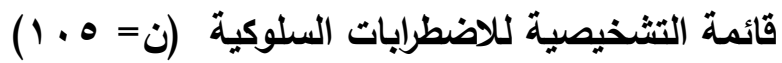

\begin{tabular}{|c|c|c|c|c|c|c|c|c|}
\hline الدالة & قيمة "ف" & المتوسطات & الحرية & المربعات & مصدر التباين & \multicolumn{3}{|c|}{ المتغيرات } \\
\hline \multirow{3}{*}{$\cdot, \cdot 1$} & \multirow{3}{*}{$1, . r 1$} & rIq,Yrq & $r$ & $\neg r \wedge, \leqslant \diamond \vee$ & بين المجموعات & \multirow{3}{*}{\multicolumn{2}{|c|}{ مص الاصابع }} & \multirow{9}{*}{ الإدادات القمية } \\
\hline & & $V, V \wedge r$ & $1 . r$ & Var, $v \vee 1$ & داخل المجموعات & & & \\
\hline & & & $1 . \varepsilon$ & $1 \leqslant r r, r Y q$ & الاجمالى & & & \\
\hline \multirow{3}{*}{$\cdot, \cdot 1$} & \multirow{3}{*}{$r \leq, \vee \wedge q$} & rqv,.ru & $r$ & $09 \leqslant, . \vee 4$ & بين المجموعات & \multirow{3}{*}{\multicolumn{2}{|c|}{ قضم الاظافر }} & \\
\hline & & $\Lambda$, Or $\Lambda$ & $1 . r$ & $\Delta v \cdot, q 1 \leqslant$ & داخل المجموعات & & & \\
\hline & & & $1 . \varepsilon$ & $1 \leq 7 \leq, 99$. & الاجمالى & & & \\
\hline \multirow{3}{*}{$\cdot, \cdot 1$} & \multirow{3}{*}{ ir,vv. } & $1 \mathrm{r} 11,74 \mathrm{~V}$ & r & $r \leqslant r r, r r r$ & بين المجموعات & \multirow{3}{*}{\multicolumn{2}{|c|}{ المجموع الكلى لاضطرابات }} & \\
\hline & & $19, \ldots 1$ & $1 . r$ & $19 r \wedge, .0 \mathrm{~V}$ & داخل المجموعات & & & \\
\hline & & & $1 \cdot \varepsilon$ & $\varepsilon r q 1, r q$. & الاجمالي & & & \\
\hline \multirow{3}{*}{$\cdot, \cdot 1$} & \multirow{3}{*}{ 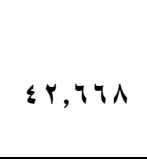 } & $\leqslant 07,+1$ & r & $919, .19$ & بين المجموعات & \multirow{3}{*}{ التبول } & \multirow{9}{*}{ الاخراج } & \multirow{9}{*}{ اضطراب } \\
\hline & & $1 \cdot, \uparrow \wedge \mathrm{V}$ & $1 \cdot r$ & $1 \cdot, 9 \cdot, 11 \leq$ & داخل المجموعات & & & \\
\hline & & & $1 . \varepsilon$ & $r \ldots r, I r r$ & الاجمالى & & & \\
\hline \multirow{3}{*}{ د. } & \multirow{3}{*}{$\cdot, \cdot r \cdot$} &., $11 \leqslant$ & $r$ & ., rrq & بين المجموعات & \multirow{3}{*}{ سلس } & & \\
\hline & & 0,701 & $1 \cdot r$ & 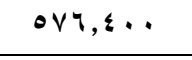 & داخل المجموعات & & & \\
\hline & & & $1 \cdot \varepsilon$ & OV 4,7 Y & الاجمالي & & & \\
\hline \multirow{3}{*}{$\cdot, \cdot 1$} & \multirow{3}{*}{$r q, \leqslant r q$} & $\leq \varepsilon Y, 1 Y \leq$ & $r$ & $\Lambda \Lambda \leqslant, Y \leqslant \Lambda$ & بين المجموعات & \multirow{3}{*}{ المجموع } & & \\
\hline & & $18, V Y T$ & $1 . r$ & $|V \cdot 0, V| \leq$ & داخل المجموعات & & & \\
\hline & & & $1 \cdot \varepsilon$ & ro19,94r & الاجمالي & & & \\
\hline \multirow{3}{*}{ د.غ } & \multirow{3}{*}{$\cdot, \cdot, \leqslant \leq$} & 1,YTV & r & r,orr & بين المجموعات & \multirow{3}{*}{\multicolumn{2}{|c|}{ عادات التغذية }} & \multirow{9}{*}{ الجسمية } \\
\hline & & $r \wedge, \leqslant \wedge !$ & $1 \cdot r$ & $r q .0, \cdot r q$ & داخل المجموعات & & & \\
\hline & & & $1 . \varepsilon$ & rq.V, ror & الاجمالى & & & \\
\hline \multirow{3}{*}{$\cdot, .1$} & \multirow{3}{*}{ Or,rAr } & $10 V \cdot, 1 Y \leq$ & $r$ & $r \mid \leq \cdot, r \leqslant \Lambda$ & بين المجموعات & \multirow{3}{*}{\multicolumn{2}{|c|}{ عادات النوم }} & \\
\hline & & $r q,\{\wedge 1$ & $1 . r$ & $r \ldots, \cdot v 1 \leq$ & داخل المجموعات & & & \\
\hline & & & $1 . \leqslant$ & $71 \leqslant 0,97 r$ & الاجمالى & & & \\
\hline & & $r V \leqslant \leqslant, \leqslant 7 V$ & r & $V \leq \wedge \Lambda, q \mu r$ & بين المجموعات & ل لاضطرابات & المجموع الكلى & \\
\hline., .1 & $0 \leqslant, 1 \leqslant 7$ & 79,100 & $1 . r$ & V.or,Arq & داخل المجموعات & & العادات ال & \\
\hline & & & $1 \cdot \varepsilon$ & $1 \leqslant 0 \leqslant r, V 4 r$ & الاجمالى & & & \\
\hline & & $91 \leqslant 1, \wedge \ldots$ & r & 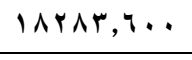 & بين المجموعات & العادات & كلى لاضطرابان & المجموع | \\
\hline 1 & 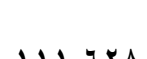 & $\wedge 1, \wedge 90$ & $1 . r$ & ArOr,r $\varepsilon$ & داخل المجموعات & & ككل & \\
\hline & & & $1 . \varepsilon$ & 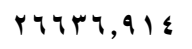 & الاجمالي & & & \\
\hline
\end{tabular}

يتضـح مـن جـدول (^) وجـود فـروق دالــة احصـائيا بـين درجـات أطفــال رفـح المهجرين و أطفـال

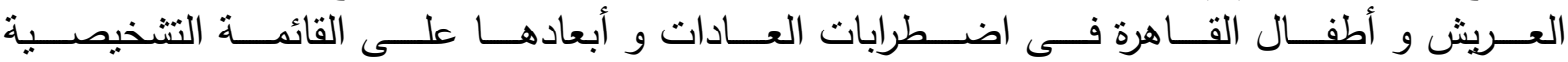

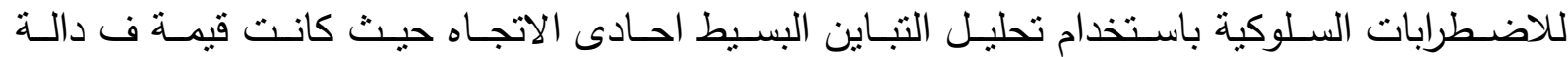


عند مسـتوى I +, • على كل الابعـاد فيمـا عـدا بعدي سـلس الغـائط و عـادات التغذيـة حيـث كانـت

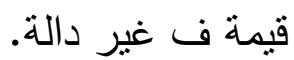

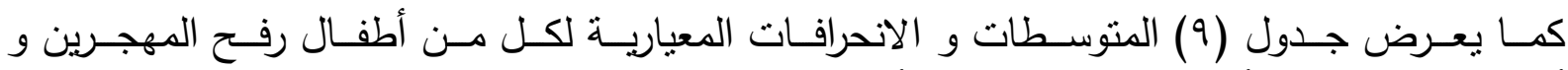

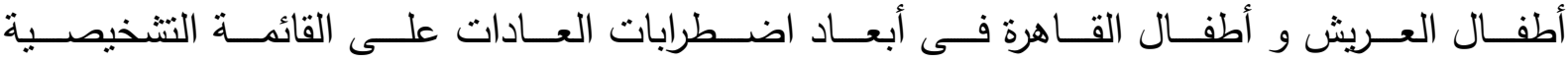
للاضطرابات السلوكية.

جدول (9)

المتوسطات والانحرافات المعيارية لكل من أطفال رفح المهجرين وأطفال العريش وأطفال القاهرة فى أبعاد

اضطرابات العادات على القائمة النشخيصية للاضطرابات السلوكية (ن = ه ه ـ 1)

\begin{tabular}{|c|c|c|c|c|c|c|}
\hline \multicolumn{2}{|c|}{ أطفال القاهرة } & \multicolumn{2}{|c|}{ أطفال العريش } & \multicolumn{2}{|c|}{ 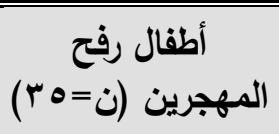 } & \multirow[t]{2}{*}{ 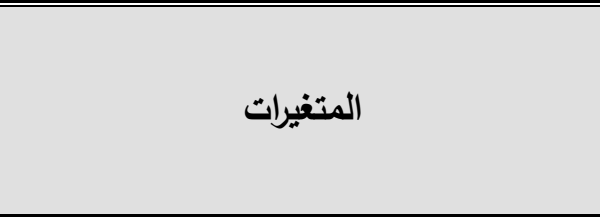 } \\
\hline$\varepsilon$ & קי & $\varepsilon$ & 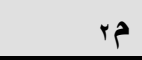 & $\varepsilon$ & 16 & \\
\hline$r, r q$ & $1 \wedge, 11$ & $r, O r$ & $r Y, O \varepsilon$ & $r, V_{1}$ & $r r, \wedge \Lambda$ & اضـطرابات العـادات الفميـة القهريــة: مسص \\
\hline$r, \cdot \Lambda$ & 17,91 & $r, 70$ & $r r, \cdot 0$ & $r,+1$ & Yl, ^० & اضـطرابات العـادات الفميـة القهريــة: قضــم \\
\hline$\Gamma, \wedge v$ & ro, r r & $\varepsilon, 9 V$ & 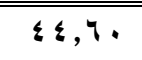 & $\varepsilon, 1 \varepsilon$ & $\varepsilon \varepsilon, V \varepsilon$ & المجموع الكلى لاضطرابات العادات الفمية القهرية \\
\hline$r, \varepsilon r$ & 17,10 & $r, \wedge \varepsilon$ & rr,,$\bullet$ & r,o. & 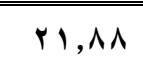 & اضطرابات الاخراج : التبول التلارادي \\
\hline Y, $\vee q$ & IT, IV & $r, r \wedge$ & $1 \mathrm{H}, 0$ & $1, \wedge 0$ & $1 \mathrm{H}, 11$ & اضطرابات الاخراج : سلس الغائط \\
\hline$\varepsilon, 7 \wedge$ & $r \cdot, \cdot r$ & 4,99 & rq, q1 & $r, 0$ & ro,.. & المجموع الكلى لاضطرابات الاخراج \\
\hline $0,9 V$ & 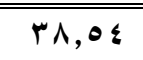 & $0, \varepsilon 0$ & r^,q1 & $\varepsilon, \varepsilon V$ & $\mathrm{r \wedge , \Lambda .}$ & اضطراب عادات التغذية \\
\hline T,Yr & $r \wedge, 91$ & $0, \wedge r$ & $\varepsilon \cdot, \varepsilon r$ & r,q & $\varepsilon \cdot, 7$ & اضطراب عادات النوم \\
\hline $9, .0$ & $9 \vee, £ \wedge$ & $9, \ldots$ & 117,40 & 7,77 & $11 \varepsilon, \varepsilon$. & المجموع الكلى لاضطرابات العادات الجسمية \\
\hline 9,79 & $\mid r r, 01$ & $q, r \varepsilon$ & $17 \cdot, 10$ & $\Lambda, \cdot r$ & $17 \cdot, 1 \leq$ & المجموع الكلى لاضطرابات العادات ككل \\
\hline
\end{tabular}

ويتضـح مـن جـدول (9) وجـود فـروق فـى المتوسـطات بـين أطفـال رفـح المهجـرين وأطفـال العـريش وأطفال القاهرة. ولتحديـد إتجـاه الفـروق اجـرت الباحثنة اختبـار تـوكى للمقارنـات البعديـة بـين المجموعـات التناتلات فىى أبعاد اضطرابات العادات على القائمة النشخيصية للاضطرابات السلوكية. ويوضـح جـدول( • () نتـائج اختبـار تـوكي للمقارنـات البعديـة بـين المجموعـات الـتلاث (أطفـال رفح المهجـرين وأطفـال العـريش وأطفـال القـاهرة) فـى أبعـاد اضـطرابات العـادات على قائمـة التشخيصـية للاضطرابات السلوكية. 


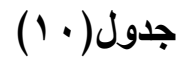

نتائج اختبار توكي للمقارنات البعدية بين المجموعات الثلاث (أطفال رفح المهجرين وأطفال العريش وأطفال

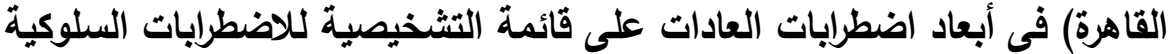

\begin{tabular}{|c|c|c|c|}
\hline מr - מ pr & מן - מש & $r^{6-16}$ & المجموعات \\
\hline$* \varepsilon, \xi Y$ & $* 0, V V$ & $1, r \varepsilon$ & مص الاصابع \\
\hline$* 0,1 \leq$ & $* \varepsilon, 9 \leqslant$ & $\cdot, r \ldots-$ & قضم الاظافر \\
\hline$* ף, \wedge \wedge$ & *ะ, १V & $1,91-$ & درجة اضطرابات العادات الفمية القهرية \\
\hline$* \vee, \cdots$ & $* \theta, \cdot r$ & $* 1,9 \vee-$ & اضطرابات الاخراج : التبول اللارادي \\
\hline$* q, \wedge \wedge$ & $* \varepsilon, 9 \varepsilon$ & $1,91-$ & المجموع الكلى لاضطرابات الاخراج \\
\hline$* 11,01$ & $* 11,7 \wedge$ & $\cdot, I V$ & اضطراب عادات النوم \\
\hline$* 1 \wedge, \vee \vee$ & $* 19,91$ & $1, \wedge 0-$ & درجة اضطراب العادات الجسمية \\
\hline 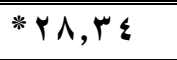 & **V,Yr & $\cdot, v_{1}$ & الارجة الكلية لأضطرابات العادات \\
\hline
\end{tabular}

$$
\text { ويتضح من الجدول(• ( ) مايلى: }
$$

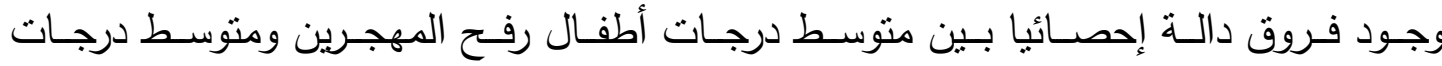

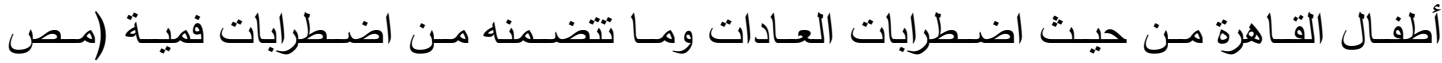

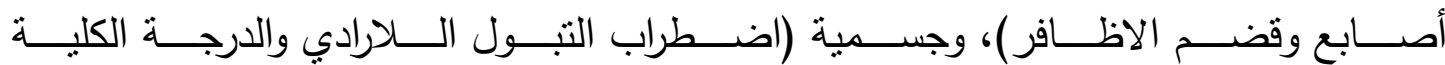

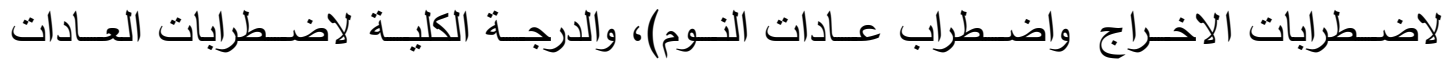
على القائمة التشخيصية للاضطرابات السلوكية فى إتجاه أطفال رفح المهجرين.

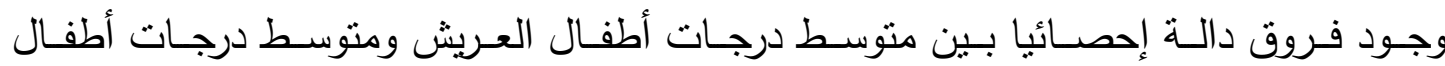

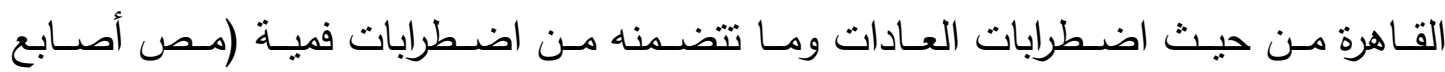

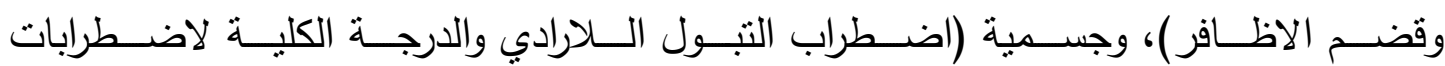

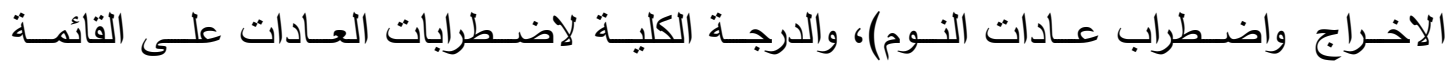
التشخيصية للاضطرابات السلوكية فى إتجاه أطفال العريش.

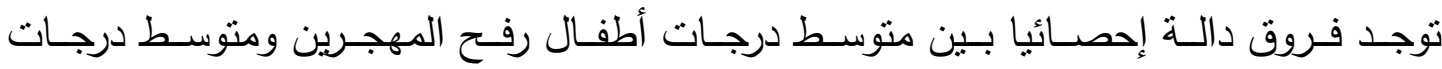

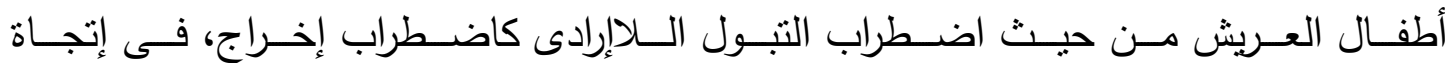

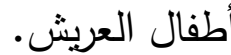

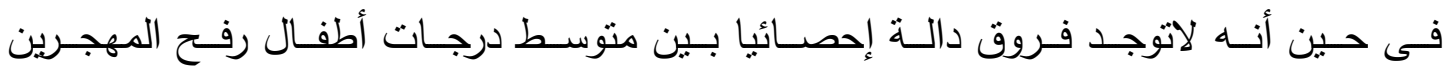

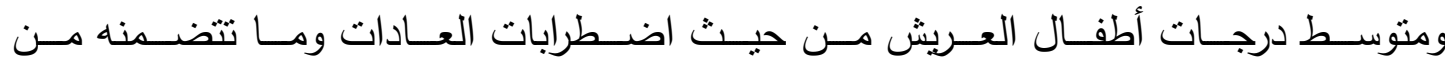

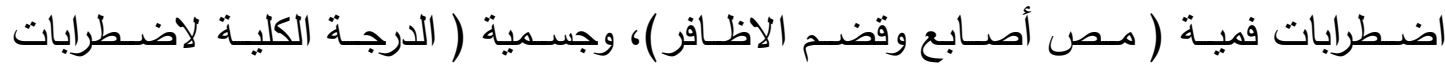

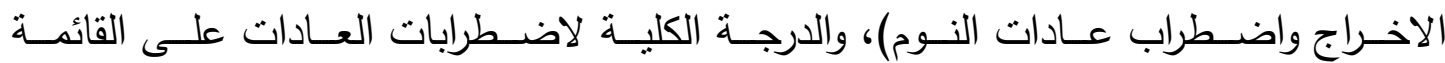
التثخيصية للاضطرابات السلوكية.

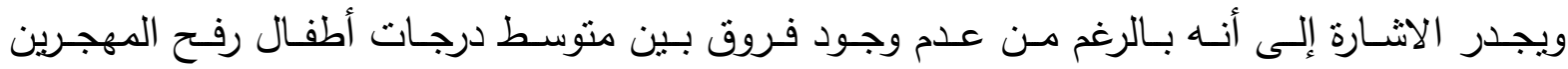

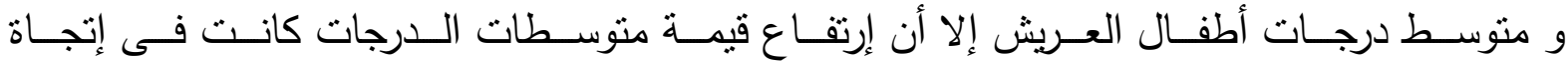


أطفــال العـريش فـى اضـــرابات العـادات الفميــة القهريـة الكليـة، و درجــة اضـــراب العـادات الجسمية الكلية بما تتضمنه من اضطرابات الاخراج.

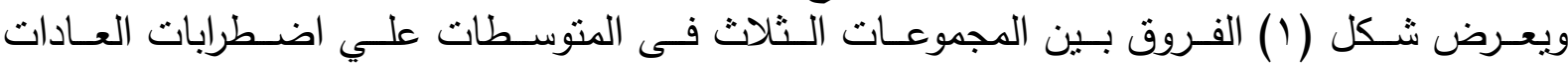
وأبعادها.

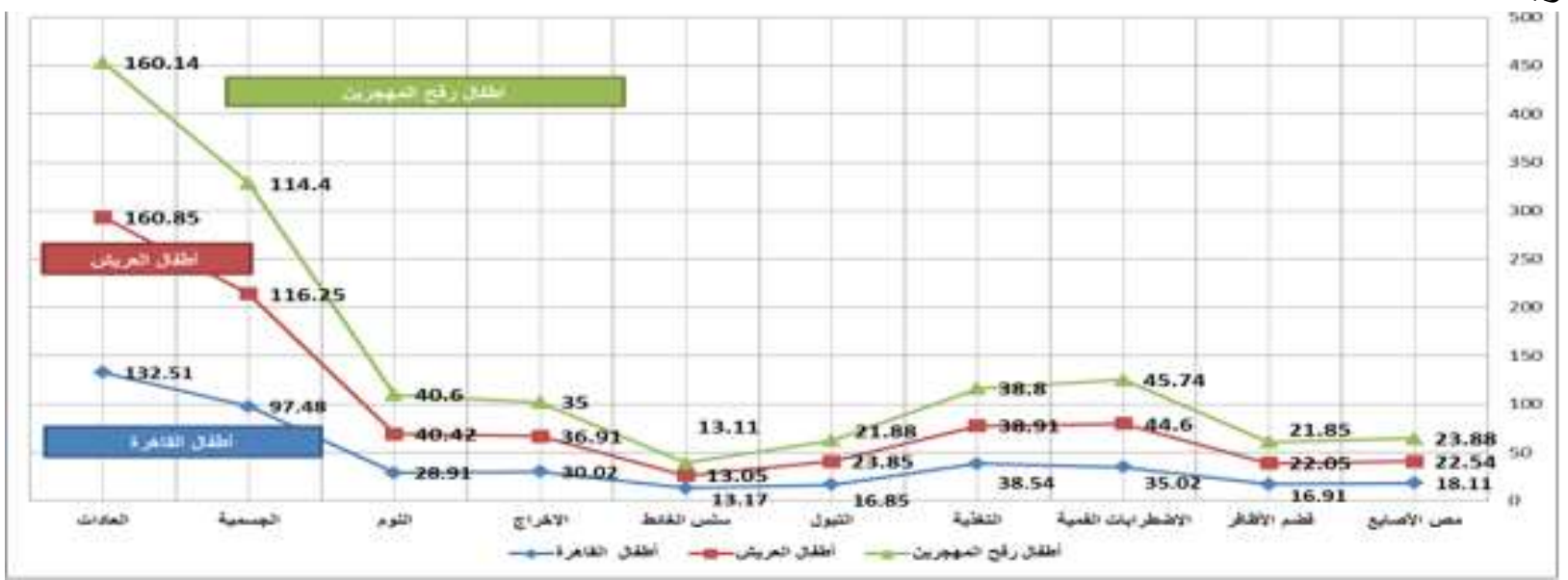

شكل (1)

الفروق بين متوسط درجات كلً من أطفال رفح المهجرين وأطفال العريش وأطفال القاهرة من حيث

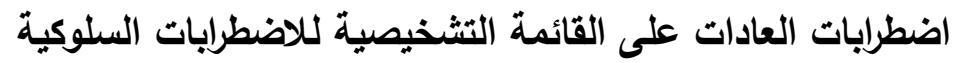

عند تتاول نتيجة العادات الفمية القهرية نجد أن أطفال رفح المهجرين يعانون من ارتفاع معدلات الاضطرابات الفمية القهرية بما تحتويه من مص الأصابع وقضم الأظافر والمجموع الكلى أكثر من أطفال القاهرة، وبمتوسطات درجات دالة عند مستوى ا +,.•، ونجد أن أطفال العريش أيضا يعانون من ارتفاع معدلات الاضطرابات الفمية القهرية بما تحتويه من مص الأصابع وقضم الأظافر والمجموع الكلى أكثر

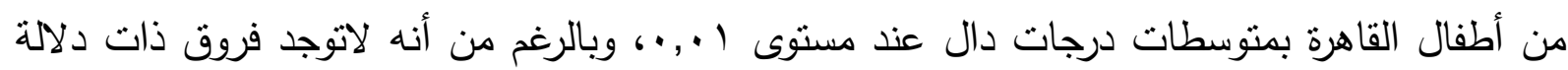

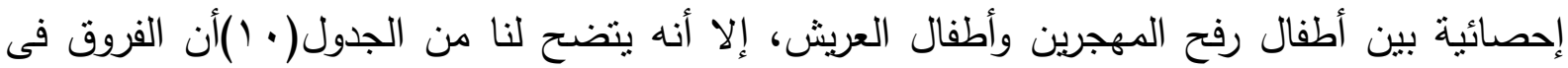
متوسطات الدرجات كانت فى إتجاة أطفال رفح المهجرين فى مص الأصابع، وفى إتجاة أطفال العريش فى لـ كلً من قضم الأظافر والمجموع الكلى للاضطرابات الفمية. وفى محاولة لمناقتة وتفسير هذه النتيجة نجد أن العادات الفمية القهرية كمص الأصابع تحدث عند تعرض الطفل لمشاكل فى بيئته يعجز عن حلها ولمواقف عصيبة كالعنف والإرهاب، تققده إحساسه بالأمان وتشعره بالعجز الجسدى والنفسى وتثير بداخله زملة انفعالات بغيضة كالخوف والتوتز والقلق فيلجأ بسببها لمص بله أصابعه، بإعتباره نكوص وارتداد لمرحلة عمرية سابقة كانت تحقق له إثباعاً عن طريق اللذة الفمية المصية، كما يمكن أن يرجع استمرارها بحسب نظرية التحليل النفسى لفرويد إلى مايسمى بالتثبيت للطاقة عند هذه المرحلة نتيجة الحرمان الزائد من الأمان، وهذا مايتعرض له أطفال رفح المهجرين وأطفال العريش بشكل مزمن غير متواجد فى بيئة أطفال القاهرة الذين لايتعرضون لها إلا نادرا، كما يمكن تقسير عدم وجود فروق

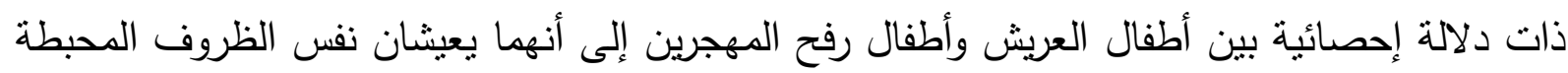
إلا أنه رغم الفروق غير الدالة، فمتوسطات درجات أطفال رفح المهجرين أعلى من متوسطات درجات أطفال 


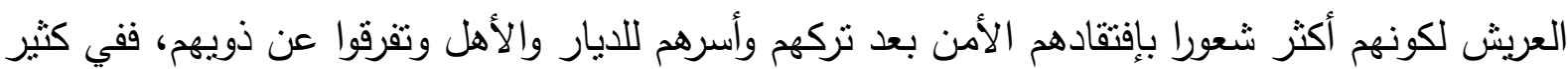

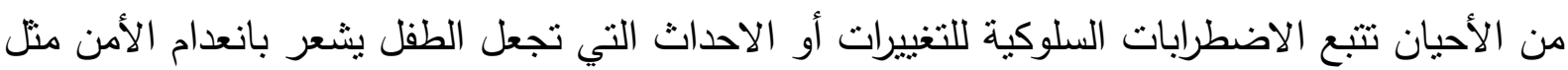
الانتقال إلى منزل جديد، وفقان أحد افراد العائلة أو الأصدقاء بالبعد عنهم والاحساس بضعف الإندات الإنتماء للمجتمع الجديد وتدنى علاقاته البين شخصية فيه وتقديره لذاته. (AACAP, 2011-A, 12) أما قضم الأظافر عند أطفال رفح المهجرين وأطفال العريش وإرتفاع معدلاته لديه لئهما بدرجة دالة عن أطفال القاهرة فيمكن تفسيره بوصفه وسيلة يقوم بها الطفل من أجل تخفيف حدة التوتز والقلق الزائدين، وكثيراً

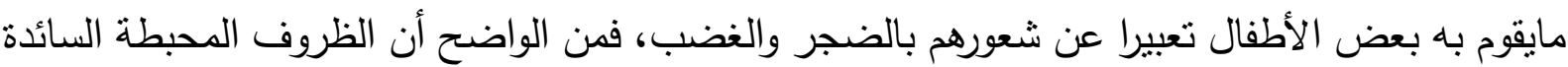

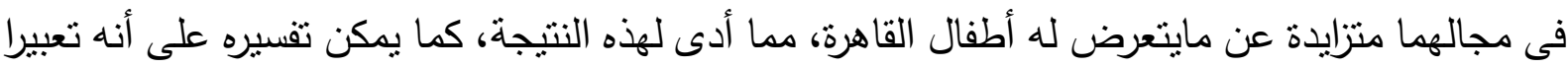
عن سوء التوافق النفسى، ويمكن إدرجه تحت مظلة السلوك العدوانى التدميرى السالبى والذى يتميز بالثدة؛

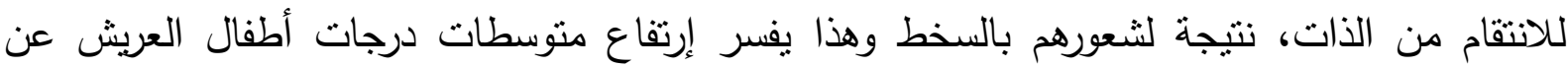

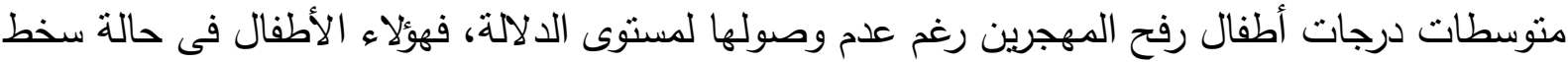

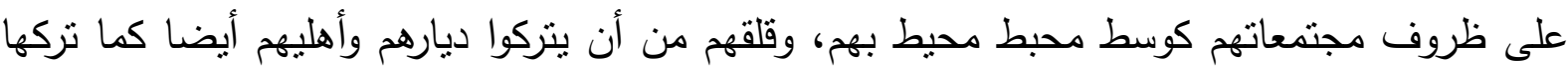

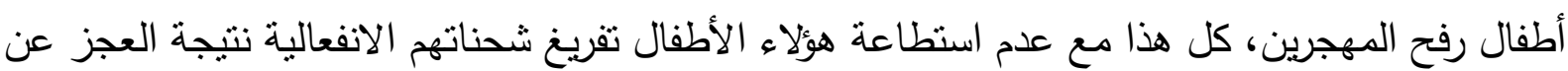
توجيه العدوان للغير فيصبح هذا السلوك تفريغاً لثحناتهم الانفعالية أكثر من غيرهم.

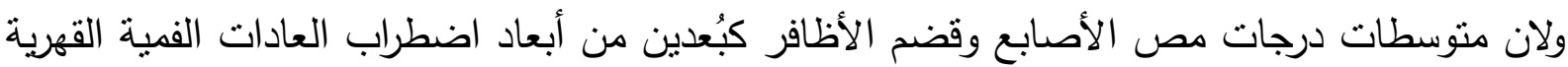

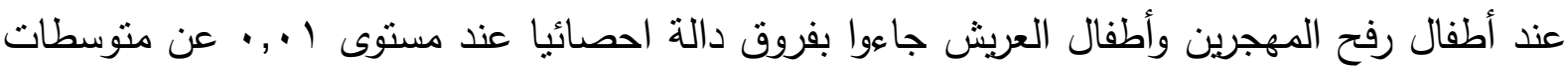
درجات أطفال القاهرة، جاءت الدرجة الكلية لاضطراب العادات الفمية القهرية بنفس النتيجة، ونفس الثنئ

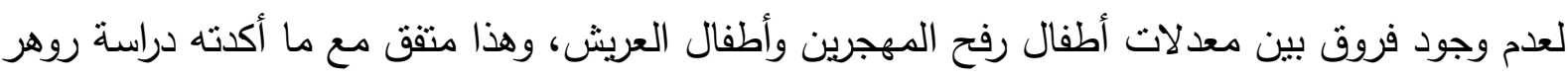

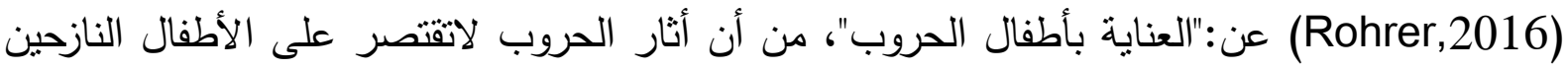

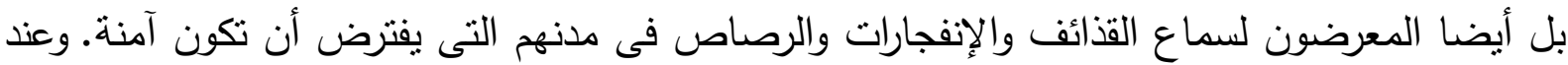
تتاول اضطرايات الاخراج ومن منطلق أن نتشئة الطفل والخبرات التي يمر بها فى سنواته الأولى نستقر فى وجدانه

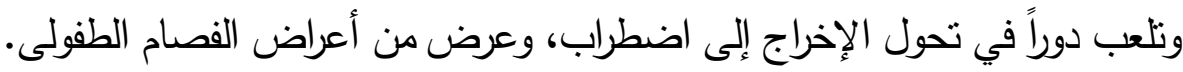
(Walle, Rittig, Bauer, et al, 2012, 978) (DiBianco, Morley\& Al-Omar, 2014, 78) يمكن اعتبار مايمر به كلً من أطفال رفح المهرين وأطفال العريش فى مجالهما جعل معدلات اضطراب

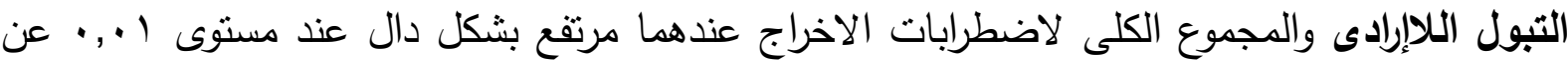
أطفال القاهرة، ومن التفسيرات المكنة لهذه النتيجة ماذهبت إليه مدرسة التحليل النفسي الفرويدي باعتبار

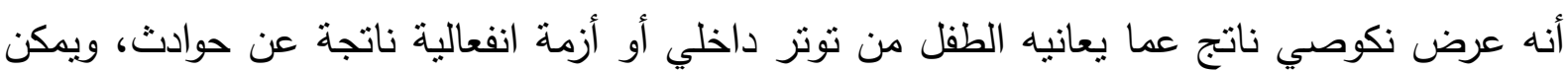
إعتباره تتبت الطفل على المرحلة الثرجية، وذهب بعض نكانية علماء التحليل النفسي إلى اعتباره عدواناً رمزياً موجهاً نحو البيئة التي يشعر بقسوتها وإحباطتها.

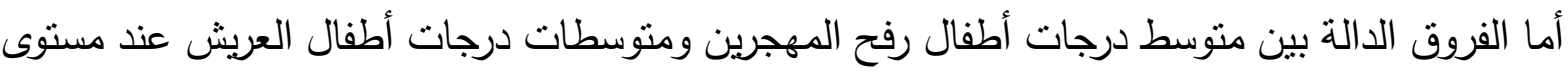

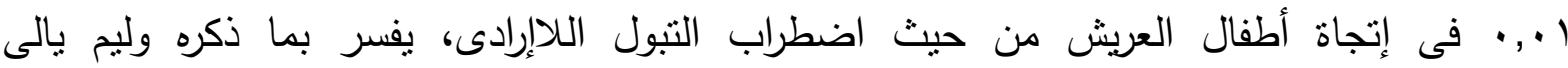


(Yule,2000,697)

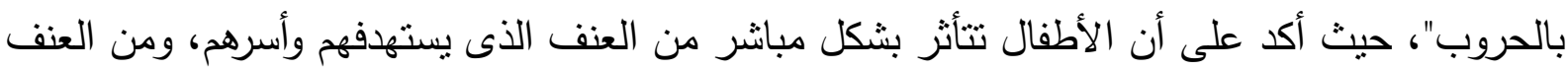

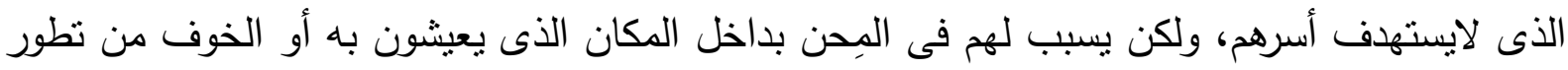

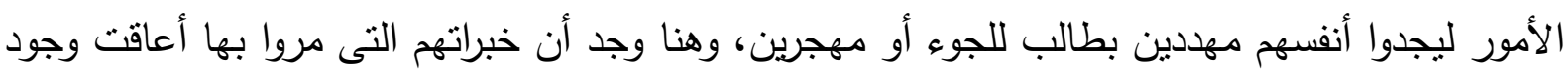

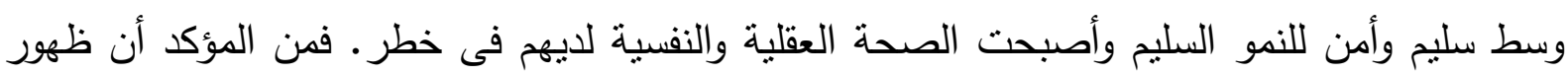
الأطفال رفح المهرين لأطفال العريش التى تعيش نفس الظروف مع الفروقات البسيطة تجعل أطفال

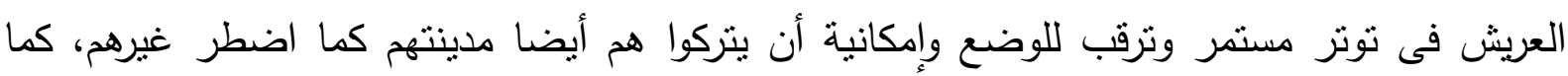

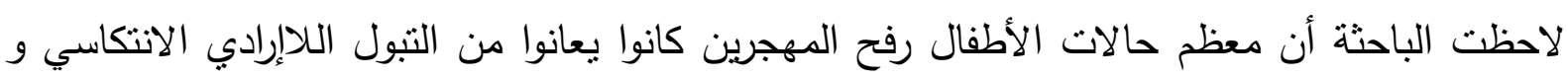

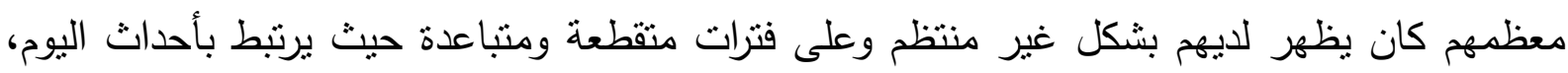

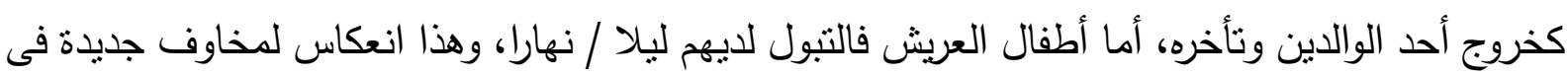

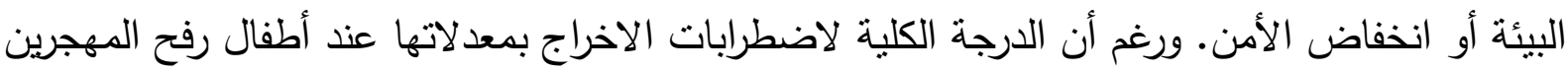

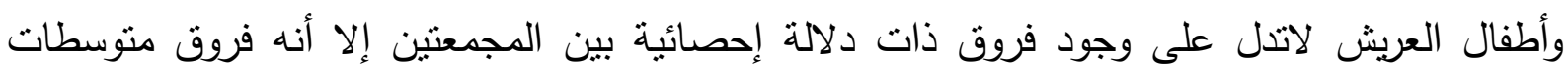

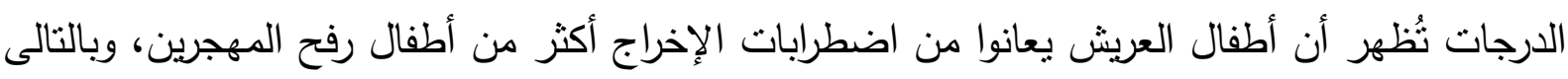

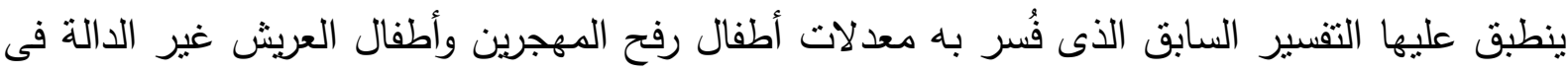

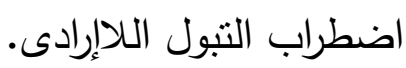
ولاحظت الباحثة أن معاناة الأطفال فى المجموعات الثلات من سلس الغائط أقل بشكل ملحوظ من معاناتهم

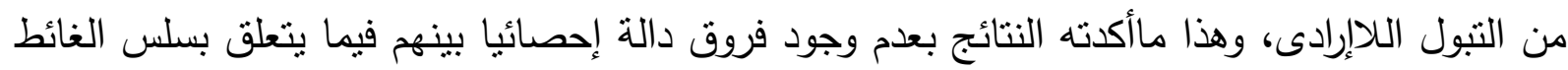

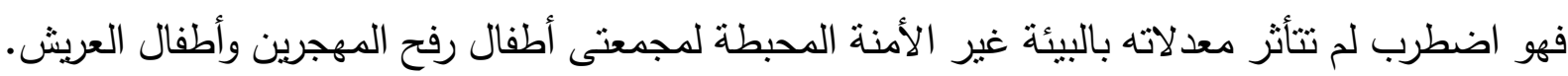

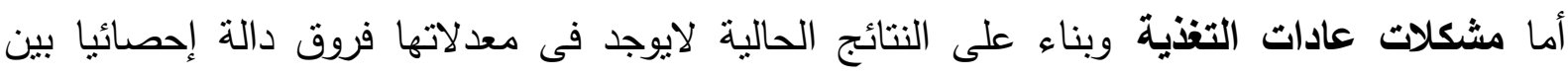

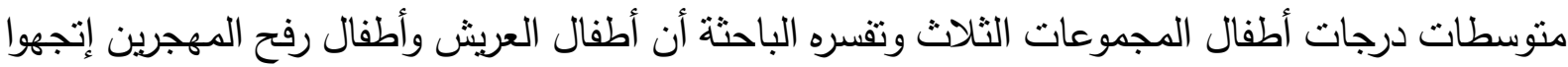

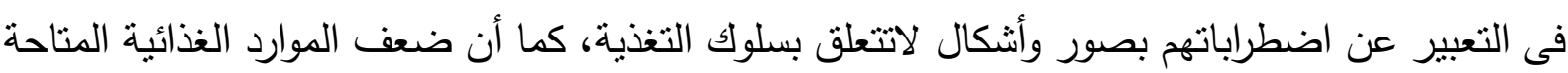

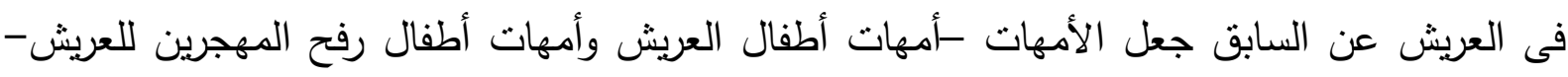

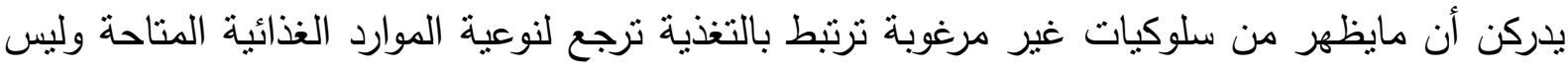

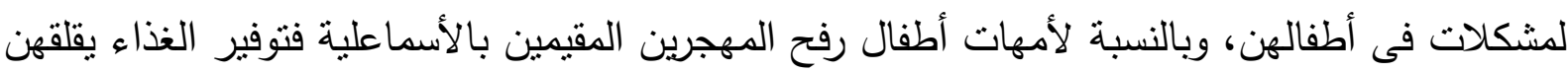

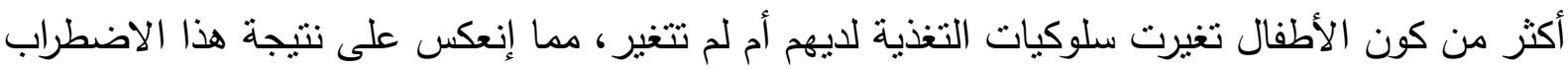

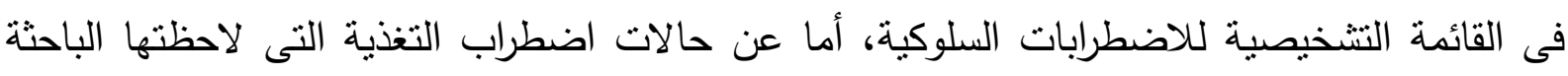
والتى عبرت عنها أمهات أطفال العريش وأطفال رفح المهجرين ففسرتها الباحثة فى حالة فقدان الأطفال

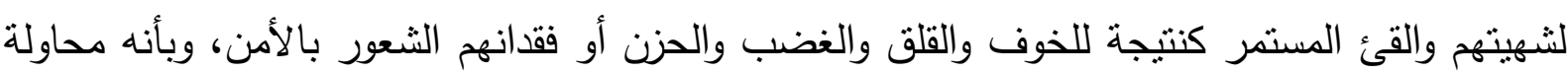

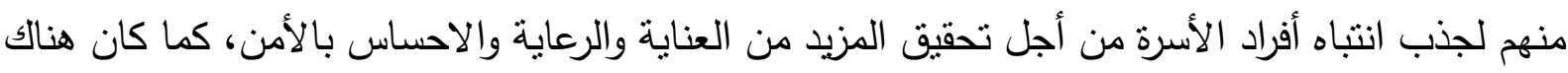

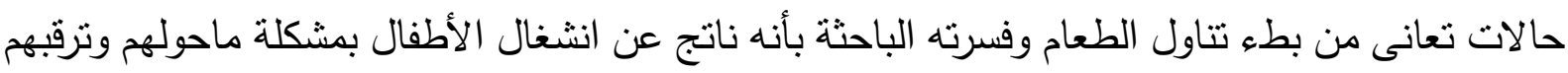

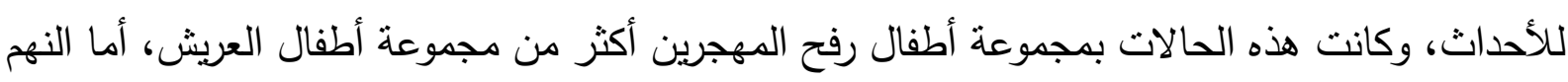


فهو حالة نفسية سيئة نتيجة عدم الاستقرار العاطفى، وانعكاس لنزعات عدائية أو الشعور بالاكتئاب المصحوب بحاجة إلى الترويح عن النفس.F, 7) وبخصوص حالات فساد الثهية فقد لاحظت الباحثة أن حالته نادرة فى العينات الثلاث فقد كانوا(؟) حالات إثثين يأكلون الورق بمجموعة أطفال القاهرة وفسرت الباحثة هذا بإنه ناتج عن افتقار الطفل لعطف الأم، أما الثالثة ففى مجموعة العريش لطفل بأكل الحشرات ويستمتع بإنمئزاز الآخرين من المنظر -كأحد

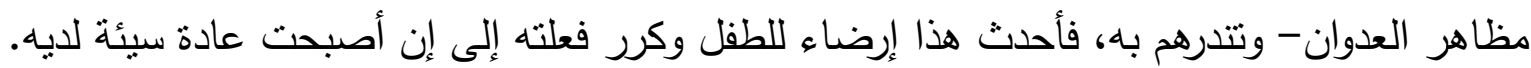
وفيما يخص اضطراب عادات النوم فالحاد منها والدائم يعطى دلالات مبكرة على قلق عاطفى عند الطفل

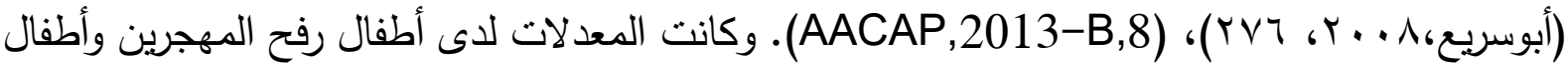

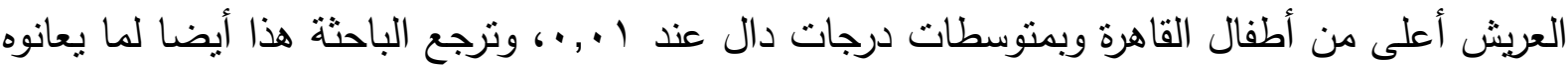
دونا عن أطفال القاهرة من توترات حياتية مستمرة، وتوقع الأمور المؤلمة فى كل وقت، مما يزيد عندهم

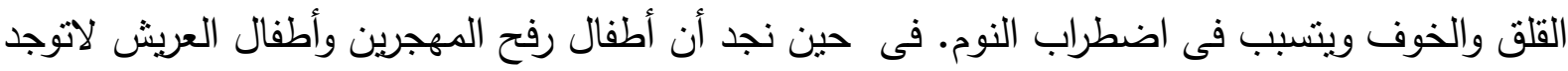
بينهما فروق دالة فى اضطراب النوم، ولكن اختلفت صوره عند كلَ من الهجموعنين؛ حيث نظهر لدى أطفال رفح المهجرين فى صورة: الكوابيس، و رعب النوم، والمشى والكلام أثناء النوم، وفسرته الباحثة بأنها وسيلة للتعبير عن التوترات الحياتية، والمعاناة من القلق والتتبه الزائد والإثارة الزائدة، وعدم الثعور بالأمن

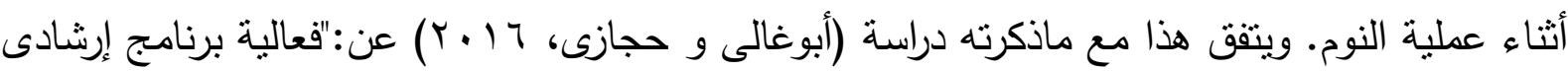

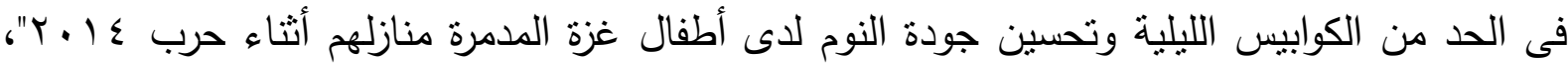
وتكونت العينة من(1) طفلا من رفح فلسطين ممن يعانون من تدنى جودة النوم بسبب تعرضهم لترك

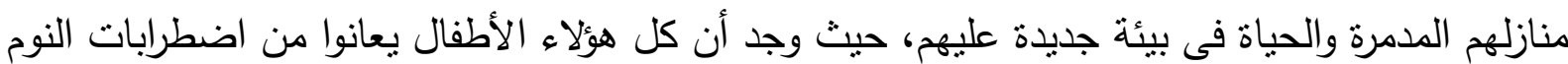

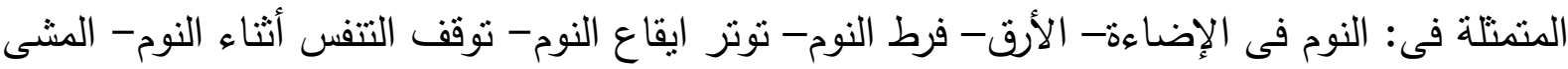
أثناء النوم- الفزع و الكوابيس الليلية. وأطفال العريش كانوا يعانون من: الكلام أثناء النوم، والنوم غير التاء المنتظ(الاستيقاظ الليلى)، والأحلام المزعجة والفزع الليلى، كنتيجة لضغوط البيئة النفسية والاجتماعية، وعدم الثعور بالأمن أثثاء عملية النوم، والخوف من غدا قد يحمل فى طياته البُعد عن الرفاق والاصحاب

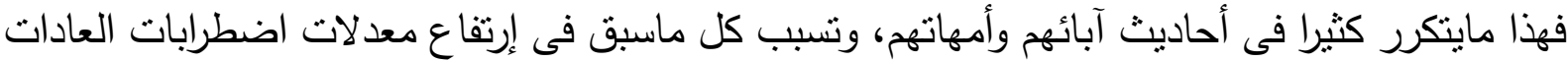

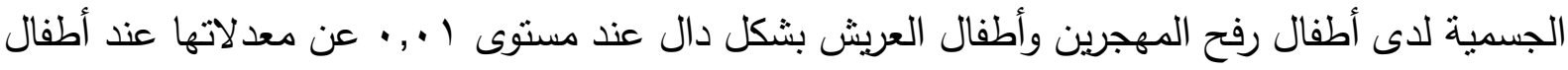

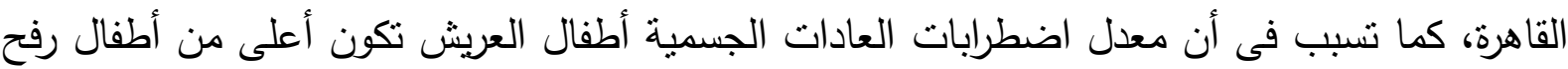
المهجرين رغم أنها غير دالة إحصائيا. وعليه يمكن تفسير اضطرابات العادات ككل وبمعدلاتها الدالة عند مستوى إ.,. بين متوسطات درجات

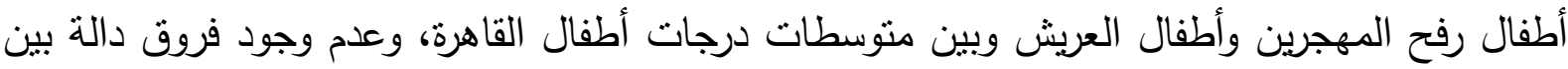
أطفال رفح المهرين وأطفال العريش بأنها متتفسا للتوتر العصبي المتزايد عند أطفال رفح المهجرين وأطفال

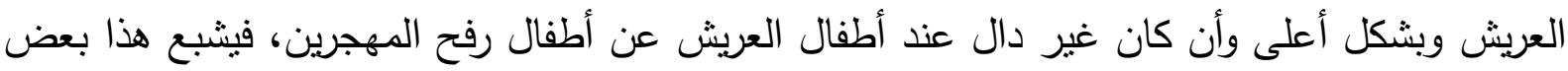

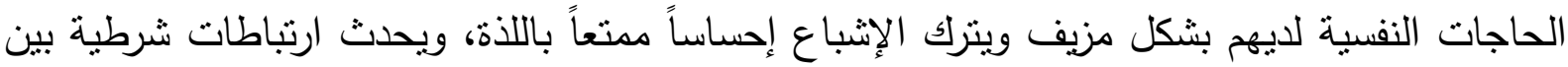


المثيرات (التوتر) والاستجابات (اضطرابات العادات)، فتقوي العادات مع مرور الوقت، وتصبر مقاومة أكثر للتغيير، وهى بذللك أعراضا لصراعات الصات داخلية.

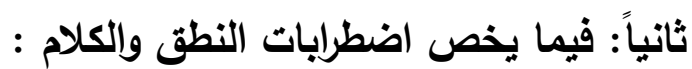

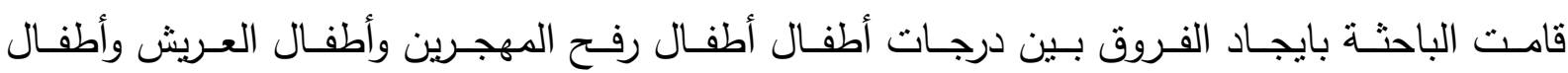

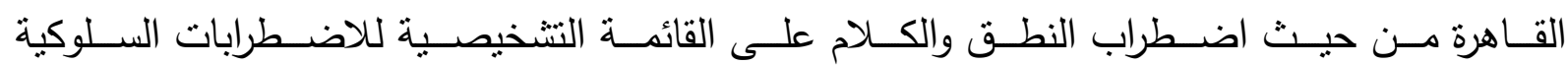

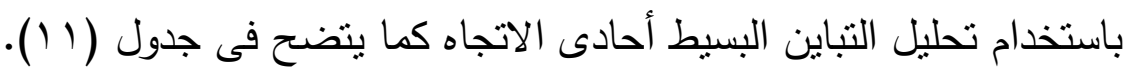
جدول (11)

نتائج تحليل التباين البسيط احادى الاتجاة بين المجموعات الثلاث من حيث اضطراب النطق والكلام على قائمة التثخيصية للاضطرابات السلوكية (ن= ه ه ـ 1)

\begin{tabular}{|c|c|c|c|c|c|c|}
\hline مستوى & قيمة ف" & متوسط المريعات & درجات الحرية & مجموع المريعات & مصدر التباين & المتغيرات \\
\hline \multirow[b]{3}{*}{$\cdot,+1$} & \multirow[b]{3}{*}{$\leqslant 9, \leqslant \leqslant 4$} & IrVY,TrA & $r$ & $r 0 \leq 0, Y \vee T$ & بين المجموعات & \multirow{3}{*}{ |ضطرابات النطق } \\
\hline & & $r O, V r \wedge$ & $1 \cdot r$ & YTYO, YOV & داخل المجموعات & \\
\hline & & & $1 \cdot \varepsilon$ & $\Delta I V \cdot, O r r$ & الاجمالي & \\
\hline
\end{tabular}

يتضح من جدول (1) (1) وجود فروق دالة احصائيا بين درجات أطفال رفح المهرين وأطفال العريش وأطفال القاهرة من حيث اضطراب النطق والكلام على القائمة التشخيصية للاضطرابات السلوكية باستخدام تحليل التباين البسيط احادى الاتجاه حيث كانت قيمة ف دالة عند مستوى الـ ل,..

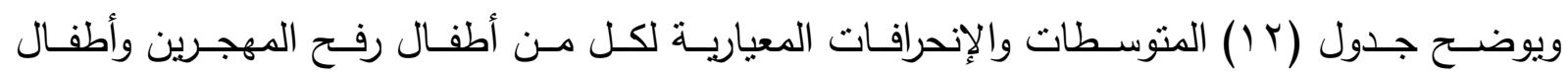

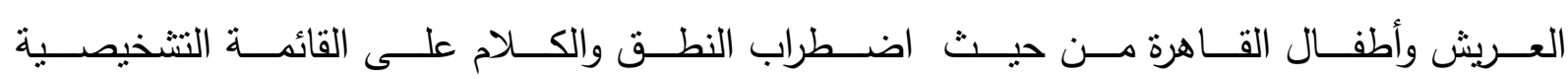
لماضطرابات السلوكية.

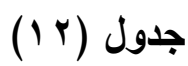

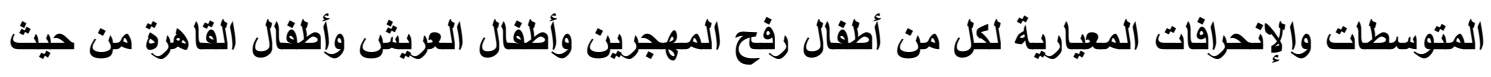

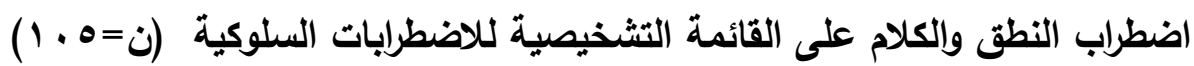

\begin{tabular}{|c|c|c|c|c|c|c|}
\hline \multicolumn{2}{|c|}{ الأطفال القاهرة } & \multicolumn{2}{|c|}{ 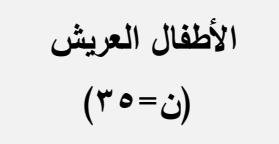 } & \multicolumn{2}{|c|}{ 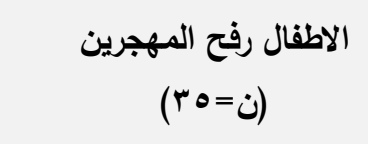 } & \multirow[t]{2}{*}{ المتفيرات } \\
\hline$\varepsilon$ & מיt & $\varepsilon$ & 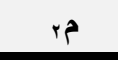 & $\varepsilon$ & pe te te & \\
\hline$\varepsilon, \varepsilon$. & 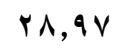 & $0, r_{0}$ & rq, & $0, \leqslant 9$ & $m a, 01$ & اضطرابات النطق والكلام \\
\hline
\end{tabular}


ويتضــــح من جدول(r ()وجود فروق فى المتوســـات بين أطفال رفح المهجرين وأطفال العريش وأطفال القاهرة، ولتحديد إتجاه الفروق أجرت الباحثة اختبار نتكي للمقارنات البعدية بين المجموعات الثلات من

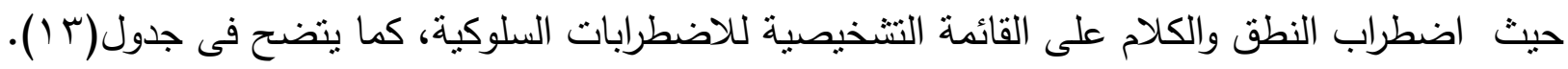
جدول (ri ( )

نتائج اختبار توكي للمقارنات البعدية بين المجموعات الثلاث (أطفال رفح المهجرين وأطفال العريش وأطفال

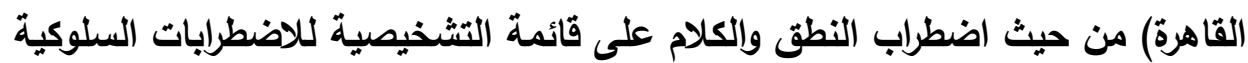

\begin{tabular}{|c|c|c|c|}
\hline pr - pr & plp & $p$ & المجموعات \\
\hline$* 1 \cdot, r \varepsilon$ & $* 1,0 \leq$ & $\cdot, r \ldots$ & اضطراب النطق والكلاد \\
\hline
\end{tabular}
يتضح من جدول (r ا ) الأتى:

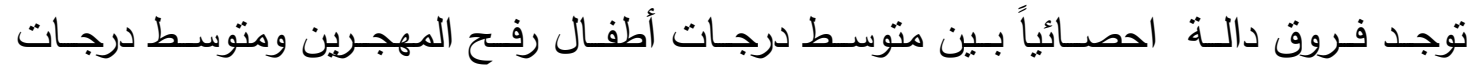

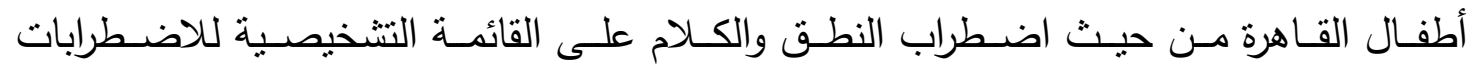
السلوكية فى اتجاه الأطفال رفح المهجرين.

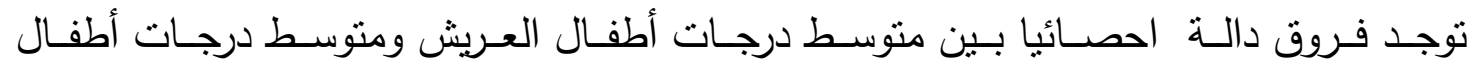
القـاهرة مـن حبـث اضـطراب النطـق والكـلام علـى قائهـة الاضـطرابات السـلـوكية فـى اتجــاه

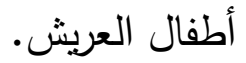

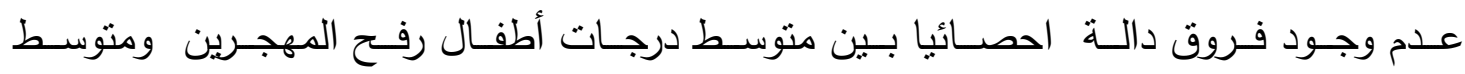

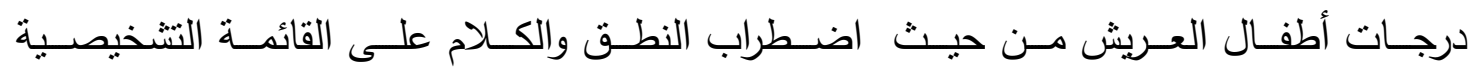
ل للاضطرابات السلوكية.

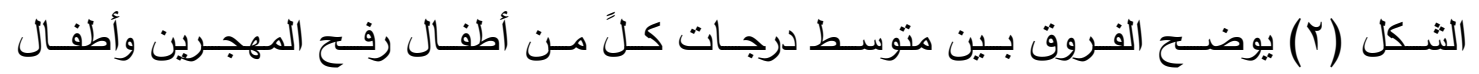

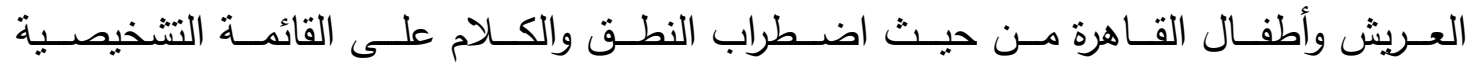
لماضطرابات السلوكية. 
شكل (r) (1) (1) (1)

الفروق بين متوسط درجات كل من أطفال رفح المهجرين و أطفال العريش وأطفال القاهرة من حيث اضطراب النطق والكلام على القائمة التشخيصية للاضطرابات السلوكية

ويتضـح لنـا مـن نتيجـة اضـطراب النطـق و الكــلام أن أطفـال رفـح المهـرين يعـانون مـن ارتفـاع معـدلاتها

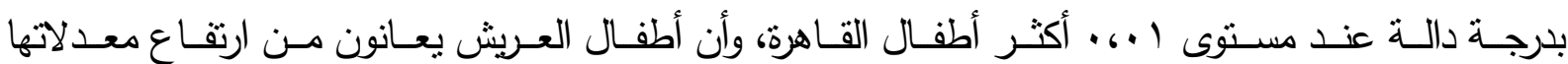

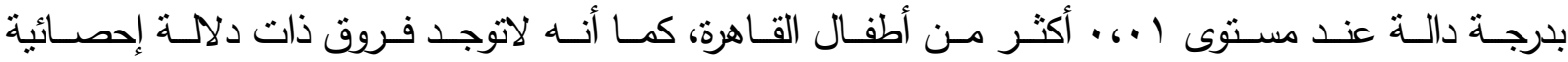

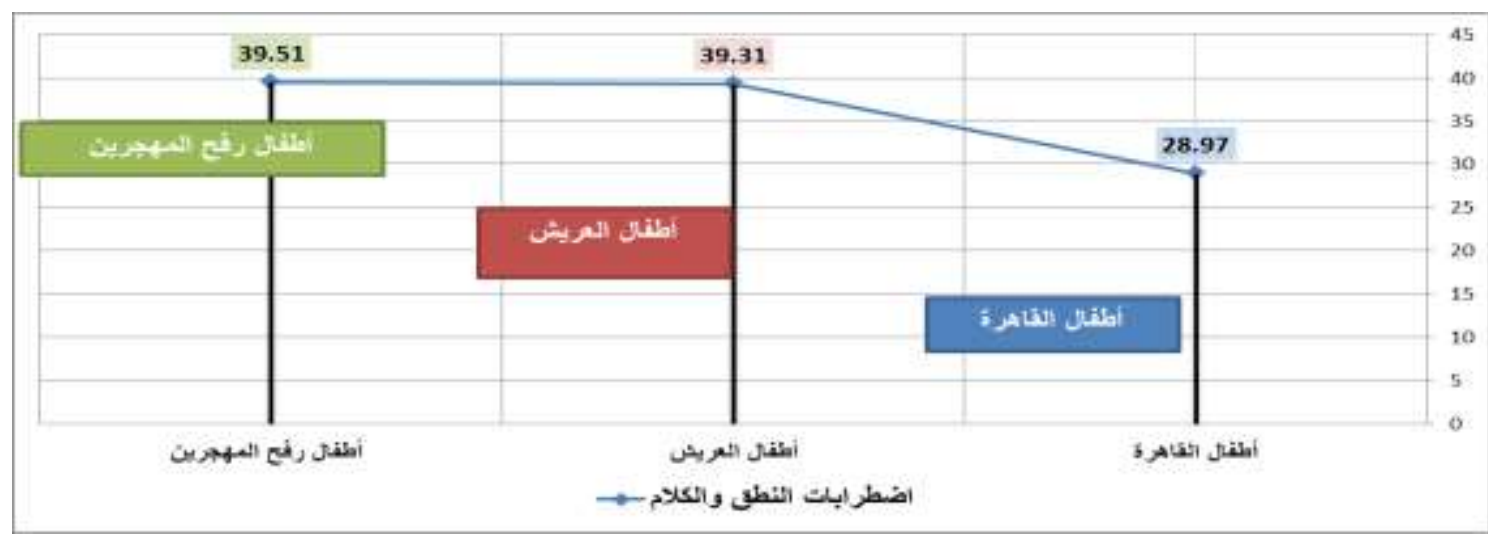

بـين

أطفال رفح المهجرين وأطفال العريش،

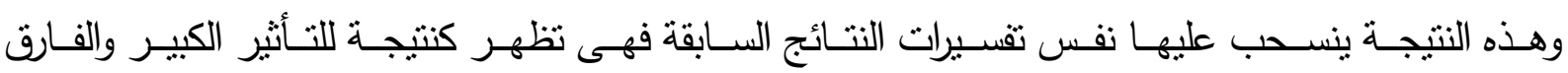

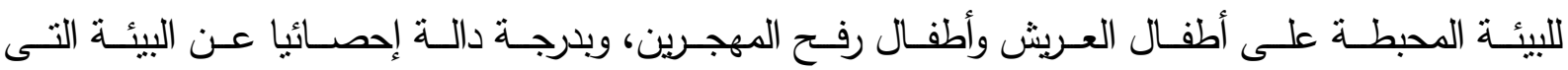
يعيثها أطفال القاهرة والتى يتمتع فيها الأطفال بالأمان والإستقرار .

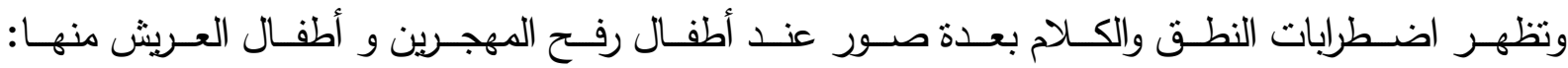

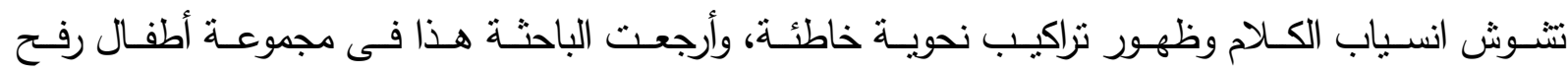

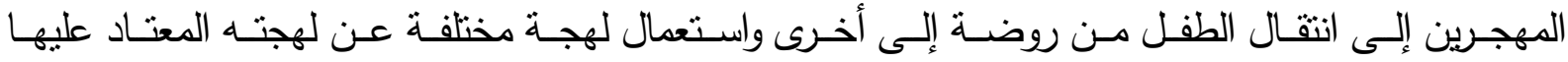

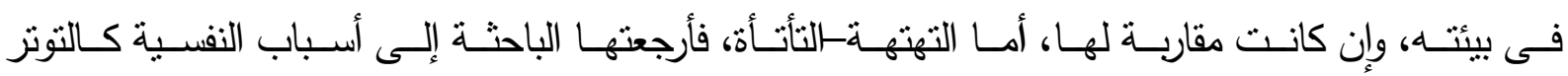
والقلـق والإحبـاط والثــور بـالنقص وعـدم الكفـاءة، وكـان لـدى عينـة رفـح طفلتـان تعانيـان مـن بكم الرهـاب

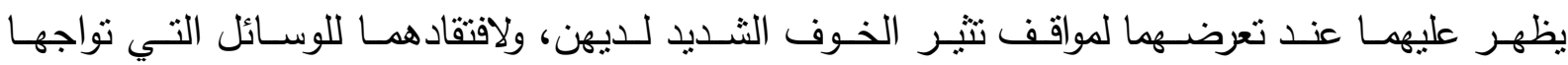

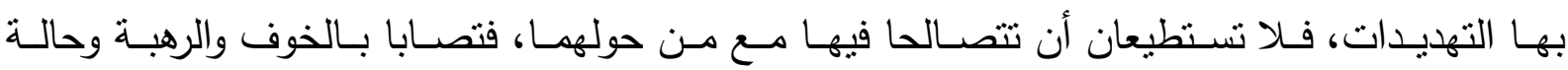
نفسـية عصـابية تظهر فـى صـورة بكم الرهـاب، وتـرى الباحثـة أن قـق الأهـل الثـديد عليهمـا بسـبب البكم جعل الطفلاتان تتماديان في اضطرابهما لإستجلاب الاهتمام والتعاطف.

ثالثاً: النتائج الخاصة بالاضطرابات الوجداتية وأبعادها: قامت الباحثة بـايجاد الفروق بين درجات أطفال رفح المهجرين وأطفال العريش وأطفال القاهرة من حيث الاضـطرابات الوجدانية بأبعادها على القائمة التشـخيصـية للاضـطرابات السـلوكية باســخدام تحليل التباين البسيط احادى الاتجاه كما يتضح فى جدول (ع (). 
جدول ( المجوع (1)

نتائج تحليل التباين البسيط احادى الاتجاة بين المجموعات الثلاث من حيث الاضطرابات الوجدانية وأبعادها على قائمة التشخيصية للاضطرابات السلوكية (ن = ه ـ 1 )

\begin{tabular}{|c|c|c|c|c|c|c|}
\hline مستوى & قيمة "ف" & متوسط المربعات & درجات & مجموع المربعات & مصدر التباين & المتغيرات \\
\hline \multirow[b]{3}{*}{$\cdot, \cdot 1$} & \multirow{3}{*}{ rr,r. o } & $r_{1.4, \leqslant 7 V}$ & $r$ & $\varepsilon r \mid r, q r r$ & بين المجموعات & \multirow[t]{3}{*}{ قلق الانفصال } \\
\hline & & $70, r .0$ & $1 \cdot r$ & $770 \cdot, 91 \leq$ & داخل المجموعات & \\
\hline & & & $1 \cdot \leq$ & $1 . \wedge \neg r, \wedge \leq \Lambda$ & الاجمالي & \\
\hline \multirow[b]{3}{*}{$\cdot, \cdot 1$} & \multirow[b]{3}{*}{ rq, . 90} & rAT\&,|A| & r & 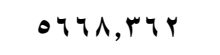 & بين المجموعات & \multirow[t]{3}{*}{ الخوف } \\
\hline & & $\vee \wedge, \diamond Y$. & $1 \cdot r$ & $1 \ldots q, \cdot r^{\prime}$ & داخل المجموعات & \\
\hline & & & $1 \cdot \varepsilon$ & $1 \leq 7 \leq, 99$. & الاجمالي & \\
\hline \multirow[b]{3}{*}{$\cdot, \cdot 1$} & \multirow[b]{3}{*}{$0 ., q r r$} & rVVO,YTV & r & r., & بين المجموعات & \multirow[t]{3}{*}{ الانسحاب } \\
\hline & & $0 \leq, 0 \ldots$ & $1 \cdot r$ & $0009, \cdot 19$ & داخل المجموعات & \\
\hline & & & $1 \cdot \varepsilon$ & $111.9,07 r$ & الاجمالي & \\
\hline \multirow[b]{3}{*}{$\cdot, \cdot 1$} & \multirow{3}{*}{ 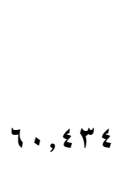 } & r117, rqo & r & TrrY,OQ. & بين المجموعات & \multirow[t]{3}{*}{ الاكتئاب } \\
\hline & & 01,070 & $1 \cdot r$ & or०q, rov & داخل المجموعات & \\
\hline & & & $1 . \leq$ & $11 \leq q r, r \leq \Lambda$ & الاجمالي & \\
\hline \multirow[b]{3}{*}{$\cdot, \cdot 1$} & \multirow[b]{3}{*}{$1 r, \leq 0}$. & D.V,rrs & r & $1 \cdot, 1 \leqslant, 7 \leqslant 1$ & بين المجموعات & \multirow[t]{3}{*}{ الغضب } \\
\hline & & rv, VIq & $1 \cdot r$ & $r \wedge \leq \vee, r) \leq$ & داخل المجموعات & \\
\hline & & & $1 \cdot \varepsilon$ & צヘฯ & الاجمالي & \\
\hline \multirow{3}{*}{$\cdot, \cdot 1$} & \multirow{3}{*}{$9, \leq 4 \leq$} & $r r \cdot, q r \leq$ & r & $741, \wedge \leq \wedge$ & بين المجموعات & \multirow[t]{3}{*}{ الغيرة } \\
\hline & & $r \varepsilon, 971$ & $1 \cdot r$ & rם & داخل المجموعات & \\
\hline & & & $1 \cdot \varepsilon$ & $71 \leq 0,974$ & الاجمالي & \\
\hline \multirow[b]{3}{*}{ د.غ } & \multirow[b]{3}{*}{$\cdot, \cdots 9$} & $\cdot, \wedge \div \vee$ & $r$ & 1, & بين المجموعات & \multirow{3}{*}{ الخطراب الجنسية } \\
\hline & & $1 \cdot 1, r q$. & $1 \cdot r$ & $1 \cdot r \leq 1, \wedge r q$ & داخل المجموعات & \\
\hline & & & $1 \cdot \varepsilon$ & & الاجمالي & \\
\hline \multirow{3}{*}{$\cdot, \cdot 1$} & \multirow{3}{*}{$\Lambda \cdot, v \leq r$} & oqrvo,r & r & 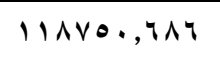 & بين المجموعات & \multirow{3}{*}{ اللاضطرابات الكلى } \\
\hline & & $V \mu \Delta, r V \leq$ & $1 \cdot r$ & STOM,ris & داخل المجموعات & \\
\hline & & & $1 . \leq$ & rצq & الاجمالى & \\
\hline
\end{tabular}

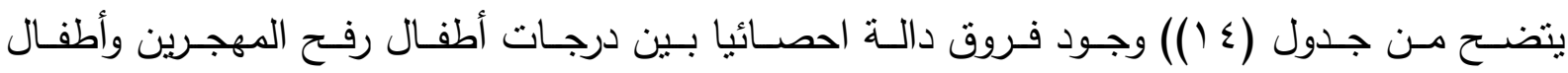

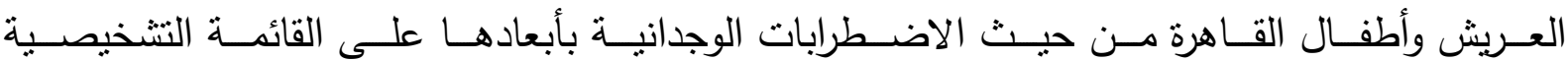

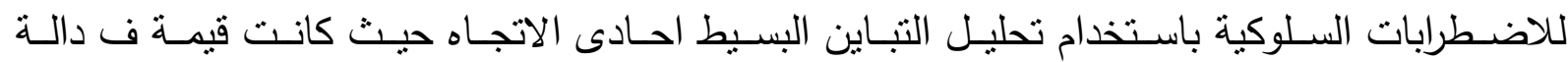
عند مستوى ا +,.، فيما عدا بعد اضطراب الهوية الجنسية حيث كانت قيمة ف غير دالة. 
ويوضـح جـدول (10) المتوسـطات والإنحرافـات المعياريـة لكـل مـن أطفـال رفـح المهجـرين وأطفـال

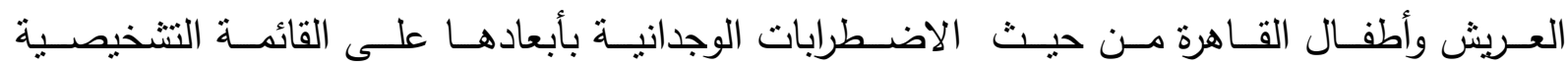

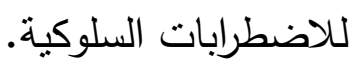

\section{جدول (10)}

المتوسطات والإنحرافات المعيارية لكلً من أطفال رفح المهجرين وأطفال العريش وأطفال القاهرة من حيث الاضطرابات الوجدانية بأبعادها على القائمة التشخيصية للاضطرابات السلوكية (ن =ه ه ـ 1)

\begin{tabular}{|c|c|c|c|c|c|c|}
\hline \multicolumn{2}{|c|}{ 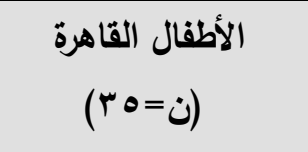 } & \multicolumn{2}{|c|}{ 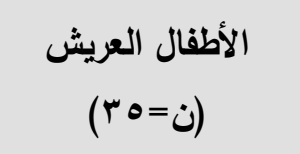 } & \multicolumn{2}{|c|}{ 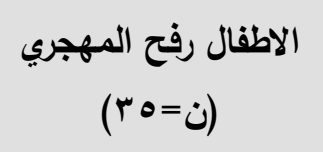 } & المتغيرات \\
\hline$\varepsilon$ & 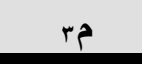 & $\varepsilon$ & 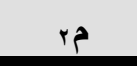 & $\varepsilon$ & is & \\
\hline$\vee, १ \wedge$ & $\varepsilon 0,11$ & $\vee, ० q$ & $\bullet V, I V$ & $\Lambda, 7 r$ & $\bullet 9,7$. & قلق الانفصال \\
\hline $1 \cdot, 1 r$ & $\varepsilon \varepsilon, \varepsilon$ & V, qr & 09,91 & $\Lambda, \mu \vee$ & $7 \cdot, .0$ & 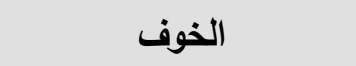 \\
\hline$\Lambda, \vee \bullet$ & $\leqslant 0, Y$ & $7,1 \wedge$ & $\Delta 9,0 \leq$ & $7,9 V$ & 91,01 & الخجل و الانسحاب الاجتماعى \\
\hline$\wedge, \wedge \uparrow$ & $\varepsilon 0, \wedge$ & 7,01 & $7 r, .0$ & $\bullet, \wedge$ & YY, Yr & الاكتئاب \\
\hline $0,1 \mathrm{~V}$ & $0 \leqslant, \leqslant Y$ & $\neg, \wedge \varepsilon$ & $0 \wedge, 91$ & $Y, Y \wedge$ & $r r, \ldots$ & الغضب \\
\hline $7,1 \leq$ & $\Delta V, Y$. & $\checkmark, Y \wedge$ & $09,7 \wedge$ & $0, Y 0$ & וז,rצ & الغيرة \\
\hline $1 \cdot, v_{1}$ & rq, qv & $1 \cdot, r \leq$ & rч, ฯo & 9,19 & rч,Ar & اضطراب الهوية الجنسية \\
\hline rq, Vq & rrq, II & $r \wedge, \varepsilon q$ & $r q r, q \varepsilon$ & $r r, O r$ & $\varepsilon \cdot 0,0 \leqslant$ & الاضطرابات الوجداتية الكلية \\
\hline
\end{tabular}

ويتضـح مـن جـدول (10) وجـود فـروق فـى المتوســات بــين أطفـال رفـح المهجـرين وأطفــال

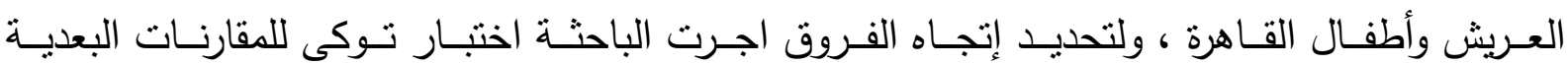

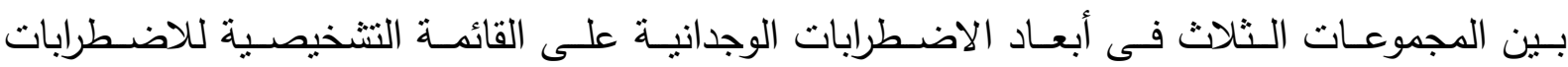
السلوكية، كما يتضح فى جدول (1 (1). 


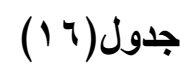

نتائج اختبار توكي للمقارنات البعدية بين المجموعات الثلاث (أطفال رفح المهجرين وأطفال العريش وأطفال

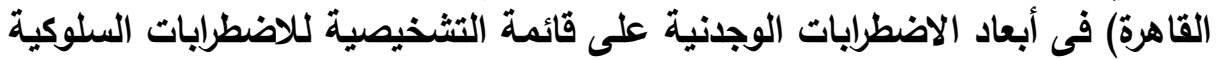

\begin{tabular}{|c|c|c|c|}
\hline מל - מלt & 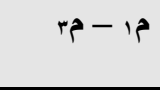 & p & المجموعات \\
\hline$* 1 Y, .0$ & $* 1 \leq, \leq \Lambda$ & $Y, \leqslant Y$ & قلق الانفصال \\
\hline$* 10,01$ & $* 10,70$ & $\cdot, 1 \leq r$ & الخوف \\
\hline$* 1 \leq, r \leq$ & $* \mid 7, \mu_{1}$ & $1,9 \vee$ & الخجل والاتسحاب الاجتماعى \\
\hline$* 17, r_{0}$ & $* 17, \leqslant Y$ & $\cdot,|V|$ & الاكتئاب \\
\hline$* \varepsilon, \leqslant \wedge$ & $* V, \diamond \mathrm{V}$ & $r, \cdot \Lambda$ & الغضب \\
\hline$r, \leqslant \wedge$ & $* 4,11$ & $* r, 7 r$ & الغيرة \\
\hline$* \curlyvee \varepsilon, \wedge r$ & $* V\urcorner, \leqslant Y$ & 11,7 & الارجة الكلية للاضطر ابات الوجدانية \\
\hline
\end{tabular}

يتضح من الجدول (1 1 ) الأتى:

يوجد فروق دالة إحصــائيا بين متوســـ درجات أطفال رفح المهجرين ومتوســـ درجات أطفال

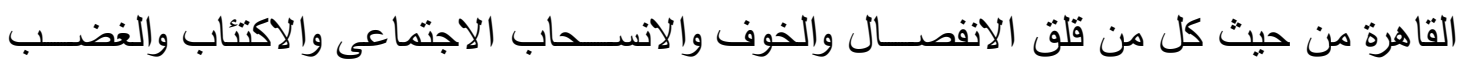
والغيرة والدرجة الكلية للاضطرابات الوجدانية فى إتجاه أطفال رفح المهجرين.

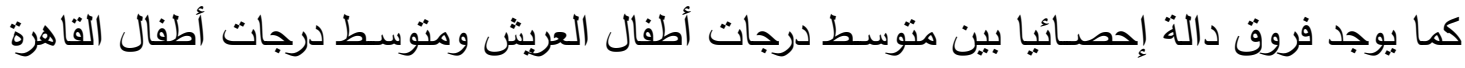
من حيث كل من قلق الانفــال والخوف والانســاب الاجتماعى والاكتئاب والغضـبـ والدرجة الكلية للاضطرابات الوجدانية فى إتجاة أطفال العريش.

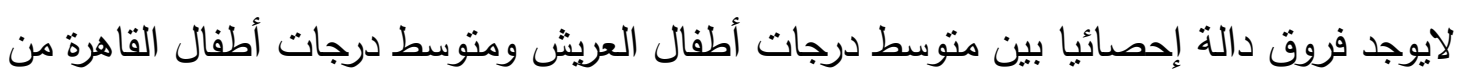

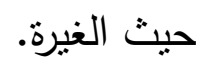
يوجد فروق دالة إحصــائيا بين متوســـ درجات الأطفال رفح المهجرين ومنوســـ درجات أطفال العريش من حيث الغيرة فى إتجاه أطفال رفح المهجرين.

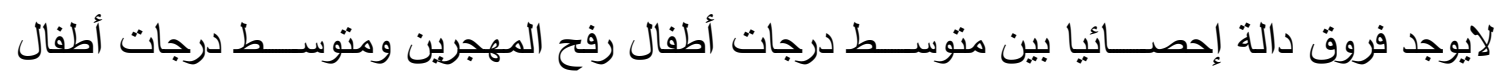

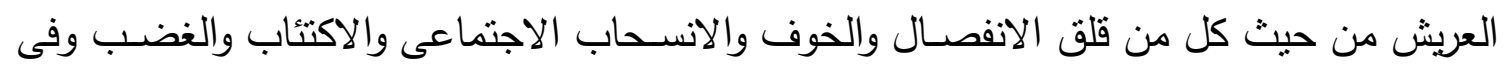
الدرجة الكلبة للاضطرابات الوجدانية. ويوضح الثكل رقم (r) الفروق بين منوسط درجات كل من أطفال رفح المهرين وأطفال العريش وأطفال القاهرة من حيث الاضطرابات الوجدانية على القائمة التشخيصية لاضطرابات السلوكية. 


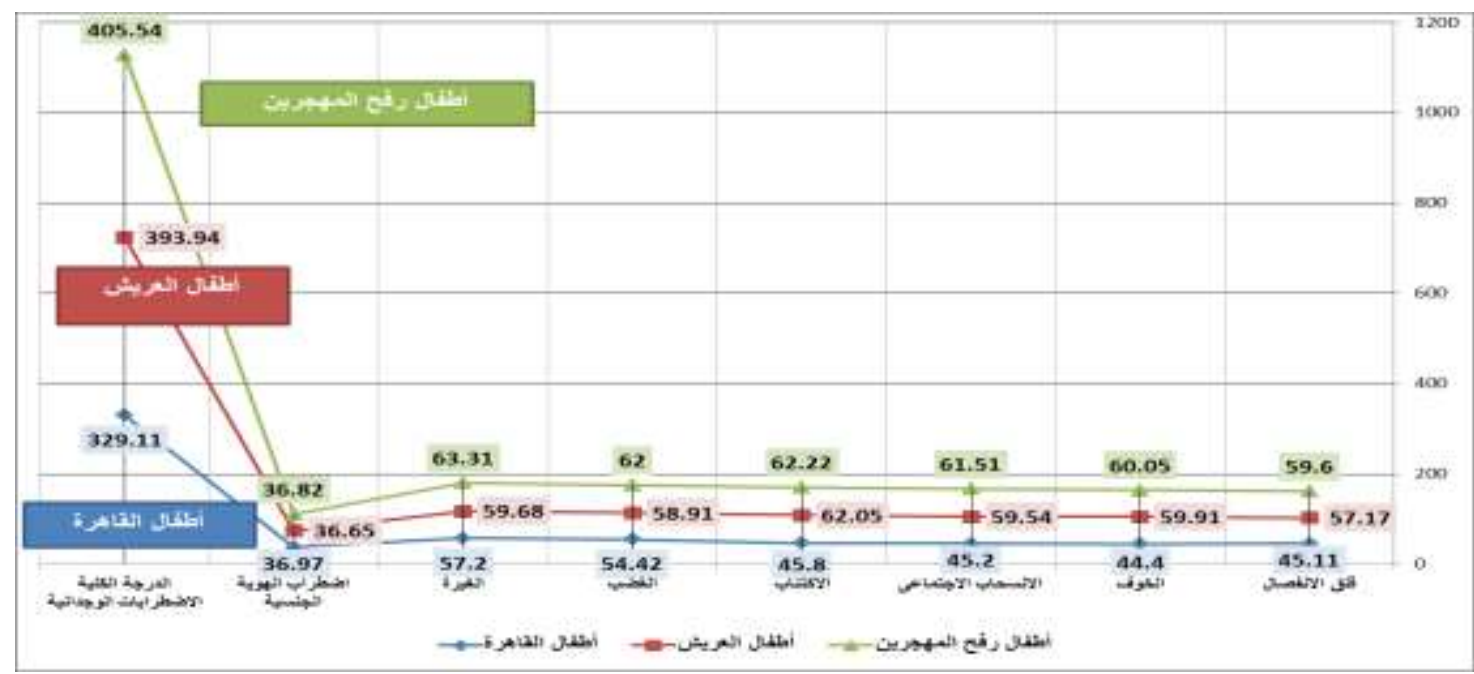

شكل (")

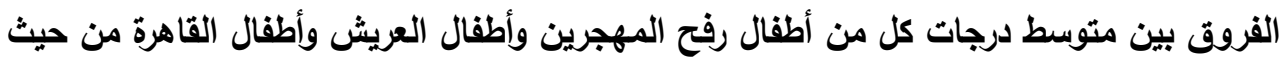
الاضطرابات الوجدانية وأبعادها على القائمة التشخيصية للاضطرابات العات السلوكية.

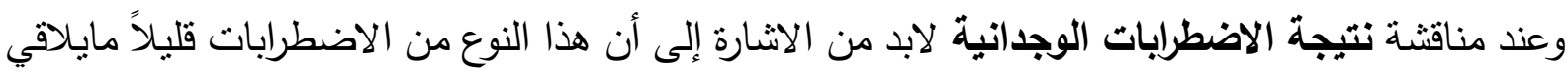

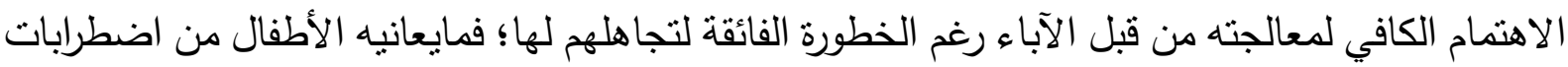

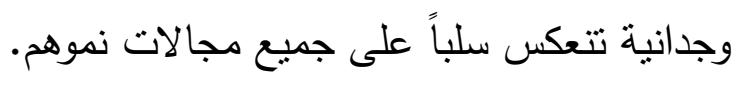

وبناء على النتيجة الخاصة بهذا الاضطراب نجد أن قلق الانفصال لاتوجد فروق دالة إحصائيا فيه بين

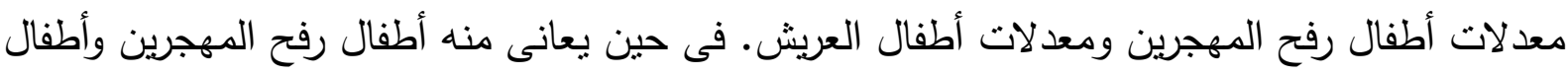

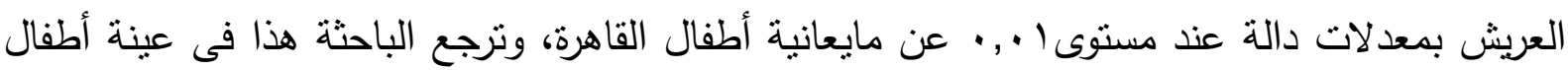

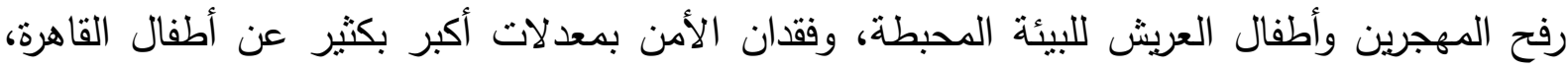

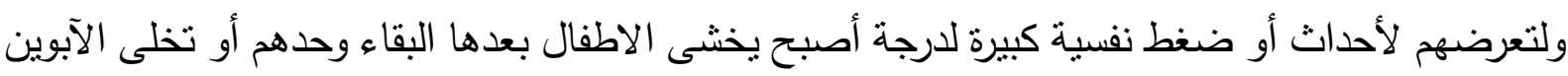

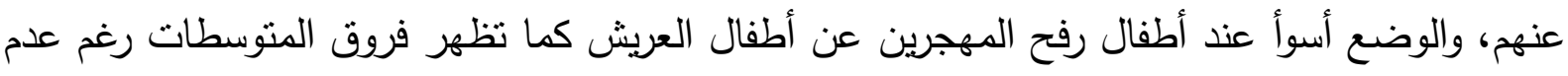

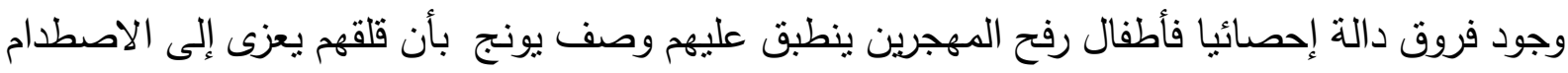

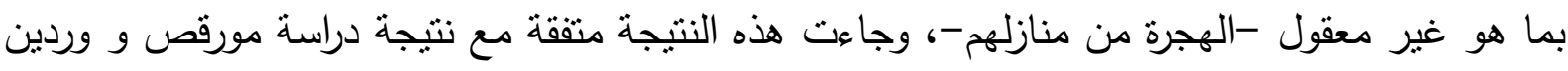

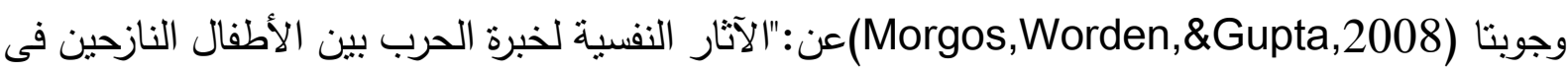

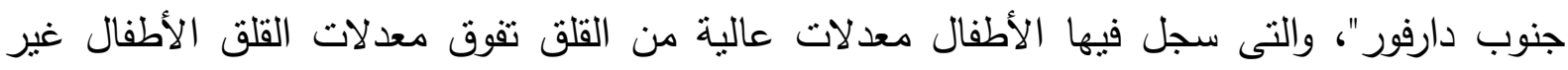

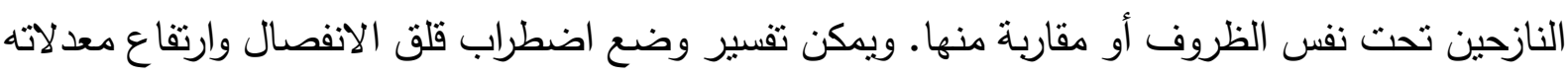

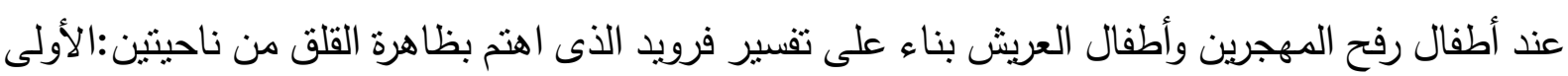

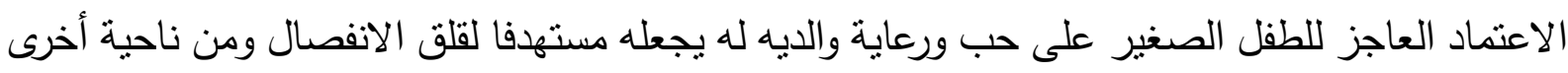

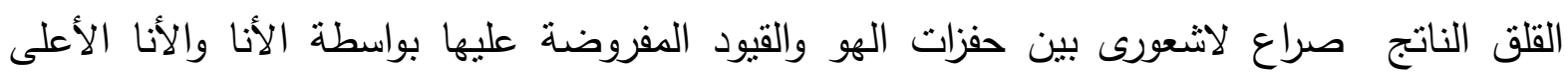

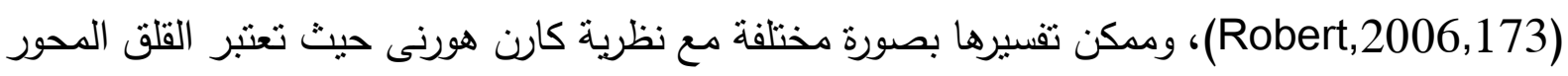


الرئيسى فى تفسير العصاب وترى أن القلق ينشأ من المؤثرات الاجتماعية البيئية فى عملية نمو الطفل أكثر

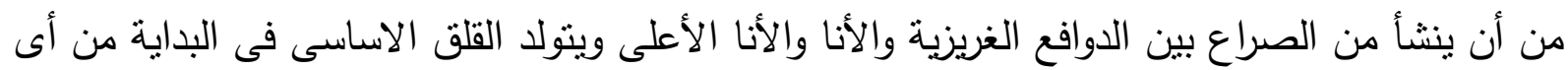
موقف اجتماعى بستثير الخوف فى الطفل وهكذا ينمو القلق عند الطفل حينما تتكون لديه دفاعات ضد البيئة التى يشعر حيالها بالعجز والعداوة والعزلة، فالبيئة تبدو بالنسبة له مهددة وباعثة على الخطر ، وأنه يعيش وسط عالم يضج بالعداوة والتناقض، وتكمن خطورة القلق كذللك عند هورنى من كونه يمكن اعتباره

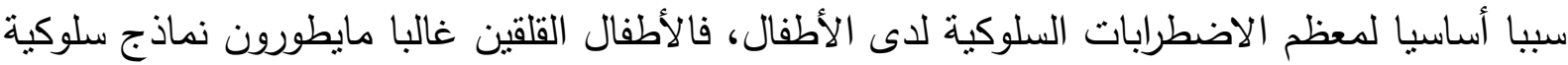

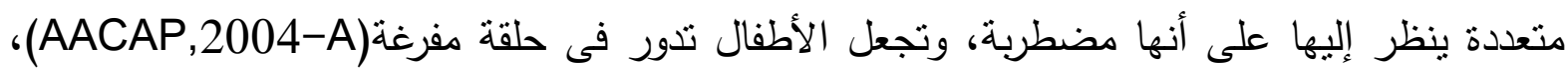
ويمكن الأخذ بما يراه أدلر بأنه يعزى إلى الاحساس بنقص حقيقى أو متخيل يبدد إرادة القوة لاى الطفل،

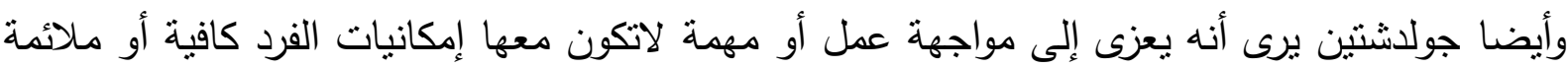

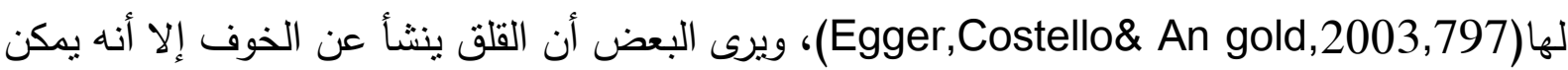
تمييزه عنه فى جوانب كثثرة فهو أكثر غموضا وعلى عكس الخوف فهو لاينشأ من موقف قائم دائما، وأنما

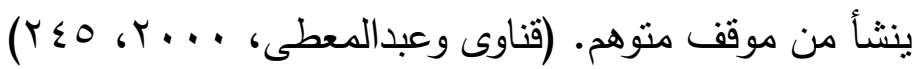

أما اضطراب الخوف فمعدلاته مرتفعة عند أطفال رفح المهرين وأطفال العريش جاءت بمعدلات دالة

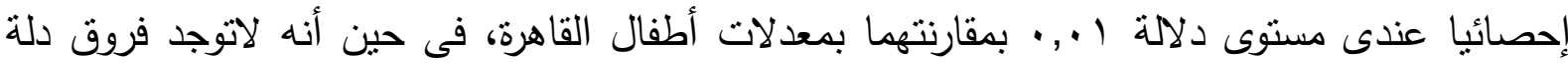

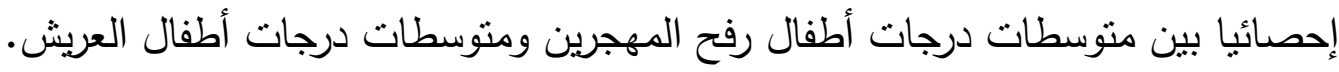
من منطلق أن الخوف عاطفة قوية غير محببة يسببها إدراك خطر ما، ومايراه أتوفينخل فى أن المخاوف داف هى العصاب الحقيقى للأطفال، حيث تستهلك المخاوف قدرا هائلا من الطاقة النفسية للطفل لمواجهة

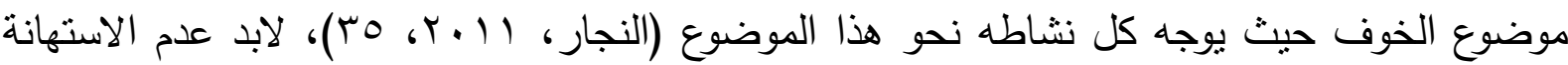
بتفسير المعدلات المرتفعة عند أطفال رفح المجرين وأطفال العريش والتى جاءت دالة إحصائيا عندى التى الته

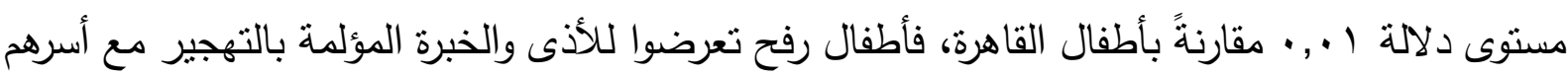
نتيجة الحرب ضد الإرهاب، ليجدوا أنفسهم غرباء يعانوا من العزلة فى مكان جديد عليهم ويحاط بهر بهري

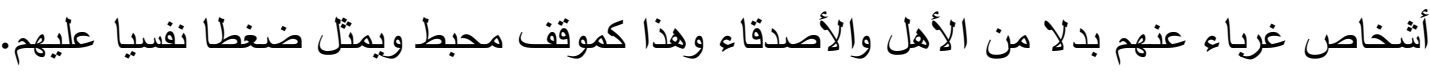

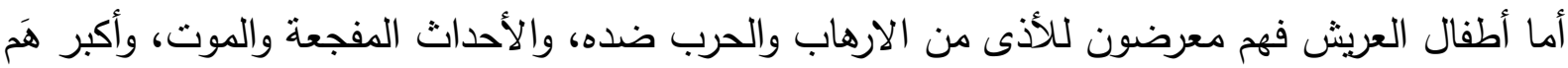

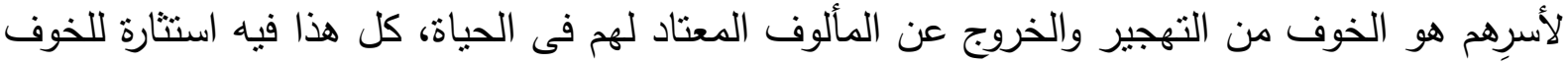
على الذات والوجود لضعف الكفاءة، فالخوف عند بياجية له علاقة بالبقاء وهو يوعى باليخاطر لحماية

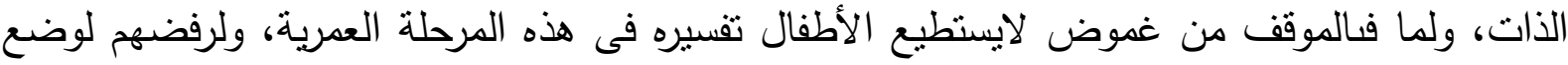

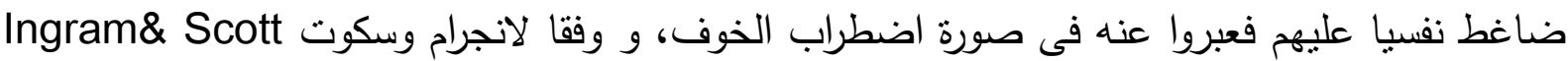
والنظرية المعرفية، فإن الأفراد يستجييون من خلال التفكير فى المواقف وتفسيرهم للحوادث من أبعاد معرفية

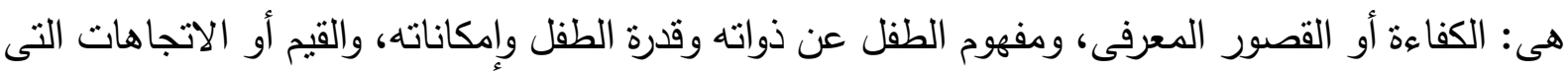


يتبناها الطفل تجاه المواقف(AACAP,2013-C,8)، والمخاوف الثنديدة لاتذهب ببساطة، والعقاب أو التجاهل لاينفعان فى حلها، والهخاوف المحددة ربما تقود إلى مشاعر عامة من القلق العائم وعدم الأمن والهواجس، كما إن المخاوف القوية وذات الأمد الطويل خطيرة، ومن المؤشرات على الحاجة إلى المساعدة

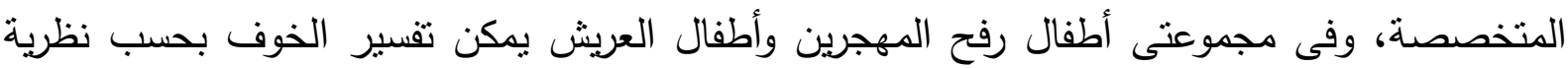
التحليل النفسى بأنه يحدث نتيجة إسقاط أو إزاحة لبعض الرغبات أو الدوافع اللاشعورية التى تثير قلقا

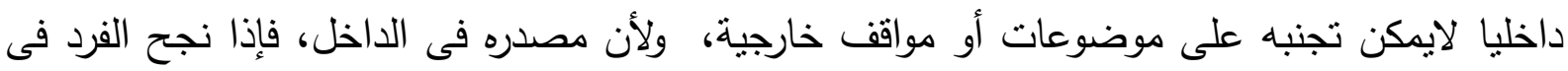

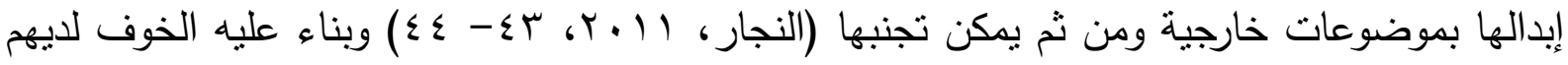

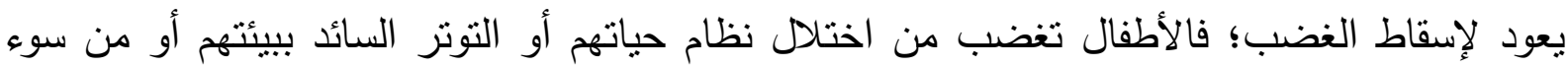

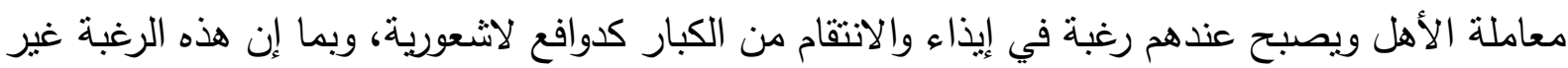

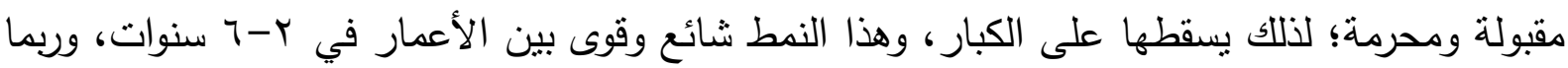

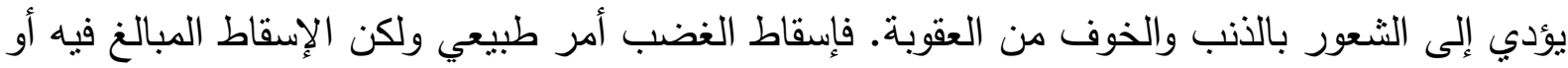

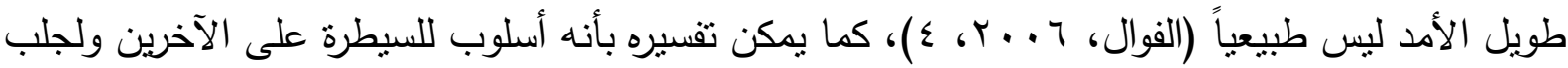

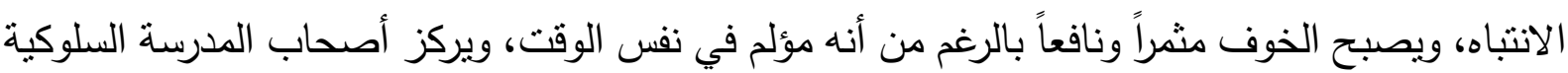

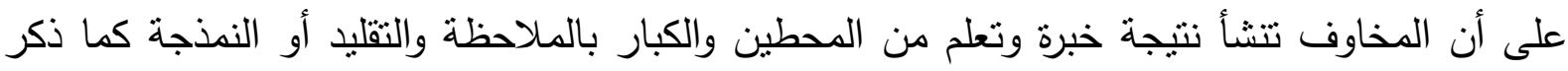

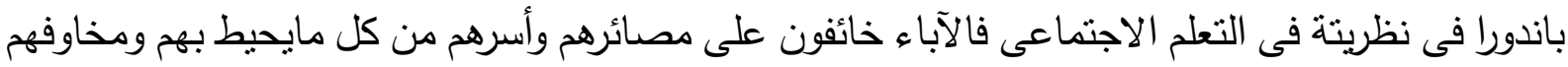

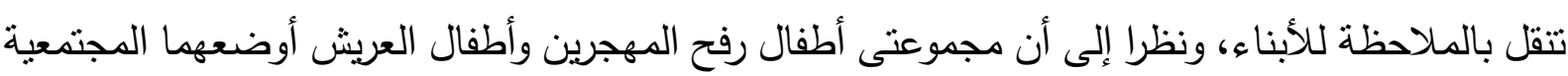
متقاربة لهذا لاتوجد بينهم فروق دالة إحصائيا.

فى حين أن الخجل والانسحاب الاجتماعى(الإنطواء) جاءت الفروق بين منوسطات درجات أطفال رفح المجرين وأطفال العريش غير دالة إحصائيا ولكنها مقارنةً بمنوسط درجات أطفال القاهرة جاءت داءت دالة عند

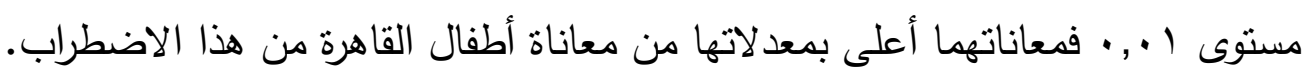

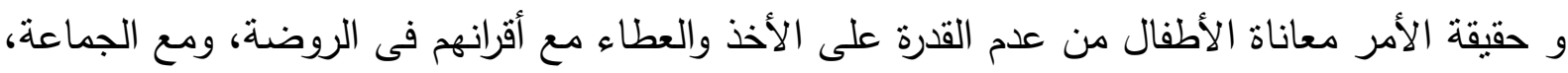

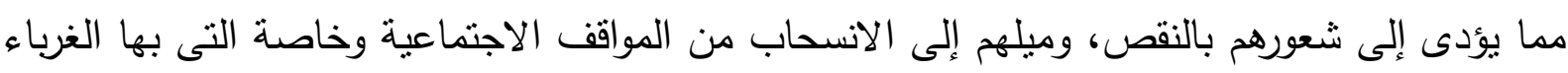

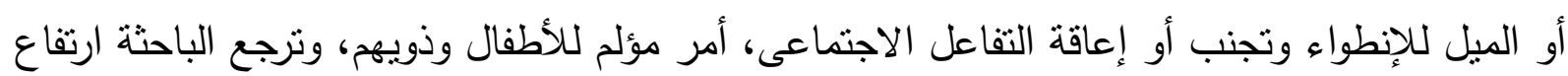

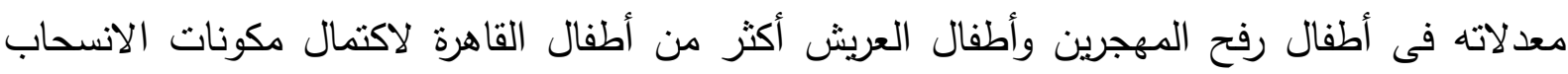

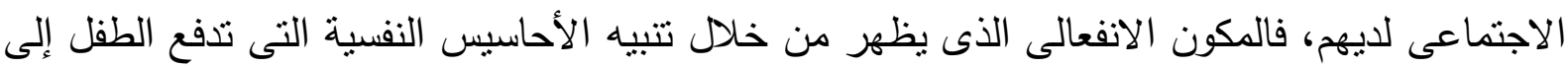

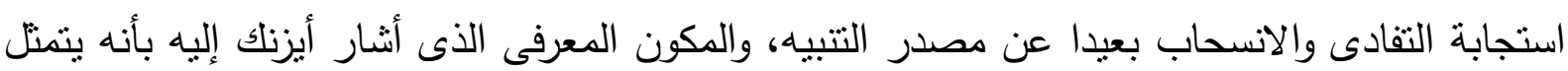

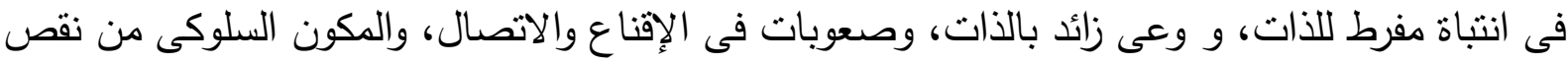

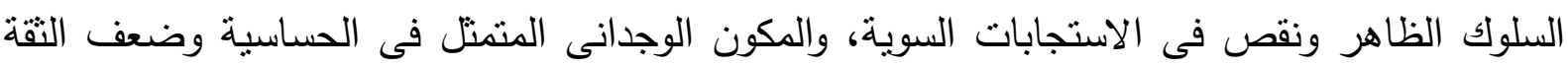

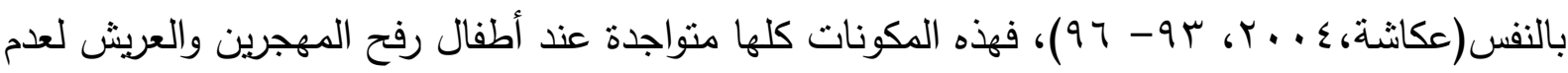
الثعور بالأمن فهم لايمارسون المهارات الاجتماعية ويزداد خجلهم بسبب قلة النشاط والحاجة إلى التغذية 
الراجعة من الآخرين المنشغلين عنهم بما هو أثد وطأة، وخوف الوالدين على الأطفال من الغرباء وخوف

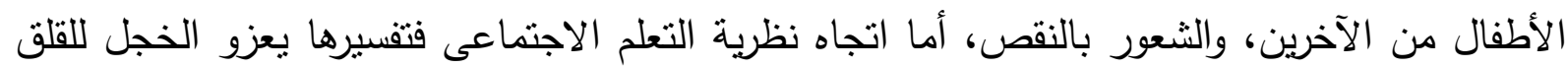

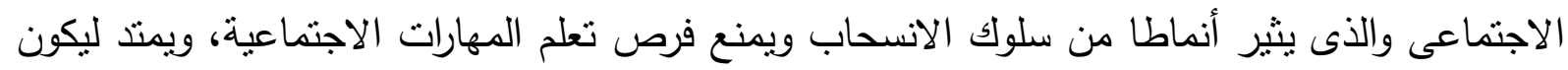
عواقب معرفية تظهر فى شكل توقع الفشل فى الموقف الاجتماعى، وحساسية مفرطة للتقيم السلبى من قبل الآخرين وميل لتقيم الذات سلبيا.(Coelho,\&Romao, 2018, 219 ) ، (Beer, 2002, 1010) من وجهة نظر الباحثة ينطبق هذا على عينة أطفال رفح المهجرين أكثر من أطفال العريش كما يفسر لنا

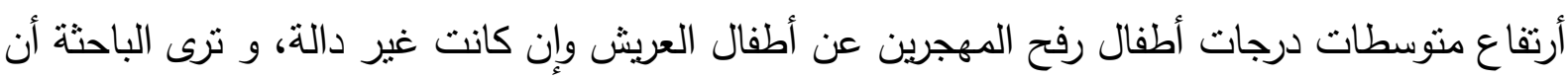

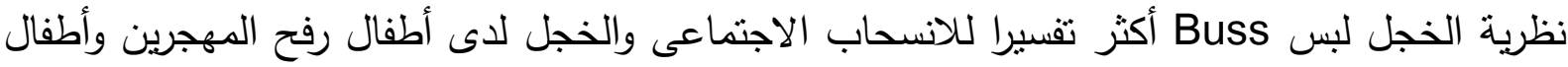

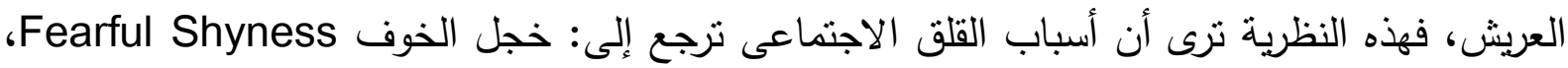

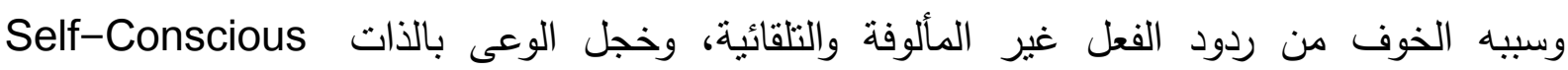
Shyness

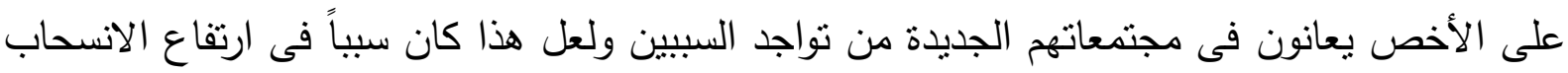

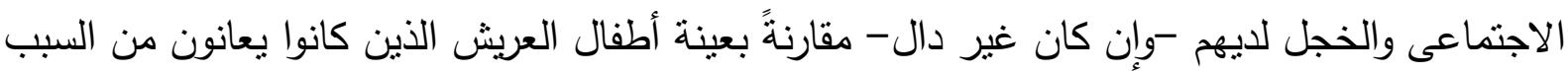

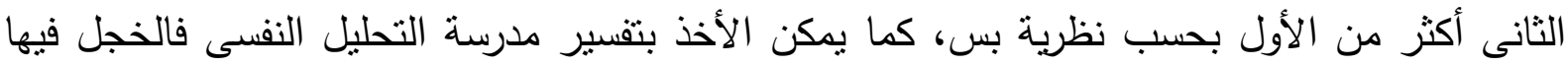

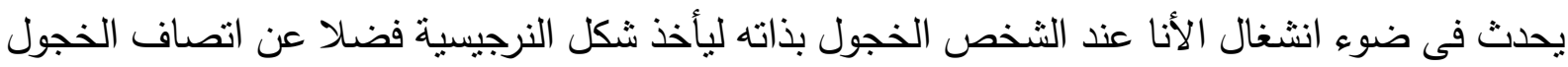
بالعدوان والعدائية. (Bass, Santo, Cunha, \&Neufeld, 2016, 250)

وبالإنتقال لاضطراب الاكتئاب نجد أنه جاءت الفروق بين متوسطات درجات أطفال رفح المهرين وأطفال

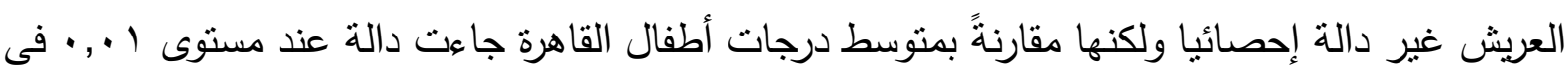
إتجاة أطفال رفح المهرين وأطفال العريش، ويمكن تقسير هذا، بأن الأبناء الذين ينتمون لآباء وأمهات

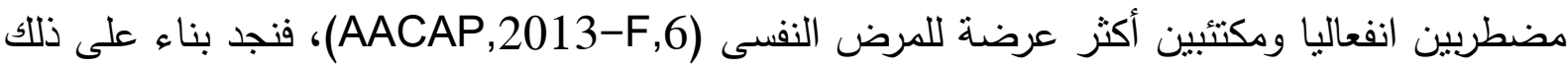

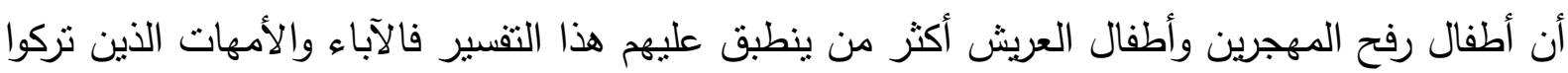

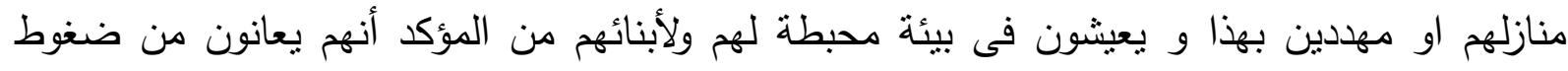

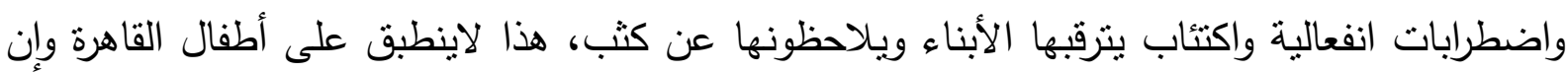

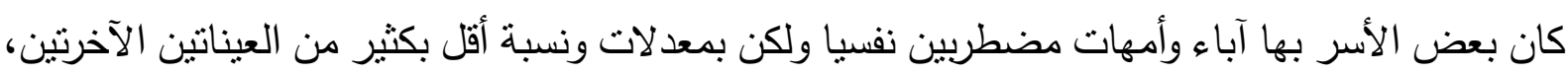

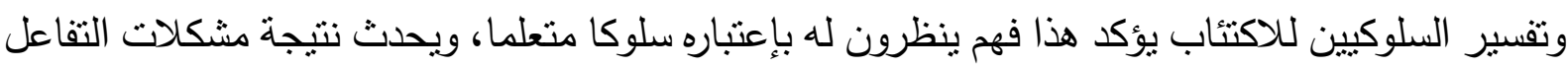

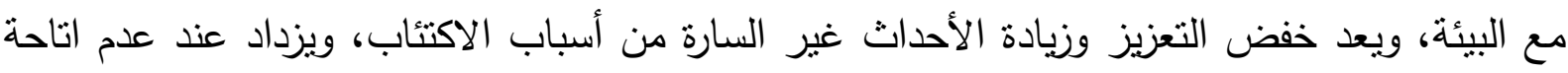

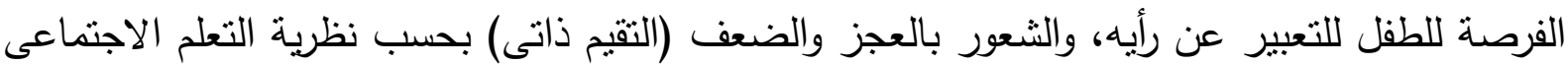
لباندور · (AACAP, 2013-E, 7) 
فى حين يرجعه فرويد لشعور الأنا بالفشل، وتحول النزعات العدوانية الناجمة عن هذا إلى الداخل فى شكل اكتنئاب(AACAP,2013-F,8)، فى حين ألبرت أليس ونظرية السلوك العقلانى تؤكد أن الاكتئاب ينتج من طريقة تفكير الثخص المكتئب ومعالجته للأحداث الخارجية وليس وجدانه (القمش والمعايطة، I ا ـ ؟، (YVV والمكتئبون بحسب النظرية المعرفية لديهم أساس معرفى سالب يؤدى بهم إلى استبعاد المعرفيات الموجبة فى مقابل ذلك تتمو المعرفيات السالبة وتظهر ثلاث أنماط معرفية سالبة تسمى بالثالوث المعرفى فى تفكير المكتئب وهى: نظرة المريض السلبية إلى نفسه وتوجيه اللوم والنبذ لذاته، والنظرة السلبية إلى العالم وأنه يتعرض للاضطهاد، والنظر السلبية للمستقبل.(Rutter,Bisho,Pine,et al,2008,31) وهذا الثالوث المعرفى متوافر فى عينة أطفال رفح المهجرين وأطفال العريش أكثر من عينة أطفال القاهرة، وتعرض أطفال رفح المهجرين لضغوط حياتية أكبر من أطفال العريش متمثلة فى الانتقال من مكان لمكان جديد، بكل مايحملة هذا الحدث من تبعيات مثل: تعرض الأسرة بكاملها بما فيهم الطفل للتغيرات الفجائية التى لاتسمح للطفل بالتكيف التدربجى، وإصابة الأسرة أو أحد أفرادها بالاكتئاب، وقلق الوالدين على الطفل فى البيئة الجديدة وفرض الحماية الزائدة عليه والتى تعرضه للفتل والاحباط، وهذا متفق مع نتائج دراسة لاينى وبينوس وآخرون (Layne,Pynoos,Saltzman, et al,2001) حيث قاموا بدراسة عن:"فاعلية المساندة المقدمة فى صورة تدخلات للعلاج المعرفى السلوكى مع الأطفال اللاجئين المصابين بمشكلات نفسية"على(00) طفلا لديهم اضطرابات سلوكية، و وجدوا أنهم يعانون من معدلات عالية وخطيرة من الإكتئاب بعد الحرب على البوسنة نتيجة للنزوح والهجرة، وكان العلاج فى شكل إعادة الهيكلة المعرفية، والذى نجح فى خفض المعدلات الاكتئاب، ولعل هذا سبب إرتفاع متوسطات درجات أطفال رفح المهجرين عن منتسطات درجات أطفال العريش وإن كانت الفروق غير دالة، علما بأن مايفرضه الوالدين من قيود ضاغطة على أطفالهم من رفح يعانى منه أطفال أسر العريش فهى تفرض نفس الحماية الزائدة على أطفالها وبالتالى يعانى أطفالهم من الاحباط والاكتئاب، كما أن ادراك الطفل للعوامل المرتبطة بالضغوط وفقدان الثعور بالأمن والنظرة السالبة نحو الذات والعالم والمستقبل وعدم القدرة على التعامل مع المشكلات وإيجاد

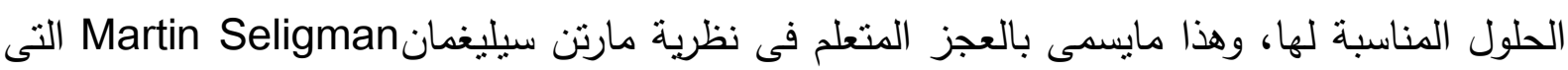
تسبب فى إكتئاب أطفال رفح المهجرين وأطفال العريش. واتفق هذا التفسير مع ماجاءت به نتائج دراسة ثابت وثابت وفوستاينيس (Thabet,Thabet,\&Vostainis,2016)، بعنوان:"العلاقة بين صدمات الحرب

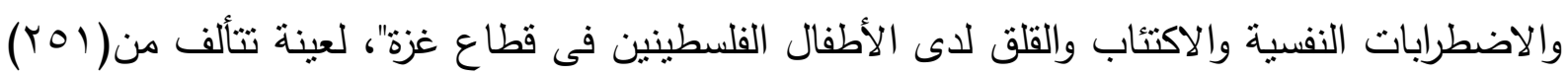
طفلا من الأطفال الذين تتراوح أعمارهم بين(7: 7 (1) سنة تم اختيارهم من مخيمات قطاع غزة، حيث وجد

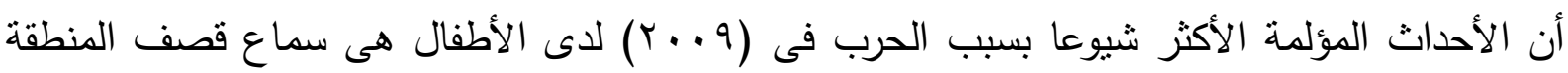

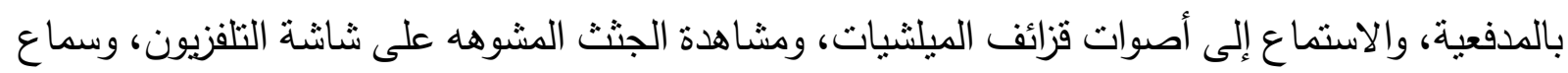

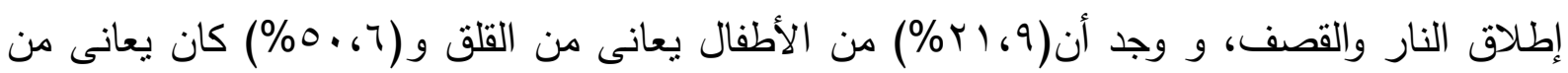
الإكتئاب، وأن كلَ من اضطرابات الإكتئاب والقلق فى الأطفال الفلسطينين مرتفعة فى مستوياتها. 
و بالنظر إلى نتائج اضطراب الفضب جاءت الفروق بين منوسطات درجات أطفال رفح المهجرين وأطفال

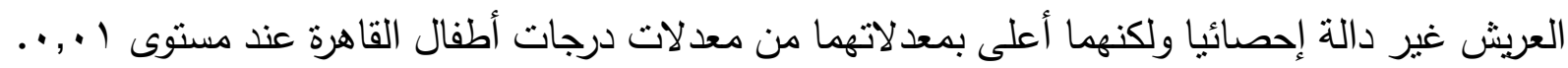

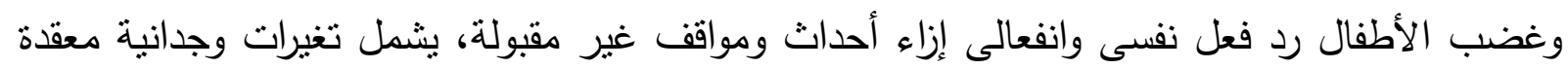

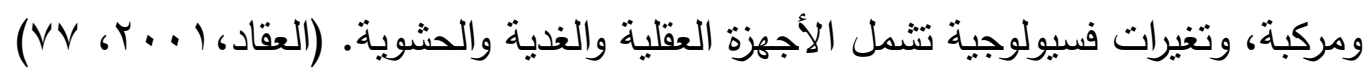

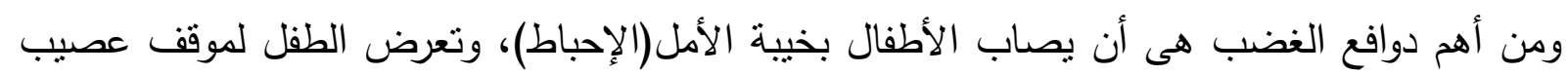

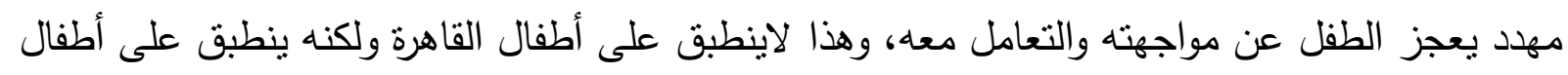

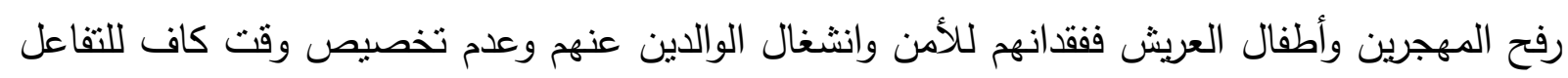

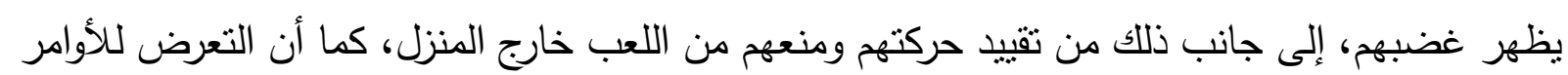

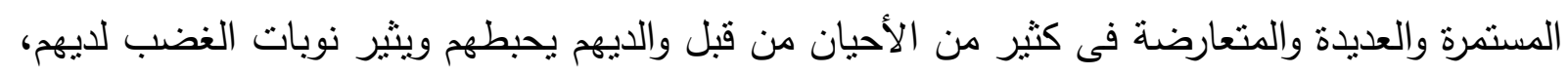

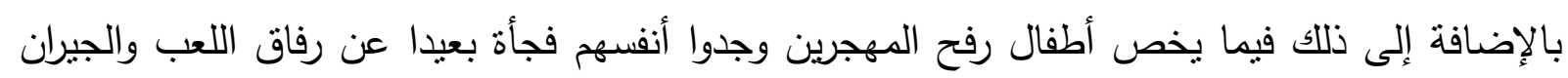

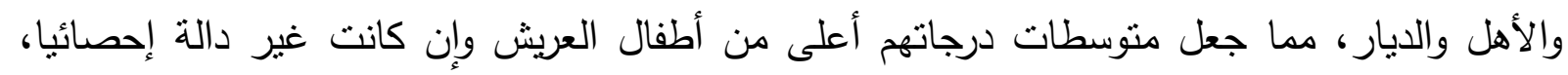

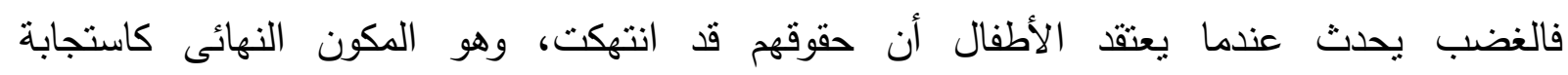

كلأحداث. (Suter\&Byrne,2000,9)

أما اضطراب الغيرة جاءت الفروق بين متوسطات درجات أطفال العريش وأطفال القاهرة غير دالة إحصائيا

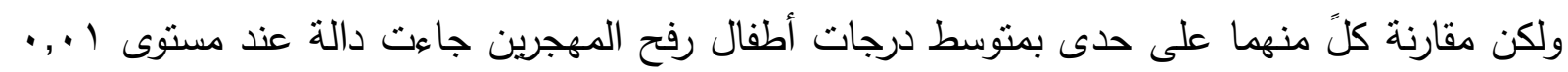
فى إتجاة أطفال رفح المهجرين.

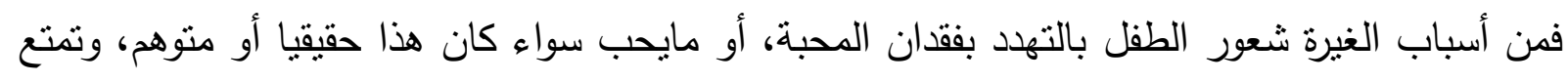

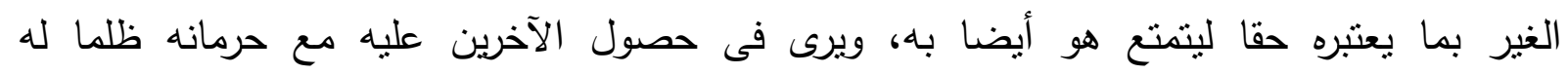

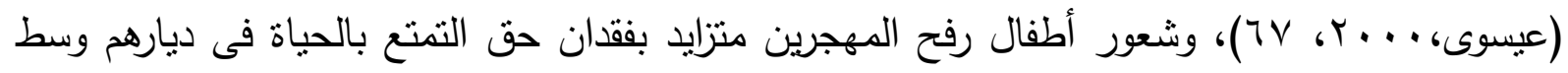

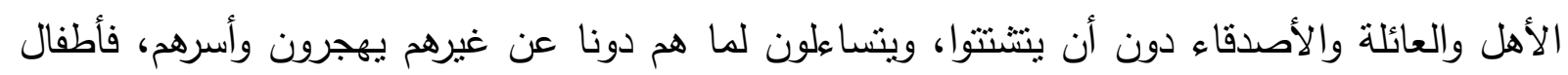

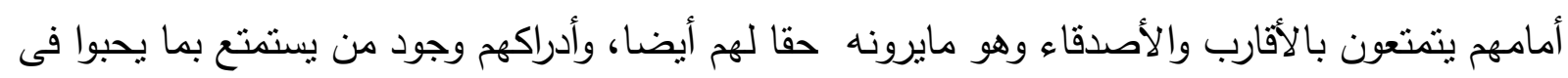

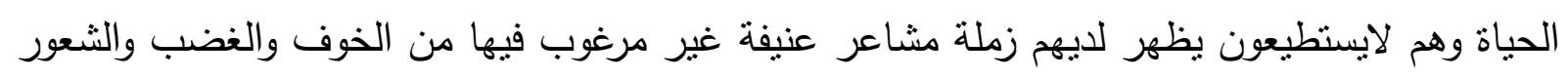

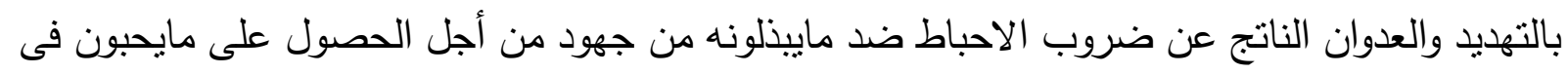

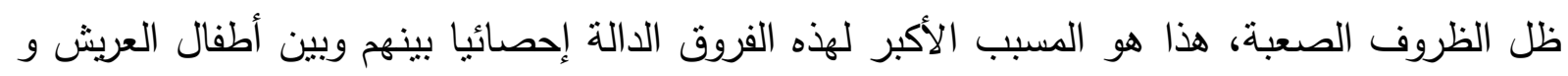

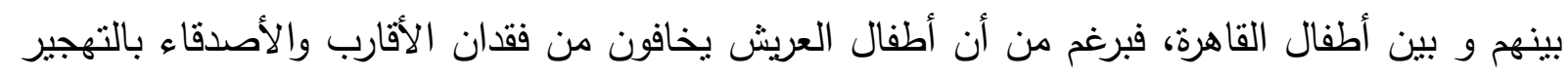

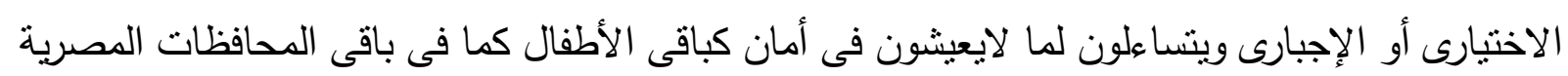

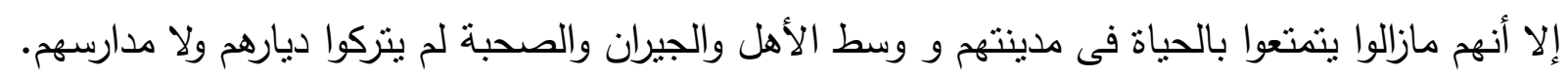

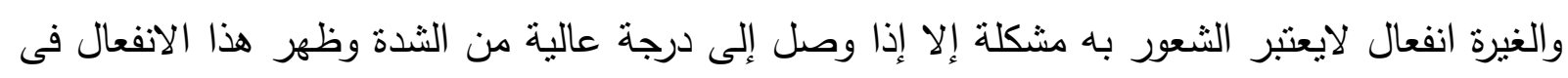
شكل مركب من الغضب والحقد والخوف، فقد يكون مصدرا لإيذاء الطفل والمحيطين به فهو النها النفعال مكدر

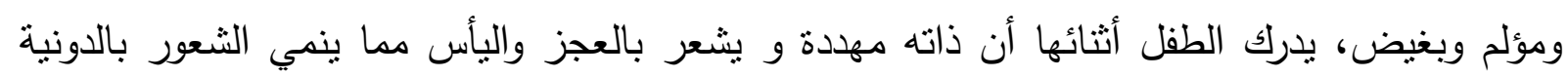




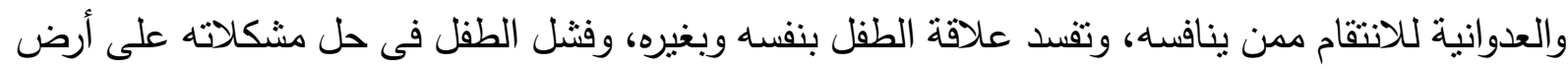
الواقع، و يلجأ إلى الحيل الدفاعية الهروبية كالإسقاط، ولذلك فهى مؤشر خطير عند ارتفاع معدلاتها.

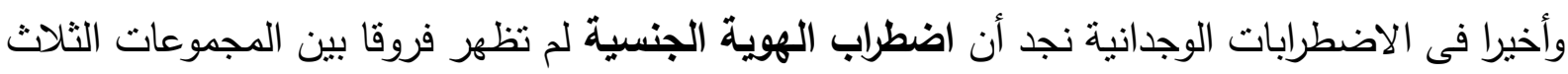

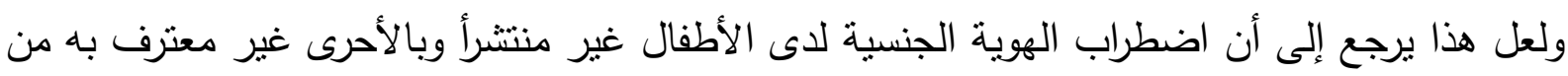

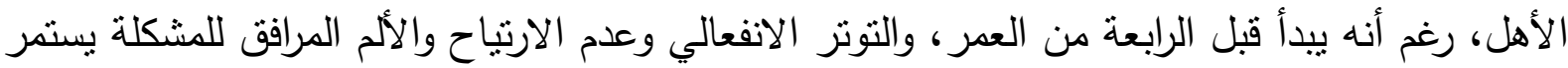

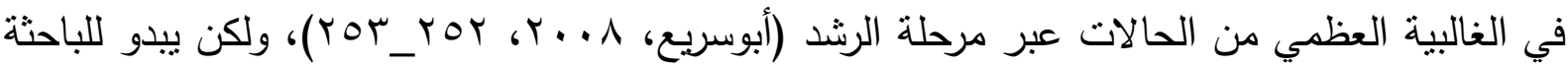

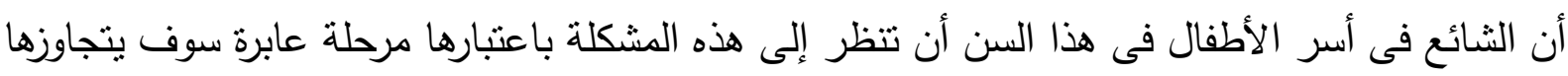

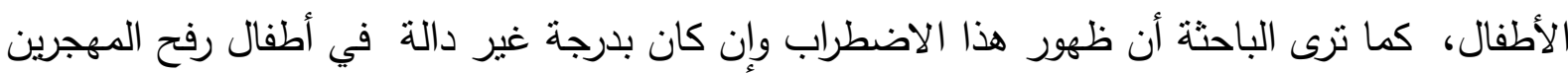

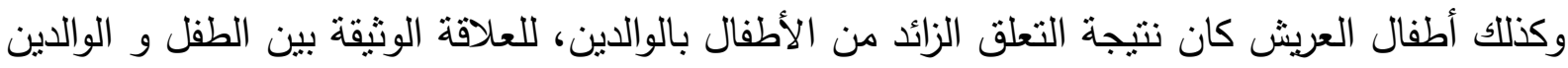
وخاصة الوالد من الجنس الآخر كنتيجة لظروف البيئة، بحيث يكون الاتصال النفسي والجسمي بين الطرفين

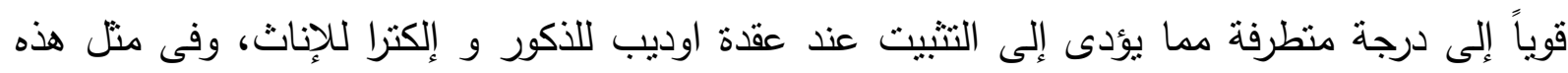

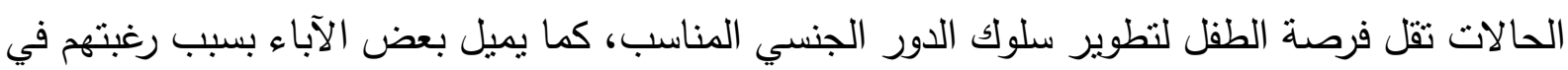

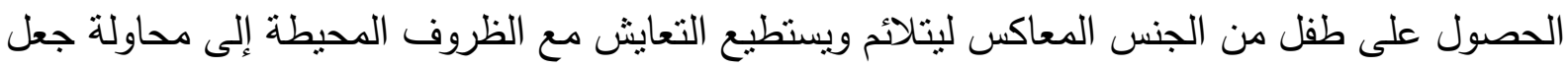
البنت تتصرف كأنها ولد، وشجع الوالدين بصمتهم أو عدم اكتراثهم لما يظهر على ألى أطفالهم لإنشغال تفكيرهم

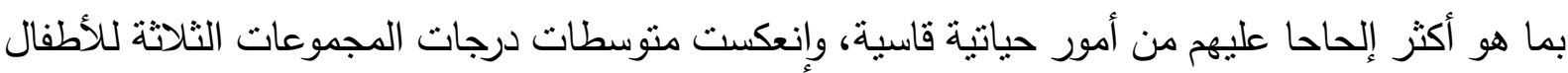

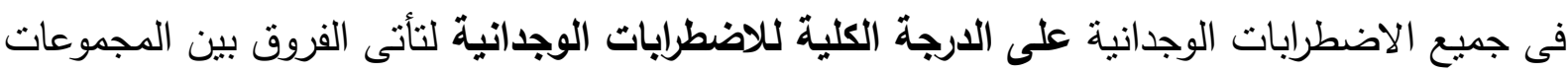
غير دالة إحصائيا بين أطفال العريش وأطفال رفح المهجرين ولكنها الإهه الفروق بين معدلاتهما ومعدلات أطفال

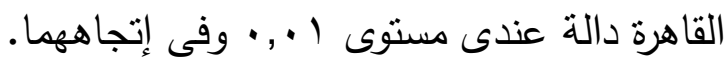

رابعاً: النتائج الخاصة بالاضطرابات السلوكية الاجتماعية وأبعادها:

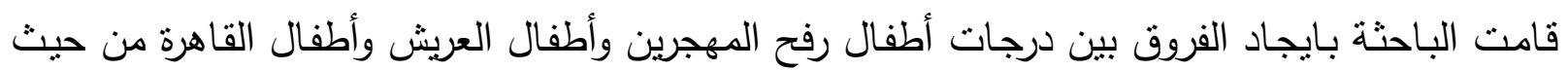
الاضطرابات السلوكية الاجتماعية بأبعادها على القائمة التتخيصية للاضطرابات التهات السلوكية باستخدام تحليل

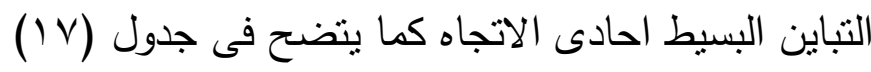




\section{جدول (IV)}

نتائج تحليل التباين البسيط احادى الاتجاة بين المجموعات الثلاث من حيث الاضطرابات السلوكية الاجتماعية وأبعادها على قائمة التشخيصية للاضطرابات السلوكية (ن= ه ه ـ )

\begin{tabular}{|c|c|c|c|c|c|c|c|}
\hline مستوى الدلالة & قيمة ف" & متوسط المربعات & درجات الحرية & مجموع المربعات & مصدر التباين & \multicolumn{2}{|c|}{ المتغيرات } \\
\hline \multirow{3}{*}{$\cdot, \cdot 1$} & \multirow{3}{*}{0,999} & $r v v, \varepsilon \ldots$ & r & $00 \leqslant, \wedge \ldots$ & بين المجموعات & \multirow{3}{*}{\multicolumn{2}{|c|}{ الكذب }} \\
\hline & & \& & $1 \cdot r$ & $\varepsilon \vee 17, \varepsilon \ldots$ & داخل المجموعات & & \\
\hline & & & $1 \cdot \varepsilon$ & orvi,r... & الاجمالي & & \\
\hline \multirow{3}{*}{ - } & \multirow{3}{*}{$\cdot, \cdot r}$. & $\cdot, \wedge \ldots$ & r & $1,7 \ldots$ & بين المجموعات & \multirow{3}{*}{\multicolumn{2}{|c|}{ العناد }} \\
\hline & & $\varepsilon \cdot, 974$ & $1 \cdot r$ & $\leqslant 1 \vee \wedge, 11 \leqslant$ & داخل المجموعات & & \\
\hline & & & $1 \cdot \varepsilon$ & $1 \leqslant 7 \leqslant, 99$. & الاجمالي & & \\
\hline \multirow{3}{*}{$\cdot, \cdot 1$} & \multirow{3}{*}{1,010} & $r q ৭, \leqslant r \wedge$ & r & $\vee ৭ \wedge, \wedge \vee \neg$ & بين المجموعات & \multirow{3}{*}{\multicolumn{2}{|c|}{ السرقة }} \\
\hline & & $\leq 7,911$ & $1 \cdot r$ & $\varepsilon \vee \wedge \varepsilon, 9 \vee 1$ & داخل المجموعات & & \\
\hline & & & $1 \cdot \varepsilon$ & $\Delta \Delta \wedge r, \wedge \leq \wedge$ & الاجمالي & & \\
\hline \multirow{3}{*}{$\cdot, .0$} & \multirow{3}{*}{$\varepsilon, V \cdot r$} & $r \cdot r, r \ldots$ & r & $\varepsilon \cdot \varepsilon, \varepsilon \ldots$ & بين المجموعات & \multirow{3}{*}{\multicolumn{2}{|c|}{ والتخريب }} \\
\hline & & $\varepsilon r, \ldots 1$ & $1 \cdot r$ & $\leq r \wedge \neg, 11 \leqslant$ & داخل المجموعات & & \\
\hline & & & $1 \cdot \leq$ & $\leq \vee 9,, 01 \leqslant$ & الاجمالي & & \\
\hline \multirow{3}{*}{$\cdot, .0$} & \multirow{3}{*}{,$\vee \div 1$} & גז & r & rVV, rVT & بين المجموعات & \multirow{3}{*}{ العدوان } & \multirow{9}{*}{ العدوان } \\
\hline & & rq, Ir. & $1 \cdot r$ & rqv., rA & داخل المجموعات & & \\
\hline & & & $1 \cdot \varepsilon$ & $r Y \leq V, \Delta T r$ & الاجمالي & & \\
\hline \multirow{3}{*}{ د. } & \multirow{3}{*}{1,741} & $07,9 Y \leq$ & r & $\| r, \wedge \leq \wedge$ & بين المجموعات & \multirow{3}{*}{ التعدوان } & \\
\hline & & $r \varepsilon, I r r$ & $1 \cdot r$ & $r \leqslant \Lambda \cdot, \leqslant \ldots$ & داخل المجموعات & & \\
\hline & & & $1 \cdot \varepsilon$ & $r \Delta q \leq, r \leq \Lambda$ & الاجمالي & & \\
\hline \multirow{3}{*}{$\cdot, .0$} & \multirow{3}{*}{ r,vo. } & $0 . V, r Y \leq$ & $r$ & $v \leq 7,19$. & بين المجموعات & \multirow{3}{*}{ 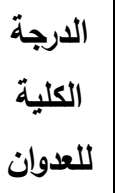 } & \\
\hline & & $r v, v 19$ & $1 \cdot r$ & $1.1 \leq V, r \ldots$ & داخل المجموعات & & \\
\hline & & & $1 \cdot \varepsilon$ & 1. $\wedge q \uparrow, r q$. & الاجمالي & & \\
\hline \multirow[b]{3}{*}{$\cdot, ., 1$} & \multirow[b]{3}{*}{$1 \cdot, 1 \ldots$} & $\leq T V r, 1 \leq r$ & r & $9 r \leq \leqslant, r \wedge \neg$ & بين المجموعات & \multirow{3}{*}{\multicolumn{2}{|c|}{ للاضطرابات الارجة الكلية }} \\
\hline & & $\varepsilon q r, O V 1$ & $1 \cdot r$ & $\varepsilon V \backslash \wedge r, r r q$ & داخل المجموعات & & \\
\hline & & & $1 \cdot \varepsilon$ & 070Y7,01 & الاجمالي & & \\
\hline
\end{tabular}

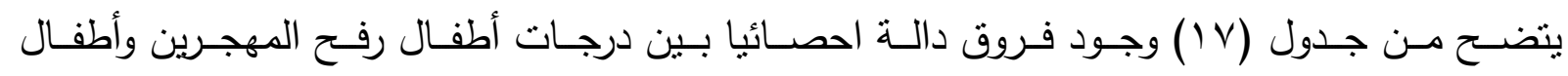

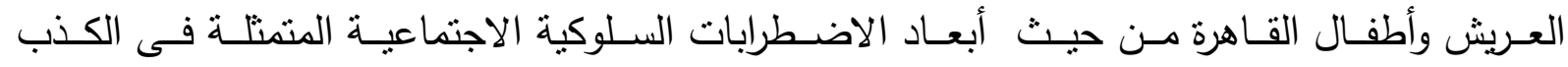

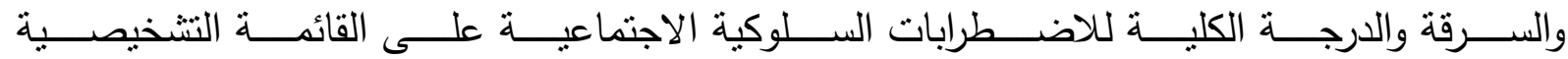


للاضـطرابات السـلوكية باسـتخدام تحليـل التبـاين البسـيط احـادى الاتجـاه حيـث كانـت قيمـة ف دالــة عند مستوى ا.,...

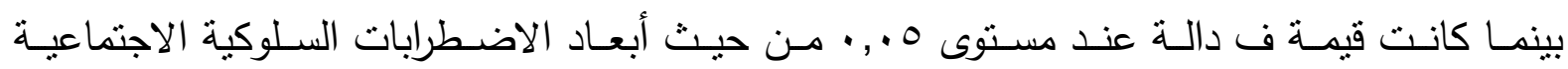

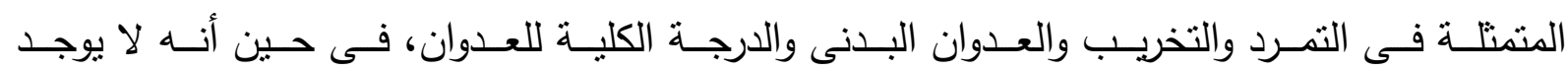

فروق دالة إحصائيا من حيث العناد والعدوان التعبيري حيث كانت قيمة ف غير دالة احصائياً. ويوضـح جـدول (1 (1) المتوسـطات والإنحرافـات المعياريـة لكـل مـن أطفـال رفـح المهجـرين و أطفـال العـريش وأطفــال القـاهرة مــن حيــث الاضـــرابات الســلوكية الاجتماعيــة بأبعادهــا علـى القائمــة النشخيصية للاضطرابات السلوكية.

جلول(1) (1) (1)

المتوسطات والإنحرافات المعيارية لكل من أطفال رفح المهجرين وأطفال العريش وأطفال القاهرة من حيث الاضطرابات السلوكية الاجتماعية بأبعادها على القائمة التشخيصية للاضطرابات السلوكية (ن = ه ه ـ 1)

\begin{tabular}{|c|c|c|c|c|c|c|}
\hline \multicolumn{2}{|c|}{ الأطفال القاهرة (ن=ه r) } & \multicolumn{2}{|c|}{ الأطفال العريش } & \multicolumn{2}{|c|}{ 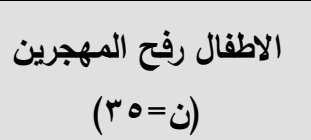 } & \multirow[t]{2}{*}{ المتغيرات } \\
\hline$\varepsilon$ & 54 & $\varepsilon$ & 55 & $\varepsilon$ & is & \\
\hline 7,71 & $r q, \diamond \varepsilon$ & $\vee, \mu \wedge$ & $\varepsilon r,\{\Lambda$ & ه & $2 \varepsilon 0,1 V$ & الكذب \\
\hline $7, \cdot 1$ & $\varepsilon 1, \leqslant \wedge$ & q & $\varepsilon 1, Y 0$ & $7, \vee v$ & $\leqslant 1,0 \leqslant$ & العناد \\
\hline 7,09 & $\{1, \varepsilon$. & $v, \cdot v$ & $\leq 0,1 \leq$ & $\curlyvee, \wedge \neg$ & $\varepsilon \wedge, 1 \leqslant$ & السرقة \\
\hline 0,00 & $\Gamma \wedge, 0 \varepsilon$ & $7,7 r$ & $\varepsilon \cdot, \cdot \Lambda$ & $V, r q$ & $\varepsilon r, Y 0$ & التمرد و التخريب \\
\hline $0,9 r$ & $\& 1, \wedge \wedge$ & $\varepsilon, \cdot V$ & $\varepsilon 0, Y r$ & 0,97 & $\leqslant 0, \varepsilon Y$ & العدوان البدني \\
\hline 0,99 & $\varepsilon 1, Y r$ & 0,09 & ו & $0,9 r$ & $\varepsilon r, 0\}$ & العدوان التعبيري \\
\hline $1 \cdot, 90$ & $\Lambda \mu, \mid$ & $\Lambda, \infty \Delta$ & $\wedge \wedge, 0 \leq$ & $1 \cdot, r o$ & $\wedge \wedge, 9 \vee$ & الارجة الكلية للعدوان \\
\hline Pr,qq & $r \leq \varepsilon, \cdot \Lambda$ & IV,r & rov,01 & ו & rqV, 1 & الدرجة الكلية للاضطر الابات الاجتماعية \\
\hline
\end{tabular}

ويتضــح مـن جـدول (1) (1) وجـود فـروق فـى المتوســطات بــن أطفــال رفـح المهجـرين وأطفــال العـريش وأطفــال القـاهرة، ولتحديــد إتجـاه الفـروق اجـرت الباحثـة اختبــار تــوكى للمقارنـات البعديـة بـين المجموعـات الـثناث فـى أبعـاد الاضــرابات السـلوكية الاجتماعيـة على القائمـة التشخيصـية للاضطرابات السلوكية ، كما يتضح فى جدول (9 ( ). 


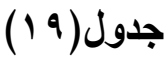

نتائج اختبار توكي للمقارنات البعدية بين المجموعات الثثلاث (أطفال رفح المهجرين وأطفال العريش وأطفال

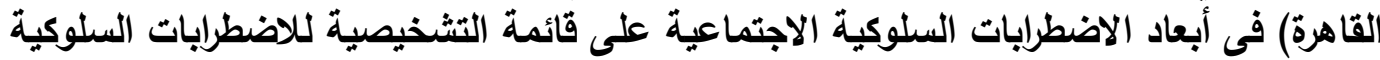

\begin{tabular}{|c|c|c|c|}
\hline 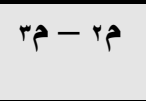 & $e^{b-16}$ & 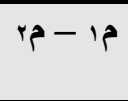 & 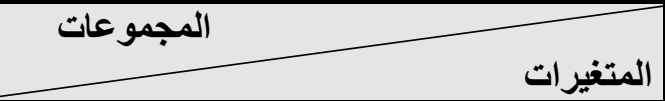 \\
\hline$r, q \leqslant$ & $* 0,7 r$ & $r, \uparrow \Lambda$ & الكنب \\
\hline$r, v \leqslant$ & $* 4, V \leqslant$ & $r, \cdots$ & السرقة \\
\hline $1,0 \leqslant$ & $* \varepsilon, \vee 1$ & $r, i v$ & التمرد و التخريب \\
\hline$* \mu, \mu \varepsilon$ & $* \mu, 0 \leqslant$ & $\cdot, r \ldots$ & العدوان البلني \\
\hline $0, \xi Y$ & 0,10 & 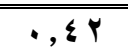 & الارجة الكلية للعدوان \\
\hline$* 1 r, \varepsilon r$ & *rr,.. & $9,0 \mathrm{~V}$ & الدرجة الكلية للاضطرابات السلوكية الاجتماعية \\
\hline
\end{tabular}

$$
\text { يتضح من الجدول (9 1 ) الأتى: }
$$

توجد فروق دالة إحصــائيا بين متوســ درجات أطفال رفح المهرين و متوسـط درجات أطفال

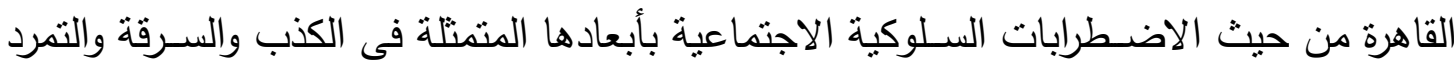
والتخريب والعدوان البدني والدرجة الكلية للاضطرابات السلوكية الاجتماعية، فى إتجاة أطفال رفح

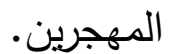
هاتوجد فروق دالة إحصـائيا بين متوسـط درجات أطفال رفح المهرين ومتوســـ درجات أطفال القاهرة من حيث الدرجة الكلية لاضطراب العدوان. توجد فروق دالة إحصـائيا بين متوسط درجات أطفال العريش ومتوسط درجات أطفال القاهرة من حيث العدوان البدنى، والدرجة الكلية لاضطرابات السلوكية الاجتماعية، فى إتجاة أطفال العريش. لاتوجد فروق ذات دلالة إحصـائية بين منوسـط درجات أطفال العريش ومتوسـط درجات أطفال القاهرة من حيث الكذب والسرقة والتمرد والتخريب والدرجة الكلية لاضطراب العدوان. لاتوجد فروق دالة إحصـائيا بين متوسطات درجات أطفال رفح المجرين ومتوسط درجات أطفال العريش فى الاضطرابات السلوكية الاجتماعية بكل ماتتضمنه من اضطرابات فرعية.

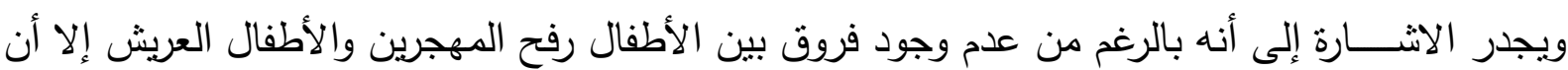
المتوسطات كانت لصالح الأطفال رفح المهجرين. ويوضـح الثــل(ع) الفروق بين متوســ درجات كل من أطفال رفح المهجرين و أطفال العريش وأطفال القاهرة من حيث الاضطرابات السلوكية الاجتماعية على القائمة التتخيصية للاضطرابات السلوكية. 


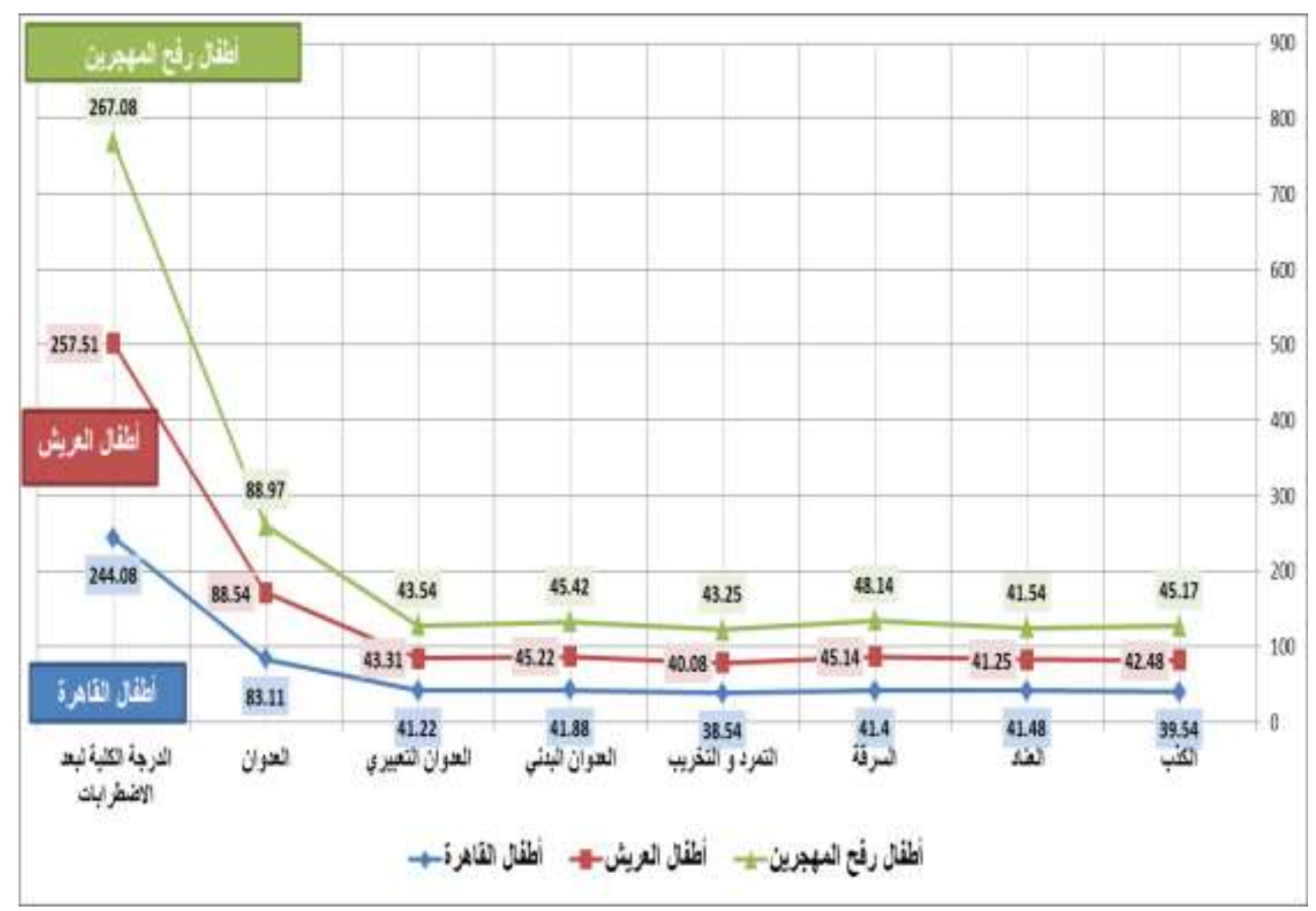

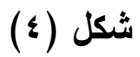

الفروق بين متوسط درجات كل من أطفال رفح المهجرين و أطفال العريش وأطفال القاهرة من حيث

الاضطرابات السلوكية الاجتماعية على القائمة التشخيصية للاضطرابات السلوكيةالاجتماعية.

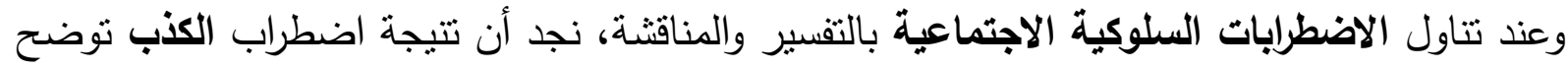

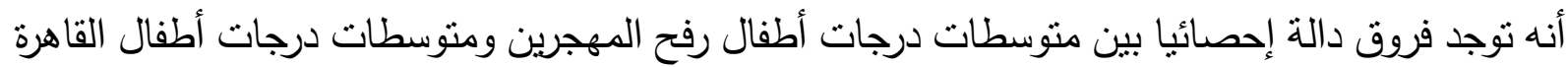
عند مستوى ا.,. فى إتجاة أطفال رفح المهرين، فى حين أنه لا توجد فروق ذات ذات دردات دلالة بين معدلات

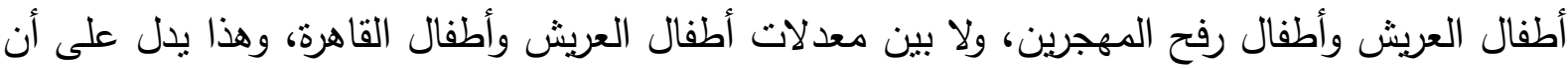
متوسطات درجات أطفال العريش فى موقف الوسط بين منوسطات درجات أطفال رفح المهجرين وأطفال

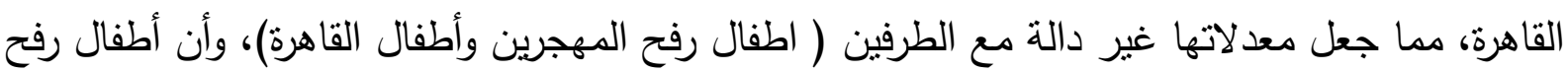
المهجرين أكثر من يعانى من الكنب، وهو كسلوك اجتماعى غير مرغوب، والثخصية الكاذبة غالبا ماتكون

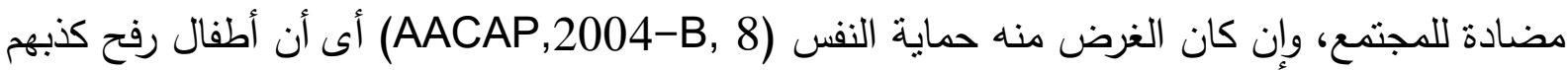

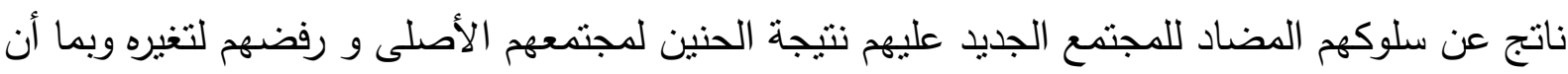

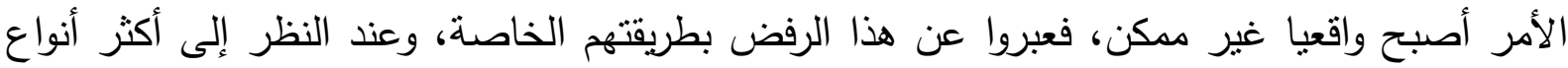

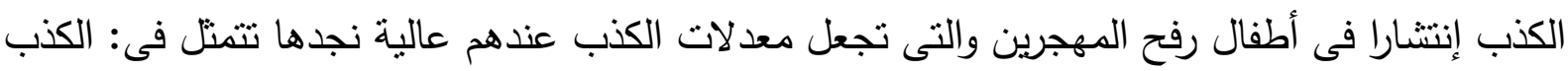
الالتباسى: ويرجع إلى عدم فهم مايدور حولهم بشكل صحيح وإدرالك الواقع من وجهة نظرهم الخاصة، وهذا

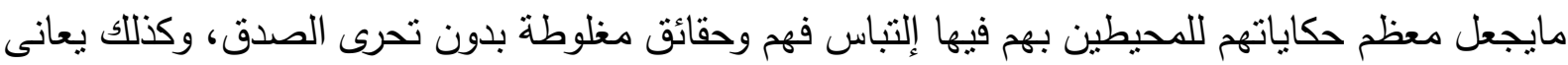

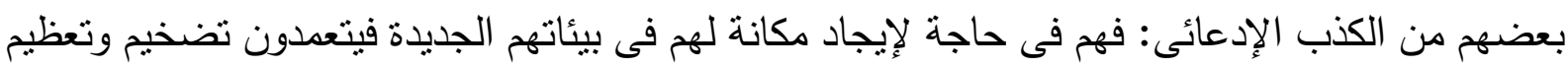

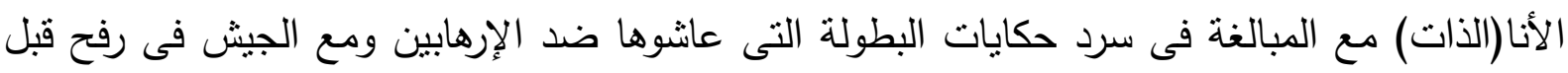


تهجيرهم، بهذف التأثير فى الآخرين؛ لمحاولة إثبات الذات وجذب الانتباه، وإظهارهم بمظهر القوة لينالوا

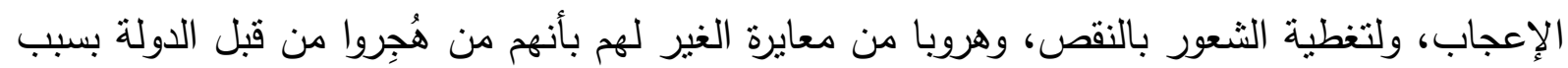

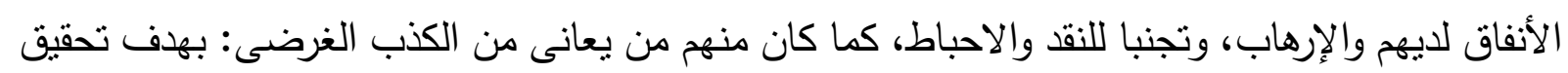

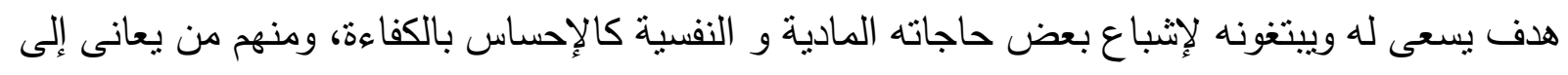

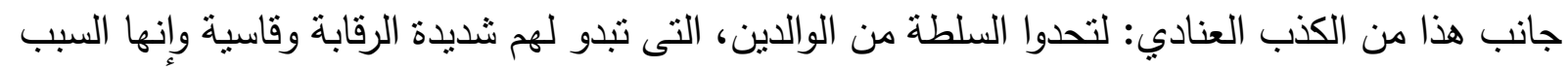

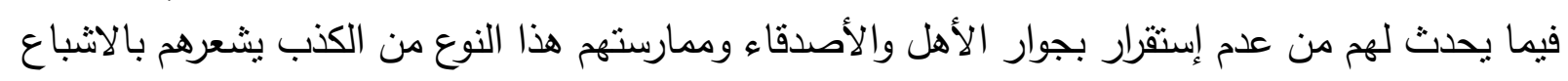

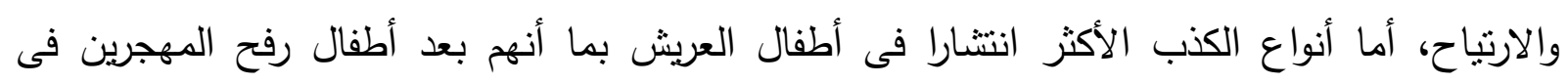

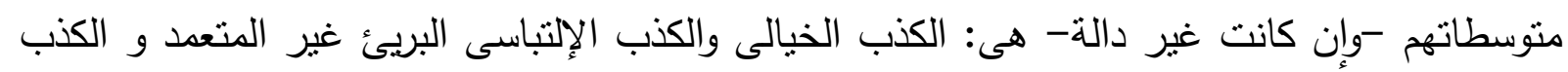

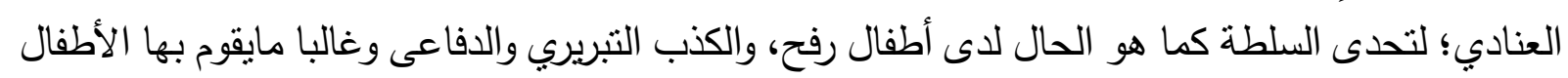

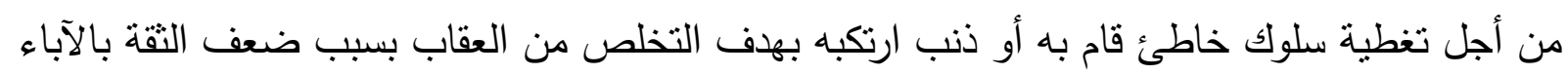

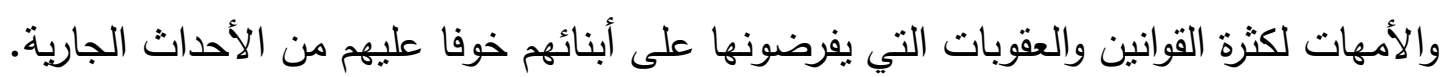

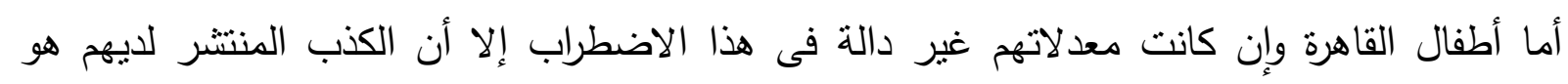

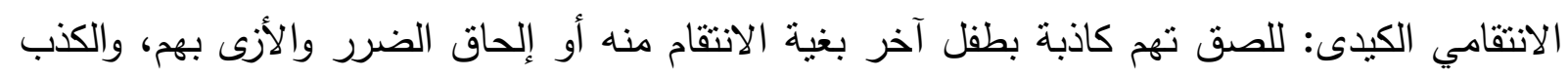

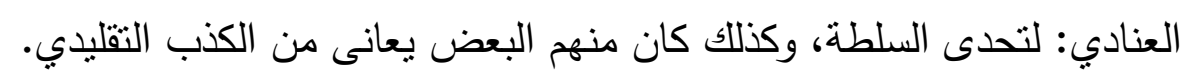

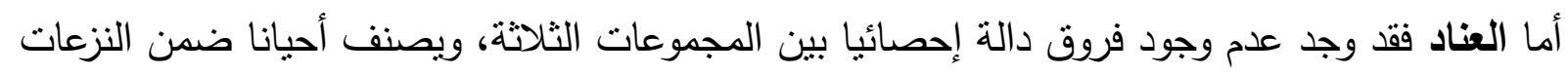

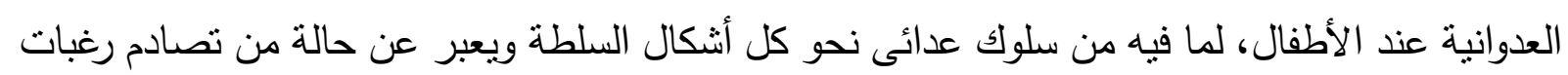

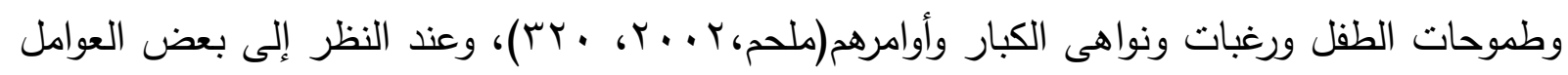

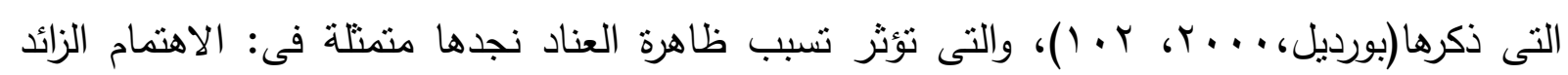

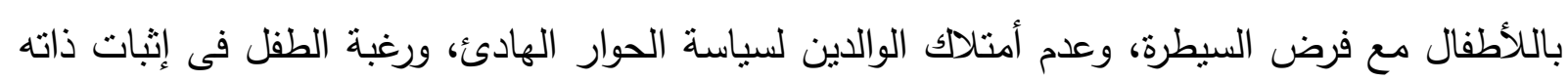

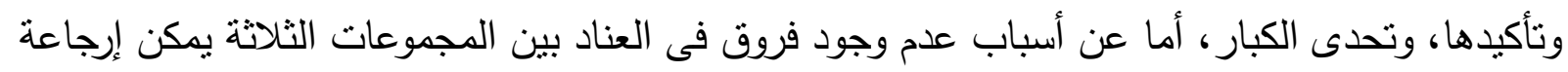

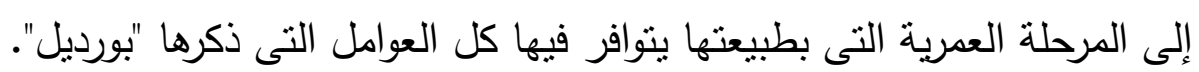

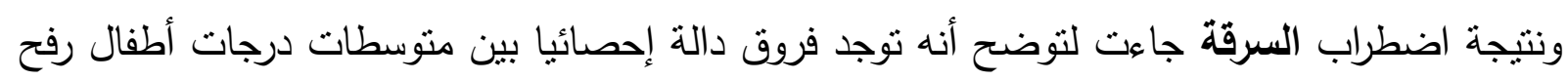

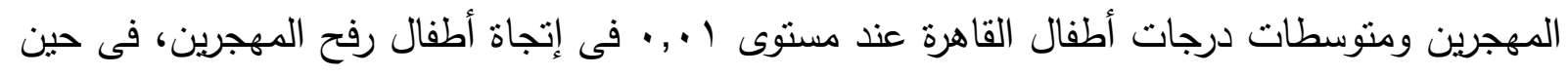

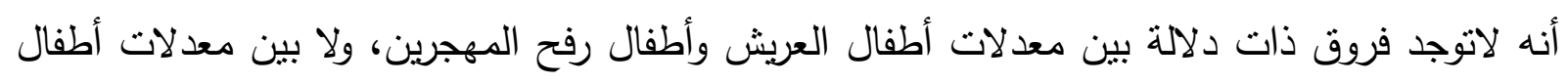

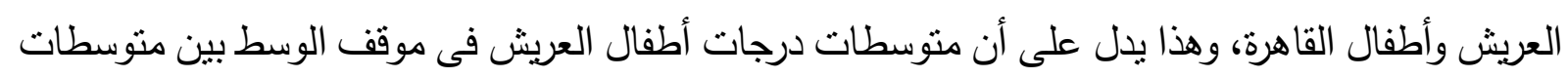

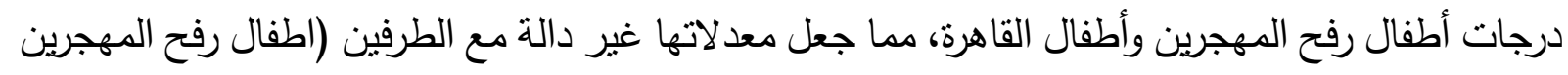

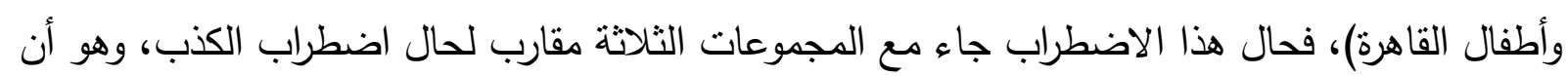

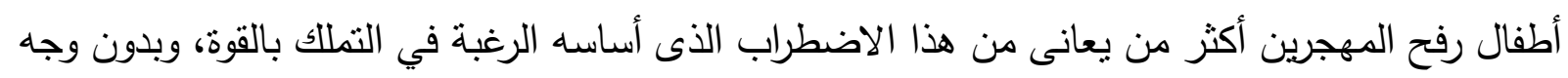

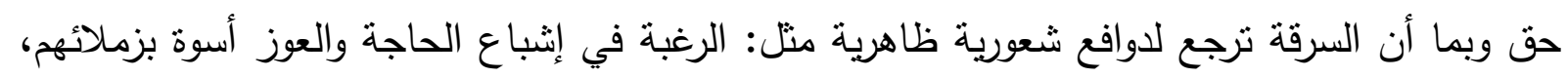

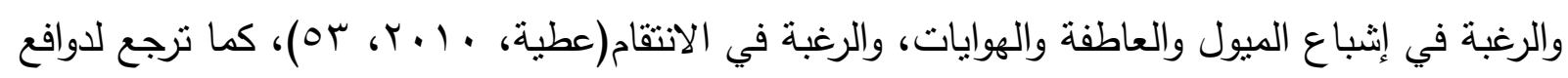
لاشعورية: وهى ناجمة عن علاقة السارق بالبيئة التي يعيش فيها، والعلاقات الاجنية التياعية السائدة فيها، 


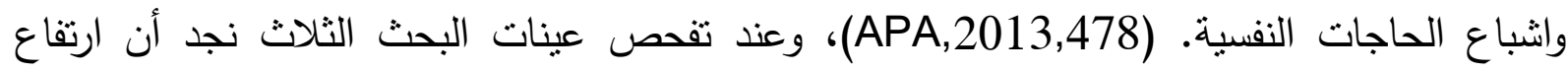

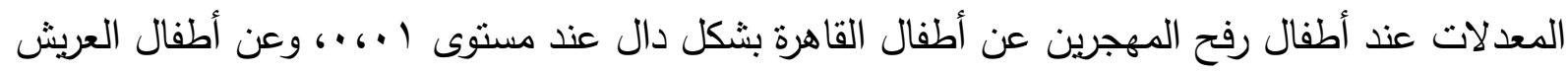

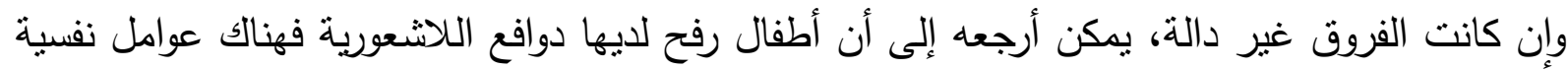

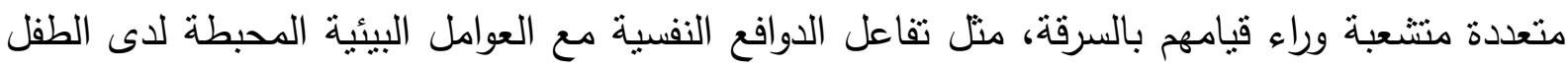

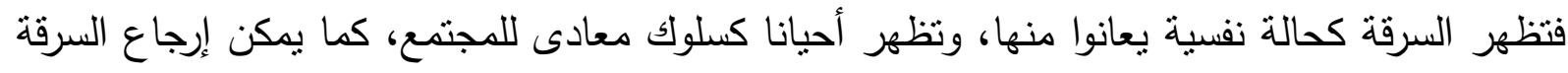

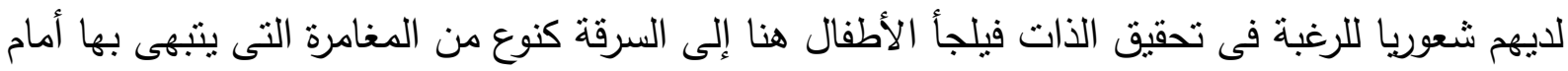
باقى الأطفال، ومن الممكن تكون السرقة لايهم نتيجة الحرمان. أما السرقة لدى أطفال العريش فترى الباحثة أنها غالبا سرقة كيدية: بعض الكضة الأطفال يلجأون إليها عقاباً للكبار

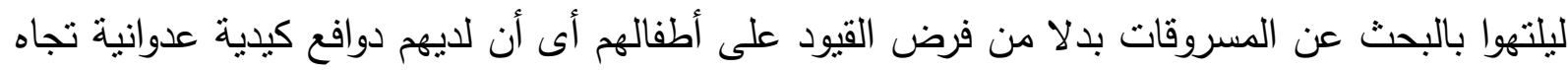

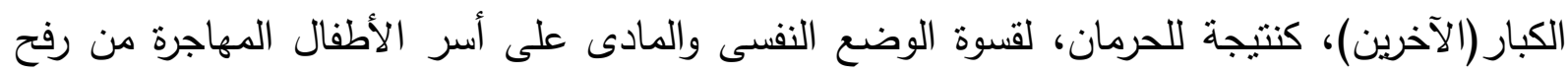

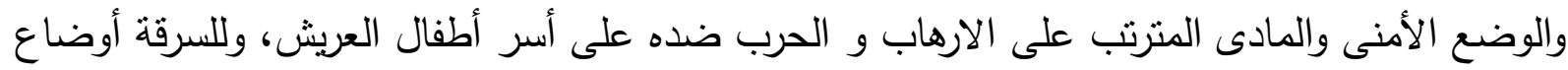

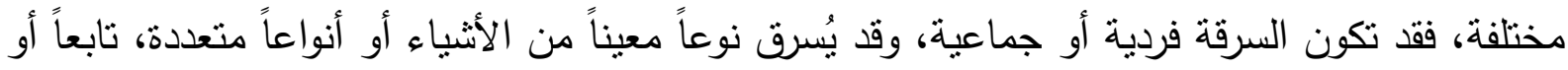

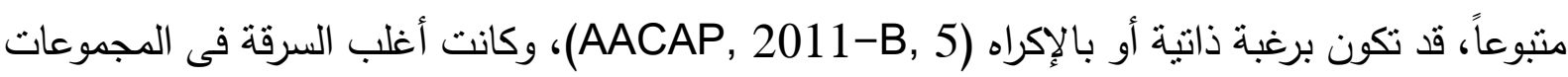
الثلاث من النوع الفزدى لأنواع متعددة، ولرغبة ذانية ذاتية.

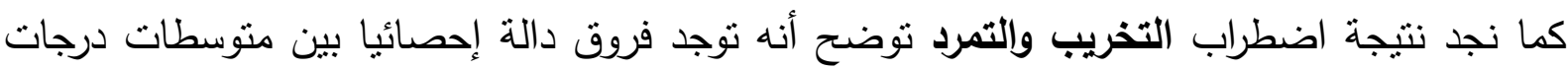

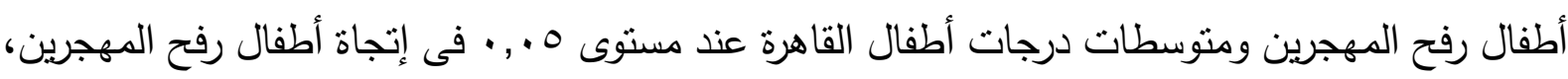

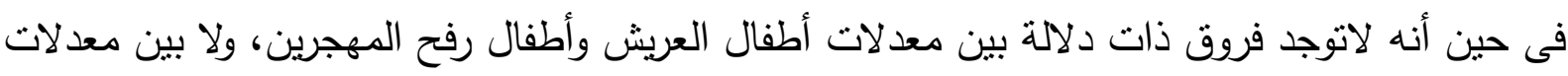

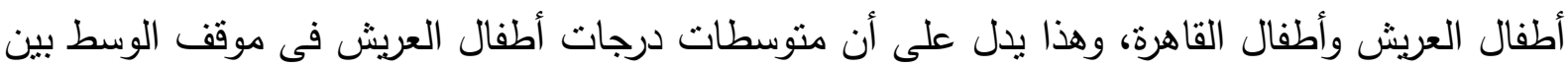

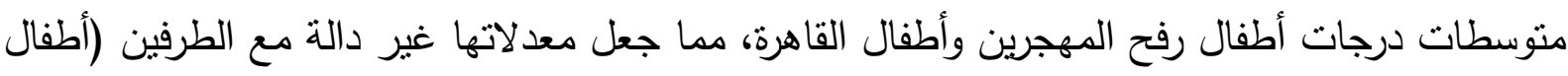
رفح المهجرين وأطفال القاهرة)، وترجع الباحثة المعدلات المرتفعة لاى أطفال رفح المهجرين عن أطفات ألفال

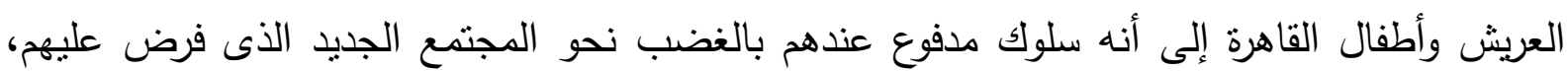

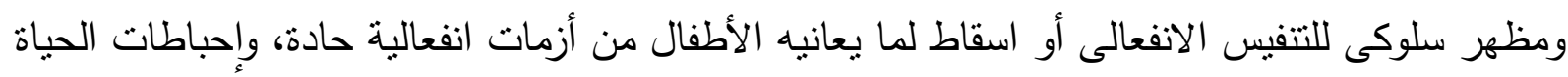

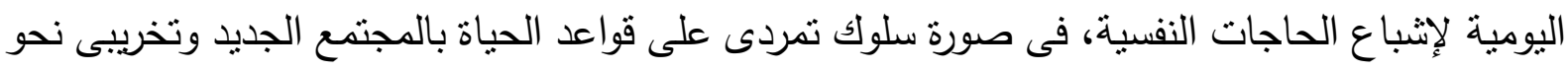

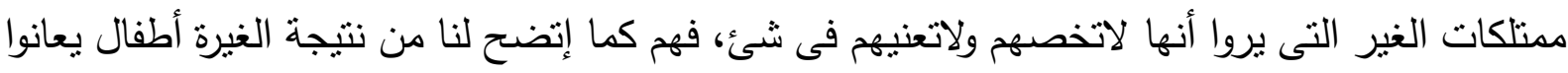

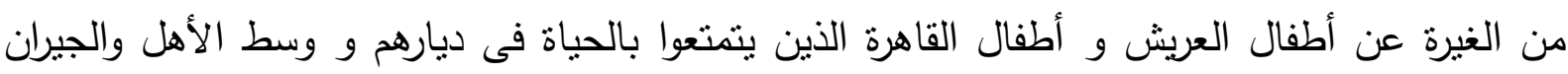

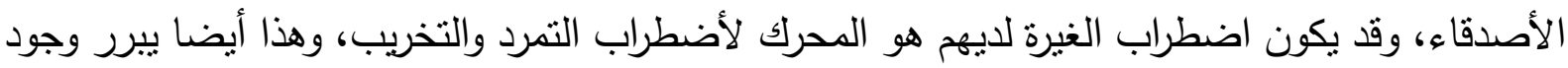

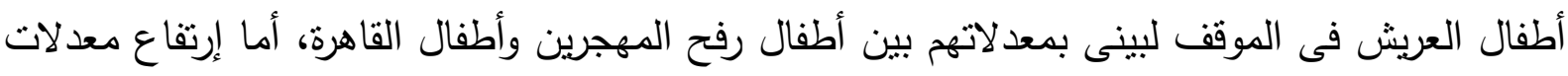

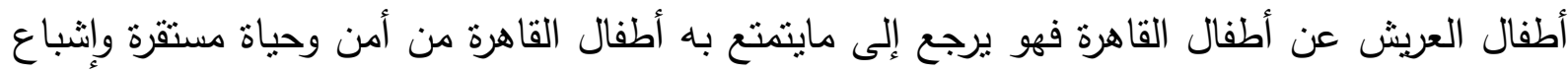

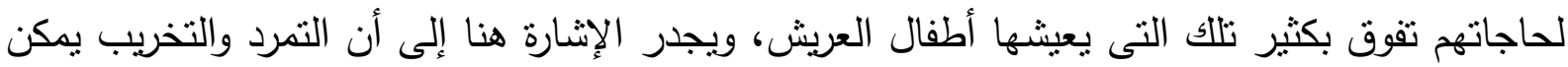

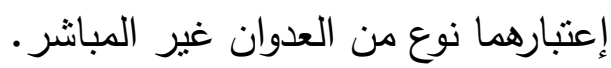


وعن تتاول نتيجة العدوان نجد أنه لايوجد فروق دالة إحصائيا فى معدلات العدوان التعبيرى بين أطفال

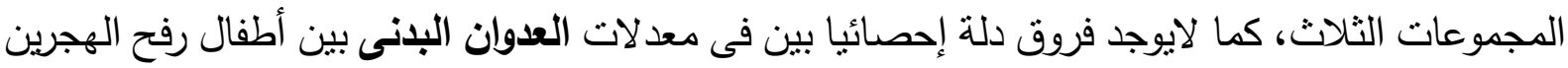

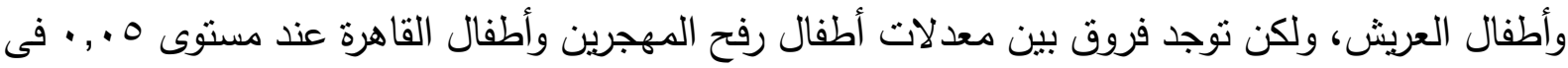

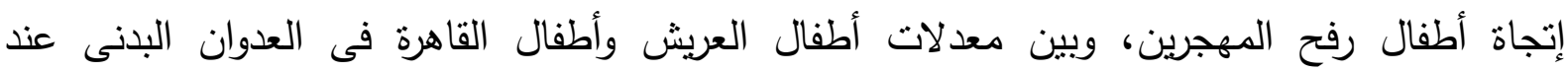

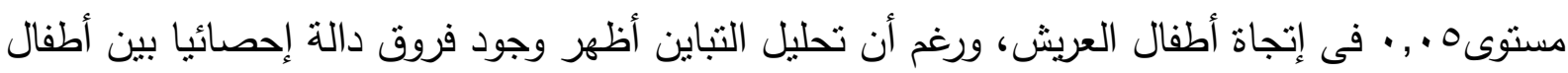

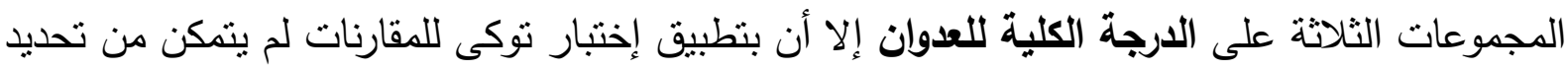

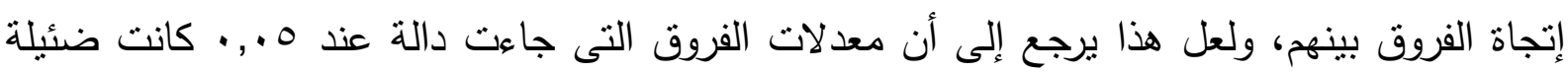
للارجة التى لم يتمكن إختبار توكى من تحديد إتجاهها.

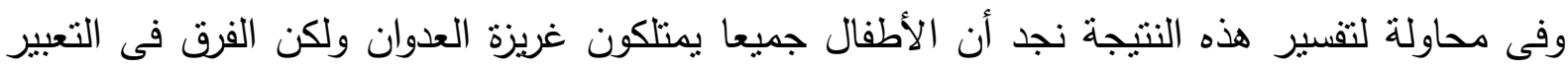

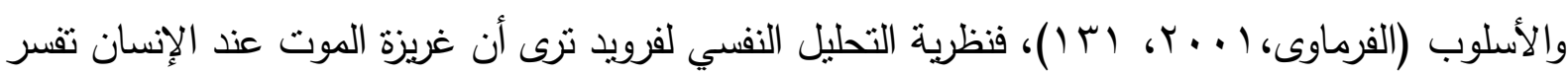

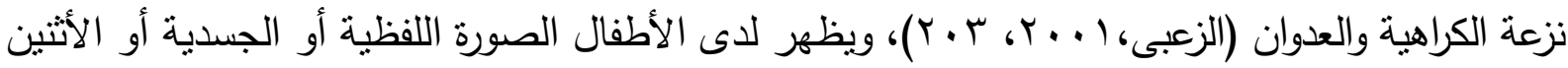

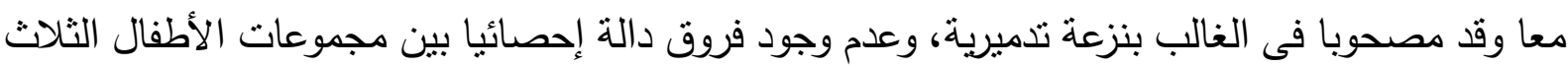

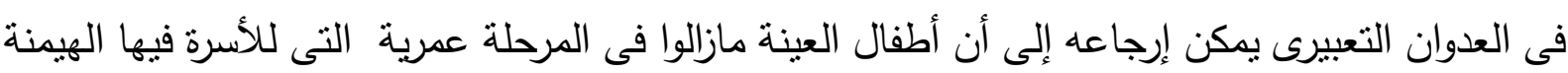

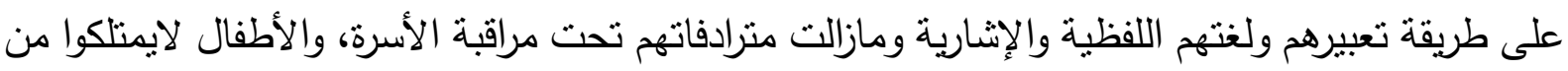

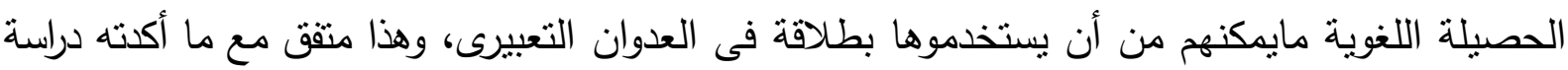

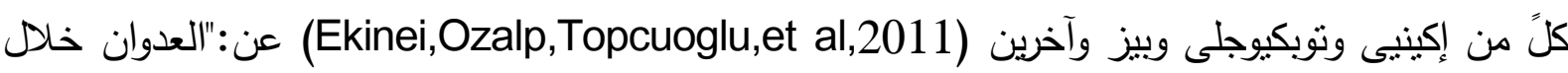

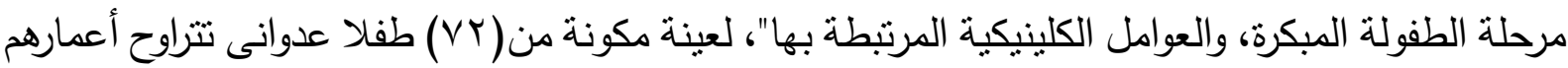

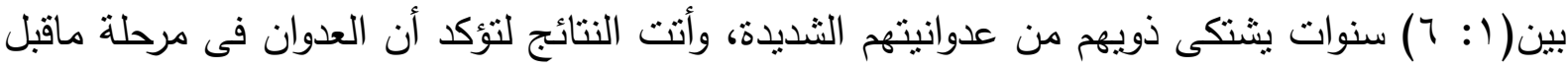
المدرسة يرتبط إيجابيا بخصائص الوالدين.

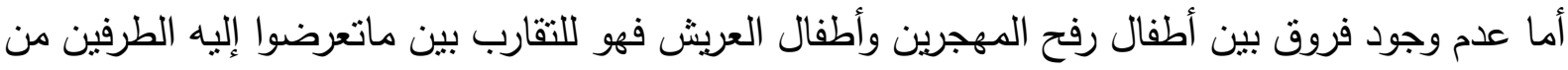

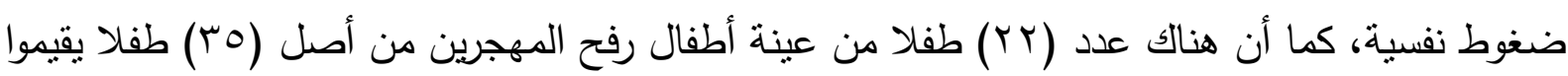

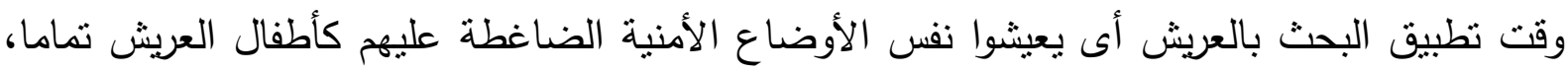

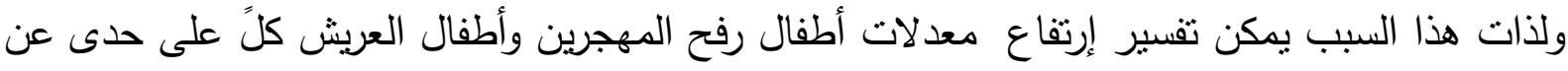

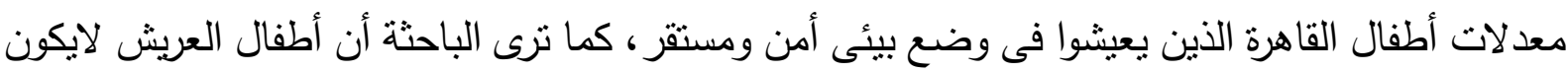

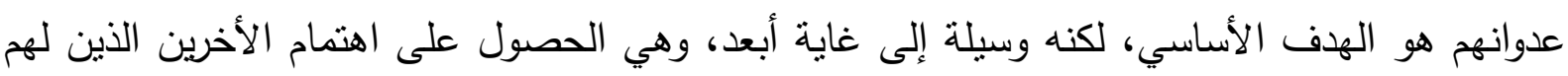

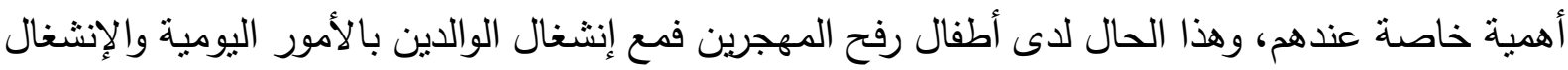

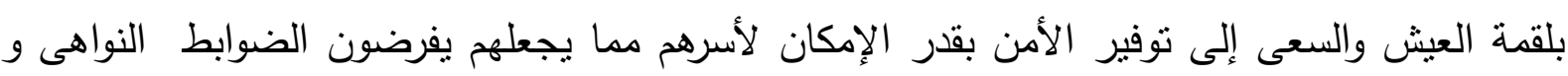

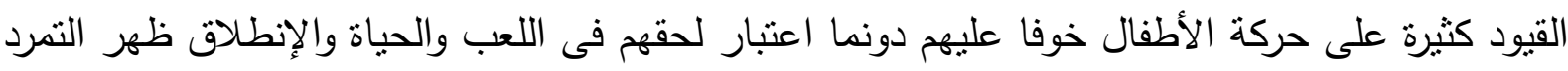

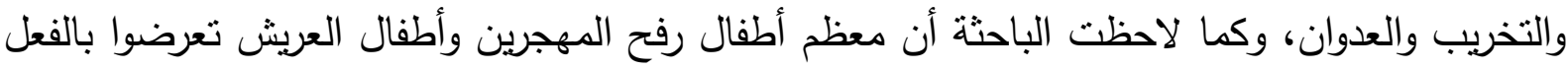

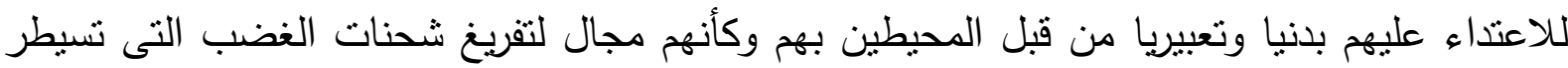

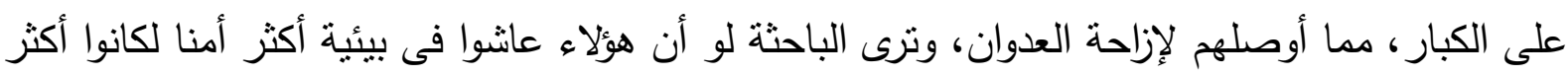


هدوءًا وسعادة، ، ويمكن تفسيره من منطلق نظرية التعلم الاجتماعى لسكوت و باندورا التى نرى أنه سلوك متعطم

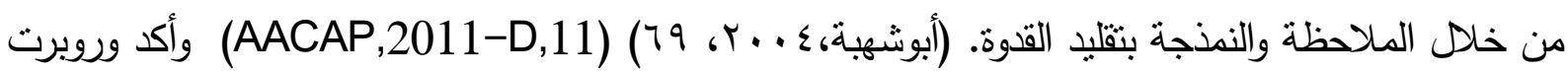

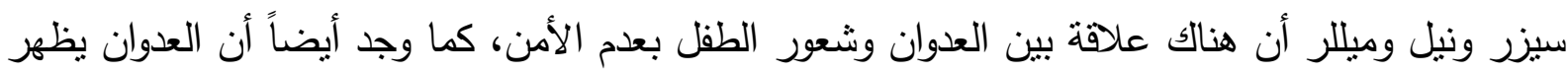

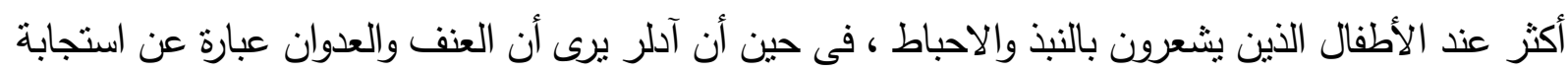

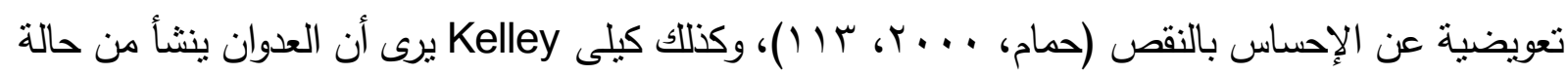

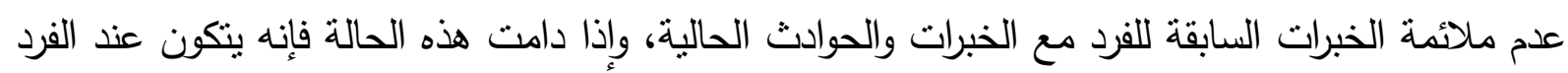

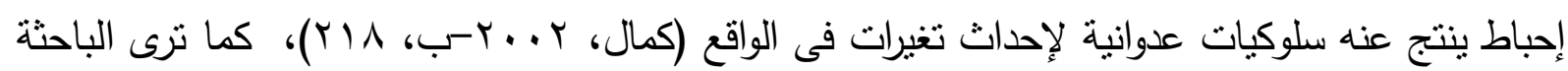

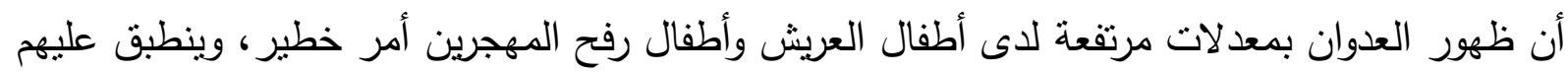

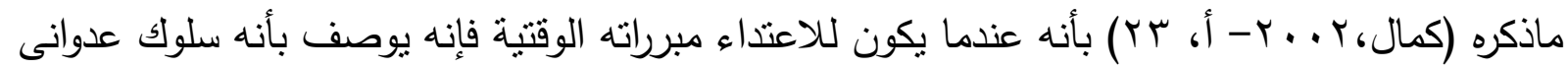

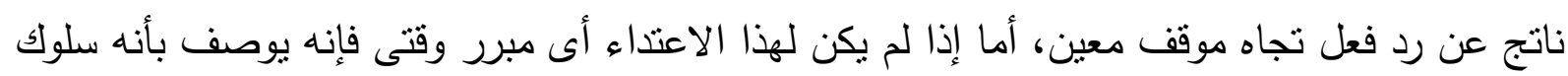

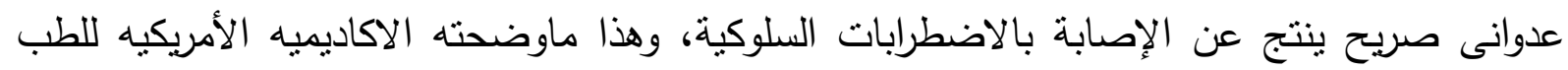

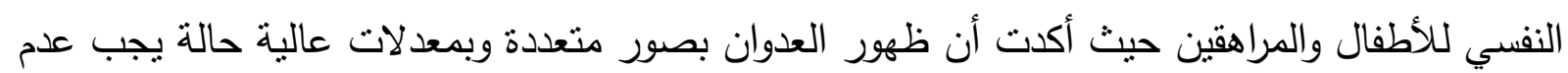

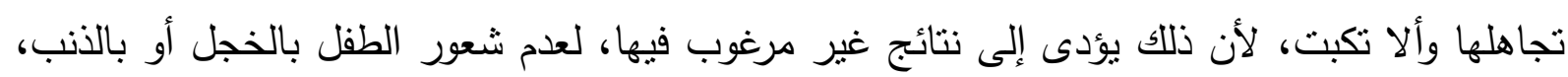

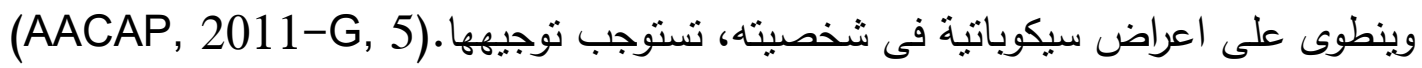

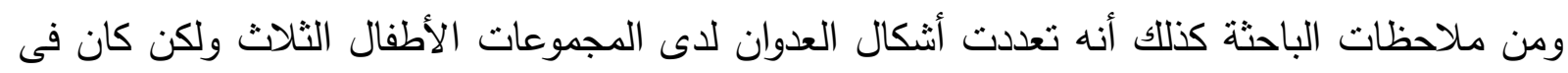

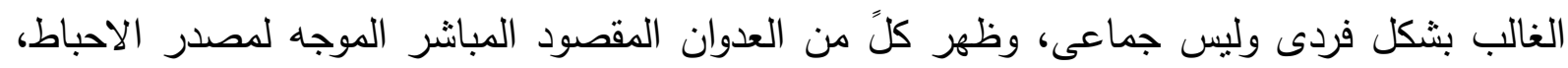

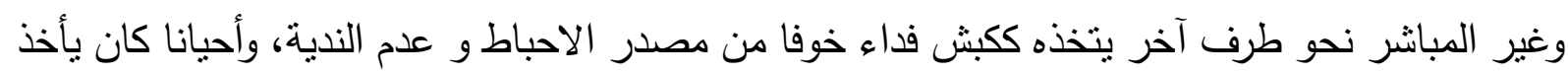

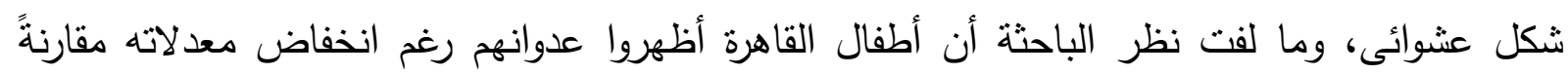

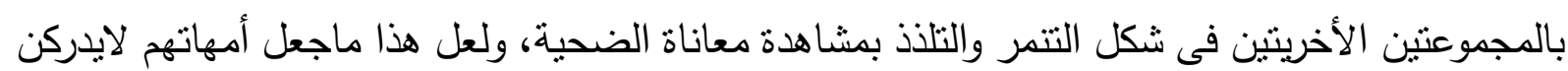
عدوانية أطفالهن بشكل دال عن أطفال رفح المهرين فئن وأطفال العريش.

\section{خامساً: الارجة الكلية للقائمة التشخيصية:}

قامت الباحثة بايجاد الفروق بين درجات أطفال رفح المهجرين وأطفال العريش وأطفال القاهرة من حيث الدرجة الكلية للقائمة التشخيصية للاضطرابات السلوكية باستخدام تحليل التباين البسيط احادى الاتجاه كما يتضح فى جدول( •r). 


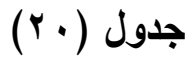

نتائج تحليل التباين البسيط احادى الاتجاة بين المجموعات الثلاث على الارجة الكلية للقائمة التشخيصية للاضطرابات السلوكية. ن = ه ـ 1

\begin{tabular}{|c|c|c|c|c|c|c|}
\hline مستوى & قيمة ف" & متوسط & درجات & مجموع المربعات & مصدر التباين & المتغيرات \\
\hline \multirow[t]{3}{*}{$\cdot,+1$} & $1 r q, 1 \leq r$ & $19 \mathrm{rVI}, .7 \mathrm{r \mu}$ & $r$ & $r \wedge 0 \leq r 1, r \vee T$ & بين المجموعات & \multirow{3}{*}{ اللثجموع الكلى } \\
\hline & & $1 \leq 9 r, r Y \leqslant$ & $1 . r$ & IOrY. T,NOV & داخل المجموعات & \\
\hline & & & $1 \cdot \varepsilon$ & OrVTrA,Irr & المجموع & \\
\hline
\end{tabular}

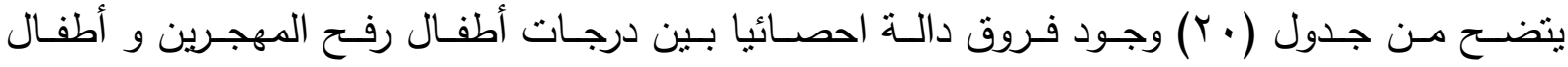

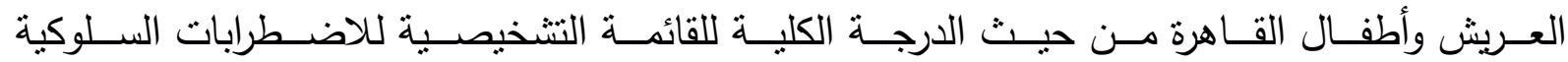

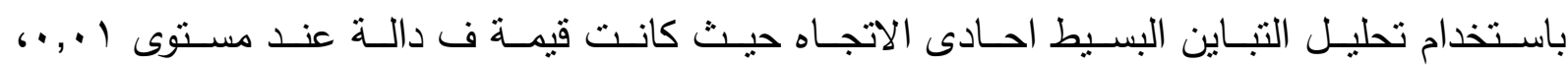
بينما كانت قيمة ف دالة عند مستوى ل •,... ويوضـح جـدول( (r) المتوسـطات والإنحرافـات المعياريــة لكـل مـن أطفــال رفـح المهجـرين وأطفـال العريش وأطفال القاهرة من حيث الدرجة الكلية للقائمة التثخيصية للاضطرابات السلوكية.

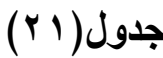

المتوسطات والإنحرافات المعيارية لكل من أطفال رفح المهجرين وأطفال العريش وأطفال القاهرة من حيث الدرجة الكلية للقائمة التثخيصية للاضطرابات السلوكية (ن= ه ـ ـ )

\begin{tabular}{|c|c|c|c|c|c|c|}
\hline \multicolumn{2}{|c|}{ 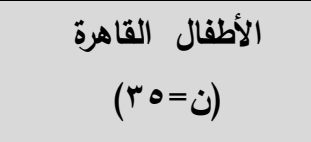 } & \multicolumn{2}{|c|}{ الأطفال العريش } & \multicolumn{2}{|c|}{ 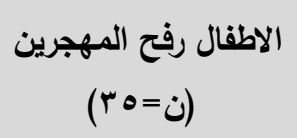 } & \multirow[t]{2}{*}{ المتنيرات } \\
\hline$\varepsilon$ & קל & $\varepsilon$ & מל & $\varepsilon$ & מל & \\
\hline$r_{\wedge, \lambda \nu}$ & $V \Psi \leqslant, V A$ & $r_{\Lambda,, r q}$ & $\lambda 01, i r$ & $r \Lambda, r r$ & AVY,YA & الإرجة الكلية للقائمة \\
\hline
\end{tabular}

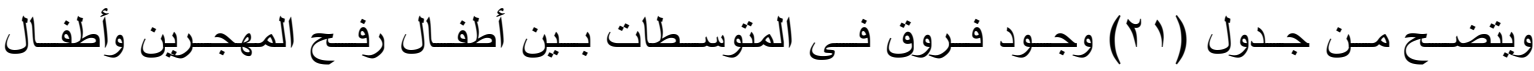

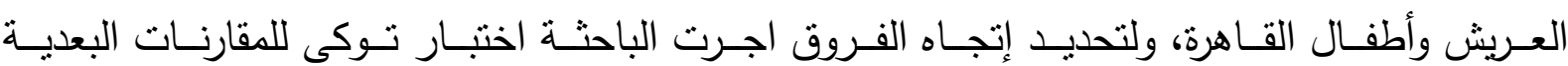

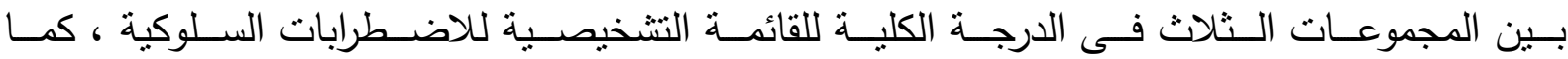

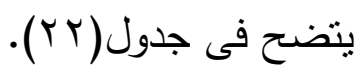




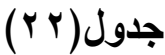

نتائج اختبار توكي للمقارنات البعدية بين المجموعات الثلاث (أطفال رفح المهجرين وأطفال العريش وأطفال

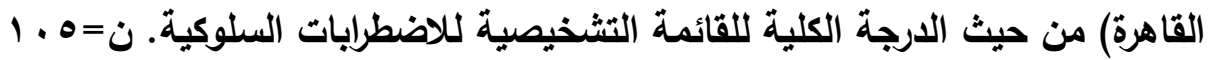

\begin{tabular}{|c|c|c|c|}
\hline p p pro & p p - pr & $p-1 p$ & لمجموعات \\
\hline$* 114,9 \leq$ & * & $r \cdot, r_{0}$ & اللارجة الكلية للقائمة التثخيصية \\
\hline
\end{tabular}

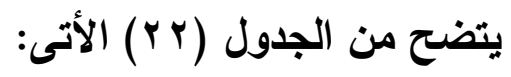

لايوجد فروق دالة إحصائيا بين منوسط درجات أطفال رفح المهرين ومنوسط درجات أطفال العريش من

حيث الارجة الكلية للقائمة التشخيصية للاضطرابات السلوكية.

توجد فروق دالة إحصـائيا بين متوسط درجات أطفال رفح المهجرين ومتوسـط درجات أطفال القاهرة من

حيث الارجة الكلية للقائمة التتخيصية للاضطرابات السلوكية فى إتجاة أطفال رفح المهرين.

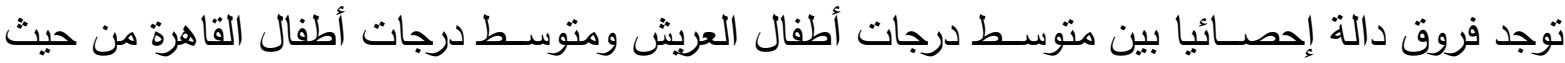

الارجة الكلية للقائمة التشخيصية للاضطرابات السلوكية ، فى إتجاة أطفال العريش. ويوضـح الثـكل رقم (0) الفروق بين منوسط درجات كل من أطفال رفح المهرين و أطفال العريش وأطفال القاهرة من حيث الدرجة الكلية على القائمة التتخيصية للاضطرابات السلوكية

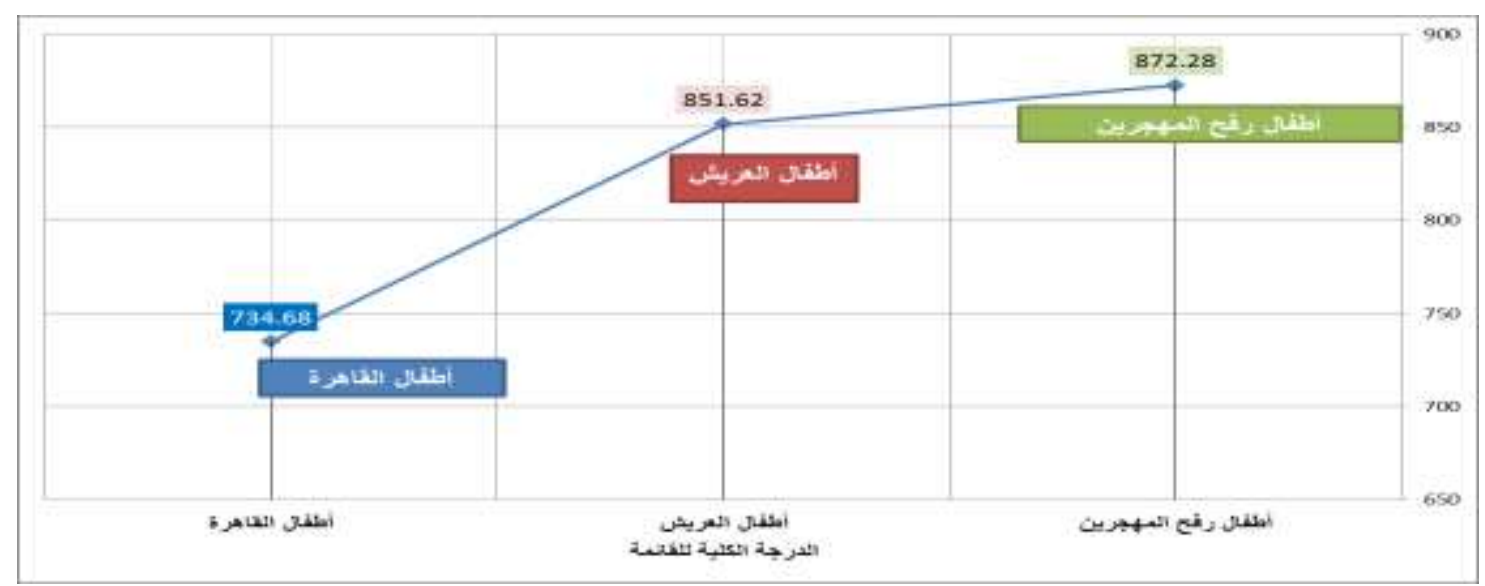

الثكل (•)

الفروق بين متوسط درجات كل من أطفال رفح المهجرين و أطفال العريش وأطفال القاهرة من حيث الارجة الكلية على القائمة التشخيصية للاضطرابات السلوكية

وعند تناول هذه النتيجة بالمناقتشة والتفسير نجد أنها تظهر لنا أنه لا توجد فروق دالة إحصائيا بين معدلات التعات أطفال رفح المهرين وأطفال العريش ولكن يوجد بين معدلات كلٌ على حدى وبين معدلات أطفال القاهرة فروق دالى إحصائيا عند مسنوى 1 .,. • فى إتجاههما. 
و يمكن إرجاع عدم وجود فروق ذات دلالة بين معدلات أطفال رفح وأطفال العريش إلى تعرضهما المباشر للإزهاب دونا عن أطفال القاهرة، ففى دراسة أجرى كوهين وجاداسى (Cohen\&Gadassi,2009) عن:

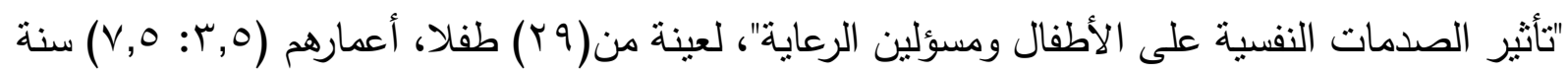

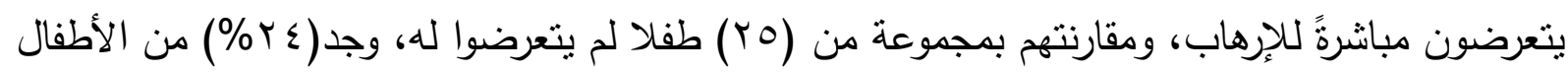
المعرضون للإرهاب معرضين للاضطرابات السلوكية. أما وجود فروق دالة عند مسنوى ال.، · بين معدلات مجموعة أطفال رفح المجرين لمعرين وأطفال العريش وبين

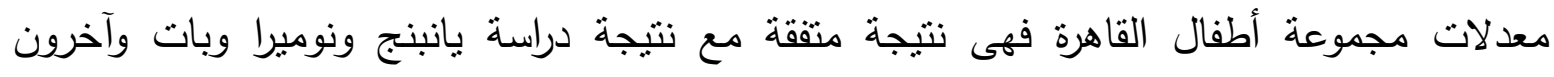
بعing,Nomura,Pat-Horenczyk,et al,2006)

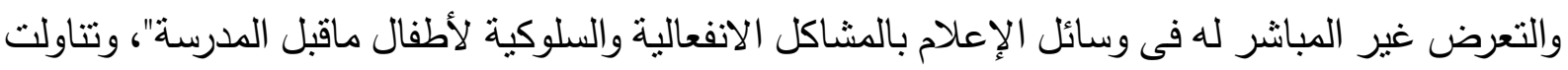

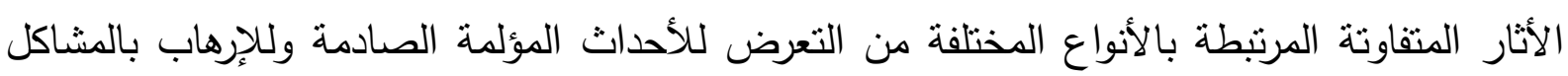

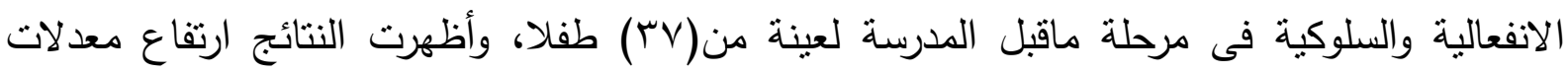
الاضطرابات السلوكية لدى الأطفال المعرضين مباشرةً للإرهاب.

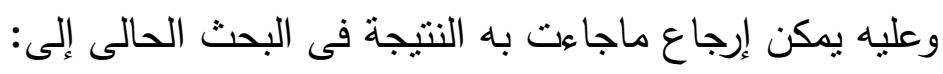
تعرض مجموعة أطفال رفح المهرين ومجموعة أطفال العريش إلى الإرهاب والعنف بآثاره النفسية المدمرة

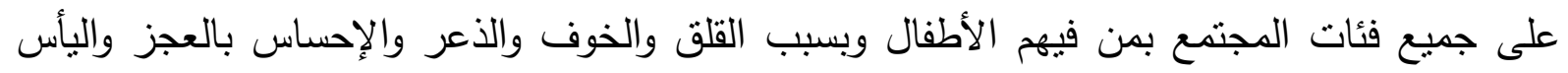

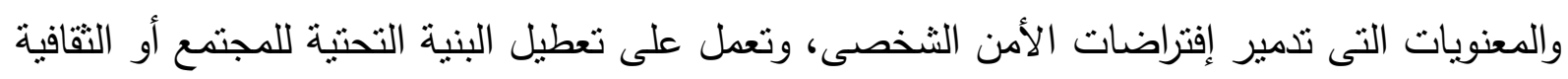

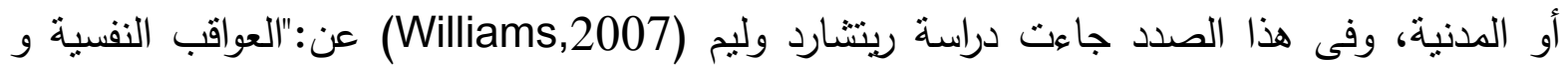

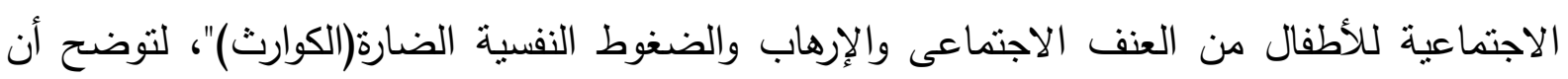

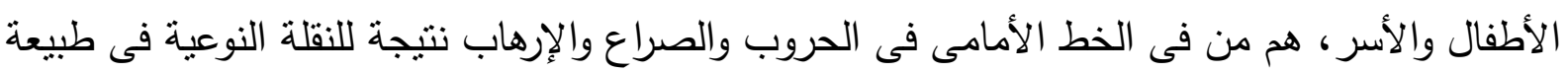

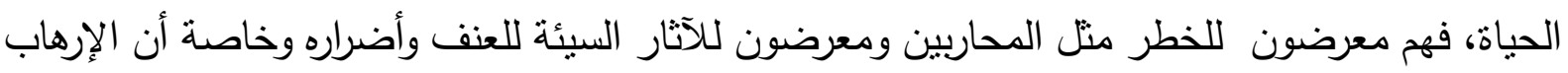
يمارس عنف جماعى، ولهذا آثار نفسية واجتماعية مباشرة وغير مباشرة على الأطفال بل وجسدية وهذانه

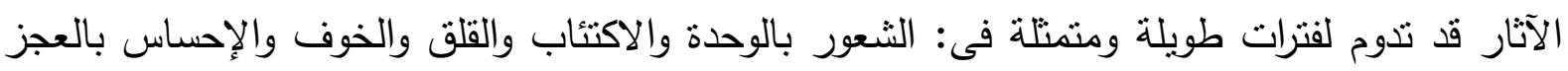

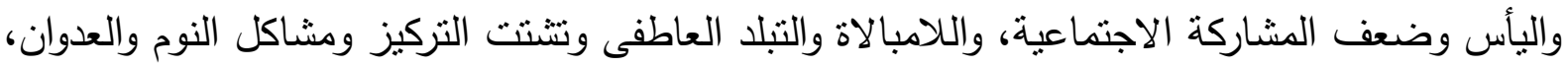
والأعراض النفسى جسمية. واحدة من أكبر التحديات التي تواجه الأسر هو أن الآباء والأطفال مطالبون بالتكيف مع حياه جديده،

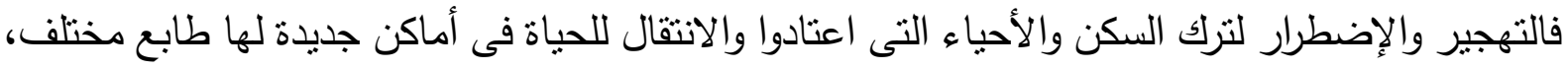

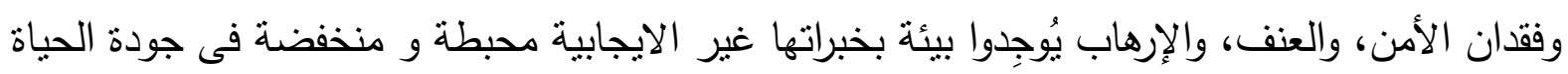
(AACAP, 2013-D,7)،(AACAP, 2011-C,8)

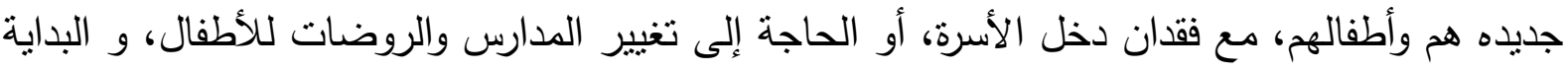

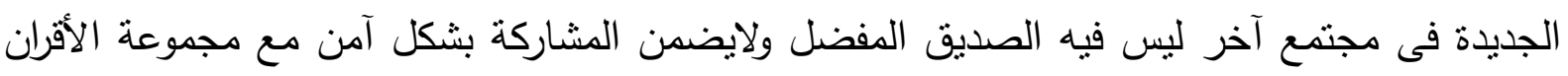

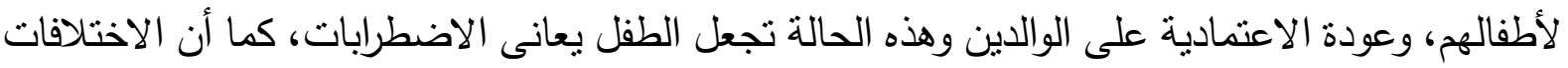


بين النقافة الجديدة والطريقة التي تتبع فى الحياة الاجتماعية بالمجتمع الجديد قد تجعل الوالدين يشعران

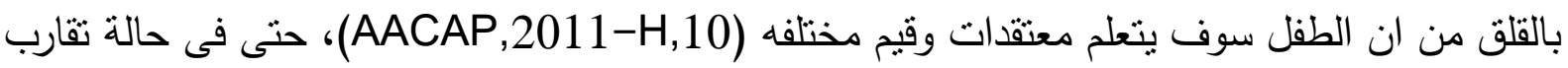
طبيعة البيئات من بعضها منت رفح والعريش. ترى الباحثة أن للإرهاب ومايترتب عليه نأثنرات عميقة وقوية وأكثر صعوبة على الأطفال؛ لأنهم فقدوا

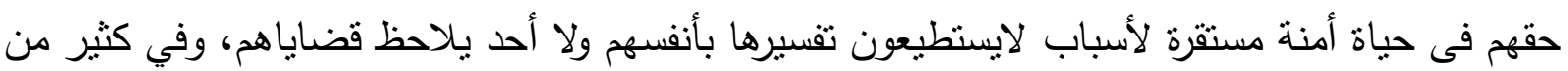

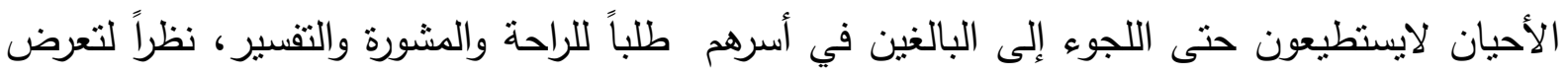

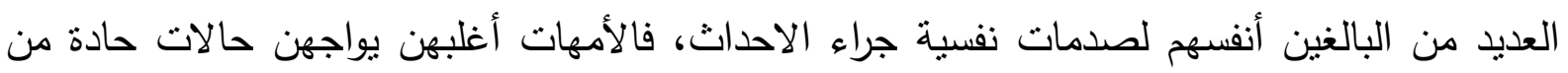

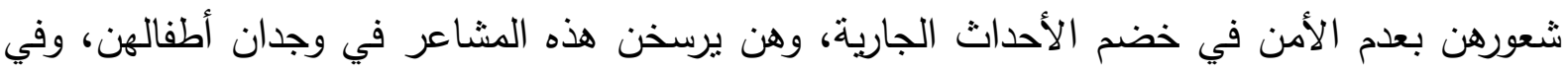

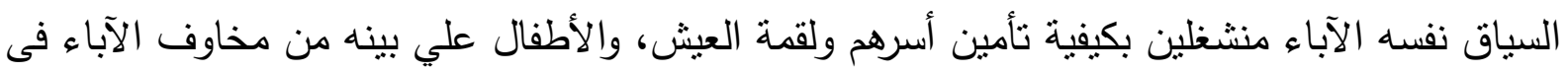

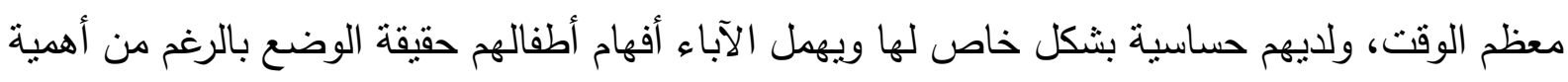

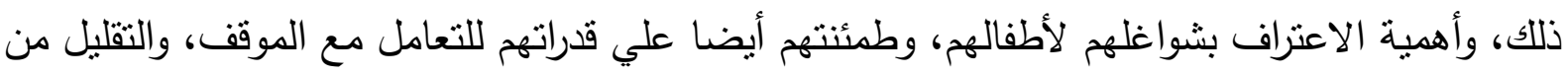

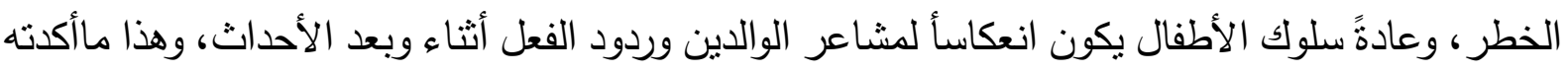

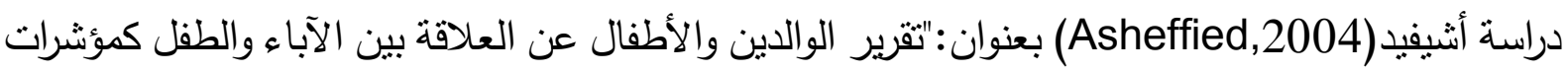

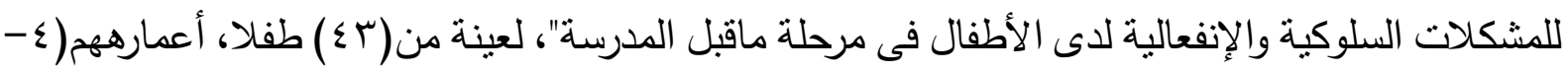

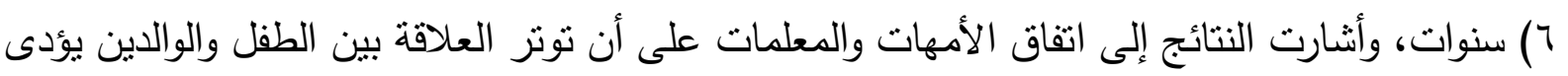

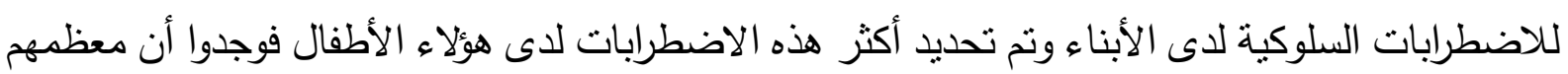

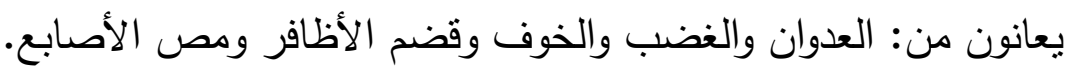

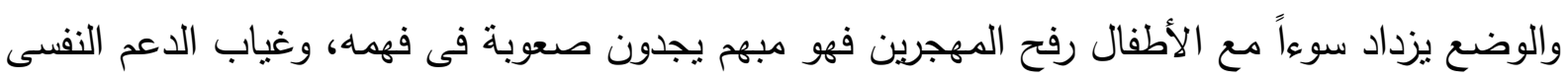

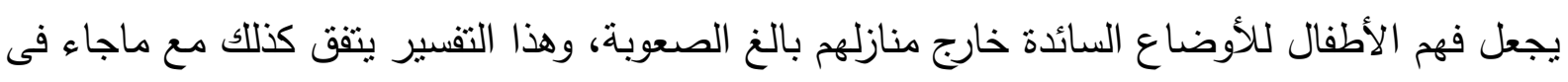

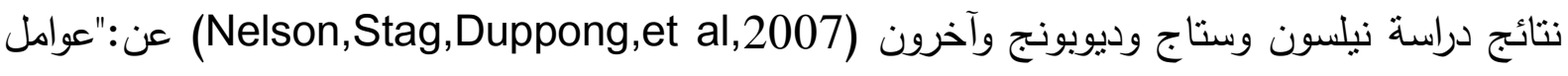

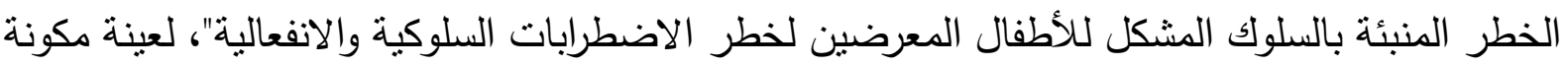

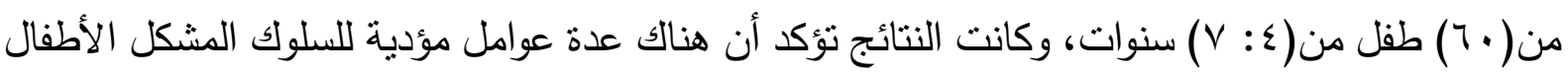

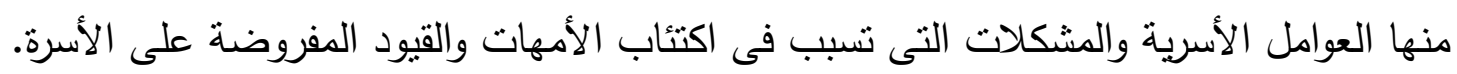

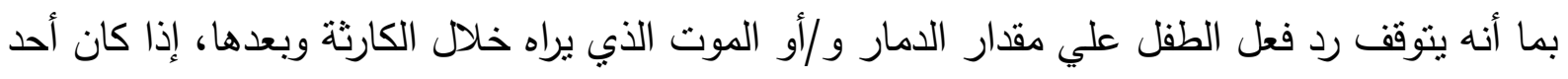

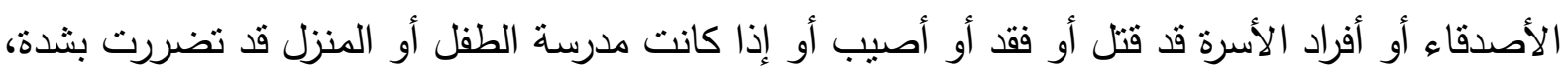

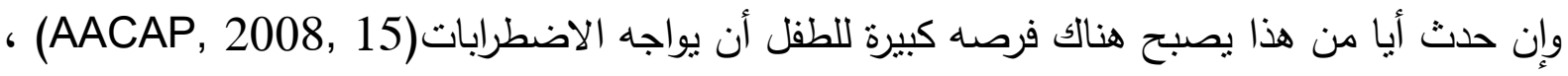

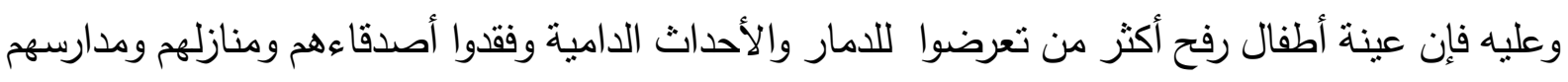

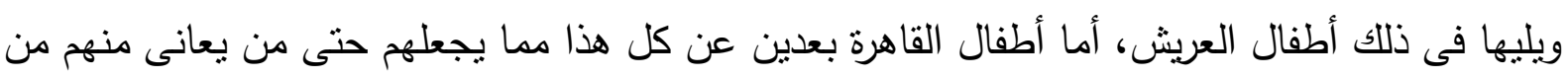

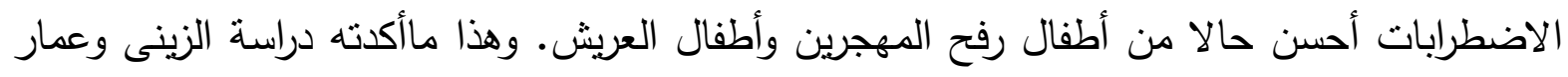

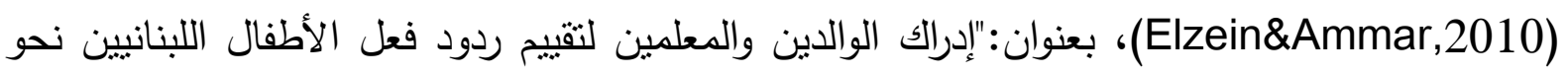

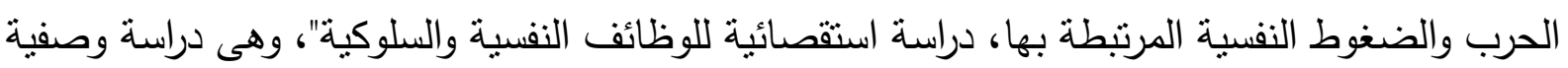


مقارنة لدراسة التأثير النفسى للحرب (T . . Y) على الأطفال اللبنانيين، والعينة مكونة من (• (1) طفلا

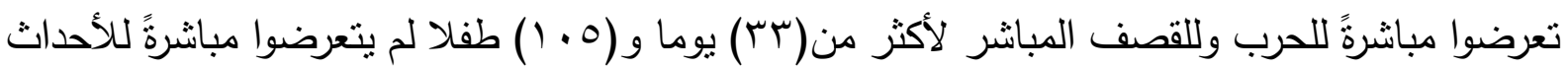

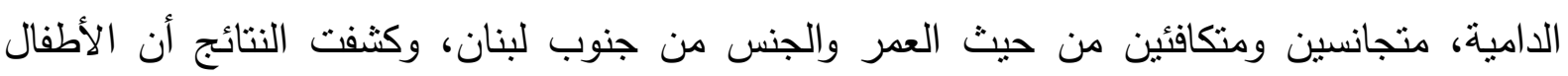

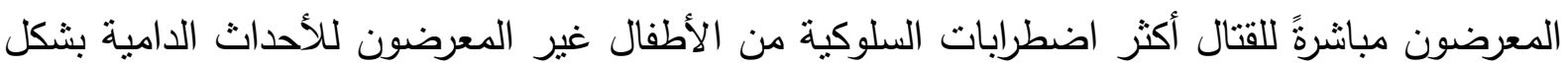

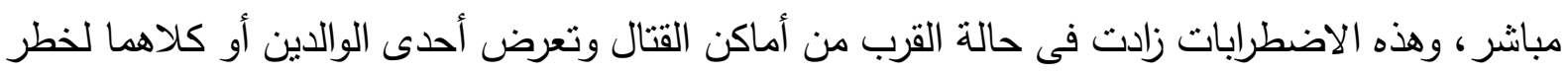
الموت والنزوح من المنازل وفقدان الممتلكات، و وجد أن الأطفال الصنار تركيزهم فئ الأسئلة عن التفاصيل

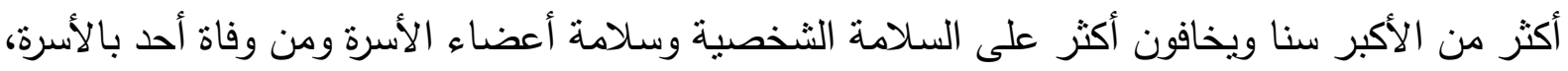
وفُسر هذا لقلة خبراتهم بالحياة وقصور قدراتهم العقلية على فهم الأحداث وعلى تحليلها، وأن النتائج السلبية

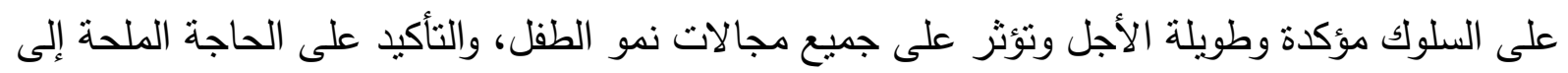

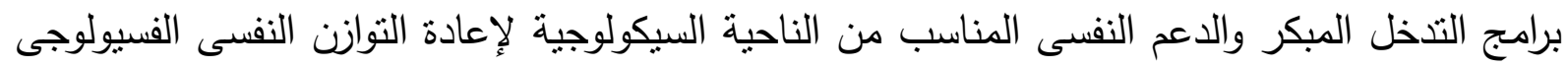

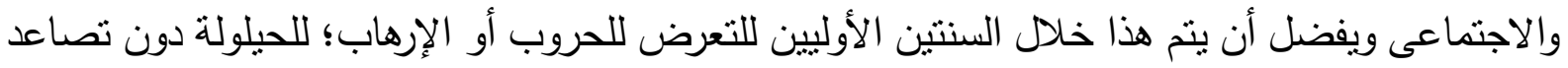

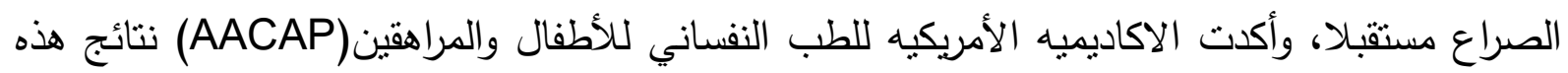

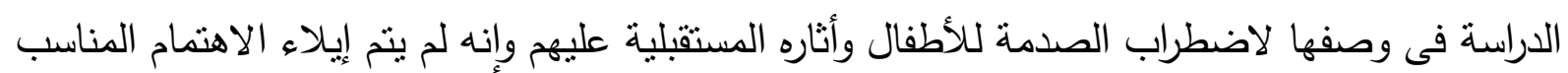

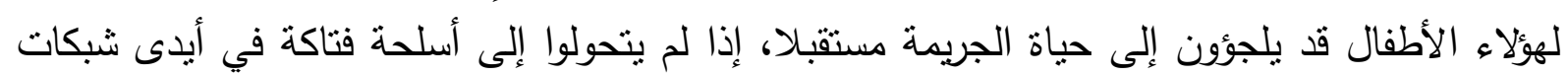

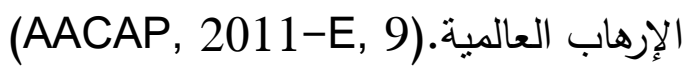

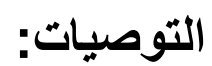

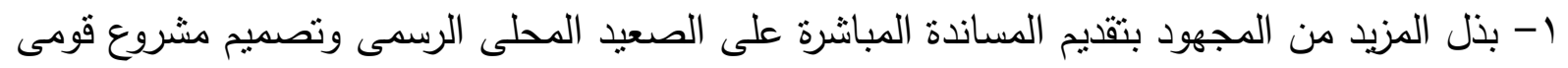
يشترك فيه كل المؤسسات الاكاديمية والحكومية المعنية بالطفولة فى مصر والمختصين فى مجال

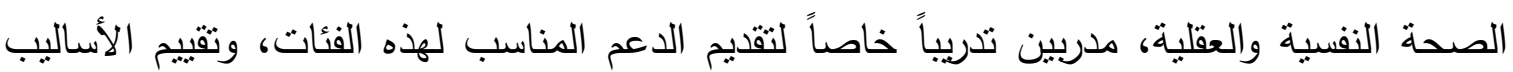

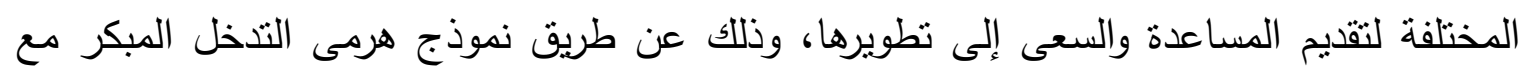

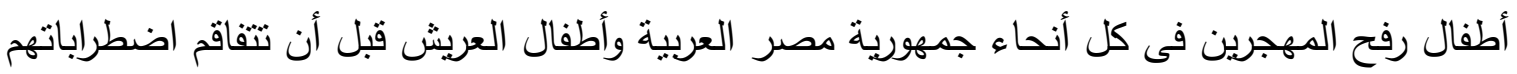

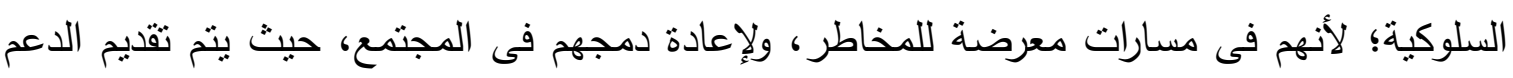

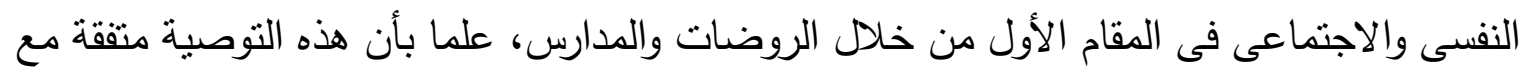

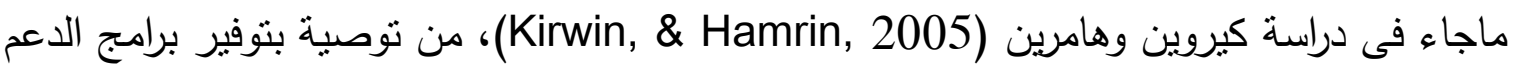

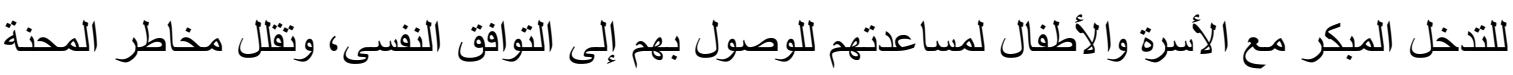

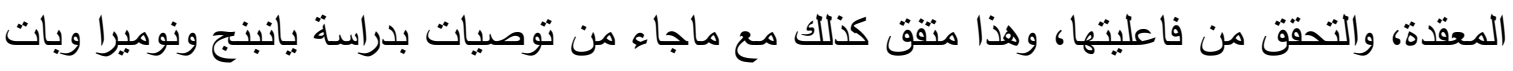

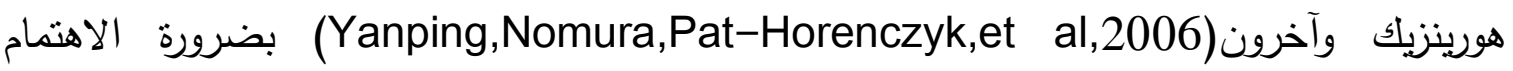
بعوامل الخطر وكيفية تطوير الوقاية الفعالة بالتدخل لتعزيز الصمود النفسى لأطفال مرحلة الطفولة

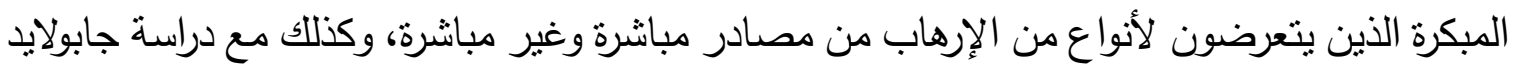

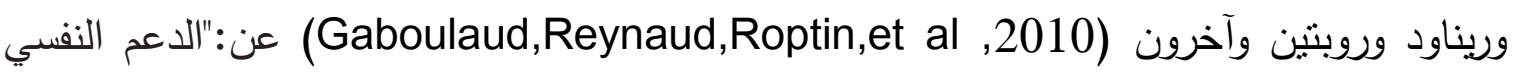
المقدم لأطفال ماقبل الددرسة الفلسطينيين: تحليل بيانات برنامج لتخفيف الاضطرابات السلوكية 
للأطفال في الأراضي الفلسطينية المحتلة"، وأظهرت النتائج فاعلية برنامج العلاج النفسي في تحسين حالة( (1\%) من الأطفال الفلسطينين حتى في أسوأ الظروف (الاعتداءات المسلحة)، مما يؤكد ضرورة التوصية بمثل هذه البرامج والاهتمام بتصميمها وتطبيقها مع الحالات المشابة.

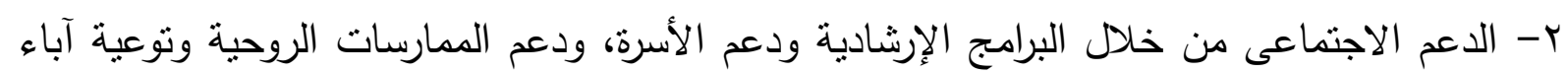
أطفال رفح وإرشادهم لكيفية مساعدة أطفالهم عن طريق تغيير الأجواء التي عاشوها خلاعله ودعل الفترة الماضية بطريقة كلية بعد توضيح المبهح لهم وإجابة أسألتهم، وتشجيع الأطفال على مواصلة الاتصال مع أصدقائهم من رفح إن إمكن، للإطمئنان بأنهم وأحبائهم فى أمان، وتعربف الأطفال بالمنطقة الجديدة ووصف مزاياها، واصطحابهم إلى رحلات، واللعب معهز، وشراء ألعاب وحاجيات لهم، وتجنب مايذكر

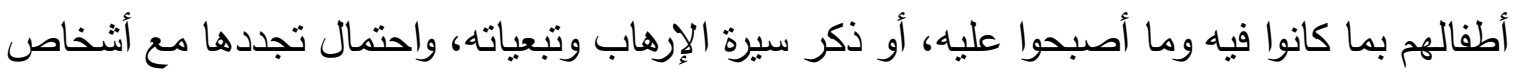
آخرين، أما آباء الأطفال بالعريش عليهم حماية الأطفال من التهديدات المباشرة والازاء المباشر -الأمان والرعاية-، وعدم الإثقال على الأطفال بمخاوفهم الشخصية، ولايتركوا الأطفال يشاهدوا الصور العنيفة

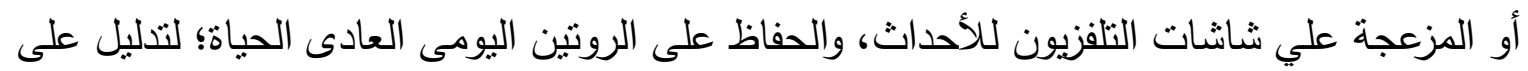
أن الحياة اليومية مستمرة؛ فحكمة الآباء كفيلة بمساعدة الأطفال على التخلص التدريجى من الآثار النفسية المتعلقة بالهجرة، أو البقاء تحت وطئة وتبعيات الحرب ضد الإرهاب، وجاءت هذه التوصية متفقة مع ماجاء بمقالة دراسة برادلى (Bradley, 2007) عن:"تصدع الوالديه: كيف للوالدين مساعدة الأطفال الذين تحت الظروف التتموية الصعبة"، الذى دعى للتركيز على مجال الوالدية وكيفية مساعدة

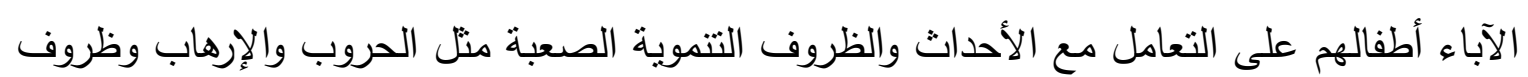
التهجير وزعزعة الاستقرار لإرجاع الأمور لوضعها الطبيعى. ب- توظيف الأسلوب البيئي فى التعامل مع الأطفال، فلايجب أن ينظر إلى الاضطرابات على أنها تخص لإنس الطفل فقط، ولكن ينظر إلبها على أنها قصور في التوازن مع النظام الاجتماعي، ولابد من إحداث تغيير في الطفل بالمشاركة فى أنشطة مخططة له لينجح فيها ليكتسب من خلالها الثقة فى التفاعل ولن

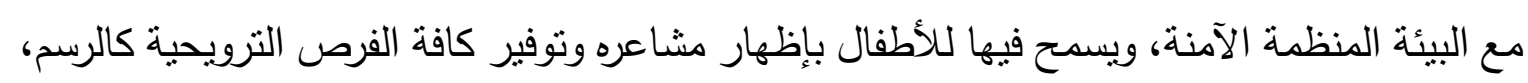
والسعى لتغير اتجاهات وتوقعات الأطفال بتتمية الميل الاجتماعى وتغيير أسلوب الحياة.

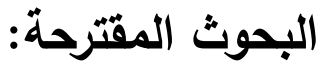

- برنامج ارشادى لخفض الاضطرابات السلوكية لدى أطفال شمال سيناء وأطفال رفح المهجرين.

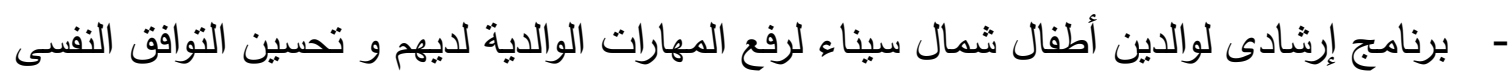
لدى أطفالهم. 
1- أبوسريع، محمد محمود.(1 + . r).المشكلات السلوكية للأطفال. القاهرة:الدار العالمية للنشر والتوزيع. r- أبوسعد، أحمد عبد اللطيف.(1) ب (r).تعديل السلوك الإنسانى" النظرية والنطبيق".عمان :دار المسيرة.

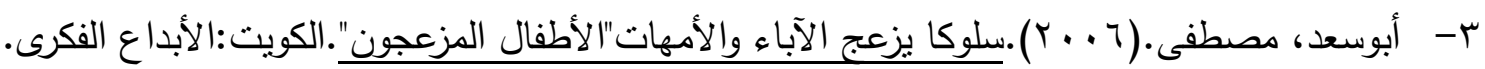

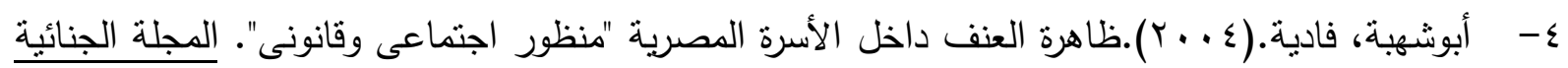

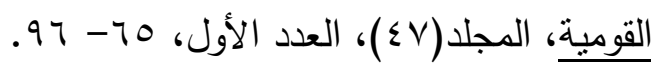

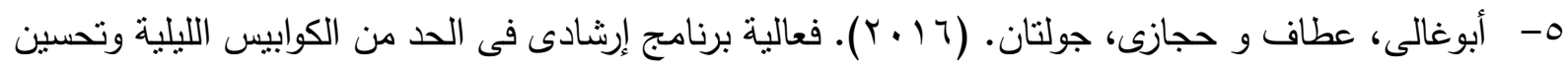

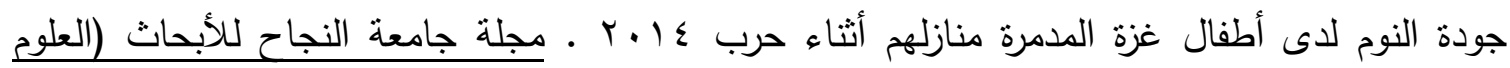

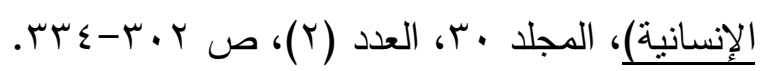

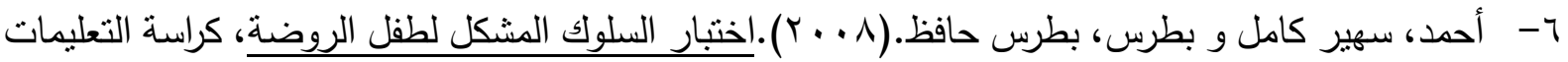

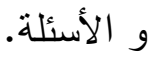
V- باظة، آمال عبدالسميع مليجى.( ( . ץ-أ).مقياس الاضطرابات السلوكية والوجدانية للأطفال ذوى الاحتياجات الخاصة والعاديين. القاهرة: مكتبة الانجلو المصرية. ^- باظة، آمال عبدالسميع مليجى.(1...ب-ب).مقياس الاضطرابات السلوكية و الوجدانية للأطفال ذوى الاحتياجات الخاصة والعاديين."كراسة التعليمات" القاهرة: مكتبة الانجلو الدصرية.

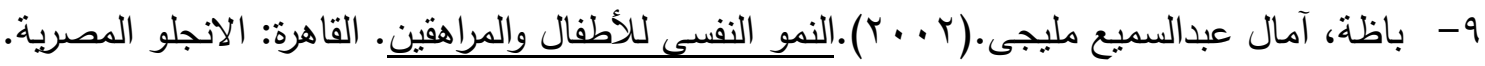
• 1- البيلاوى، إيهاب.(9 . + ץ).التوجية والإرشاد النفسى والمدرسى"|ستراتيجيات عمل الاختصاص النفسى لمدارس

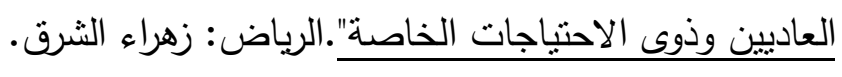

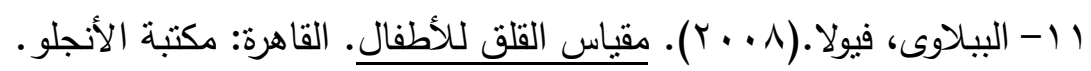

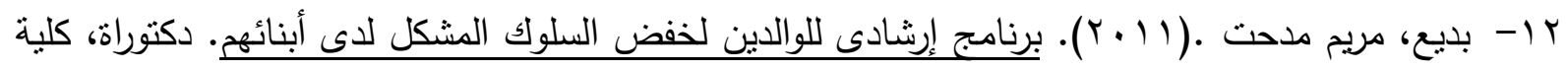
رياض الأطفال، جامعة القاهرة. r ا- بطرس، بطرس حافظ. (1 ..ץ). المشكلات النفسية وعلاجها. عمان: دار المسيرة.

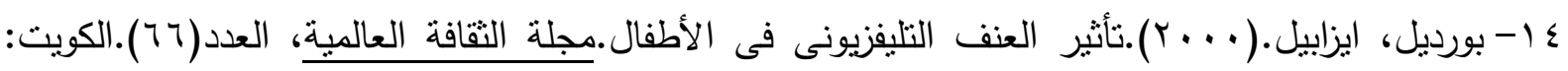
المجلس الوطني للنقافة و الفنون والآداب.

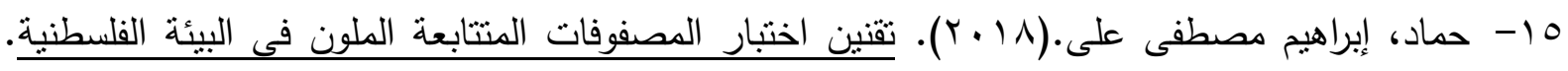
ماجستير، الجامعة الإسلامية بغزة، كلية التربية. 17- حمام، فادية كامل. (... (†). السلوك العدوانى ومظاهره لاى طفل ماقبل الددرسة فى ضوء متغيرى السن

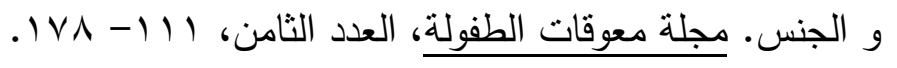


V V - حمدى، نزية و هارون، رمزى و أبو طالب، صابر • (• • (Y). مشكلات الأطفال و طرف العلاج. القاهرة: الشركة العربية المتحدة للتسويق و التوريدات.

1 ا- الزعبى، أحمد محمود.( ( . . ؟).الأمراض النفسية والمشكلات السلوكية و الدراسية عند الأطفال.عمان: دار زهران للنشر •

9 ا - الزيمارى، محمود عودة و شعث، رمضان إسماعيل.(1 . . ץ). نمو الطفل و رعايته. القاهرة: الشركة العربية المتحدة للتسويق و التوريدات.

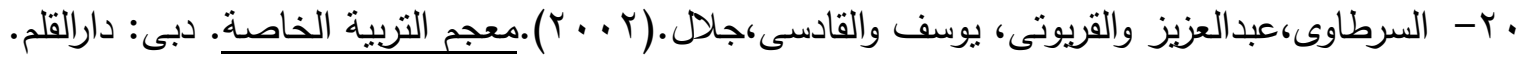
اب-سليم، عبد العزير إبراهيم. (11 + r).المشكلات النفسية و السلوكية لدى الأطفال. عمان: دار المسيرة. r r - سليمان، عبدالرحمن سيد. (ع . . Y).المضطربون سلوكيا. الرياض: مكتبة الرشد.

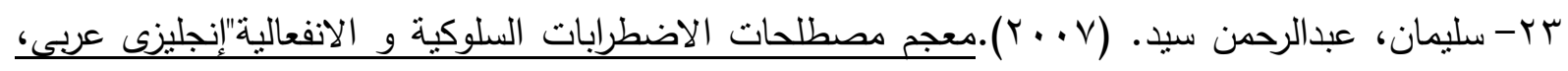
عربى إنجليزى". القاهرة: مكتبة زهراء الثرق.

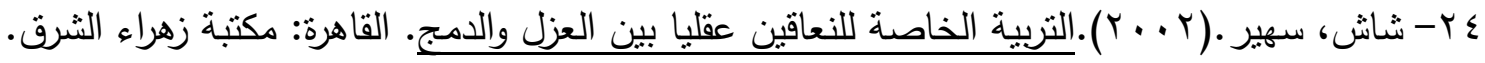
هץ- شقير، زينب محمود. (9 . . ץ-أ).بطارية الكذب مقاييس الخبرات الشخصية المرتبطة بوصف الكذب عند الأطفال (مرحلة الطفولة متوسطة- متأخرة). القاهرة: الانجلو المصرية. جr- شقير، زينب محمود.(9 + . r- ب).بطارية الكذب مقاييس الخبرات الثخصية المرتبطة بوصف الكذب عند الأطفال(مرحلة الطفولة متوسطة- متأخرة)."كراسة التعليمات والاسئلة". القاهرة: الانجلو المصرية. V V - الثوربجى، نبيلة.(r . . r).المشكلات النفسية للأطفال"أسبابها وعلاجها".القاهرة: دارالنهضة العربية. ^ץ - عبدالسيد، إميل اسحق . ( r). فعالية برنامج إرشادى لتحسين بعض المهارات الوالديه فى خفض المشكلات السلوكية لدى الأطفال. دكتوراة،كلية التربية، جامعة عين شمس. و - - عطية، محسن على وخليفة، إيناس خليفة.(1 . . ץ).المشكلات السلوكية لأطفال الروضة.عمان:دار المناهج. •r- عطية، محمد عبدالرؤوف. (• ( • (ץ).طفولة بلا مشاكل.القاهرة:دار طيبة للنشر والتوزيع. اب- العقاد،عصام عبداللطيف.( ( . + ب).سيكولوجية العدوانية وترويضها "منحى علاجى معرفى جديد". القاهرة: دار غريب.

r r- عكاشة، عبدالمنان محمود. (ع . ץ). المشاكل النفسية للطفل.عمان:الاخوة للنشر والتوزيع. rr- عيسوى،عبد الرحمن. ( . . r). اضطرابات الطفولة والمرهقة وعلاجها. بيروت: دار الراتب الجامعية. ع ب- الفرماوى، حمدى. ( ( . ب). ركائز البناء النفسى "دراسة تحليلية تفسيرية توجيهية فى سلوك الإنسان". القاهرة: دار إيتراك للطبعة والنشر والتوزيع. 
0ب- الفوال، محمد خير أحمد. (T . . ץ). مقاومة الخوف والسلوك الفردى عند الأطفال. مؤتمر فلادليفيا الدولى

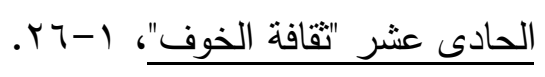

צr- القشش، مصطفى نورى و المعايطة، خليل عبدالرحمن.(r ץ).الاضطرابات السلوكية والانفعالية. طع. عمان:دار المسيرة.

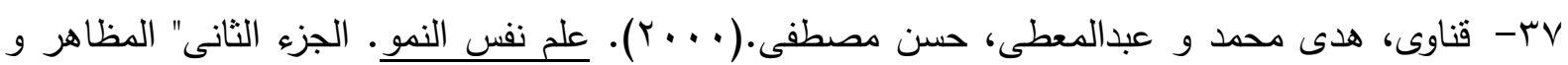

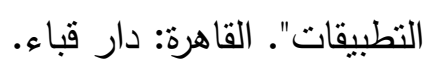

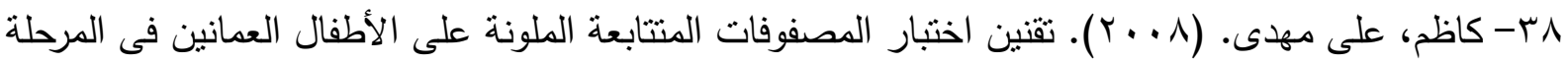

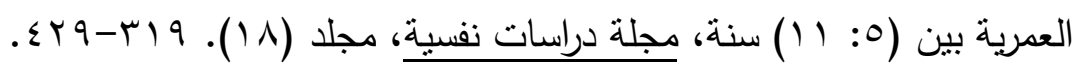

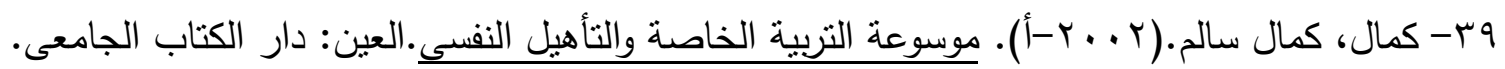

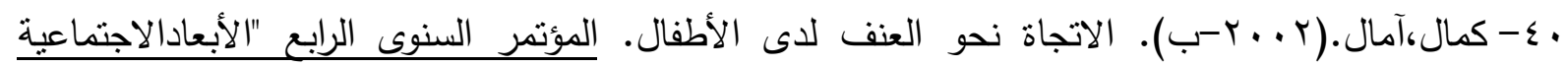
والجنائية للعنف فى المجتمع المصرى".المجلد الأول،القاهرة: المركز القومى للبحوث الاجتماعية و الجنائية، $. r \leqslant \Lambda: Y \mid r$

اع- هاريس د.ب.(ع . ץ).إختبار رسم الرجل لجودانف.ترجمة:محمد فرغلى، صفية مجدى،حمود عبد الحليم.

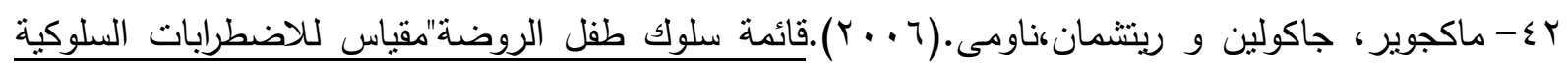
لأطفال الروضية. تعريب وتقنين: أنسى قاسم و خالد عبد الرازق، الأسكندرية: مركز الأسكندرية للكتاب. rع - مخيمر ،عماد و على، هبة محمد. (T . . ץ).المشكلات النفسية للأطفال بين عوامل الخطورة و طرق الوقاية والعلاج. القاهرة: الانجلو المصرية.

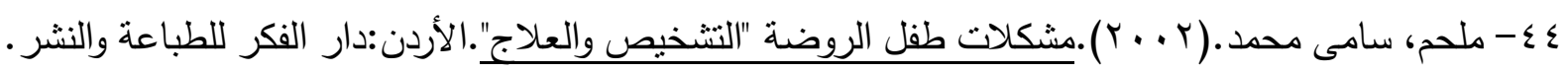
0ـ - النجار ، فاطمة الزهراء.(11 ـ ب).مشكلات الأطفال السلوكية والانفعالية.الأسكندرية: دار الوفاء لدنيا الطباعة.

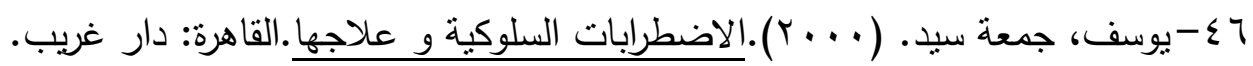

47- Abdeen, Z; Qasrawi, R; Nabil, S\& Shaheen, M. (2008).“Psychological Reactions to Israeli Occupation: Findings from the National Study of School-Based Screening in Palestinian Rafah".International Journal of Behavioral Development, Vol.32 No (4), $290-297$.

48- Alexandra. A. (2012). "War-Affected Children: Psychological Trauma and Intervention”.Master's Course in International Medicine-Health Crisis Management, RIA Hills: Athens. 
49- Altawil, M; Nel, P.W; Asker, A; Samara, M; \& Harrold, D. (2010). "The Effects of Chronic War Trauma among Palestinian Children. In M. Parsons (Ed.) Children: The Invisible Victims of War- An Interdisciplinary Study”. Peterborough-England: DSM Technical Publications Ltd.

50- American Psychiatric Association (APA).(1994). Diagnostic and statistical manual of mental disorders. $\left(\mathrm{DSM}-\mathrm{IV}^{\mathrm{tm}}\right)$. Washington, DC: American Pavchiatric Publishing.

51- American Psychiatric Association (APA).(2013).Diagnostic and statistical Manual of Mental disorders. (DSM-5 $\left.{ }^{\mathrm{tm}}\right)$. Washington, DC: American Pavchiatric Publishing.

52- Aqeel, M; Al-Ghzawi, K; Khatib, R; Samir, K\&Nawasreh, O. (2011). "Frequency of Post-Traumatic Stress Disorder in Children in Gaza Strip and Rafah". Journal of the Royal Medical Services, Vol.18, No (3), 52-58.

53- Asheffied, A. (2004). Child and Parental Report of the Parent Child Relationship as Predictors of Behavior and Emotional Problems in Per-School Children. Research Child Development: Washington.

54- Bass, E; Santo, J. B ; Cunha, J. M \& Neufeld, C.(2016).Classroom Context and the Relations between Social Withdrawal and Peer Victimization. Journal of Cognitive Education and Psychology, Vol.15 No (2), 248- 267.

DOI: $10.1891 / 1945-8959.15 .2 .248$.

55- Beer J.S. (2002). Implicit self-theories of shyness. Journal of Personality Social Psychology, Vol.83No (4):1009-1024.

56- Blumberg, H.H. (1998). Peace Psychology after the Cold War: A Selective Review. Genetic, Social \& General Psychology Monographs, Vol. 124 Issue (1), 5-33.

57- Bradley, R.H.(2007).Parenting in the Breach: How Parents Help Children Cope with developmentally challenging Circumstances. Parent:Science \& Practice, Vol.7 No (2), 99- 148. 
58- Buss, A.H. (1986).A Theory of Shyness. Shyness, 39- 46. DOI 10.1007/978-14899-0525-3_4.

59- CATS Consortium. (2007). Implementing CBT for Traumatized Children and Adolescent after September 11: Lessons Learned from the Child and Adolescent Trauma Treatment and Services (CATS) project. Journal of Clinical Child \& Adolescent Psychology, Vol.36 No (4), 581-592.

60- Coelho, V. A \& Romao, A. M. (2018).The relation between social anxiety, social withdrawal and (cyber) bullying roles: A multilevel analysis. Computers in Human Behaviour.Vol (86), 218-226. DOI:10.1016/j.chb.2018.04.048.

61- Cohen,E\&Gadassi,R.(2009).Effects of Trauma on Children, Adolescents And/ or Their Caregivers:Posttraumatic Stress Disorder in Young Children Exposed to Terrorism: Validation of the Alternative Diagnostic Criteria. Journal of Child \& Adolescent Trauma, Vol.2, 229-241. DOI: 10.1080/19361520903317295.

62- Devakumar,D;Birch,M; Rubenstein,L;Osrin,D;Sondorp,E \&Wells,J.(2015).Child Health in Syria:Recognizing the Lasting Effects of Warfare on Health.Conflict \&Health.Vol.9 No (34), 1-4. DOI: 10.1186/s13031-015-0061-6.

63- DiBianco, J. M; Morley, C \& Al-Omar, O. (2014). Nocturnal Enuresis:A Topic Review and Institution Experience.Avicenna J Med, Vol.4 No (4), 77-86, DOI: $10.4103 / 2231-0770.140641$.

64-Dubow, E. F; Boxer, P. L; Huesmann, R; Shikaki, K; Landau, S; Gvirsman, S.D\& Ginges, J. (2010). "Exposure to Conflict and Violence across Contexts: Relations to Adjustment among Palestinian Children in Rafah”. Journal of Clinical Child and Adolescents Psychology, Vol.39 No (1), 103-116.

DOI: $10.1080 / 15374410903401153$

65- Egger, H \& Angold, A. (2011). Common Emotional and Behavioral Discovers in Preschool Children: Presentation, Nosology, and Epidemiology. Journal of Child Psychology and Psychiatry, Vol. 47, Issue (3-4), 313-337. 
66- Egger, H.L; Costello, E.J\& Angold, A. (2003). School Refusal and Psychiatric Disorders: A Community Study. J Am Academy Child Adolescent Psychiatry, Vol. 42 No (7), 797-807. DOI: 10.1097/01.CHI.0000046865.56865.79.

67- Ekinei, O; Topcuoglu, V; Bez, Y; Sabuncuoglu,O \& Berkem,M. (2011). Aggression During Early Childhood: Associated Factors in a Clinical Sample. Marmara Medical Journal. Vol. 24 Issue (3), 174-180.

DOI: 10.5472/MMJ.2011.02013.1.

68- Elzein, H \& Ammar, D. (2010).Parent and Teacher Perceptions of Assessing Lebanese Children's Reaction to War-Related Stress: A Survey of Psychological and Behavioural Functioning. Journal of Child \& Adolescent Trauma, Vol.3, 255278. DOI: $10.1080 / 19361521.2010 .523060$.

69- Farzadfard.S.A; Abdekhodaer.M.S\& Abadi. A.G.C. (2015). Effectiveness of combined purposeful play therapy and narrative therapy on pre-school children's attention and concentration. Journal of Fundamentals of Mental Health, Psychiatry and Behavioural Sciences, Research Center, Mashhad University Of Medical Sciences, 222-228.

70- Fonagy.P; Gergely.G\&Target.M.(2007).The parent-infant dyad and the construction of the subjective self.Journal of Child Psychology and Psychiatry, Vol. 48 No (3/4), 288-328. DOI:10.1111/j.14697610.2007.01727.x.

71- Gaboulaud, V; Reynaud, C; Roptin, J; Lachal, C; Brown, V \& Baubet, T. (2010). "Psychological Support for Palestinian Children and Adults: An Analysis of Data from People Referred to The Medecins Sans Frontie'res Programme for Behavioral And Emotional Disorders In The Occupied Palestinian Territory”. Intervention, Vol. 8 No (2), $131-142$.

72- Gagro, S. F. (2015).The role and activities of the UN bodies on protection of children affected by armed conflicts. Zbornik Pravnog Fakulteta Sveucilista u Rijeci, Vol.36 Issue (2), 759-786. 
73- Garbarino, J; Governale, A; Henry, p \& Nesi, D. (2015). Children and Terrorism. Social Policy Report. Society for Research in Child Development, Vol. 29 No (2), $1-39$.

74- Glisson,C. (2002).The Organizational Context of Children's Mental Health Services.Clinical Child and Family Psychology Review, Vol. 5, 233- 254.

75- Goldie, P. (2002). The Emotions "Philosophical Exploration”. Oxford: University press.

76- Greenberg, M. (2005). “A Parental Education Program for Helping Parents to cope up with Their Children Psychological Problems". American Journal of Preventive Medicine, No. (22).

77- Gurwitch, R.H.; Pfefferbaum, B \& Leftwich, M. J.T. (2002). The impact of terrorism on children: considerations for a New Era. Journal of Trauma Practice, Vol. 1 Issue (3/4), 101-124.

78- Hautmann, C; Stein, P; Eichelberger, E; Hanisch,C; Plucking,J; Walter, D\& Dopfner,M. (2011). The severely impaired do Profit Most: Differential Effectiveness of a Parent Management Training for Children with Externalizing Behavior Problems in Natural Setting. Journal of Child and Family Studies, Vol. 20 No (4), 424-435.

79- Itani, L; Jaalouk, D; Fayyad, J; Garcia,J.T;Chidiac,F \& Karam, E.(2015). Exposure to War-Related Traumata among Arab Children and Adolescents .ㅁ Review.Arab Journal of Psychiatry, Vol.26 Issue(2), 107-128.

80- John, A. (2009). The Effectiveness of a Guidance Program for Decreasing Anxiety for Preschool Children in Poor Slums of Tajikistan. Wakefield Press.

81- Kelso, S. (2008).The Impact of Domestic Violence on Problem Behaviors among Children.Global Journal of Business Research,Vol.4 No(2), 77-48.

82- Kirk, S; Gallagher, J; Coleman, M.R \& Anastasiow, N (2009) .Educating Exceptional children.Tenth Edition, Boston,New York: Houghton Mifflin Harcourt Publishing Company. 
83- Kirwin, K \& Hamrin, V. (2005). Decreasing the Risk of Complicated Bereavement and Future Psychiatric Disorders in Children. Journal of Child and Adolescent Psychiatric Nursing, Vol. 18 No (1).62-78.

84- Layne, C.M; Pynoos, R.S; Saltzman, W.R.; Arslanagie, B; Black M. \& Sarjak, N.(2001).Trauma grief focused group psychotherapy: school-based post war. Intervention with traumatized Bosnian adolescents.Group Dyn, Vol.5, 277-290.

85- Lin.Y.W \& Bratton.S.C. (2015). A Meta-Analytic Review of Child-Centered Play Therapy Approaches. Journal of Counselling \& Development. DOI: 10.1002/j.1556-6676.2015.00180.x.

86- Massad, S. F; Nieto, J; Palta, M; Smith,M; Clark, R \& Thabet, A. (2010). Mental Health of Children in Palestinian Kindergartens: Resilience and Vulnerability. Child and Adolescent Mental Health, Vol.14 No (2). 89-96.

87- Masten, A.S\& Osofsky, J.D. (2010). Disasters and Impact on Child Development: Introduction to the Special Section. Child Development, Vol. 81 No (4), 10291039.

88- Morgos, D; Worden, W \& Gupta, L.(2008).Psychological Effects of War Experiences among Displaced Children in South Darfur.Journal of Death and Dying, Vol. 56, 229-253.

89- Nelson,L;Stag,S;Duppong,K;Synhorst,L\& Epstein,M.(2007).Risk factors predictive of the problem behavioral.Exceptional children, Vol,73No(3),367: 379.

90- Niaz, U. (2015).Psycho Trauma in Children Exposed to the War Atrocities. Journal of Pakistan Psychiatric Society, Vol.12 No (1),32-35.

91- Panter, B; Goodman, A; Tol, W \& Eggerman, M. (2011).Mental Health and Childhood Adversities:A Longitudinal Study in Kabul,Afghanistan.Journal of the American Academy of Child and Adolescent Psychiatry, Vol. 50, 349-363.

92- Repetti, R. L; Taylor, S. E \& Seeman, T. E. (2002). Risky Families: Family Social Environments and the Mental and Physical Health of Offspring. The American Psychological Association. Vol.128 No (2), 330- 366. 
DOI: 10.1037//0033-2909.128.2.330.

93- Robert, S.(2006). How Children Develop "Exploring Child Develop Student Media Tool Kit\& Scientific American Reader to Accompany How Children Develop". New York: Worth Publishers.

94-Rohrer, J.E. (2016). Caring for the Children of War. The Journal of Health Care Organization, Provision, and Financing. Vol. 53 Issue (1),1-10.

DOI: $10.1177 / 0046958016671500$.

95-Russell, S; Subramanian, B\& Russell, P.S. (2005). Revision and Validation of Child Behaviour Check List- Post-Traumatic Stress Disorder Scale.In Tamil. International Journal of Disaster Medicine, Vol. 3 Issue(1-4), 41-44. DOI: $10.1080 / 15031430500266564$.

96- Rutter, M; Bishop,D.V; Pine, D.S; Scott, S; Stevenson, J; Taylor, E \& Thapar, A. (2008). Child and Adolescent Psychiatry. ( $5^{\text {th }}$ Ed), London: Blackwell.

97- Schoenberg, P.L \& David, A.S. (2014).Biofeedback for Psychiatric Disorders: A Systematic Review. Apply Psychophysiology Biofeedback, Vol. 39, 109 -135. DOI: $10.1007 / \mathrm{s} 10484-014-9246-9$.

98- Suter, J \& Byrne, M. (2000). Female Offenders Are Different From Male Offenders: Anger as an Example. Women in Corrections: Staff and Clients. Women Conference Convened by the Australian Institute of Criminology in Conjunction with the Department for Correctional Services SA and Held in Adelaide, 1-12.

99- Thabet, A, A; Stretch, D \& Vostanis, P. (2000). Child Mental Health Problems in Arab Children: Application of the Strengths and Difficulties Questionnaire, International. Journal of Social Psychiatry,Vol.46,266-280.

100- Thabet, M ; Thabet, S \& Vostainis, p. (2016).The Relationship Between War Trauma ,PTSD, Depression and Anxiety among Palestinian Children in The Gaza Strip. Health Science Journal,ISSN 1791-809X, Vol.10 No (5:3),1-9. DOI: 10.4172/1791 809X.1000100503. 
101- The American Academy of Child and Adolescent Psychiatry (AACAP). (2004-A).The Anxious Child. "Facts for Families", No. 47 (11/04).

102- The American Academy of Child and Adolescent Psychiatry (AACAP). (2004-B). Children and Lying. "Facts for Families",No. 44(11/04).

103- The American Academy of Child and Adolescent Psychiatry (AACAP). (2008).Helping Children after A Disaster.“Facts for Families”,No.36 (12/08). 104- The American Academy of Child and Adolescent Psychiatry (AACAP). (2011_A). Bedwetting. "Facts for Families", No. 18 (12/11).

105- The American Academy of Child and Adolescent Psychiatry (AACAP). (2011- B).Children Who Steal. "Facts for Families", No. 12 (5/11).

106- The American Academy of Child and Adolescent Psychiatry (AACAP). (2011-C).Children and Family Moves."Facts for Families”, No.14 (5/08).

107- The American Academy of Child and Adolescent Psychiatry (AACAP). (2011- D). Understanding Violent Behaviour in Children and Adolescents. "Facts for Families", No. 55 (12/11).

108- The American Academy of Child and Adolescent Psychiatry(AACAP). (2011-E).Posttraumatic Stress Disorder PTSD, "Facts for Families", No.70 (3/11).

109- The American Academy of Child and Adolescent Psychiatry(AACAP).(2011-F). Obesity. "Facts for Families", No. 79 (3/11).

110- The American Academy of Child and Adolescent Psychiatry(AACAP).(2011-G). Fighting and Biting. "Facts for Families", No. 81 (3/11).

111- The American Academy of Child and Adolescent Psychiatry(AACAP).(2011-H). Talking to Children about Terrorism and War."Facts for Families", No.87(3/11).

112- The American Academy of Child and Adolescent Psychiatry(AACAP).(2013-A). Conduct Disorder."Facts for Families",No.33 (8/13).

113- The American Academy of Child and Adolescent Psychiatry(AACAP).(2013-B). Children's Sleep Problems."Facts for Families”, No.34 (8/13). 
114- The American Academy of Child and Adolescent Psychiatry(AACAP).(2013-C). Panic Disorder in Children and Adolescents.Facts for Families”,No.50 (07/13).

115- The American Academy of Child and Adolescent Psychiatry(AACAP).(201ץ-D). Finding Mental Healthcare for Children of Immigrants. "Facts for Families", No. $\operatorname{lir}(3 / 1 r)$.

116- The American Academy of Child and Adolescent Psychiatry(AACAP).(2013-E). The Depressed Child. "Facts for Families", No. 4 (5/08).

117- The American Academy of Child and Adolescent Psychiatry(AACAP).(2013-F). Children and Grief. "Facts for Families", No. 8 (5/13).

118- Tol, W.A; Song, S \& Jordans, M.J.(2013).Annual Research Review: Resilience and Mental Health in Children and Adolescents living in Areas of Armed Conflict - A Systematic Review of Findings in Low and Middle Income Countries. Journal of Child Psychology \& Psychiatry, Vol. 54 Issue (4), 445- 460.

119- United Nations Human Rights.(2018).Convention the Right of the Child.Article6, Office of the High Commissioner.

120- Wahlsten, S; Ahmad, A \& A-L von Knorring, A.(2001).Traumatic Experiences and Post-Traumatic Stress Reactions in Children from Kurdistan and Sweden. Acta Paediatr, Vol. 90, $563-568$.

121- Walle, J. V ; Rittig, S; Bauer, S ; Eggert, P ; Marschall-Kehrel, D \& Tekgul, S. (2012). Practical Consensus Guidelines for the Management of Enuresis. Eur J Pediatr.Vol. 171 Issue (6), 971-983. DOI: 10.1007/s00431-012-1687-7.

122- Williams, R. (2007). The Psychosocial Consequences for Children of Mass Violence, Terrorism and Disasters.International Review of Psychiatry, Vol, 19 No (3), 263-277. DOI: 10.1080/09540260701349480.

123- Wilson, B.G. (2008). Media and Children's Aggression, fear, and altruism. Future of Children, Vol. 18 Issue (1), 87- 118.

124- Yanping, W; Nomura, Y; Pat-Horenczyk, R; Doppelt, O; Abramovitz, R; Brom, D \&Chemtob, C. (2006). Association of Direct Exposure to Terrorism, Media 
Exposure to Terrorism, and other Trauma with Emotional and Behavioral problems in Preschool Children. Annals of the New York Academy of Sciences. Vol. 1094 Issue (1), 363-368. DOI:10.1196/annals.1376.051.

125- Young, A; Kenardy, J \& Cobham, V. (2011).Trauma in Early Childhood: A neglected population. Chinical Child \& Family Psychology Review, Vol. 14 Issue (3).231-250. DOI 10.1007/s10567-011-0094-3.

126- Yule, W. (2000).Emanuel Miller Lecture from Pogroms to "Ethnic Cleansing": Meeting the Needs of War Affected Children. Journal of Child Psychology and Psychiatry, Vol. 41 No (6), 695-702. 